\title{
Results of Copper Catalyzed Peroxide Oxidation (CCPO) of Tank 48H Simulants
}

\author{
T. B. Peters \\ J. M. Pareizs \\ J. D. Newell \\ F. F. Fondeur \\ C. A. Nash \\ T. L. White \\ S. D. Fink
}

December 2012

Savannah River National Laboratory Savannah River Nuclear Solutions, LLC Aiken, SC 29808

Prepared for the U.S. Department of Energy under contract number DE-AC09-08SR22470. 
SRNL-STI-2012-00342

Revision 1

\section{DISCLAIMER}

This work was prepared under an agreement with and funded by the U.S. Government. Neither the U.S. Government or its employees, nor any of its contractors, subcontractors or their employees, makes any express or implied:

1. warranty or assumes any legal liability for the accuracy, completeness, or for the use or results of such use of any information, product, or process disclosed; or

2. representation that such use or results of such use would not infringe privately owned rights; or

3. endorsement or recommendation of any specifically identified commercial product, process, or service.

Any views and opinions of authors expressed in this work do not necessarily state or reflect those of the United States Government, or its contractors, or subcontractors.

\section{Printed in the United States of America \\ Prepared for \\ U.S. Department of Energy}




\title{
Results of Copper Catalyzed Peroxide Oxidation (CCPO) of Tank 48H Simulants
}

\author{
T. B. Peters \\ J. M. Pareizs \\ J. D. Newell \\ F. F. Fondeur \\ C. A. Nash \\ T. L. White \\ S. D. Fink
}

December 2012

Savannah River National Laboratory Savannah River Nuclear Solutions, LLC Aiken, SC 29808

Prepared for the U.S. Department of Energy under contract number DE-AC09-08SR22470. 


\section{REVIEWS AND APPROVALS}

\section{AUTHORS:}

T. B. Peters, Author, SRNL/SASP

Date

J. M. Pareizs, Co-author, SRNL/PTP

Date

J. D. Newell, Co-author, SRNL/PTP

Date

F. F. Fondeur, Co-author, SRNL/SASP

Date

C. A. Nash, Co-author, SRNL/ACP

Date

T. L. White, Co-author, SRNL/AD

Date

TECHNICAL REVIEW:

C. J. Martino, Technical Reviewer, SRNL/ACP

Date

APPROVAL:

S. D. Fink, SRNL/SASP, Manager

Date

S. L. Marra, SRNL/E\&CPT Research Programs, Manager

Date

K. H. Subramanian, Manager, SRR Chief Technology Officer

Date 


\section{EXECUTIVE SUMMARY*}

Savannah River National Laboratory (SRNL) performed a series of laboratory-scale experiments that examined copper-catalyzed hydrogen peroxide $\left(\mathrm{H}_{2} \mathrm{O}_{2}\right)$ aided destruction of organic components, most notably tetraphenylborate (TPB), in Tank 48H simulant slurries. The experiments were designed with an expectation of conducting the process within existing vessels of Building 241-96H with minimal modifications to the existing equipment.

Results of the experiments indicate that TPB destruction levels exceeding $99.9 \%$ are achievable, dependent on the reaction conditions. The following observations were made with respect to the major processing variables investigated.

- A lower reaction $\mathrm{pH}$ provides faster reaction rates $(\mathrm{pH} 7>\mathrm{pH} 9>\mathrm{pH} 11)$; however, $\mathrm{pH} 9$ reactions provide the least quantity of organic residual compounds within the limits of species analyzed.

- Higher temperatures lead to faster reaction rates and smaller quantities of organic residual compounds. A processing temperature of $50^{\circ} \mathrm{C}$ as part of an overall set of conditions appears to provide a viable TPB destruction time on the order of 4 days.

- Higher concentrations of the copper catalyst provide faster reaction rates, but the highest copper concentration $(500 \mathrm{mg} / \mathrm{L})$ also resulted in the second highest quantity of organic residual compounds. The data in this report suggests 100-250 $\mathrm{mg} / \mathrm{L}$ as a minimum.

- Faster rates of $\mathrm{H}_{2} \mathrm{O}_{2}$ addition lead to faster reaction rates and lower quantities of organic residual compounds. An addition rate of $0.4 \mathrm{~mL} / \mathrm{hour}$, scaled to the full vessel, is suggested for the process.

- SRNL recommends that for $\mathrm{pH}$ adjustment, an acid addition rate $42 \mathrm{~mL} /$ hour, scaled to the full vessel, is used. This is the same addition rate used in the testing.

- Even though the TPB and phenylborates can be destroyed in a relative short time period, the residual organics will take longer to degrade to $<10 \mathrm{mg} / \mathrm{L}$.

- Low level leaching on titanium occurred, however, the typical concentrations of released titanium are very low ( $\sim 40 \mathrm{mg} / \mathrm{L}$ or less). A small amount of leaching under these conditions is not surprising and is consistent with a previous study. ${ }^{1}$

\footnotetext{
- This version of the report incorporates appreciable amounts of new data and is a substantial update of the entire report. Hence, revision bars are not depicted as this report is considered to supersede the prior edition in all aspects.
} 
- Acidification with phosphoric and formic acids, in lieu of nitric acid, provides benefits in reducing the amount of benzene emitted over the lifetime of a reaction.

- Analyses of the post-reaction residual material indicate that slurry initially adjusted down to a $\mathrm{pH} 7$ produced a greater degree of energetic material than material initially adjusted to a $\mathrm{pH}$ of $9 .^{2}$

- No more than $140 \mu \mathrm{g} / \mathrm{m}^{3}$ of mercury was indicated in reactor head spaces at any time. An estimation of less than $1 \%$ of the initial mercury was vaporized in each experiment.

- A limited number of replicate tests were performed to determine experimental reproducibility. These tests indicate a reasonable degree of reproducibility.

The conclusion of the simulant testing has provided a set of reaction conditions that can destroy the TPB and phenylborates quickly. While longer times will be required to degrade the residual organics, the reactions appear to perform in a consistent manner. A real waste test or tests are recommended and further investigation into the use of phosphoric or formic acid is warranted. 


\section{Contents}

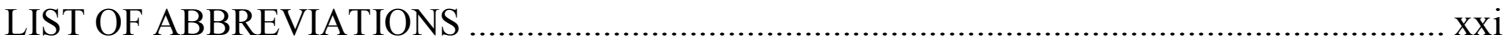

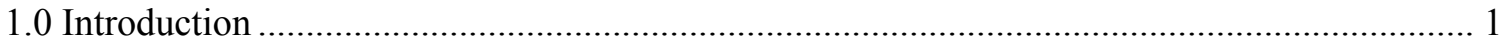

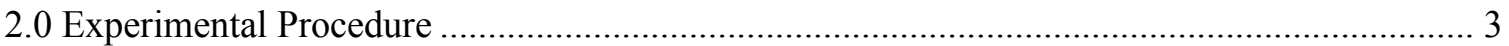

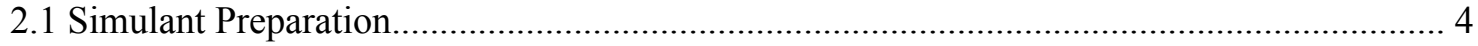

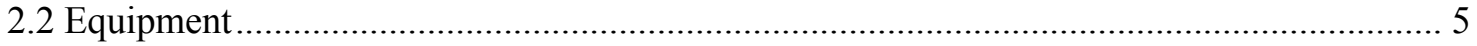

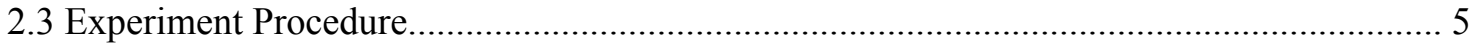

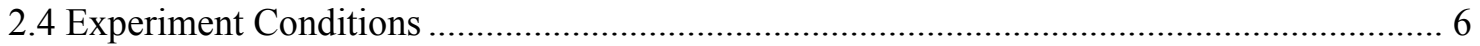

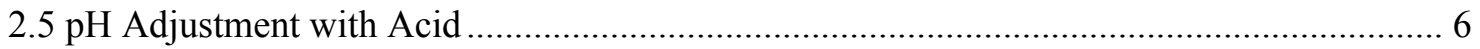

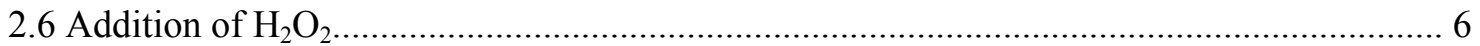

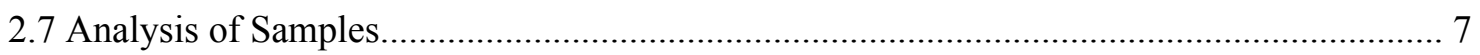

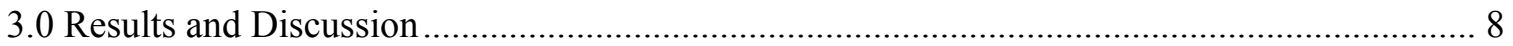

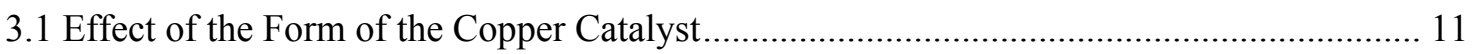

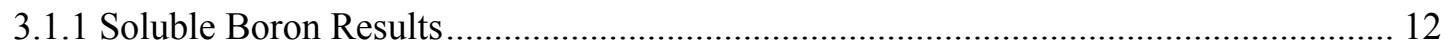

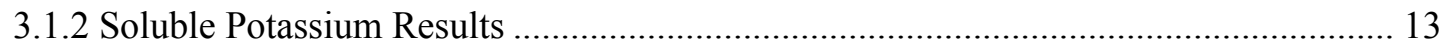

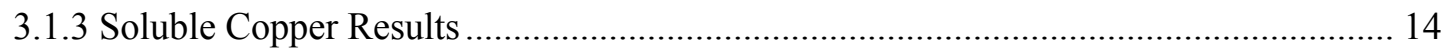

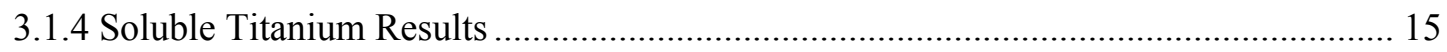

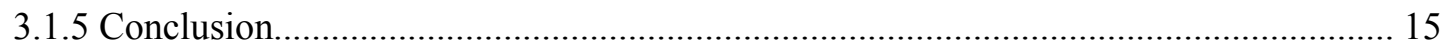

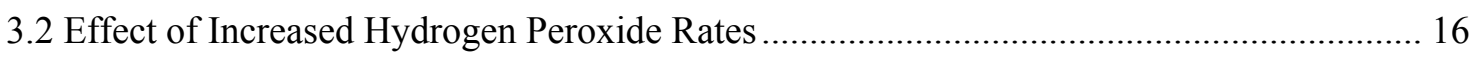

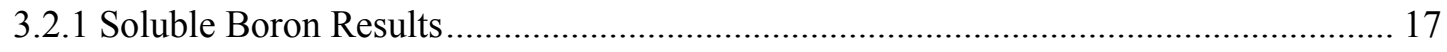

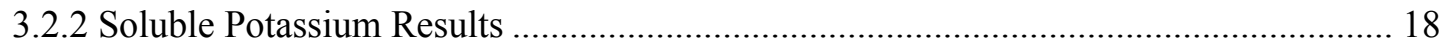

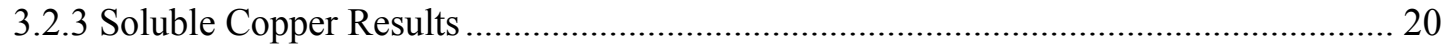

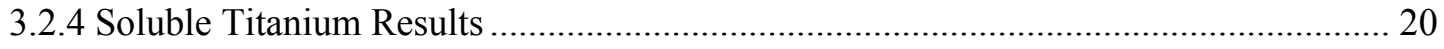

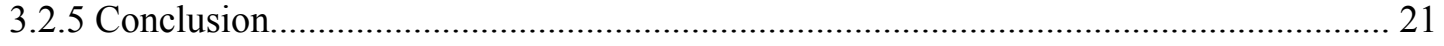

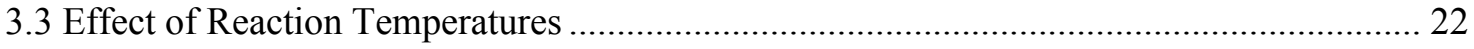

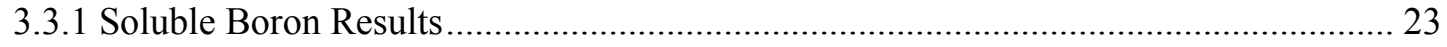

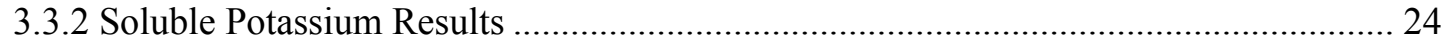

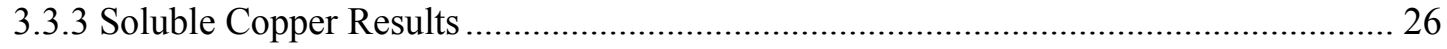

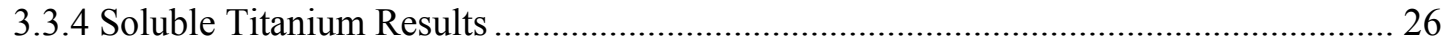

3.3.5 Analysis of Residual Slurry After Reaction............................................................... 27

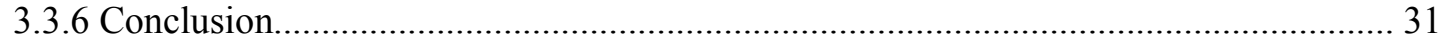

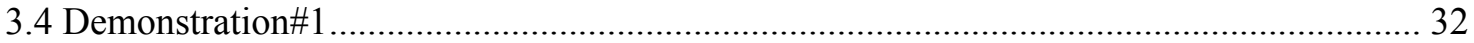




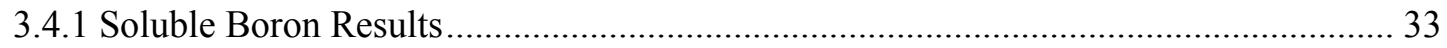

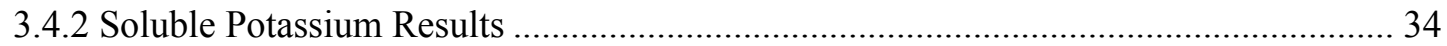

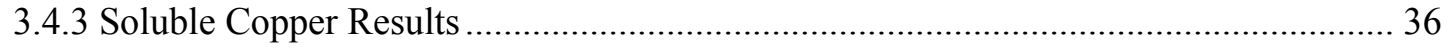

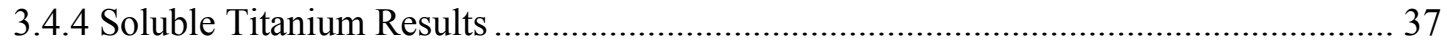

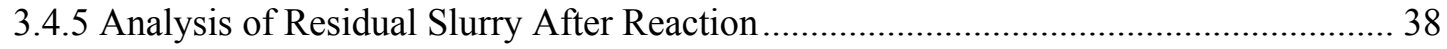

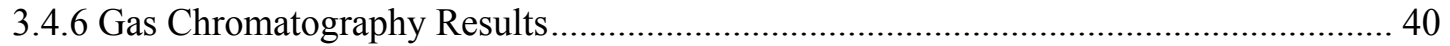

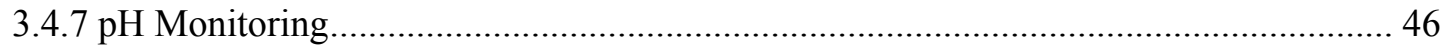

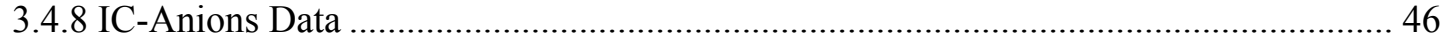

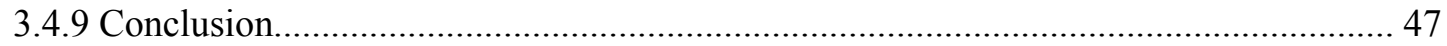

3.5 Comparison of Demonstration 1 and the 2004 Final Test ............................................... 48

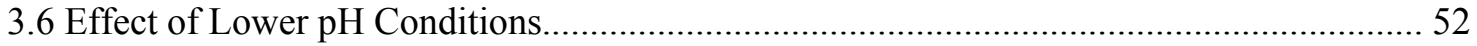

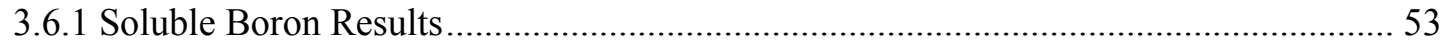

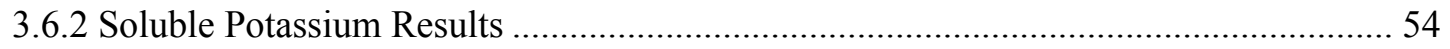

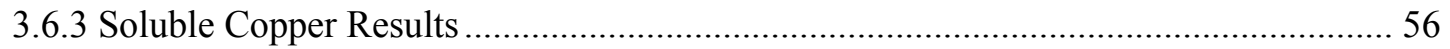

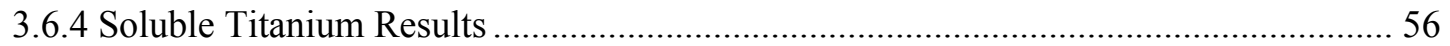

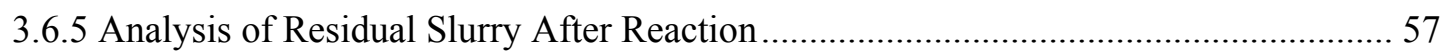

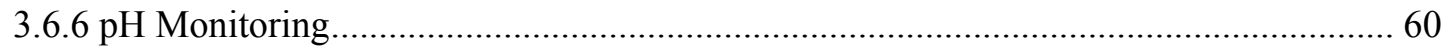

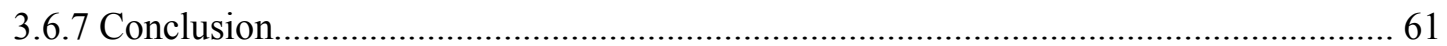

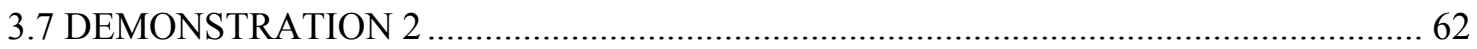

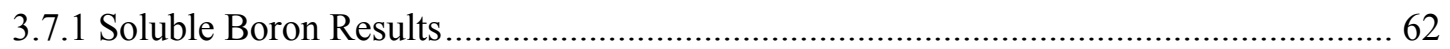

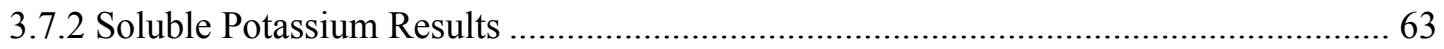

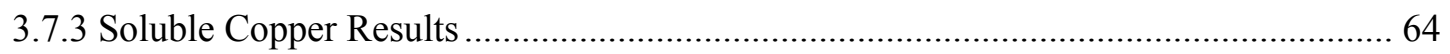

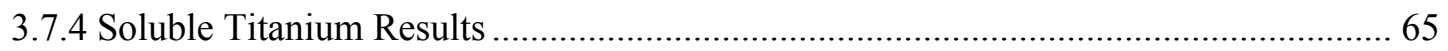

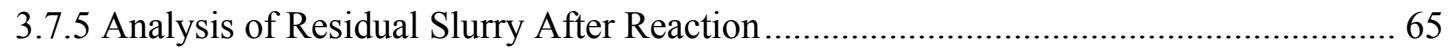

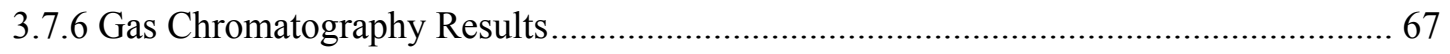

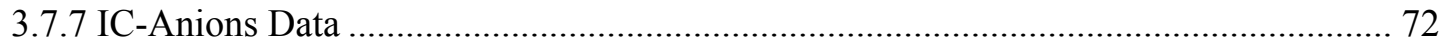

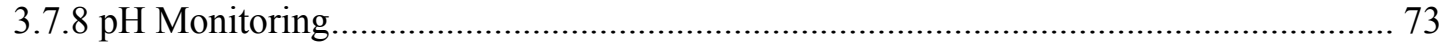

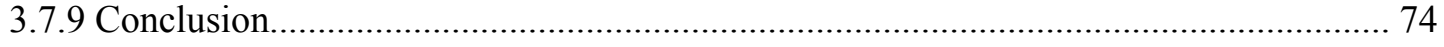

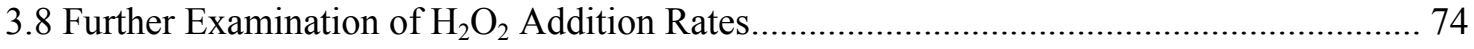

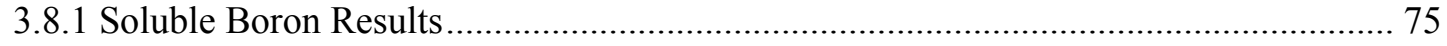

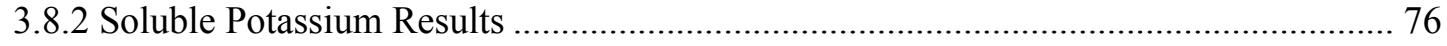

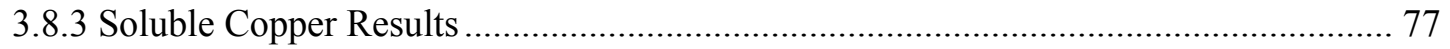

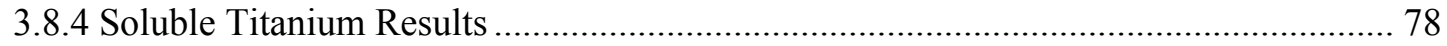

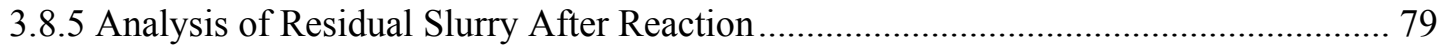




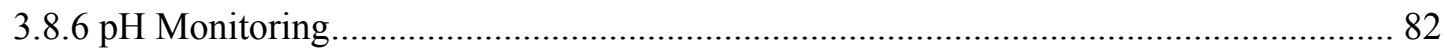

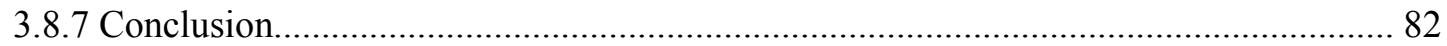

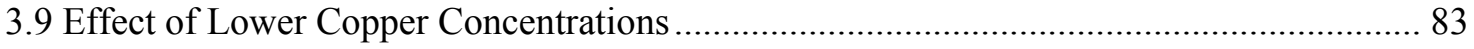

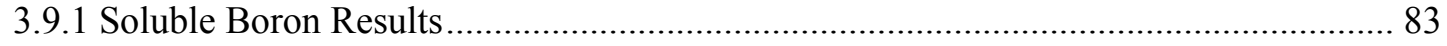

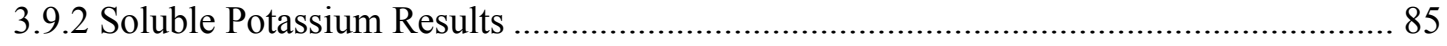

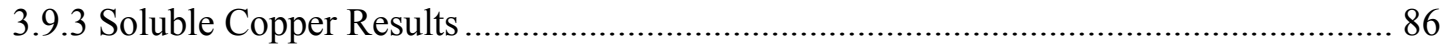

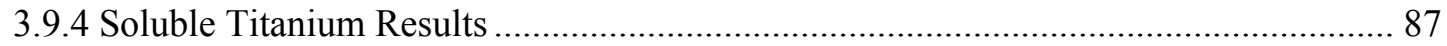

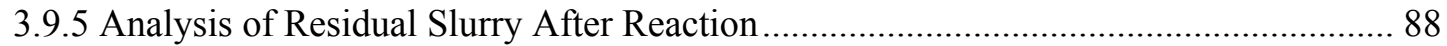

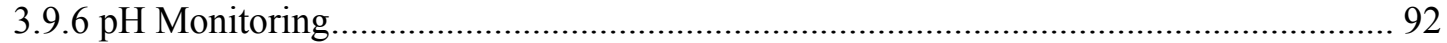

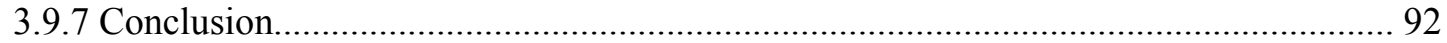

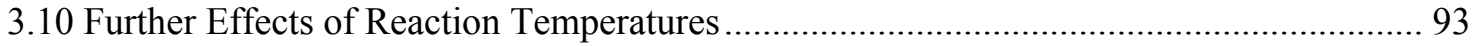

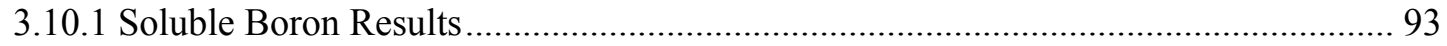

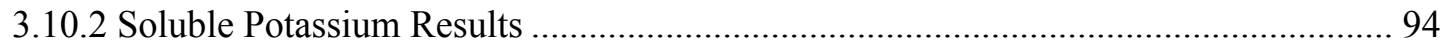

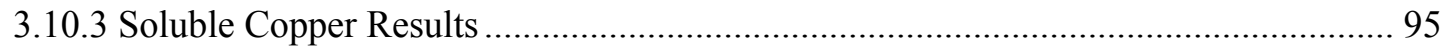

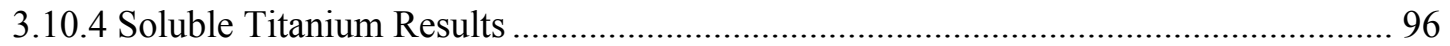

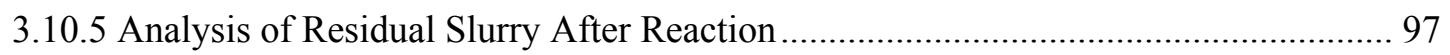

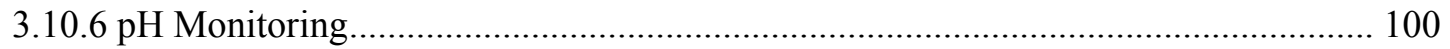

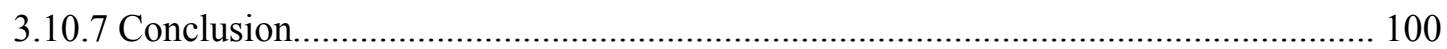

3.11 Further Effects of $\mathrm{H}_{2} \mathrm{O}_{2}$ Addition Rates at Lower Copper Additions ............................ 101

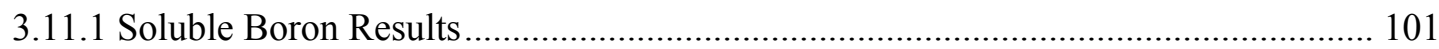

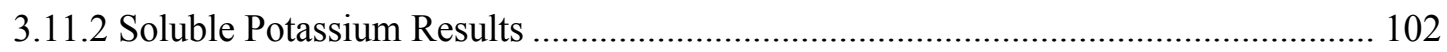

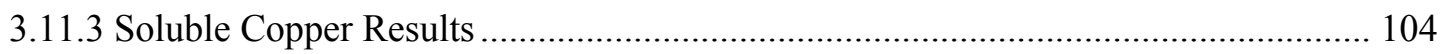

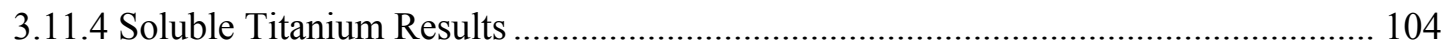

3.11.5 Analysis of Residual Slurry After Reaction ......................................................... 105

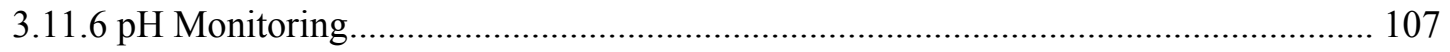

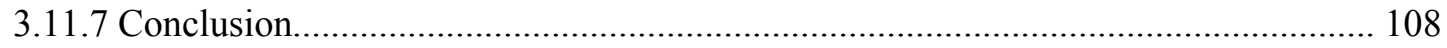

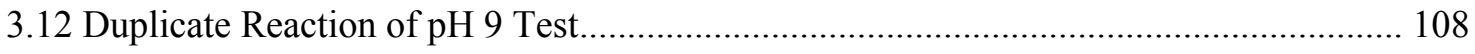

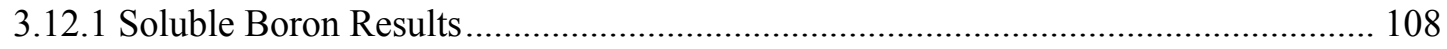

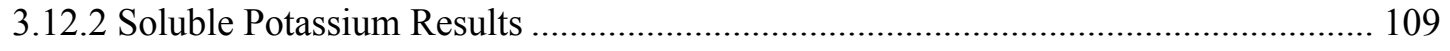

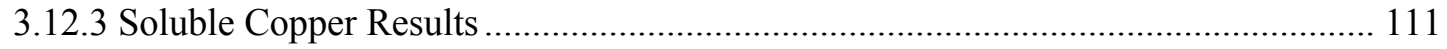

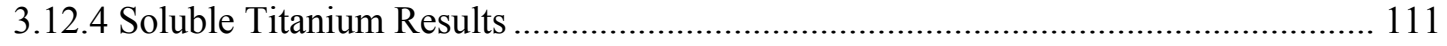

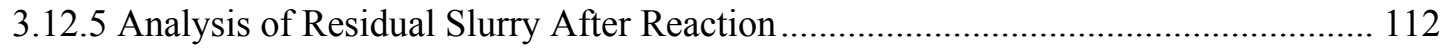

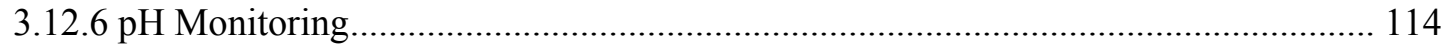

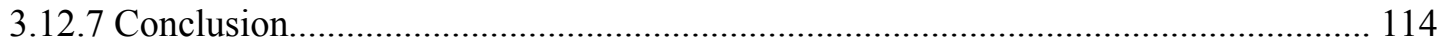




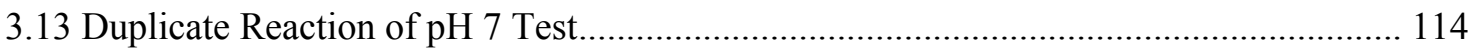

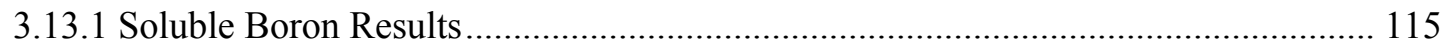

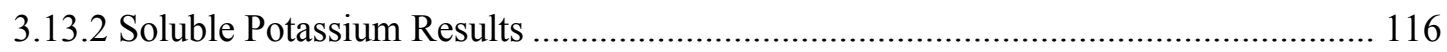

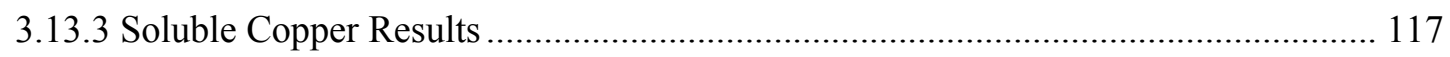

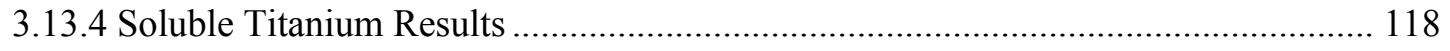

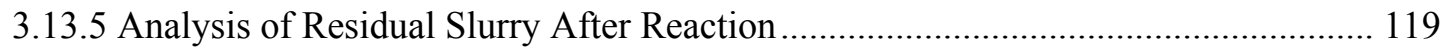

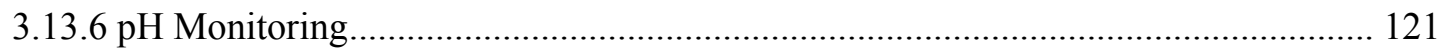

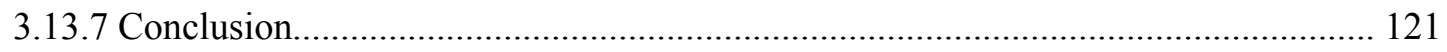

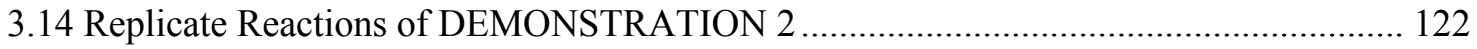

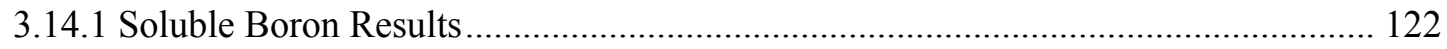

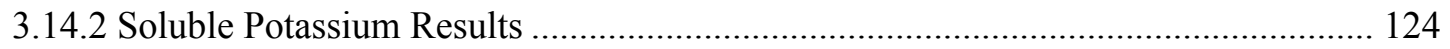

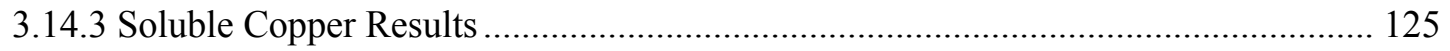

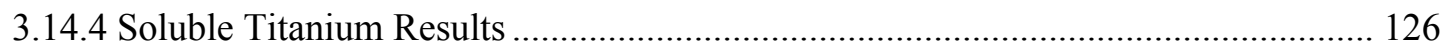

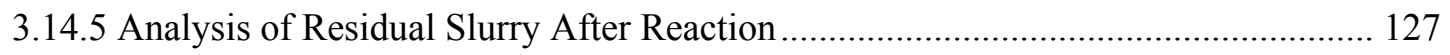

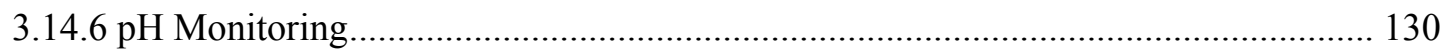

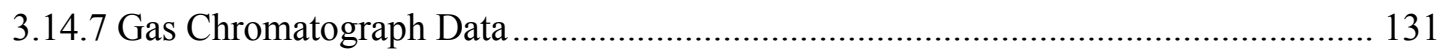

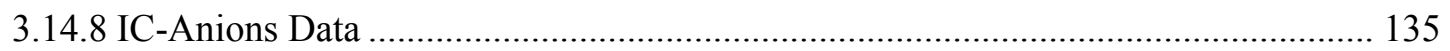

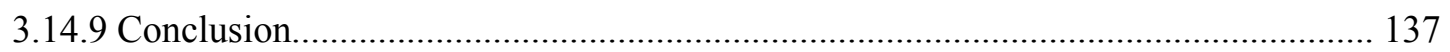

3.15 Comparison of Tests with No Added Copper (DEMO 4 and Test 2c) ........................... 137

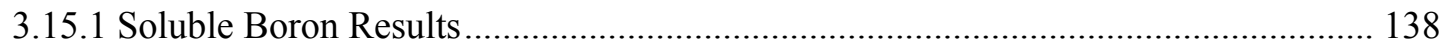

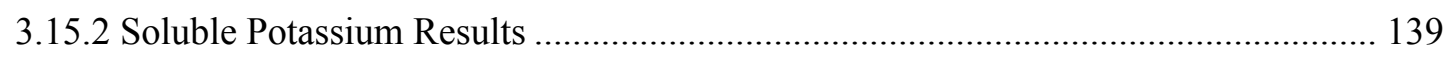

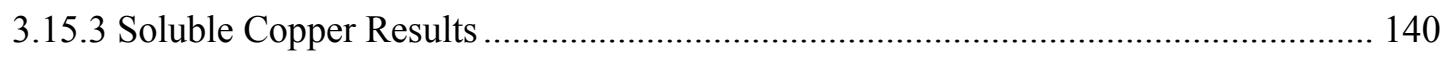

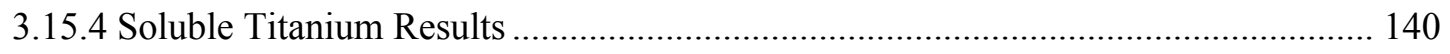

3.15.5 Analysis of Residual Slurry After Reaction ......................................................... 141

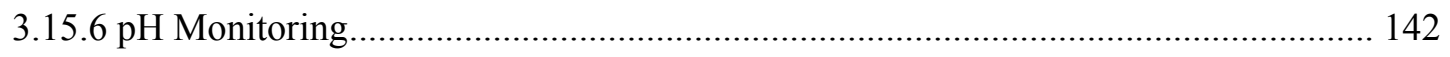

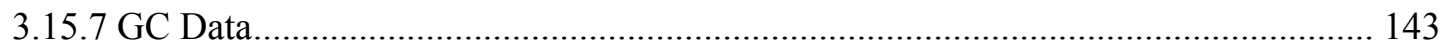

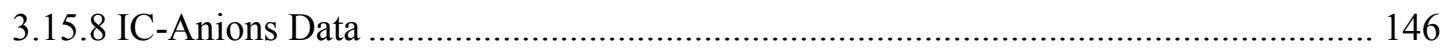

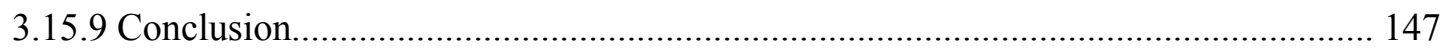

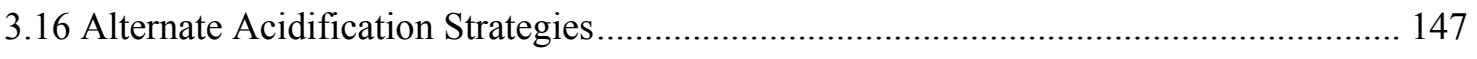

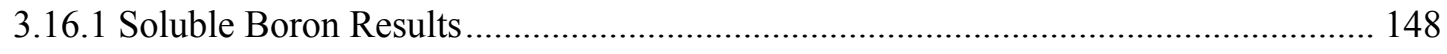

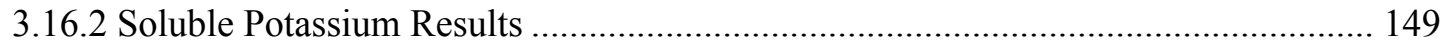

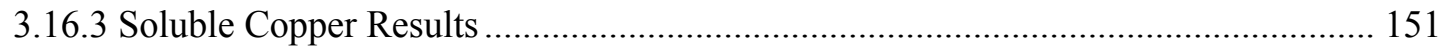

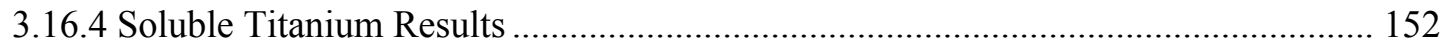

3.16.5 Analysis of Residual Slurry After Reaction ........................................................... 152 
SRNL-STI-2012-00342

Revision 1

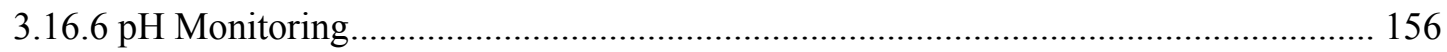

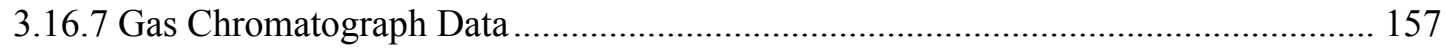

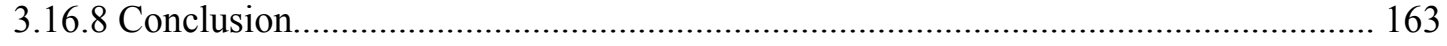

3.17 Mercury Measurements in Reactor Head Spaces .......................................................... 164

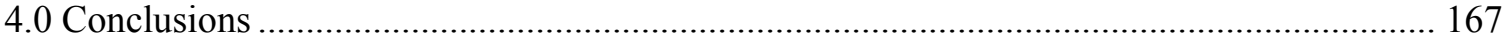

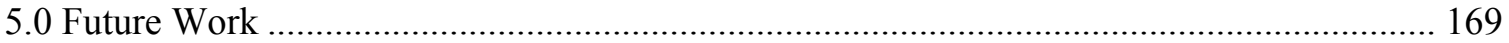

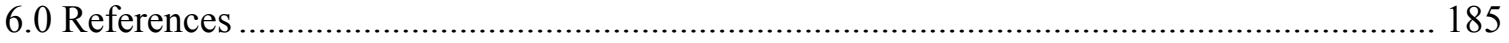




\section{List of Tables}

Table 1. Simulant Slurry Recipe (nominal $500 \mathrm{~mL}$ slurry) .................................................... 4

Table 2. Total TPB Destruction from Final Boron Results for Varying Copper Compounds ..... 13

Table 3. Total TPB Destruction from Final Potassium Results for Varying Copper Compounds 14

Table 4. Total TPB Destruction from Final Boron Results at Varying Peroxide Addition Rates 18

Table 5. Total TPB Destruction from Final Potassium Results at Varying Peroxide Addition Rates.

Table 6. Total TPB Destruction from Final Boron Results at Varying Temperatures ................. 24

Table 7. Total TPB Destruction from Potassium Results at Varying Temperatures.................... 25

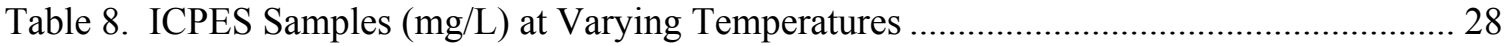

Table 9. HPLC Results from Residual Slurry After Reaction Analyses (mg/L) at Varying Temperatures 28

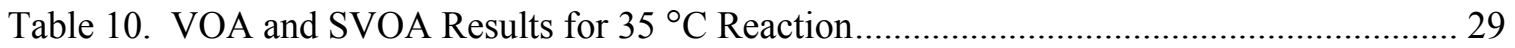

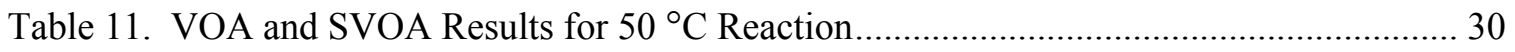

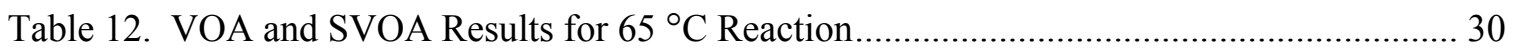

Table 13. Total TPB Destruction from Final Boron Results for Demonstration 1....................... 34

Table 14. Total TPB Destruction from Potassium Results for Demonstration 1 ........................ 35

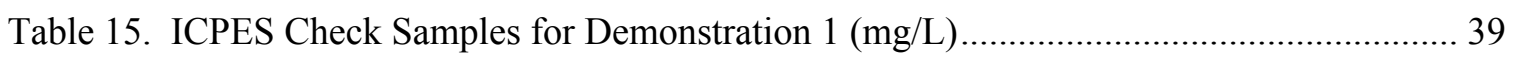

Table 16. HPLC Results from Residual Slurry After Reaction Analysis (mg/L) for

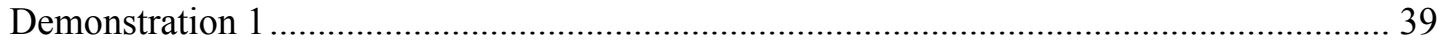

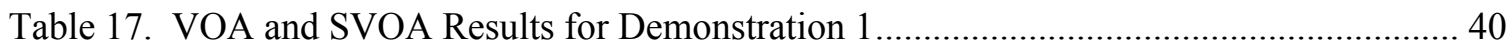

Table 18. IC-Anions Concentration Results for DEMO 1 Samples (mg/L) ................................. 47

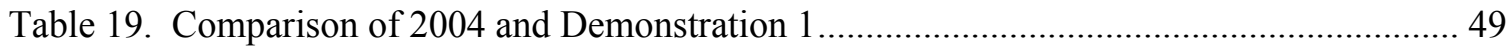

Table 20. Total TPB Destruction from Final Boron Results for Initial $\mathrm{pH}$ of 7 and $9 \ldots \ldots \ldots \ldots \ldots . . . . .53$

Table 21. Total TPB Destruction from Potassium Results for Initial pH of 7 and 9.................... 54

Table 22. ICPES Check Samples (mg/L) for Varying Initial $\mathrm{pH}$ Reactions .............................. 58

Table 23. HPLC Results from Residual Slurry After Reaction Analyses (mg/L) ....................... 58

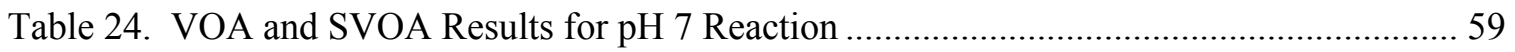

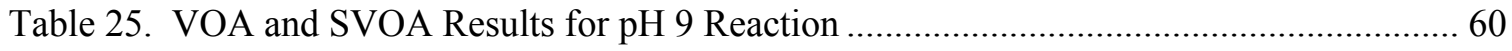

Table 26. Total TPB Destruction from Final Boron Results: Demonstration 2 .......................... 63 
Table 27. Total TPB Destruction from Potassium Results: Demonstration 2 ............................. 64

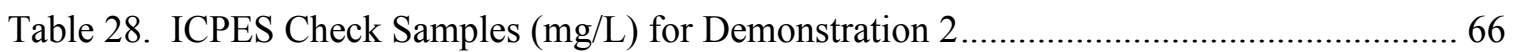

Table 29. HPLC Results from Residual Slurry After Reaction Analyses (mg/L) for

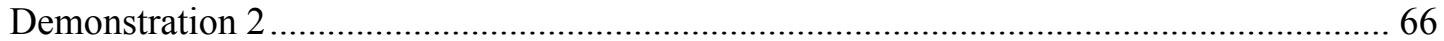

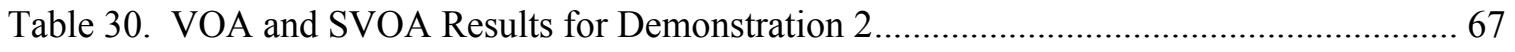

Table 31. IC-Anions Concentration Results for DEMO 2 Samples (mg/L) ................................ 73

Table 32. Total TPB Destruction from Final Boron Results: $5 \times$ Peroxide Addition Rate ........... 75

Table 33. Total TPB Destruction from Potassium Results at $5 \times$ Peroxide Addition Rate........... 77

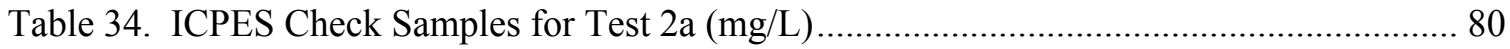

Table 35. HPLC Results from Residual Slurry After Reaction Analyses for Test 2a (mg/L)...... 80

Table 36. HPLC Results from Time = 207, 304 Hour Slurry Samples for Test 2a (mg/L) ........ 81

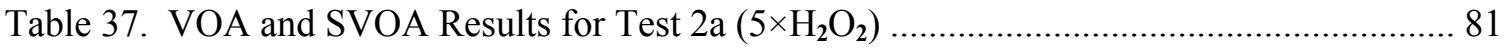

Table 38. Total TPB Destruction from Final Boron Results .................................................... 85

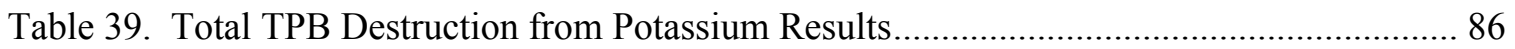

Table 40. ICPES Check Samples (mg/L) for Varying Amounts of Added Copper ..................... 89

Table 41. HPLC Results from Residual Slurry After Reaction Analyses (mg/L) for Lesser

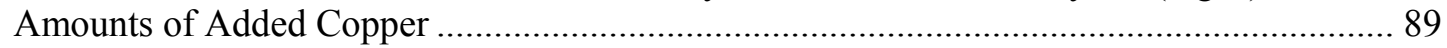

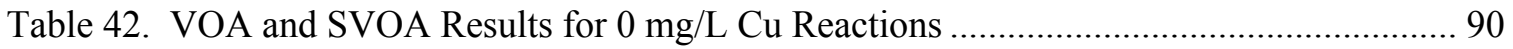

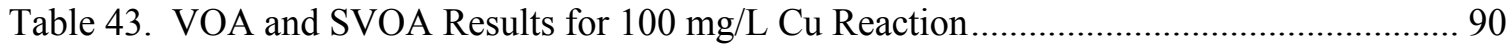

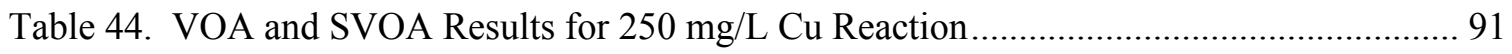

Table 45. Total TPB Destruction from Final Boron Results at Varying Temperatures ............... 94

Table 46. Total TPB Destruction from Potassium Results at Varying Temperatures.................. 95

Table 47. HPLC Results from Residual Slurry After Reaction Analyses (mg/L) at Varying

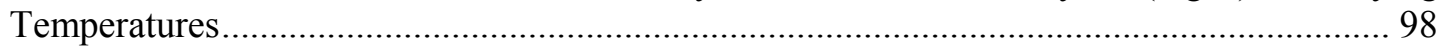

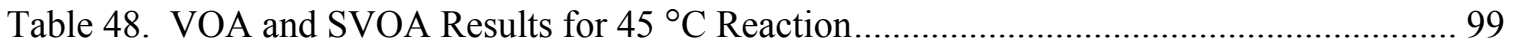

Table 49. Total TPB Destruction from Final Boron Results for Varying Peroxide Addition Rates 102

Table 50. Total TPB Destruction from Potassium Results at Varying Peroxide Addition Rates103

Table 51. HPLC Results from Residual Slurry After Reaction Analyses for Varying Peroxide

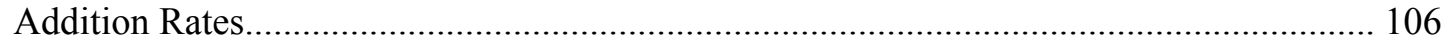

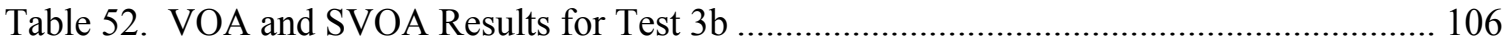


Table 53. Total TPB Destruction from Final Boron Results between Duplicate ...................... 109

Table 54. Total TPB Destruction from Final Potassium Results between Duplicate.................. 110

Table 55. HPLC Results from Residual Slurry After Reaction Analyses (mg/L) ..................... 112

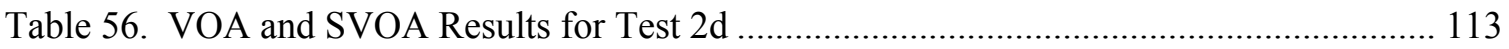

Table 57. Total TPB Destruction from Final Boron Results between Duplicate ....................... 116

Table 58. Total TPB Destruction from Final Potassium Results between Duplicate................. 117

Table 59. HPLC Results from Residual Slurry After Reaction Analyses (mg/L) ..................... 119

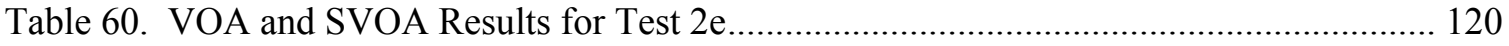

Table 61. Total TPB Destruction from Final Boron Results between DEMO 2 Replicate

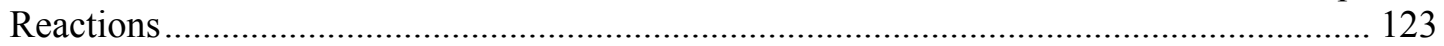

Table 62. Total TPB Destruction from Final Potassium Results between DEMO 2 Replicate

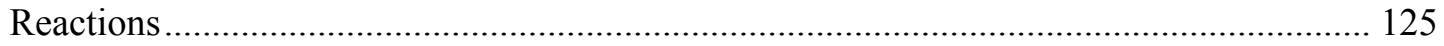

Table 63. HPLC Results from Residual Slurry after Reaction Analyses (mg/L)..................... 128

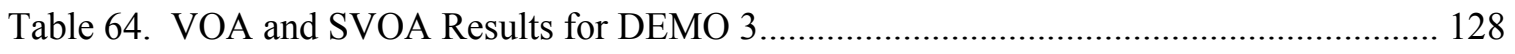

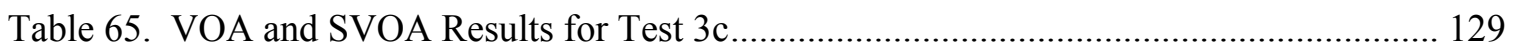

Table 66. Correlation between Reaction Duration and Residual Organics ............................... 130

Table 67. $\mathrm{CO}_{2}$ and Benzene Generation for DEMO 2 Replicates........................................... 134

Table 68. IC-Anions Concentration Results for DEMO 2 Replicates....................................... 136

Table 69. Total TPB Destruction from Boron Results - DEMO 4 vs. Test 2c ......................... 138

Table 70. Total TPB Destruction from Potassium Results - DEMO 4 vs. Test 2c.................... 140

Table 71. HPLC Results from Residual Slurry After Reaction Analyses (mg/L) ..................... 141

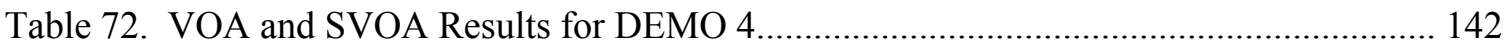

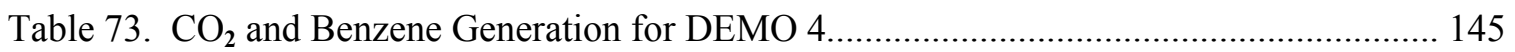

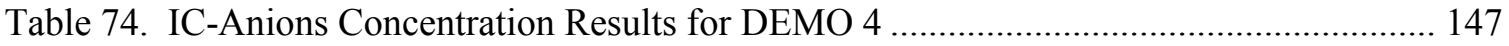

Table 75. Total TPB Destruction from Final Boron Results between Alternate Acidifications 149

Table 76. Total TPB Destruction from Final Potassium Results between Alternate Acidifications 150

Table 77. HPLC Results from Residual Slurry After Reaction Analyses (mg/L) ...................... 153

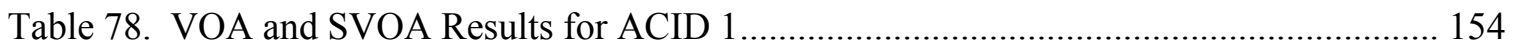

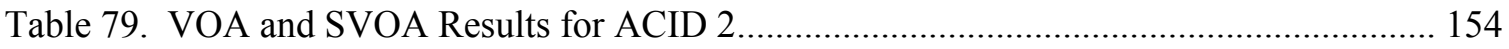




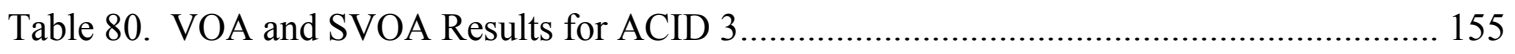

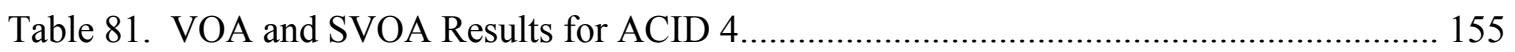

Table 82. Peak Benzene Generation Rates in the Alternate Acidification Tests........................ 158

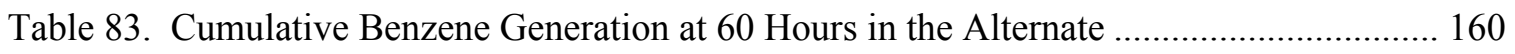

Table 84. Peak $\mathrm{CO}_{2}$ Generation Rates in the Alternate Acidification Tests.............................. 161

Table 85. Total $\mathrm{CO}_{2}$ Generation at 60 Hours in the Alternate................................................ 162

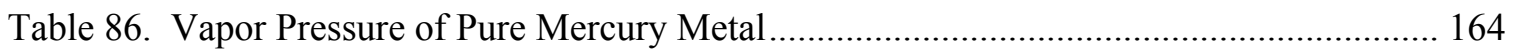

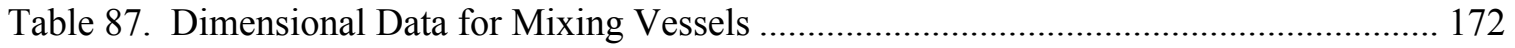

Table 88. Mixing Time Predictions and Mixing Power ........................................................ 174

Table 89. Summary of Reversed-phase HPLC Methods for TPB and Degradation Products ... 178

Table 90. Summary of Reversed-phase Gradient HPLC Method for Degradation Products ..... 179

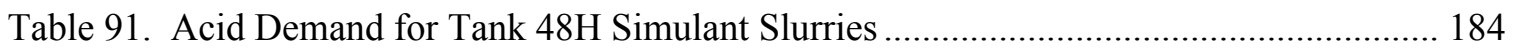




\section{List of Figures}

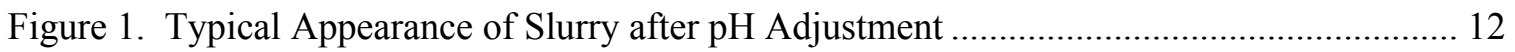

Figure 2. Boron Results Comparison for Varying Copper Compounds....................................... 13

Figure 3. Potassium Results Comparison for Varying Copper Compounds ............................... 14

Figure 4. Soluble Copper Concentration Comparison for Reactions with Varying Copper

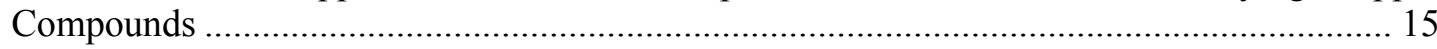

Figure 5. Titanium Concentration Comparison for Reactions with Varying Copper Compounds16

Figure 6. Boron Concentration Comparison at Varying Peroxide Addition Rates ...................... 17

Figure 7. Potassium Concentration Comparison at Varying Peroxide Addition Rates ................ 19

Figure 8. Copper Concentration Comparison at Varying Peroxide Addition Rates..................... 20

Figure 9. Titanium Concentration Comparison at Varying Peroxide Addition Rates.................. 21

Figure 10. Picture of One of the Designed Reactor Components............................................. 22

Figure 11. Boron Concentration Comparison at Varying Temperatures..................................... 24

Figure 12. Potassium Concentration Comparison at Varying Temperatures .............................. 25

Figure 13. Soluble Copper Concentration Comparison at Varying Temperatures....................... 26

Figure 14. Titanium Concentration Comparison at Varying Temperatures ................................ 27

Figure 15. Boron Concentration Results for Demonstration 1 ............................................. 34

Figure 16. Potassium Concentration Results for Demonstration 1............................................ 35

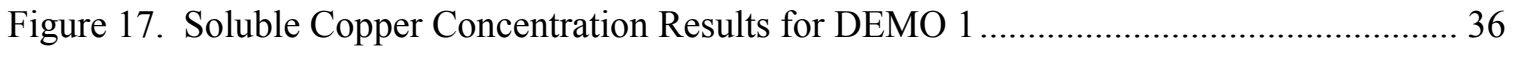

Figure 18. Soluble Boron and Copper Concentration Behavior Correlation for DEMO 1 .......... 37

Figure 19. Titanium Concentration Results for Demonstration 1 ............................................. 38

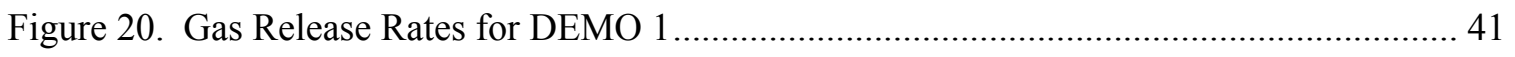

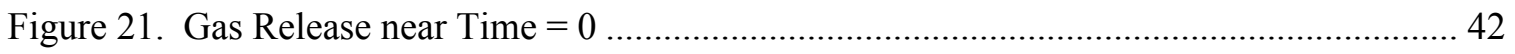

Figure 22. Cumulative Off-gas Release in Demonstration 1.................................................... 44

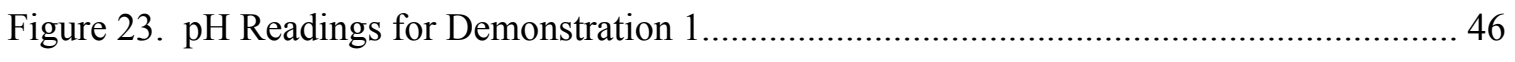

Figure 24. Comparison of 2004 pH11 Test and Demonstration 1 ............................................. 50

Figure 25. Comparison of the \%Destruction by Boron Results in the 2004 and Current Work .. 51

Figure 26. Comparison of the \%Destruction by Potassium Results in the 2004 and Current Work 
Figure 27. Boron Concentration Comparison between pH 7 and 9 Reactions ............................ 53

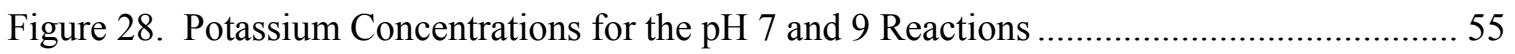

Figure 29. Soluble Copper Concentration Results for $\mathrm{pH} 7$ and 9 Reactions ............................. 56

Figure 30. Titanium Concentration Results for $\mathrm{pH} 7$ and 9 Experiments ................................... 57

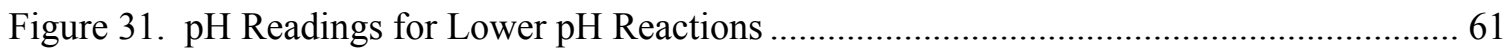

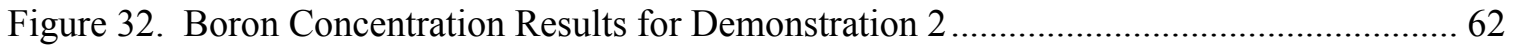

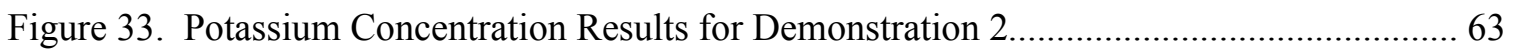

Figure 34. Soluble Copper Concentration Results for Demonstration 2 .................................... 64

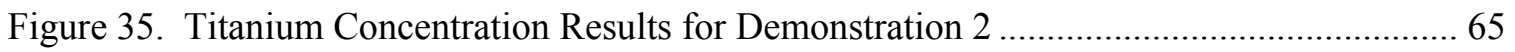

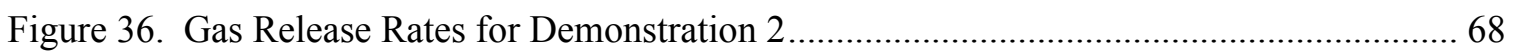

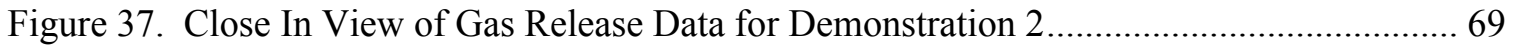

Figure 38. Cumulative Off-gas Release in Demonstration 2 ................................................. 70

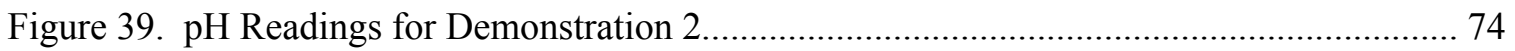

Figure 40. Boron Concentration Results Comparison at Varying Peroxide Addition Rates........ 76

Figure 41. Potassium Concentration Results Comparison at Varying Peroxide Addition Rates 77

Figure 42. Soluble Copper Concentration Results for Increased $\mathrm{H}_{2} \mathrm{O}_{2}$ Addition ........................ 78

Figure 43. Titanium Concentration Results for Increased $\mathrm{H}_{2} \mathrm{O}_{2}$ Addition ............................... 79

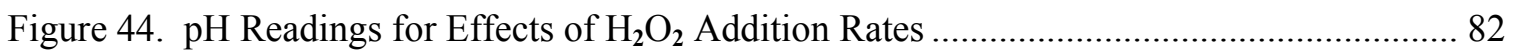

Figure 45. Boron Concentration Comparison From Low Copper Reactions ............................... 84

Figure 46. Potassium Concentration Comparison from Low Copper Reactions.......................... 85

Figure 47. Soluble Copper Concentration Results for Low Copper Reactions ............................ 87

Figure 48. Titanium Concentration Results for Low Copper Experiments................................ 88

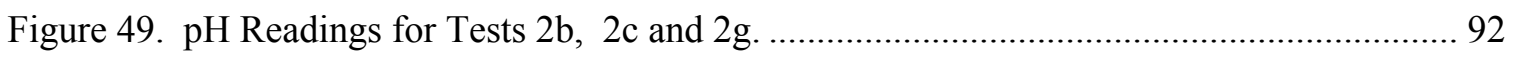

Figure 50. Boron Concentration Comparison at Varying Temperatures...................................... 94

Figure 51. Potassium Concentration Comparison at Varying Temperatures .............................. 95

Figure 52. Soluble Copper Concentration Comparison at Varying Temperatures....................... 96

Figure 53. Titanium Concentration Comparison at Varying Temperatures ................................. 97

Figure 54. pH Readings for Varying Peroxide Addition Rates ............................................. 100

Figure 55. Boron Concentration Results Comparison at Varying Peroxide Addition Rates...... 102 
Figure 56. Potassium Concentration Results Comparison at Varying Peroxide Addition Rates 103 Figure 57. Soluble Copper Concentration Results for Varying Peroxide Addition Rates ......... 104

Figure 58. Titanium Concentration Results for Varying Peroxide Addition Rates.................... 105

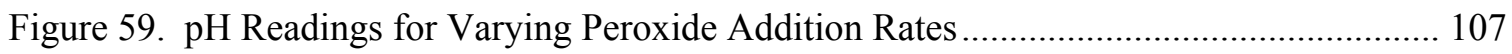

Figure 60. Boron Concentration Comparison between Duplicate pH 9 Tests ............................ 109

Figure 61. Potassium Concentration Comparison Between Duplicate pH 9 Tests ................... 110

Figure 62. Soluble Copper Concentration Comparison between Duplicate pH 9 Tests............. 111

Figure 63. Titanium Concentration Comparison between Duplicate pH 9 Tests....................... 112

Figure 64. pH Readings between Duplicate pH 9 Tests....................................................... 114

Figure 65. Boron Concentration Comparison between Duplicate pH 7 Tests ........................... 115

Figure 66. Potassium Concentration Comparison between Duplicate $\mathrm{pH} 7$ Tests ..................... 116

Figure 67. Soluble Copper Concentration Comparison between Duplicate pH 7 Tests............. 118

Figure 68. Titanium Concentration Comparison between Duplicate pH 7 Tests....................... 119

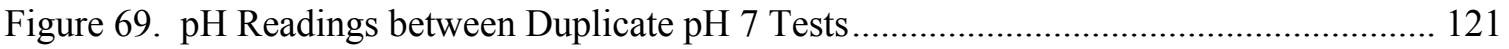

Figure 70. Boron Concentration Comparison between Replicates of ....................................... 123

Figure 71. Potassium Concentration Comparison between Replicates of DEMO 2 ….............. 124

Figure 72. Soluble Copper Concentration Comparison between DEMO 2 Replicate Reactions 126

Figure 73. Titanium Concentration Comparison between DEMO 2 Replicate Reactions .......... 127

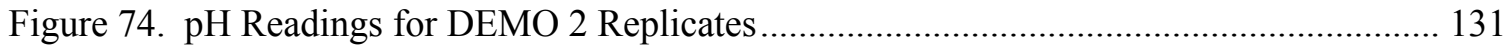

Figure 75. Gas Release Rates for Demonstration 3 ........................................................... 132

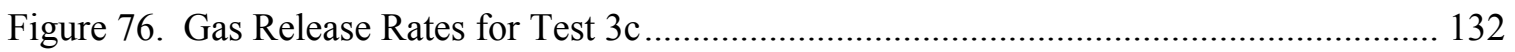

Figure 77. Cumulative Off-gas Release in Demonstration 3................................................. 133

Figure 78. Cumulative Off-gas Release in Test 3c............................................................... 134

Figure 79. Boron Concentration Results Comparison at Varying Peroxide Addition Rates...... 139

Figure 80. Potassium Concentration Results Comparison at Varying Peroxide Addition Rates 139

Figure 81. Titanium Concentration Results for Increased $\mathrm{H}_{2} \mathrm{O}_{2}$ Addition .............................. 140

Figure 82. pH Readings for Effects of $\mathrm{H}_{2} \mathrm{O}_{2}$ Addition Rates .............................................. 143

Figure 83. Gas Release Rates for Demonstration 4 ........................................................... 144

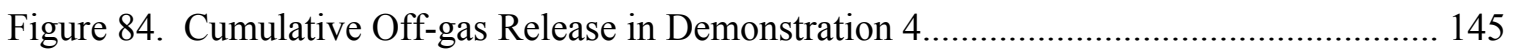


Figure 85. Boron Concentration Comparison between Alternate Acidifications....................... 148

Figure 86. Potassium Concentration Comparison between Alternate Acidifications ................. 150

Figure 87. Soluble Copper Concentration Comparison between Alternate Acidifications........ 151

Figure 88. Titanium Concentration Comparison between Alternate Acidifications .................. 152

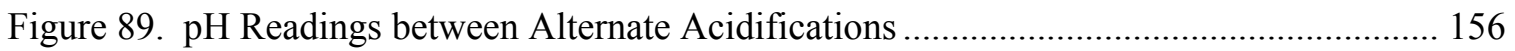

Figure 90. Benzene Generation Rates in the Alternate Acidification Tests ............................. 157

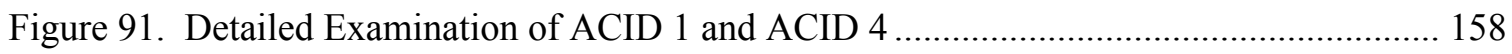

Figure 92. Cumulative Benzene Generation at 60 Hours in the Alternate Acidification Tests.. 159

Figure 93. $\mathrm{CO}_{2}$ Generation Generation Rates in the Alternate Acidification Tests ................... 161

Figure 94. Total $\mathrm{CO}_{2}$ Generation at 60 Hours in the Alternate Acidification Tests ................... 162

Figure 95. Mercury Vapor Concentration for Test DEMO3 …............................................. 165

Figure 96. Mercury Vapor Concentration for Test 3b......................................................... 166

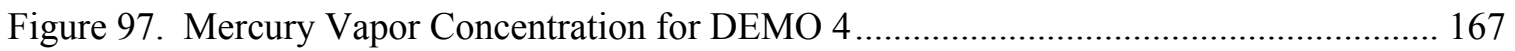

Figure 98. Chromatogram of TPB (11 min), 3PB (16 min) and 2PB (9 min) .......................... 178

Figure 99. Chromatogram $100 \mathrm{mg} / \mathrm{L}$ Standard in Acentonitrile of PBA (10 min), Phenol (15 min), Nitrobenzene (28 min), Nitrosobenzene (30 min), 4-Phenylphenol (31 min), 2-Phenylphenol (33 min), Diphenylamine (37 min), Biphenyl (40 min), o-Terphenyl (43 min), $m$-Terphenyl

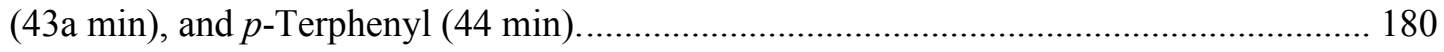

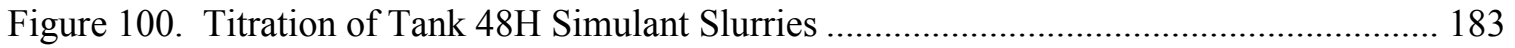




\section{List of Appendices}

Appendix A - Design of a Mixing Vessel for TPB/Peroxide Reactions

Appendix B - Analysis for Tetraphenylborate and Decomposition Products Sample Preparation

Appendix C - List of Experiments and Conditions

Appendix D - Nitric Acid Titration of Tank 48H Simulant Slurries 


\section{LIST OF ABBREVIATIONS}

\begin{tabular}{ll} 
1PB & phenylborinic acid \\
2PB & diphenylboronic acid \\
3PB & triphenylborane \\
ARP & Actinide Removal Process \\
ASTM & American Society for Testing and Materials \\
B & boron \\
CCPO & Copper Catalyzed Peroxide Oxidation \\
CCV & Continuing Calibration Verification \\
DWPF & Defense Waste Processing Facility \\
FBSR & fluidized bed steam reformer \\
GC & gas chromatograph \\
GCMS & Gas Chromatographic Mass Spectroscopy \\
HPLC & high performance liquid chromatography \\
IC-Anions & Ion Chromatography Anions \\
ICPES & Inductively-Coupled Plasma Emission Spectroscopy \\
ICV & Initial Calibration Verification \\
ITP & In-Tank Precipitation \\
K & potassium \\
LIMS & Laboratory Information Management System \\
MCU & Modular Caustic-Side Solvent Extraction Unit \\
MST & monosodium titanate \\
PUREX & Plutonium Uranium Extraction \\
PVC & polyvinylchloride \\
SRNL & Savannah River National Laboratory \\
SRS & Savannah River Site \\
SS & stainless steel \\
SVOA & Semi-Volatile Organic Analysis \\
SWPF & Salt Waste Processing Facility \\
TIC/TOC & Total Inorganic Carbon/Total Organic Carbon \\
TPB & tetraphenylborate \\
TTQAP & Task Technical and Quality Assurance Plan \\
TTR & Task Technical Request \\
VOA & Volatile Organic Analysis \\
\% RSD & percent relative standard deviation \\
\hline
\end{tabular}




\subsection{Introduction}

Tank $48 \mathrm{H}$ currently holds legacy material containing organic tetraphenylborate (TPB) compounds from the operation of the In-Tank Precipitation (ITP) process. The TPB was added during the ITP process to remove soluble cesium $\left({ }^{137} \mathrm{Cs}\right)$, but excessive benzene generation curtailed this treatment method. The contents of Tank $48 \mathrm{H}$ are not compatible with the waste treatment facilities at SRS since the organic content and the associated flammability issues pose a challenge to the salt processing and sludge processing facilities within the liquid waste system. As such the contents of Tank $48 \mathrm{H}$ must be treated to destroy the organic compounds before the tank can be emptied. Tank $48 \mathrm{H}$ currently contains $\sim 240,000$ gallons of alkaline slurry with approximately $19,000 \mathrm{~kg}$ $(42,000 \mathrm{lb})$ of potassium and cesium tetraphenylborate (KTPB and CsTPB). In the last 10 years, the volume in the tank has remained fairly constant with evaporation balanced to some degree by caustic addition for corrosion control.

Recent efforts to use fluidized bed steam reformer (FBSR) technology to remediate the Tank $48 \mathrm{H}$ contents were put on hold. ${ }^{3}$ During this hold period, SRNL has been tasked with re-examining previous work performed from 2003 through 2005. This work consisted of a series of tests that examined the ability of a copper catalyst and hydrogen peroxide to destroy the TPB in Tank $48 \mathrm{H}$ simulant slurries. Former emphasis with respect to the Copper Catalyzed Peroxide Oxidation (CCPO) process was, however, placed on in-situ treatment of the Tank $48 \mathrm{H}$ waste. However, Tank $48 \mathrm{H}$ is constructed from carbon steel which corrodes rapidly in contact with low $\mathrm{pH}$ solutions. In alkaline solutions the formation of protective films greatly reduces the corrosion rate, and thus the successful application of the CCPO process at $\mathrm{pH} 11^{4}$ was considered compatible with processing in-situ in Tank $48 \mathrm{H}$. (Also, processing at higher $\mathrm{pH}$ requires lesser dilution and lesser $\mathrm{pH}$ adjustment of the treated slurry to maintain compatibility with the downstream processing facilities.) In contrast the current application of the CCPO process is intended to take place in two stainless steel (SS) tanks located in 241-96H with each tank having a liquid capacity of approximately 6200 gallons. These tanks were considered unavailable in previous treatment evaluations due to their use for the Actinide Removal Process (ARP), as monosodium titanate (MST) strike tanks. They will, however, become available once processing operations commence in Salt Waste Processing Facility (SWPF), and ARP operations are discontinued; the intent is to transfer batches of waste from Tank 48 to the $241-96 \mathrm{H} \mathrm{SS}$ tanks for organic treatment via the CCPO process.

In a Technical Task Request (TTR) issued to SRNL, ${ }^{5}$ the work scope outlined a series of simulant and real waste tests. (Subsequently, a decision was made to defer the radioactive tests due to budget restrictions.) These tests were designed to examine individual reaction condition parameters. The overall goal was to examine and optimize the reaction so that the Tank $48 \mathrm{H}$ actual waste can be safely processed in Building 241- 
$96 \mathrm{H}$ utilizing a minimum of time and reagents. In particular, the following process attributes were considered of significant importance

- Complete (or Near-Complete) Organic Destruction - the required level of organic destruction is dictated by the destination of the treated waste and the organic limits imposed on a particular transfer destination. A flow-sheet options report has been developed ${ }^{6}$ to assess various transfer options for the CCPO-processed waste and to determine whether the treated waste meets feed composition requirements with respect to allowable levels of chemical (including organic species) and radioactive constituents.

- Repeatable and Predictable Levels of Organic Destruction - it is necessary to develop a process with a sufficiently robust operating envelope that provides both repeatable and predictable levels of organic destruction.

- Enhanced Reaction Kinetics - improving the reaction kinetics (while maintaining safe operation) will enable completion of the Tank $48 \mathrm{H}$ clean up within the currently devised Liquid Waste System Plan. ${ }^{7}$

- Minimized Chemical Addition - the CCPO process, as originally conceived, postulates the addition of nitric acid, copper catalyst, hydrogen peroxide, and potentially both anti-foam and sodium hydroxide. (The current study also considers alternates to nitric acid.) It is desirable to limit the proportion of chemicals added to the waste to negate potential downstream impacts with respect to the composition. For example, there is a limit on the amount of copper that can be incorporated into vitrified glass, and thus the goal would be to minimize the proportion of catalyst required without significantly impacting the reaction kinetics or level of organic destruction.

- Minimized Processed Waste Volume - due to the addition of the aforementioned chemicals the volume of waste increases. The 2004 study indicated a volume increase of $183 \%{ }^{4}$ It is advantageous with respect to both processing life-cycle and cost to minimize the volume of waste that must subsequently be disposed as Saltstone grout or vitrified glass.

- Minimized Reaction Temperature - the 2004 study ${ }^{4}$ ultimately utilized a temperature of $75^{\circ} \mathrm{C}$ to achieve a TPB destruction $>99.8 \%$. However, it is recognized that lower process temperatures yield benefits in terms of reducing system complexity, operation costs, and safety. Thus the goal is to promote the reaction at the lowest achievable temperature while maintaining the required reaction kinetics and level of organic destruction. The CCPO reaction vessels (MST strike tanks) do not have a dedicated heating capability and the current intent is to utilize the coiling coils for heating also. A thermal calculation will be 
required to determine the maximum achievable temperature in the reaction vessel by passing a heated medium through the currently installed cooling coils.

- Minimized Volatile Organic Compounds (VOCs) - VOCs, most notably benzene derived from degradation of the TPB, can volatilize to produce a flammable mixture in the vapor space of the reaction vessel. Minimizing the formation (and subsequent volatility) of the benzene will reduce risks associated with its flammability and the controls required to manage the vapor space.

- Minimized Hazardous Emissions - with respect to environmental emission compliance it is desirable to minimize the proportion of hazardous emissions, such as benzene and mercury. It may be possible to affect the off-gas composition by, for example, optimizing conditions for the peroxide oxidation reaction (at higher $\mathrm{pH}$ ) as opposed to the hydrolysis reaction (at lower $\mathrm{pH}$ ). It is believed that the latter results in higher benzene concentrations in the off-gas.

- Minimized MST Decomposition - a concern exists with the respect to degradation of the MST during CCPO-processing resulting in desorption and potential dissolution of the adsorbed actinides.

This work built off of previous work performed during the period of 2001-2005., ${ }^{4,9,10}$ SRNL issued a Task Technical and Quality Assurance Plan (TTQAP) that encompasses the customer's scope. ${ }^{11}$

\subsection{Experimental Procedure}

The intent of this investigation was to essentially verify the organic destruction data from the 2004 experiment, and thereafter to optimize the CCPO process. Prior to verifying the 2004 data some preliminary studies were conducted to determine if (1) copper nitrate could be substituted for copper sulfate as the source for the copper catalyst, and (2) increasing the rate of peroxide addition resulted in enhanced reaction kinetics. Based on the data from these initial experiments the verification test (termed Demonstration \#1) was conducted using copper nitrate (in lieu of copper sulfate) but with a similar peroxide addition to the 2004 studies. Concurrently with, or subsequent to, Demonstration \#1 (henceforth termed DEMO 1) two principal processing variables were modified in an effort to improve the organic destruction efficiency and reaction kinetics; namely $\mathrm{pH}$ and temperature. Optimized processing $\mathrm{pH}$ and temperature were subsequently utilized in a second demonstration (DEMO 2). Following DEMO 2 additional testing sought to further optimize the CCPO process with respect to both copper loading and hydrogen peroxide addition rate. Details with respect to the experimental procedure, and the derived data, for all of the aforementioned experiments are provided in this section, and Section 3, respectively.

See Appendix $\mathrm{C}$ for an overview of the conditions from each test. 


\subsection{Simulant Preparation}

The Tank $48 \mathrm{H}$ simulant was prepared from reagent grade chemicals, doped with nonradioactive $\mathrm{Cs}$, and catalytically active metals known to be present in Tank $48 \mathrm{H}$. The actual material and recipe are outlined in a published document. ${ }^{12}$ Previously prepared simulant components from FBSR testing were used as a cost savings. From this recipe, SRNL prepared a number of slurries, ranging in size from 100 to $500 \mathrm{~mL}$. Table 1 provides the generic recipe.

"Metals A" is a solution of various metal salts of $\mathrm{Pd}, \mathrm{Cu}, \mathrm{Zn}, \mathrm{Pb}, \mathrm{Sn}, \mathrm{Ca}, \mathrm{Sr}, \mathrm{La}, \mathrm{Cd}, \mathrm{Ce}$, $\mathrm{Rh}$, and $\mathrm{Ru}$. "Metals B" is a solution of $\mathrm{Cr}$ and Mo salts. "PUREX sludge" is a caustic sludge that is a simulant for Plutonium Uranium Extraction (PUREX) waste sludge. "Salt solution" is a typical caustic salt simulant containing enough potassium to precipitate the TPB as KTPB. The salt simulant also contains $335 \mathrm{mg} / \mathrm{L}$ of B-52 IIT antifoam. The benzene ( $44 \mu \mathrm{L}$ for a $500 \mathrm{~mL}$ slurry volume) is added to the simulant just before the commencement of testing to avoid benzene evaporative losses. The amount of added benzene was trivial and was ignored later analyses.

Upon mixing, the Tank $48 \mathrm{H}$ simulant slurry is slightly off white, and a large fraction of the KTPB floats to the surface. The slurry is capable of being well mixed, but this requires constant agitation. This is in contrast to the actual Tank $48 \mathrm{H}$ slurry, where the insoluble TPB salts have settled and no longer foam or entrain air easily. ${ }^{13}$

Simulant slurries were typically prepared a few days before use. To avoid heterogeneity issues with sampling and material balances, the slurries were prepared in individual bottles - one bottle of slurry per test. The benzene for the slurry was not added until after it was $\mathrm{pH}$ adjusted to avoid excessive evaporation.

Table 1. Simulant Slurry Recipe (nominal 500 mL slurry)

\begin{tabular}{|c|c|}
\hline Chemical & Amount required (g) \\
\hline NaTPB Solution & 85.2 \\
\hline Salt Solution & 513.6 \\
\hline Metals A & 4.35 \\
\hline Metals B & 0.55 \\
\hline PUREX Sludge & 2.15 \\
\hline MST Sludge & 5.75 \\
\hline sodium metasilicate & 0.465 \\
\hline phenol & 0.495 \\
\hline biphenyl & 0.32 \\
\hline diphenylmercury & 0.009 \\
\hline benzene & $44 \mu \mathrm{L}$ \\
\hline B-52 IIT antifoam & $335 \mathrm{mg} / \mathrm{L}$ \\
\hline
\end{tabular}




\subsection{Equipment}

For each test, care was taken to use materials that would not interfere with the CCPO process. Reaction vessels were fabricated of glass, stainless steel, or polypropylene. The nitric acid and hydrogen peroxide were metered into each reaction vessel using a gastight syringe, polyvinylchloride (PVC) flexible tubing, and stainless steel disposable needle. Agitation was provided either by a magnetic stirrer and Teflon coated sir-bar, or by a stainless steel agitator and stainless steel paddles. See Figure 10 for an example of one of the reaction vessels. The first three tests (two described in Section 3.1 and one described in Section 3.2) used 1L polypropylene bottles and stir bars as the reaction vessels were not fabricated at the time.

\subsection{Experiment Procedure}

The general sequence of events for each experiment follows.

- The slurry for an experiment was dispensed into the reaction vessel.

- With constant agitation, the slurry was $\mathrm{pH}$ adjusted (at room temperature) to the desired $\mathrm{pH}$ using $10.4 \mathrm{M}$ nitric acid. The acid was added at a rate of $42 \mathrm{~mL} /$ hour using a syringe pump. (In tests examining other acids, the concentration of the acid and addition rate is defined later in this report.) For the first three tests (see Sections 3.1 and 3.2), the slurry was $\mathrm{pH}$ adjusted first and subsequently dispensed into the reaction vessel as the complete reaction vessels were not yet fabricated.

- At time $=0$ a sample of slurry was removed from the reaction vessel and archived for later analysis.

- The required amount of benzene per the simulant recipe (Table 1) was added at this time.

- The required amount of copper catalyst (typically, $500 \mathrm{mg}$ per $\mathrm{L}$ of solution of $\mathrm{Cu}$, in the form of $\mathrm{Cu}\left(\mathrm{NO}_{3}\right)_{2} \bullet 2.5 \mathrm{H}_{2} \mathrm{O}$ ) was dissolved into $\sim 4 \mathrm{~mL}$ of deionized water and added drop-by-drop to the slurry with agitation.

- If the reaction required heating, the heater was turned on, and the heating bath was allowed to come to temperature (requiring typically 10 minutes or less).

- The $\mathrm{H}_{2} \mathrm{O}_{2}$ addition (using $50 \mathrm{wt} \% \mathrm{H}_{2} \mathrm{O}_{2}-17.5 \mathrm{M}$ ) was initiated (at time $=0$ ). 
- Throughout the experiment, samples were removed from the vessel, filtered, and stored for later analysis. In a limited number of instances, a slurry sample (without filtration) was collected for analysis.

At the end of the experiment, the $\mathrm{H}_{2} \mathrm{O}_{2}$ addition was stopped (temperature bath turned off, no further material additions, but allowed to stir) and the vessel was passively cooled to room temperature. The residual slurry after reaction was poured from the vessel into a tared 1L poly bottle. The weight of the recovered slurry was noted, and well-stirred subsamples were sent for analysis. The recovered slurry weight does not include a small and varying amount of material which was deposited on top of glass reactor head.

\subsection{Experiment Conditions}

Reaction conditions were varied between the tests to identify a set of optimal processing parameters. Experiments detailed in this report examined the effects of temperature, peroxide addition rates, form of copper catalyst, starting $\mathrm{pH}$, and acid used. See Appendix $\mathrm{C}$ for an overview of test conditions.

\section{$2.5 \mathrm{pH}$ Adjustment with Acid}

For process economy, it is important to minimize the volumes of added chemicals to the experiment to match the limitations of the existing Building $241-96 \mathrm{H}$ equipment. This is not so much a limitation for the laboratory-scale experiments, but for the real waste

process. Since the reaction vessel capacity in $241-96 \mathrm{H}$ is 6200 gallons, large additions of chemicals will drastically reduce the quantity of real waste that can be processed in each batch and increase the waste volumes. For this reason, SRNL and the customer decided to use $50 \mathrm{wt} \%$ nitric acid for the majority of the tests. A later series of tests examine use of formic and phosphoric acids. However, a disadvantage of using strong acids is related to the formation of tars and intractable solids upon contact with TPB solids, ${ }^{8}$ in addition to the potential for benzene formation via an acid hydrolysis reaction. ${ }^{14}$ Also, addition of concentrated nitric acid increases the risk of formation of nitrated compounds that may prove energetic.

SRNL performed a series of $\mathrm{pH}$ adjustment tests using 15, 35, and $50 \mathrm{wt} \%$ nitric acid, and two different addition rates $(4.2 \mathrm{~mL} /$ hour, and $42 \mathrm{~mL} /$ hour $)$. See Appendix D. There was no difference in acid demand, so SRNL chose the faster delivery rate for economy of time.

\section{6 $\underline{\text { Addition of } \mathrm{H}_{2} \underline{\mathrm{O}}_{2}}$}

Hydrogen peroxide was added as a $50 \mathrm{wt} \%$ solution, and was added at a rate of $0.1 \mathrm{~mL} /$ hour for $250 \mathrm{~mL}$ of simulant slurry, and twice that rate for $500 \mathrm{~mL}$ of simulant slurry. This rate of addition is referred to as " $1 \times \mathrm{H}_{2} \mathrm{O}_{2}$ ". Reactions that have faster $\mathrm{H}_{2} \mathrm{O}_{2}$ 
delivery rates are integer multiples of the $1 \times \mathrm{H}_{2} \mathrm{O}_{2}$ rate. These rates approximately matched the rates used in the 2004 work, after scaling for volume differences.

Although the 2004 work used $30 \mathrm{wt} \% \mathrm{H}_{2} \mathrm{O}_{2}$, a decision was made to keep the addition rate the same despite the differences in $\mathrm{H}_{2} \mathrm{O}_{2}$ concentration. There were no anticipated negative processing effects in using a higher peroxide concentration, and $50 \mathrm{wt} \% \mathrm{H}_{2} \mathrm{O}_{2}$ should ultimately reduce the final waste volume.

\subsection{Analysis of Samples}

Filtrate samples from the reactions were analyzed by any or all of Inductively Coupled Plasma Emission Spectroscopy (ICPES), IC-Anions, and wet chemistry techniques, all of which have a $10 \%$ analytical uncertainty. Samples of the slurry were removed from the reaction and analyzed by any or all of volatile organic analysis (VOA), semi-volatile organic analysis (SVOA), Total Inorganic Carbon/Total Organic Carbon (TIC/TOC), and high performance liquid chromatography (HPLC). VOA and SVOA methods have a $20 \%$ analytical uncertainty. TIC/TOC and HPLC have a 10\% analytical uncertainty.

Measurement (analytical) uncertainty is defined as a parameter associated with the result of a measurement that characterizes the dispersion of the values that could reasonably be attributed to the measured quantity. SRNL Analytical Development methods employ several techniques for estimating and calculating measurement uncertainty. These range from propagation of all sources of uncertainty within a method to monitoring of control charts. ${ }^{15}$ All estimated uncertainties are applied to customer sample results, available in LIMS.

ASTM Committee E-19 conducted a cooperative program on the study of the quantitation of HPLC which revealed that the technique is generally accurate and precise with relative standard deviations ranging from $3 \%$ to $8 \%$ for nearly all of the participating laboratories. ${ }^{16}$ For HPLC and IC, Initial Calibration Verification and Continuing Calibration Verification (ICV/CCV) standards are analyzed before and after each batch of samples and the results are maintained between $\pm 10 \%$ of the value of the standard. Graphing the ICV/CCV values on control charts shows most values are within 5\%, at $1 \sigma$ confidence level, of the standard average in keeping with the literature. Analytical Development sets the uncertainty of measurement at $10 \%$, at the $1 \sigma$ confidence level for IC and HPLC to capture the variety of matrices, bias, and the range of analyte concentrations in summited samples.

For ICP-ES, the uncertainty at the $1 \sigma$ confidence level is calculated using the equation $\sqrt{a^{2}+b^{2}}$ where $a$ is the variance allowed in the measurement of the CCV standards $( \pm$ $10 \%$ of the value of the standard) and $b$ is the deviation associated with the triplicate integrations for each sample at the instrument. 
The uncertainty for the GCMS methods, general SVOA scan and VOA scan techniques is estimated from CCV values that are maintained between $\pm 20 \%$ of the value of the standard. An uncertainty value of $20 \%$ at the $1 \sigma$ confidence level is reported based on multiple CCV replicates.

The uncertainty for the TIC-TOC method is estimated from CCV values that are maintained between $\pm 10 \%$ of the value of the standard. An uncertainty value of $10 \%$ at the at $1 \sigma$ confidence level is reported based on multiple $\mathrm{CCV}$ replicates.

While tables of data give error values, graphs of the data do not include error bars for reasons of clarity.

\subsection{Results and Discussion}

During the course of each reaction, the main method utilized for determining the progression of the reaction was ICPES analysis of filtrate samples. Prior to reaction, all of the boron in the simulant is associated with the solid KTPB. The total amount of boron in the simulant slurry is calculated to be on average approximately $548 \mathrm{mg} / \mathrm{L}$ though this value may vary slightly between slurries. As the KTPB, and its phenylborate decomposition compounds triphenyl borane (3PB), diphenylborinic acid (2PB) and phenyl boronic acid (1PB), are broken down during CCPO processing soluble boron species are derived. Soluble boron is derived from nitric acid attack (hydrolysis) of the TPB and phenylborate decomposition compounds during $\mathrm{pH}$ adjustment, and the later peroxide aided destruction of the same. Changes in the boron concentration for filtrate samples retrieved at various reaction times are indicative of the time-dependent decomposition of TPB. It is, however, important to note that since it is not known whether all of the derived boron species formed during processing are soluble, the boron concentration in the filtrate may not provide an absolute measurement with respect to the degree of TPB destruction. A definitive value for the extent of TPB destruction rather is provided by the determining the post-reaction concentration of residual TPB via HPLC.

A sample is removed after $\mathrm{pH}$ adjustment (time $=0$ ), but prior to addition of the copper catalyst or $\mathrm{H}_{2} \mathrm{O}_{2}$; this sample serves as an indicator with respect to the proportion of TPB destruction associated with the $\mathrm{pH}$ adjustment alone. Due to the fact that multiple samples were removed from the reaction vessels for intermediate analyses, and added volume from the addition of the $\mathrm{H}_{2} \mathrm{O}_{2}$, each set of sample results is normalized to the time $=0$ sample results by using the sodium concentration as the normalization factor (i.e., comparing the sodium concentrations of the retrieved sample to that of the sample at time $=0)$.

At the end of each test, the extent of boron dissolution associated with the TPB destruction was calculated. The proportion of TPB destruction associated with acid addition is defined as follows 


$$
\left[B_{t=0}\right] /\left[B_{\text {total }}\right]
$$

The proportion of TPB destruction provided by the $\mathrm{H}_{2} \mathrm{O}_{2}$ /copper oxidation reaction is defined as:

$$
\frac{\left[B_{\text {final }}\right]-\left[B_{t=0}\right]}{\left[B_{\text {total }}\right]}
$$

where variable $\left[\boldsymbol{B}_{t=0}\right]$ is defined as the analyzed boron concentration in the time $=0$ filtrate sample (after acid addition), variable $\left[\boldsymbol{B}_{\text {total }}\right]$ is defined as the concentration of boron if all the boron was in solution, and variable $\left[\boldsymbol{B}_{\text {final }}\right]$ is defined as the boron in the final filtrate sample.

The total TPB destruction is the sum of both contributions. This sum, as defined from the boron data can sometimes plateau at less than $100 \%$ destruction. It is possible that the boron-containing organic breakdown products are less than completely soluble; therefore the percent destruction values are possibly lower bounds. In this case, when the soluble boron indicates a leveling off, this can be assumed to imply total TPB destruction.

The presence of soluble potassium $(\mathrm{K})$ in the filtrate is also used as an indicator of the extent of destruction of the KTPB. The starting amount of potassium in the slurry simulant filtrate (i.e., not associated with solid KTPB) is calculated to be $\sim 278 \mathrm{mg} / \mathrm{L}$ though this value may vary slightly between slurries. The total amount of potassium in the simulant slurry is calculated to be $\sim 2260 \mathrm{mg} / \mathrm{L}$ which will also vary between slurries. Soluble potassium is derived from nitric acid attack on the KTPB during $\mathrm{pH}$ adjustment, and the later peroxide aided destruction of the same. As the time $=0$ sample is removed after $\mathrm{pH}$ adjustment, but before addition of the copper catalyst or $\mathrm{H}_{2} \mathrm{O}_{2}$, this sample serves as an indicator of the amount of destruction provided by the $\mathrm{pH}$ adjustment.

At the end of each test, the extent of potassium dissolution associated with the TPB destruction was calculated. In each case, the proportion of KTPB destruction from $\mathrm{pH}$ adjustment is defined as follows

$$
\frac{\left[K_{t=0}\right]-\left[K_{\text {filtrate }}\right]}{\left[K_{\text {total }}\right]-\left[K_{\text {filtrate }}\right]}
$$

The proportion of KTPB destruction provided by the $\mathrm{H}_{2} \mathrm{O}_{2} /$ copper is defined as: 


$$
\frac{\left[K_{\text {final }}\right]-\left[K_{t=0}\right]}{\left[K_{\text {total }}\right]-\left[K_{\text {filtrate }}\right]}
$$

where variable $\left[\boldsymbol{K}_{t=0}\right]$ is defined as the analyzed potassium concentration in the time $=0$ filtrate sample, variable $\left[\boldsymbol{K}_{\text {filtrate }}\right]$ is defined as the concentration of potassium in the filtrate before acidification, variable $\left[\boldsymbol{K}_{\text {total }}\right]$ is defined as the concentration of potassium if all the potassium was in solution, and variable $\left[\boldsymbol{K}_{\text {final }}\right]$ is defined as the potassium in the final filtrate sample.

The total KTPB destruction is the sum of both contributions.

The aforementioned formulas (1-4, above) are used to derive the percent destruction. However, per a customer request, SRNL is incorporating the analytical uncertainty into these values. As a result, the percent TPB destruction results are given as ranges, based upon the 1-sigma analytical uncertainty. To calculate the range, the uncertainty in each calculation is applied to certain variables to derive a low and high value. For this purpose, the following variables have a $10 \%$ analytical uncertainty$$
B_{t=0}, B_{\text {final }}, K_{t=0}, K_{\text {final }}
$$

The other variables are derived from gravimetric data and are assumed to have an uncertainty small enough to ignore for this purposes of calculating the ranges. Furthermore, as $\boldsymbol{B}_{\text {final }}$ and $\boldsymbol{K}_{\text {final }}$ are subject to normalization from sodium data this would normally trigger a new uncertainty propagation calculation, and consequently a third error propagation from the combination of the two original uncertainties. Rigorous error analysis to this degree is far outside the scope of this document, and SRNL is of the opinion that the level of error propagation presented here is reasonable.

In addition, the ICPES results also provide the soluble copper $(\mathrm{Cu})$ and titanium (Ti) concentrations. The concentration of soluble copper in the slurry is of interest since it indicates the proportion of the added copper catalyst that actually dissolves. Dissolved copper is more likely to function as a catalyst species, although at this time the form of the presumed copper catalyst species in unknown. The starting amount of copper in the slurry simulant filtrate is calculated to be effectively zero. While there is $\sim 2 \mathrm{mg} / \mathrm{L}$ of $\mathrm{CuSO}_{4} \bullet 5 \mathrm{H}_{2} \mathrm{O}$ in the "Metals A" component of the waste simulant, the quantity is small relative to the $500 \mathrm{mg} / \mathrm{L}$ copper added as the catalyst.

The concentration of titanium in the filtrate is utilized as a measurement of the extent of solubility of the titanium cation. The only source of titanium in the slurry simulant is from the MST component, and therefore any significant ingrowth of titanium in solution 
is of concern since it indicates the decomposition of MST and potential release of sorbed fissionable materials $(\mathrm{U}$ and $\mathrm{Pu})$.

HPLC results are also used to derive a percent TPB destruction value. A series of gravimetric measurements (density, weight, etc), as well as a pair of duplicate HPLC measurements are used as inputs. As with the percent TPB destruction values derived from boron and potassium data, the customer has requested that SRNL report the percent TPB destruction by HPLC as a range of values that incorporate the analytical uncertainty $(10 \%)$. As with the aforementioned calculations, SRNL assumes that the variables derived from gravimetric data are assumed to have an uncertainty small enough to ignore for this purposes of calculating the ranges. As the HPLC results are duplicate results, SRNL consulted with a statistician. From this discussion, SRNL has determined that presenting the average of the duplicate data points with the \%RSD already encompasses the analytical uncertainty, and therefore, presenting the data as a range of results is technically incorrect. Therefore, these analytes are reported as single values with a \%RSD. For calculated values derived directly from these analytes, value ranges are calculated by treating these analytical results as if they were single point results, where the range is derived from applying the \%RSD to the reported result. If the HPLC measurements provided a detection limit result (typically either $<4$ or $<10 \mathrm{mg} / \mathrm{L}$ ) it is assumed there is no uncertainty associated with the HPLC result and therefore, there is no range of values, only a single value reported.

The SVOA analysis is used to measure the quantity of residual organics (not counting $\mathrm{TPB}, 3 \mathrm{~PB}, 2 \mathrm{~PB}, 1 \mathrm{~PB}$, or phenol) in the residual slurry after reaction. Due to a customer request, the results are reported as a range of results when appropriate. For results that are single point results, the range is derived from the analytical uncertainty (20\%) applied to the reported result. Duplicate results are resolved as with the HPLC method above. The residual organics do not include a small and varying amount of material deposited in the top of the reactor dome. This material was likely mostly biphenyl and was isolated for future analysis if necessary.

\subsection{Effect of the Form of the Copper Catalyst}

While the precise downstream destination of the CCPO-processed waste is not known, it is quite likely that some portion of the waste will ultimately be transferred to the Defense Waste Processing Facility (DWPF). The DWPF melter is sensitive to the amount of sulfate and, therefore, there is a desire to minimize further additions of this anion.

In the 2004 work, ${ }^{4}$ SRNL used copper sulfate $\left(\mathrm{CuSO}_{4} \bullet 5 \mathrm{H}_{2} \mathrm{O}\right)$ as the source of the copper catalyst. The first set of tests SRNL performed in the current work scope was to examine the effect of changing the copper catalyst from $\mathrm{CuSO}_{4} \bullet 5 \mathrm{H}_{2} \mathrm{O}$ to $\mathrm{Cu}\left(\mathrm{NO}_{3}\right)_{2} \bullet 2.5 \mathrm{H}_{2} \mathrm{O}$. It was not anticipated that the change in chemical form would reduce the reactivity. 
For this experiment, two $1 \mathrm{~L}$ poly bottles each with a magnetic stirrer and stir bar were configured. Two sets of slurries $(250 \mathrm{~mL}$ each) were generated according to the recipe in Table 1. Each slurry was adjusted with $50 \mathrm{wt} \%(10.4 \mathrm{M})$ nitric acid to a final $\mathrm{pH}$ of 11 . The $\mathrm{pH}$ adjustment resulted in $\sim 300 \mathrm{~mL}$ of brown slurry, with some heterogeneous solids present. See Figure 1. The slurry was used without further changes. To one bottle, copper catalyst was added in the form of $\mathrm{CuSO}_{4} \bullet 5 \mathrm{H}_{2} \mathrm{O}$, and in the other bottle, the copper was added in the form of $\mathrm{Cu}\left(\mathrm{NO}_{3}\right)_{2} \bullet 2.5 \mathrm{H}_{2} \mathrm{O}$. For each test $500 \mathrm{mg} / \mathrm{L}$ of copper was utilized. Tests were conducted at ambient laboratory temperature (typically $21{ }^{\circ} \mathrm{C}$ ). Hydrogen peroxide was added at a rate of $0.1 \mathrm{~mL} /$ hour.

The filtrate samples started with a dark orange and lightened over time. The slurry in the reaction vessel changed color from brown, to a slightly more green-brown.

Figure 1. Typical Appearance of Slurry after pH Adjustment

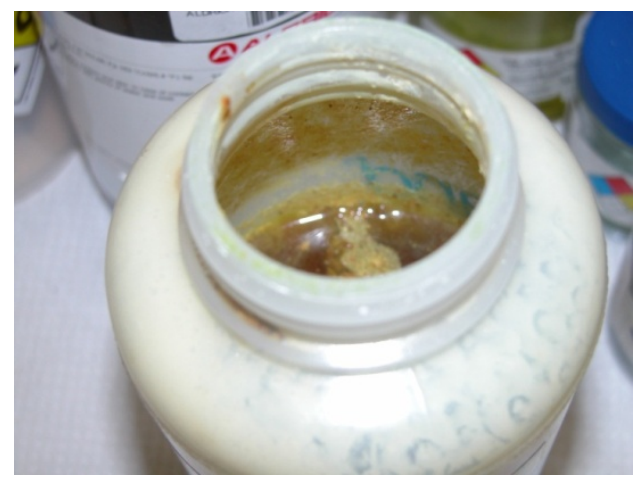

A total of 16 samples were removed (during the 3 week test period) for analysis by ICPES. From the ICPES results, the boron, potassium, copper, sodium, and titanium concentration results were examined. Results from each test were compared to establish potential differences in reactivity.

\subsubsection{Soluble Boron Results}

After the start of the $\mathrm{H}_{2} \mathrm{O}_{2}$ addition, the boron concentration in the filtrate samples slowly increased over time. See Figure 2.

The total TPB destruction is shown in Table 2. 
SRNL-STI-2012-00342

Revision 1

\section{Table 2. Total TPB Destruction from Final Boron Results for Varying Copper Compounds}

\begin{tabular}{|c|c|cc|cc|}
\hline \multicolumn{2}{|c|}{ Destruction by Acid } & \multicolumn{2}{c|}{ Destruction by $\mathrm{H}_{2} \mathrm{O}_{2}$} & \multicolumn{2}{c|}{ Total Destruction } \\
\hline Cu-nitrate & Cu-sulfate & Cu-nitrate & Cu-sulfate & Cu-nitrate & Cu-sulfate \\
\hline $23.8-29.1 \%$ & $24.1-29.4 \%$ & $31.9-46.0 \%$ & $28.9-42.4 \%$ & $58.9-72.0 \%$ & $56.1-68.6 \%$ \\
\hline
\end{tabular}

During the length of the experiment, both reactions provided virtually identical results, resulting in a total average TPB destruction of $62-65 \%$.

Figure 2. Boron Results Comparison for Varying Copper Compounds

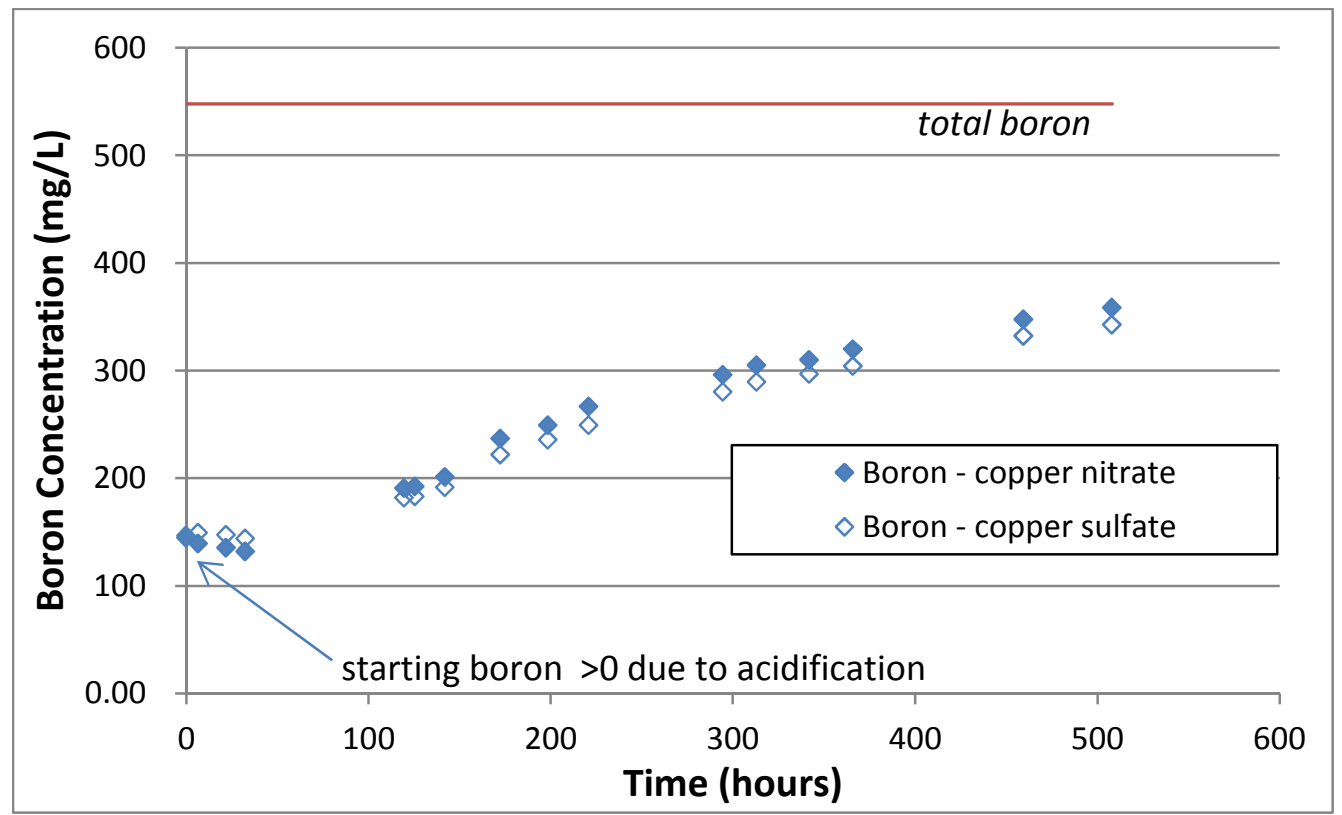

\subsubsection{Soluble Potassium Results}

Data for soluble potassium indicate the same time-dependent trends previously discussed for boron. See Figure 3.

The TPB destruction levels (based on the soluble potassium data) are shown in Table 3. 


\section{Table 3. Total TPB Destruction from Final Potassium Results for Varying Copper Compounds}

\begin{tabular}{|cc|cc|cc|}
\hline \multicolumn{2}{|c|}{ Destruction by Acid } & \multicolumn{2}{c|}{ Destruction by $\mathrm{H}_{2} \mathrm{O}_{2}$} & \multicolumn{2}{c|}{ Total Destruction } \\
\hline Cu-nitrate & Cu-sulfate & Cu-nitrate & Cu-sulfate & Cu-nitrate & Cu-sulfate \\
\hline $33.7-44.3 \%$ & $37.1-48.5 \%$ & $27.6-48.7 \%$ & $18.9-39.5 \%$ & $68.0-86.2 \%$ & $63.4-80.6 \%$ \\
\hline
\end{tabular}

Figure 3. Potassium Results Comparison for Varying Copper Compounds

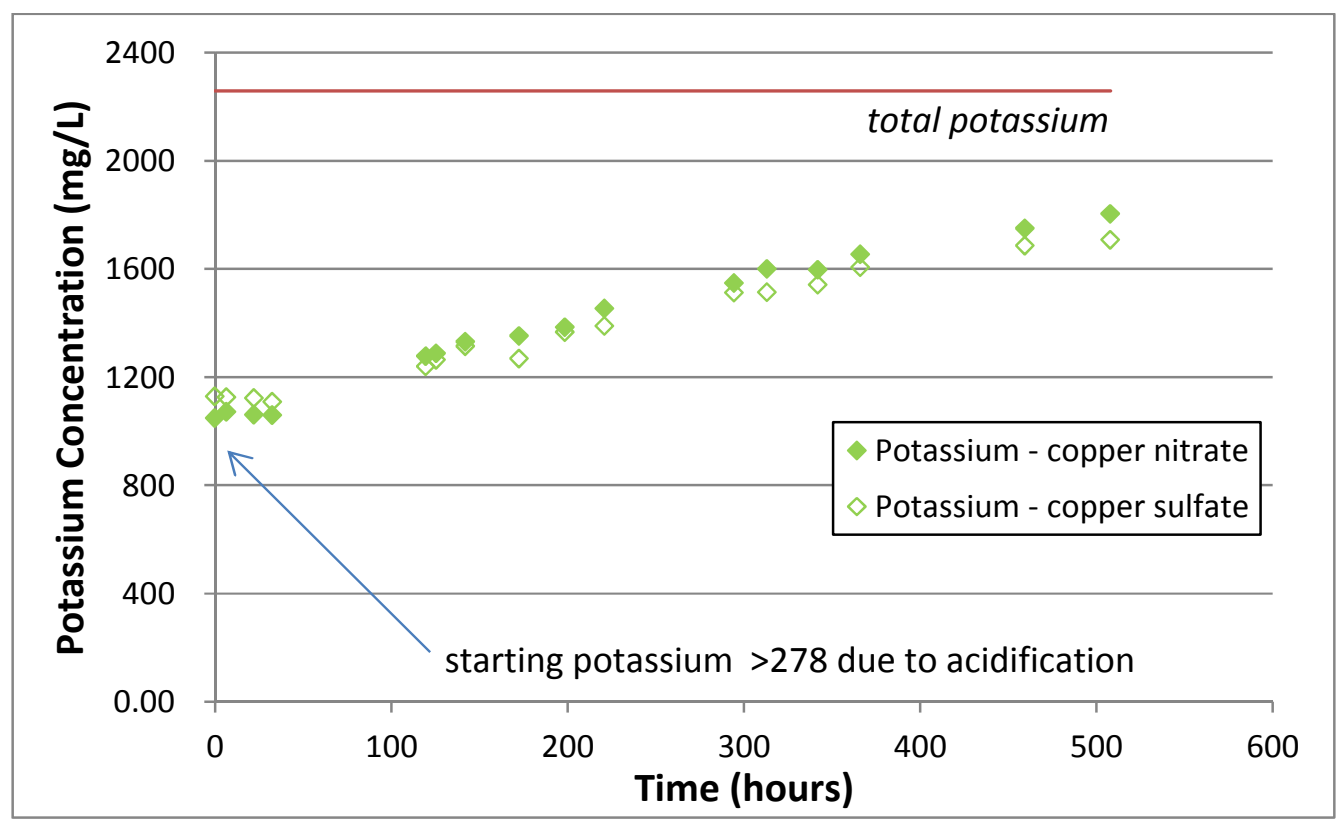

During the length of the experiment, both reactions provided virtually identical results, resulting in a final total average TPB destruction of $\sim 72-77 \%$. There is an offset in the boron and potassium derived TPB destruction values, possibly due to the fact that once KTPB is degraded, the potassium remains free in solution, whereas the organoboron degradation compounds may not be as soluble.

\subsubsection{Soluble Copper Results}

After the start of the $\mathrm{H}_{2} \mathrm{O}_{2}$ addition the copper in the filtrate samples slowly increased over time to a maximum of $\sim 100 \mathrm{mg} / \mathrm{L}$ (or $20 \%$ of the total added copper). See Figure 4.

Both reactions provided virtually identical filtrate results for the copper. This finding is not surprising as both copper salts are highly water soluble and possess anions that are 
relatively non-coordinating (i.e. uninvolved in chemical reactions). The low percentage of dissolved copper suggests that both copper salts have a low initial solubility in the caustic salt slurry. Future work may be directed towards assessing alternative forms of copper catalyst addition to improve the copper solubility, as presumably, improved copper solubility may improve the catalytic function.

\section{Figure 4. Soluble Copper Concentration Comparison for Reactions with Varying Copper Compounds}

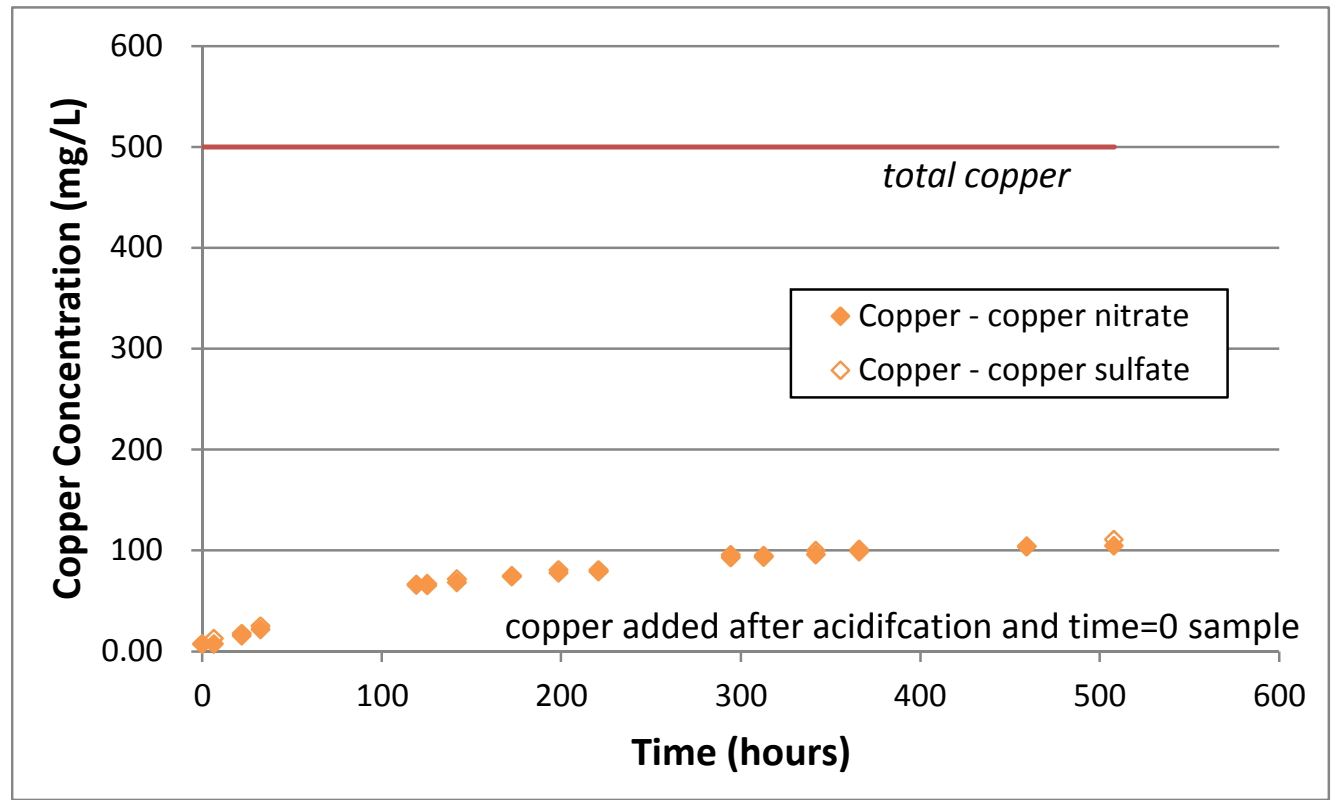

\subsubsection{Soluble Titanium Results}

Titanium is another element that requires monitoring as ingrowth of titanium in solution is indicative of leaching of titanium from MST. After the start of the $\mathrm{H}_{2} \mathrm{O}_{2}$ addition, the titanium concentration in the filtrate samples slowly increased to a maximum of $\sim 10$ $\mathrm{mg} / \mathrm{L}$ (see Figure 5). There was no significant difference between the proportion of soluble Ti for each of the tests. The slight ingrowth of titanium is probably due to the addition of the $\mathrm{H}_{2} \mathrm{O}_{2}$, and not the particular form of the copper. Previous work has shown that MST is known to react with $\mathrm{H}_{2} \mathrm{O}_{2}{ }^{17}$

\subsubsection{Conclusion}

The cation dissolution data presented in previous sections indicates no significant differences in performance of the CCPO process when either copper sulfate, or copper nitrate, are utilized as the source of the copper catalyst. As such all subsequent 
experiments utilized $\mathrm{Cu}\left(\mathrm{NO}_{3}\right)_{2} \bullet 2.5 \mathrm{H}_{2} \mathrm{O}$ due the potential downstream impacts of sulfate for DWPF. While this material performs adequately, its low soluble concentration in the caustic environment indicates the need to investigate the optimal addition of copper nitrate, and in addition, to establish whether more soluble copper-based compounds are available.

\section{Figure 5. Titanium Concentration Comparison for Reactions with Varying Copper} Compounds

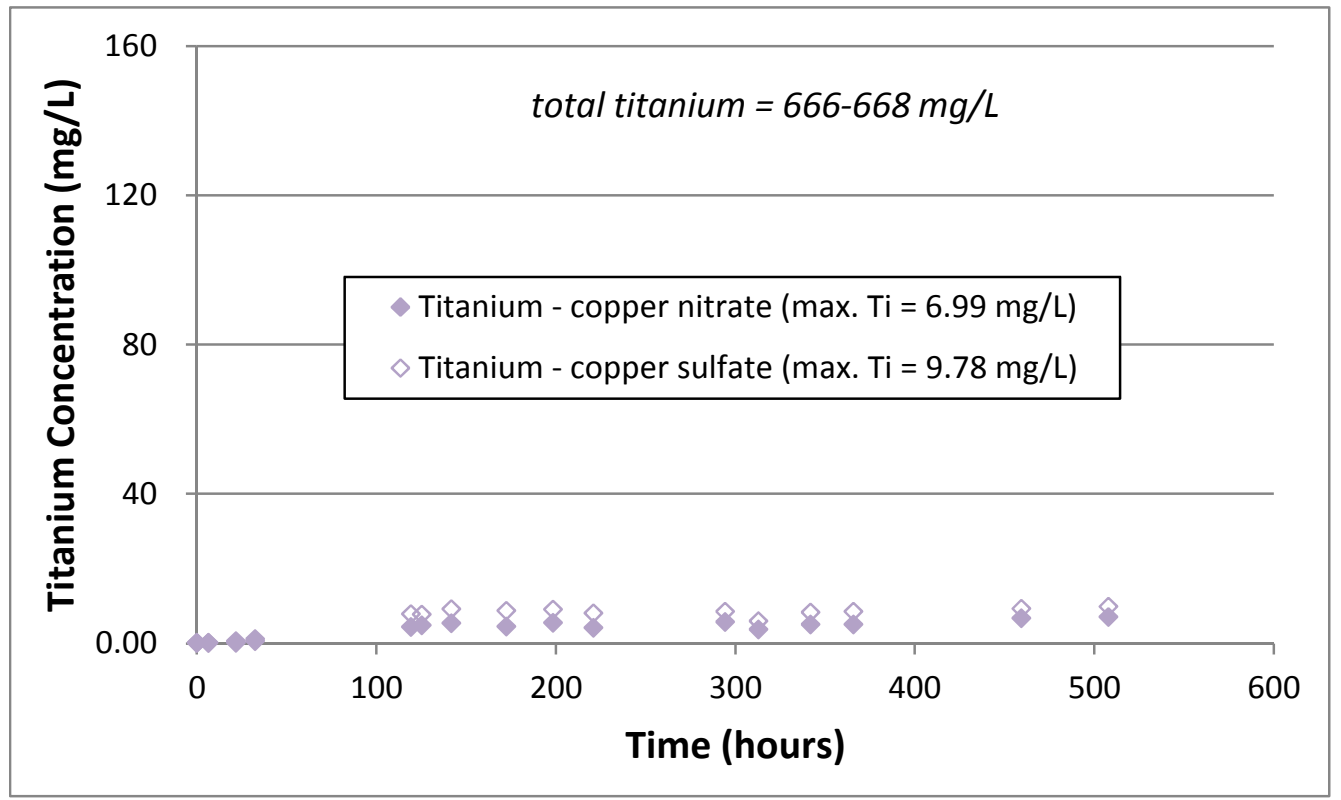

\subsection{Effect of Increased Hydrogen Peroxide Rates}

The baseline rate of $\mathrm{H}_{2} \mathrm{O}_{2}$ addition to the reaction vessels was chosen to approximately match the delivery rates from the 2004 work. At this delivery rate, the estimated time to for process completion is approximately 3 weeks. It is desirable to reduce the process duration as much as possible to reduce the overall cycle time for each batch of waste.

For this experiment, a single $1 \mathrm{~L}$ poly bottle with a magnetic stirrer and stir bar was used. A $250 \mathrm{~mL}$ slurry was generated according to the simulant recipe (Table 1). The slurry was adjusted with $50 \mathrm{wt} \%(10.4 \mathrm{M})$ nitric acid to a final $\mathrm{pH}$ of 11 . The $\mathrm{pH}$ adjustment resulted in $\sim 300 \mathrm{~mL}$ of slurry. For each test $500 \mathrm{mg} / \mathrm{L}$ of copper was utilized. Tests were conducted at ambient laboratory temperature (typically $21^{\circ} \mathrm{C}$ ). Hydrogen peroxide was added at a rate of $1 \mathrm{~mL} /$ hour which is equivalent to $10 \times$ the nominal addition rate. 
As the rate of $\mathrm{H}_{2} \mathrm{O}_{2}$ delivery was $10 \times$ the nominal rate, the test duration was reduced to approximately 12 days. A total of 13 filtrate samples were retrieved throughout the test period for determination of the soluble boron, potassium, copper, sodium, and titanium contents by ICPES. Results from this test were compared to the results from the previous test that used (see Section 3.1) $\mathrm{Cu}\left(\mathrm{NO}_{3}\right)_{2} \bullet 2.5 \mathrm{H}_{2} \mathrm{O}$ as the copper form.

\subsubsection{Soluble Boron Results}

After the start of the $\mathrm{H}_{2} \mathrm{O}_{2}$ addition the boron in the filtrate samples slowly increased over time. See Figure 6.

\section{Figure 6. Boron Concentration Comparison at Varying Peroxide Addition Rates}

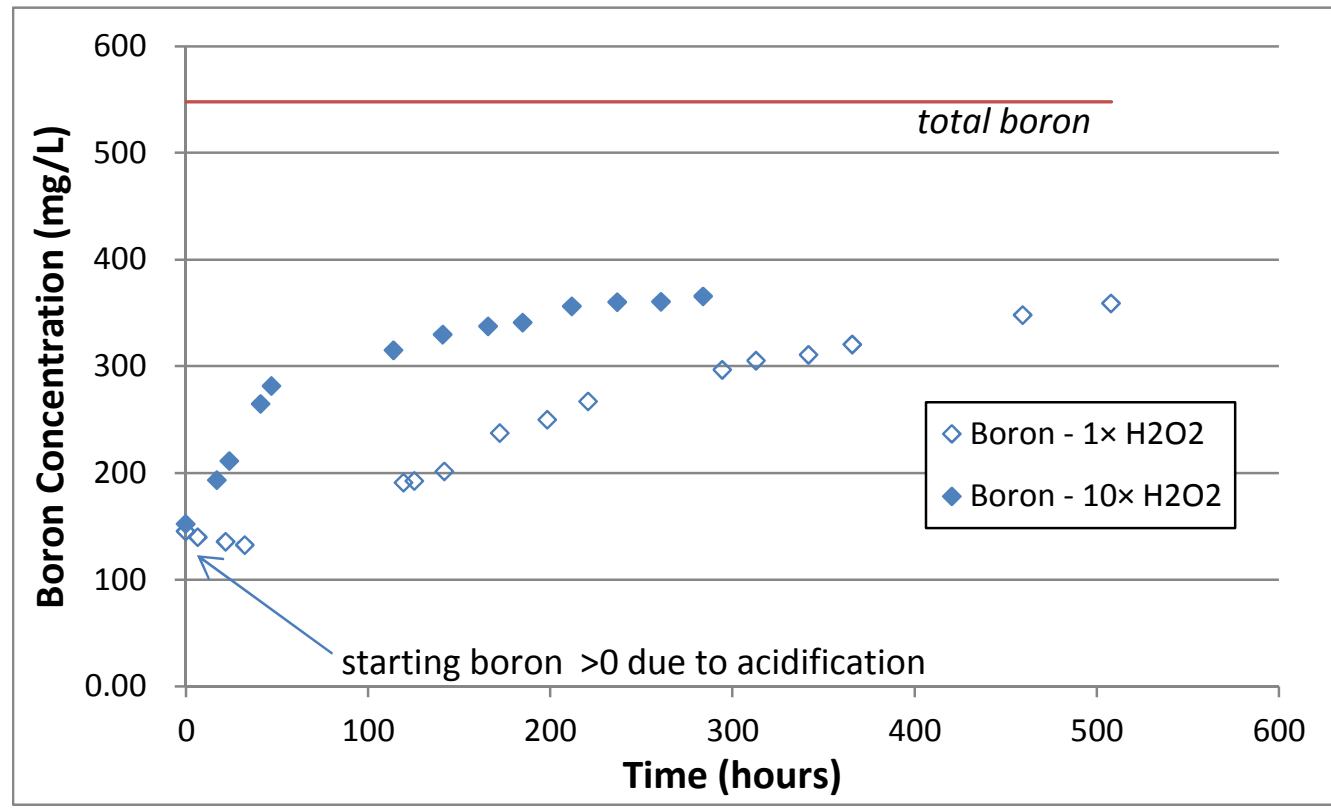

In Figure 6, the blue triangles represent data from the previous test using the nominal $1 \times$ peroxide addition rate (see Section 3.1.1). Note that the duration of this test was $>500$ hours in comparison to the shorter duration of 284 hours for the test utilizing a $10 \times$ peroxide addition rate.

The reaction was halted after 284 hours, and the extent of destruction for both reactions was calculated using the same methodology as in Section 3.1.1 (see Table 4). 
SRNL-STI-2012-00342

Revision 1

\section{Table 4. Total TPB Destruction from Final Boron Results at Varying Peroxide} Addition Rates

\begin{tabular}{|c|c|c|c|c|c|}
\hline \multicolumn{2}{|c|}{ Destruction by Acid } & \multicolumn{2}{c|}{ Destruction by $\mathrm{H}_{2} \mathrm{O}_{2}$} & \multicolumn{2}{c|}{ Total Destruction } \\
\hline $1 \times \mathrm{H}_{2} \mathrm{O}_{2}$ & $10 \times \mathrm{H}_{2} \mathrm{O}_{2}$ & $1 \times \mathrm{H}_{2} \mathrm{O}_{2}$ & $10 \times \mathrm{H}_{2} \mathrm{O}_{2}$ & $1 \times \mathrm{H}_{2} \mathrm{O}_{2}$ & $10 \times \mathrm{H}_{2} \mathrm{O}_{2}$ \\
\hline $23.8-29.1 \%$ & $24.8-30.3 \%$ & $28.9-42.4 \%$ & $31.5-45.9 \%$ & $58.9-72.0 \%$ & $59.7-72.9 \%$ \\
\hline
\end{tabular}

Both the $1 \times$ and $10 \times \mathrm{H}_{2} \mathrm{O}_{2}$ peroxide reactions provided the same final level of TPB destruction; 65-66\%. However, the $10 \times \mathrm{H}_{2} \mathrm{O}_{2}$ reaction proceeded at a much faster initial rate before tapering off. The $10 \times \mathrm{H}_{2} \mathrm{O}_{2}$ reaction also continued for a shorter time - about half the time of the $1 \times \mathrm{H}_{2} \mathrm{O}_{2}$ reaction. As a rough comparison, at the termination of the $10 \times \mathrm{H}_{2} \mathrm{O}_{2}$ test (284 hours), the average total destruction was $66.3 \%$, compared to the $54.1 \%$ for the $1 \times \mathrm{H}_{2} \mathrm{O}_{2}$ test (295 hours). While the difference is not statistically significant by itself, it does suggest an improvement in destruction rates.

While the $10 \times$ peroxide addition rate clearly plays a role in the rate of TPB destruction during the initial stages of the reaction it does not appear to enhance the total TPB destruction. Therefore utilizing a $10 \times$ addition rate would effectively result in prohibitively increased waste volume with little overall enhancement in final destruction. As such additional experiments (see Section 3.7) to investigate the effects of peroxide addition rate were limited to $5 \times \mathrm{H}_{2} \mathrm{O}_{2}$ or less.

\subsubsection{Soluble Potassium Results}

After the start of the $\mathrm{H}_{2} \mathrm{O}_{2}$ addition the potassium concentration in the filtrate samples slowly increased over time. See Figure 7.

The reaction was halted after 284 hours and the extent of potassium dissolution associated with acid hydrolysis and peroxide oxidation calculated using the same methodology as in Section 3.1.1 (see Table 5). 


\section{Figure 7. Potassium Concentration Comparison at Varying Peroxide Addition Rates}

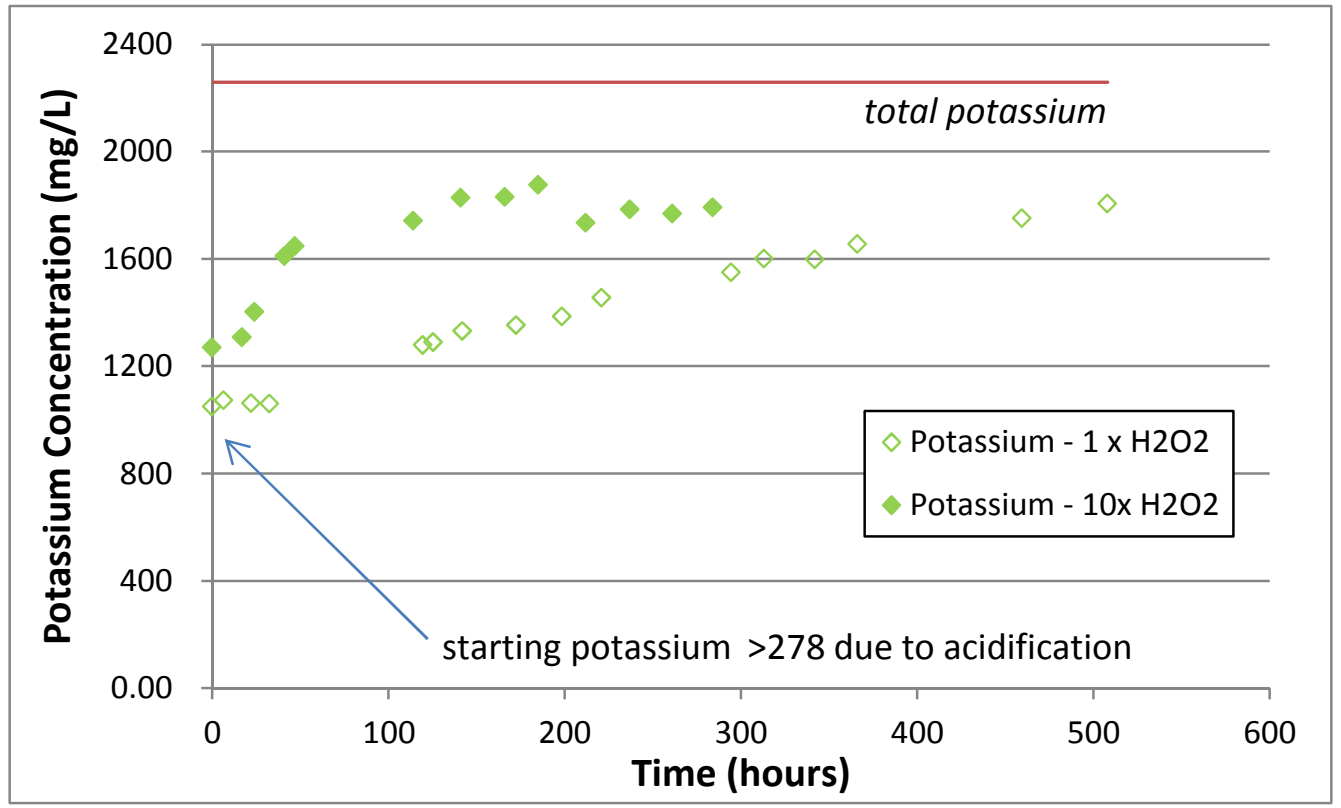

Table 5. Total TPB Destruction from Final Potassium Results at Varying Peroxide Addition Rates

\begin{tabular}{|c|c|c|c|c|c|}
\hline \multicolumn{2}{|c|}{ Destruction by Acid } & \multicolumn{2}{c|}{ Destruction by $\mathrm{H}_{2} \mathrm{O}_{2}$} & \multicolumn{2}{c|}{ Total Destruction } \\
\hline $1 \times \mathrm{H}_{2} \mathrm{O}_{2}$ & $10 \times \mathrm{H}_{2} \mathrm{O}_{2}$ & $1 \times \mathrm{H}_{2} \mathrm{O}_{2}$ & $10 \times \mathrm{H}_{2} \mathrm{O}_{2}$ & $1 \times \mathrm{H}_{2} \mathrm{O}_{2}$ & $10 \times \mathrm{H}_{2} \mathrm{O}_{2}$ \\
\hline $33.7-44.3 \%$ & $43.4-56.1 \%$ & $18.9-39.5 \%$ & $15.2-37.3 \%$ & $68.0-86.2 \%$ & $67.0-85.0 \%$ \\
\hline
\end{tabular}

Both the $1 \times$ and $10 \times \mathrm{H}_{2} \mathrm{O}_{2}$ peroxide rates provided approximately the same level of total TPB destruction, $\sim 76-77 \%$ destruction. All of the same trends and conclusions that are seen in the boron data also apply to the potassium data. The initial rate of destruction was more rapid, but then tapered off.

As a rough comparison, at the end of the $10 \times \mathrm{H}_{2} \mathrm{O}_{2}$ test (284 hours), the total destruction was $76.0 \%$, compared to $64.2 \%$ for the $1 \times \mathrm{H}_{2} \mathrm{O}_{2}$ test. While the difference is not statistically significant by itself, it does suggest an improvement in destruction rates. 


\subsubsection{Soluble Copper Results}

After the start of the $\mathrm{H}_{2} \mathrm{O}_{2}$ addition the copper concentration in the filtrate samples slowly increased over time. See Figure 8.

Figure 8. Copper Concentration Comparison at Varying Peroxide Addition Rates

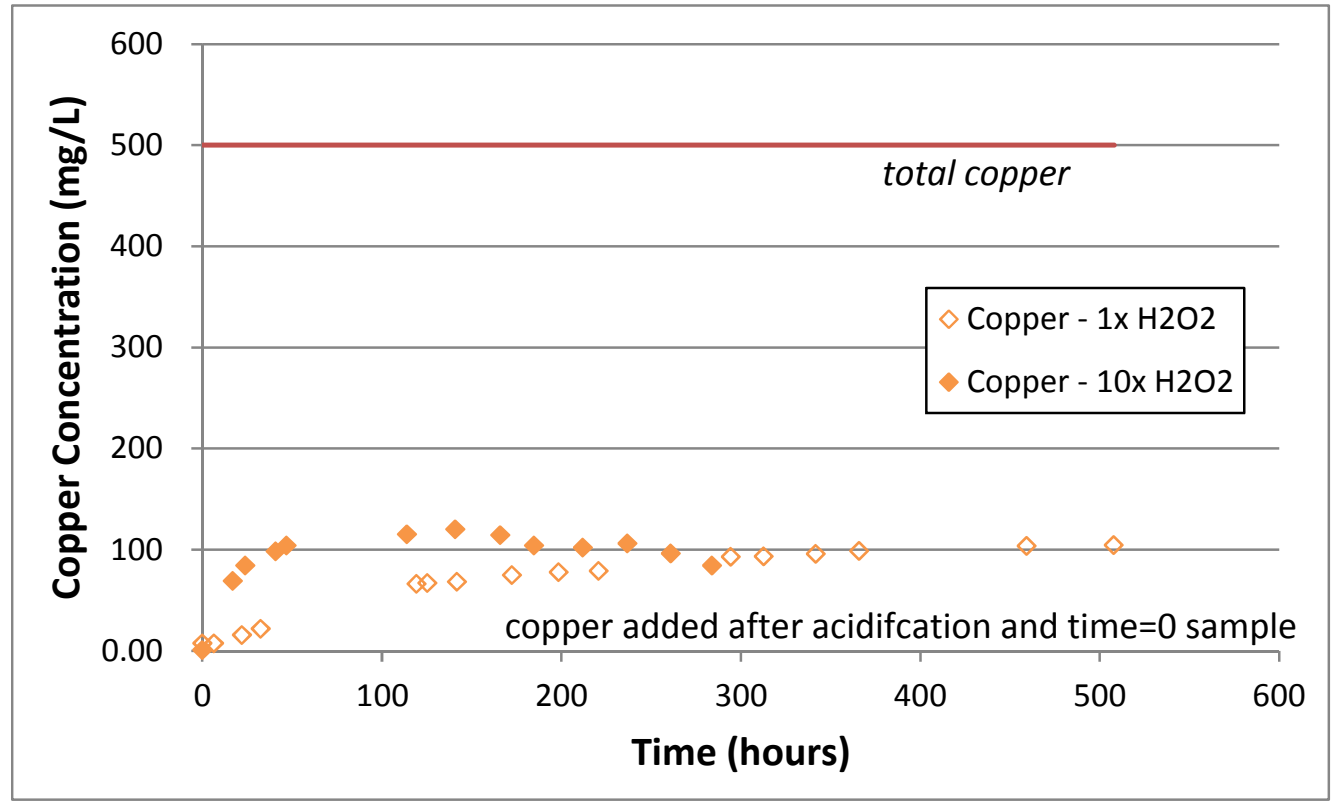

The trends seen in the boron and potassium results continue here. For both reactions the dissolution of copper initially increases with time. While both the $1 \times$ and $10 \times \mathrm{H}_{2} \mathrm{O}_{2}$ peroxide rates indicated a maximum copper soluble concentration of approximately $20 \%$, the $10 \times \mathrm{H}_{2} \mathrm{O}_{2}$ reaction provides a higher initial rate of copper dissolution which then tapered off.

In agreement with the data presented in Section 3.1 the majority of the added copper remains in an insoluble, and presumably, non-reactive form. Future work may consider modifying the form of the added copper to improve the solubility.

\subsubsection{Soluble Titanium Results}

The titanium concentrations in solution are monitored for the reasons outlined in Section 3.1.4 (see Figure 9). 


\section{Figure 9. Titanium Concentration Comparison at Varying Peroxide Addition Rates}

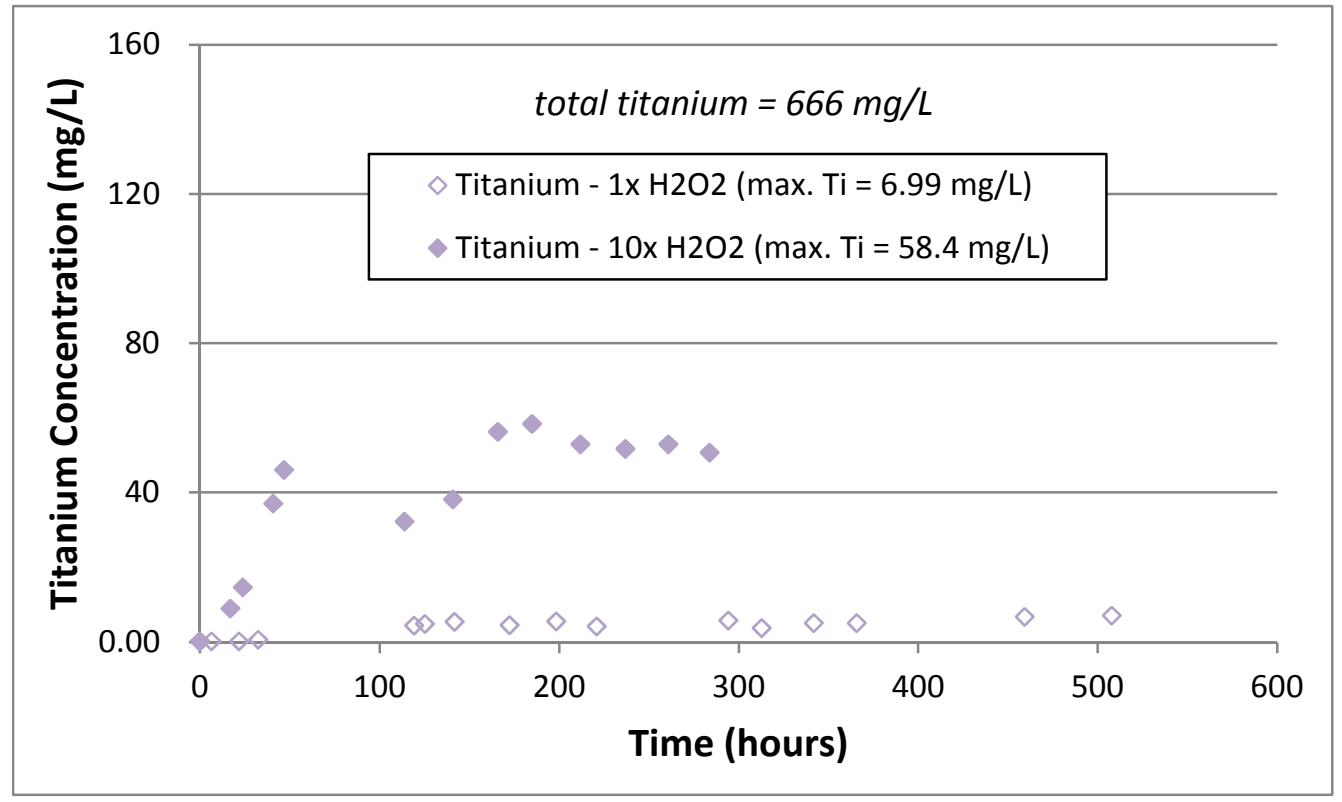

After the start of the $\mathrm{H}_{2} \mathrm{O}_{2}$ addition the titanium in the filtrate samples increased over time. However, unlike the other analytes, the titanium soluble concentration showed the largest differences between the two reactions. In the $1 \times \mathrm{H}_{2} \mathrm{O}_{2}$ reaction, the titanium in solution reached a maximum of $<10 \mathrm{mg} / \mathrm{L}$. In the $10 \times \mathrm{H}_{2} \mathrm{O}_{2}$ reaction, the titanium reached a maximum of $\sim 60 \mathrm{mg} / \mathrm{L}$. Furthermore, the rate of ingrowth of the titanium in the $10 \times \mathrm{H}_{2} \mathrm{O}_{2}$ reaction was more rapid and essentially complete in $\sim 2$ days. The excess $\mathrm{H}_{2} \mathrm{O}_{2}$ (at the $10 \times$ addition rate) likely results in enhanced reactivity between the $\mathrm{H}_{2} \mathrm{O}_{2}$ and the MST. This subsequently produces a soluble Ti-containing species which remains relatively stable for the duration of the experiment.

\subsubsection{Conclusion}

Adding $\mathrm{H}_{2} \mathrm{O}_{2}$ at a ten-fold increased rate has several effects with respect to reaction characteristics. First, the rate of ingrowth of soluble boron, potassium and copper increased for the duration of the $10 \times \mathrm{H}_{2} \mathrm{O}_{2}$ reaction. Each analyte shows the same ingrowth trend. Second, while the initial ingrowth is noticeable, the end state remains approximately the same in comparison to the $1 \times \mathrm{H}_{2} \mathrm{O}_{2}$ reaction, although the duration of the two reactions was different. While there was no visible evidence of $\mathrm{H}_{2} \mathrm{O}_{2}$ autodecomposition (burping or foaming), the data suggests that in the $10 \times \mathrm{H}_{2} \mathrm{O}_{2}$ reaction, the $\mathrm{H}_{2} \mathrm{O}_{2}$ is not being used as efficiently as in the $1 \times \mathrm{H}_{2} \mathrm{O}_{2}$ reaction. Nevertheless, increasing the rate of $\mathrm{H}_{2} \mathrm{O}_{2}$ addition appears to increase the initial reaction rate. 
The presence of the additional $\mathrm{H}_{2} \mathrm{O}_{2}$ also causes a higher initial and final concentration of titanium to come into solution, which must be from the MST solids. The amount of leaching titanium though is only a small fraction of the total MST inventory, $\sim 7.5 \%$ by mass.

\subsection{Effect of Reaction Temperatures}

In the 2004 work, processing temperatures were changed from $35{ }^{\circ} \mathrm{C}$ to $75^{\circ} \mathrm{C}$ (with intermediate holds at $45^{\circ} \mathrm{C}$ and $55^{\circ} \mathrm{C}$ ) over the lifetime of the demonstration. For fullscale operation, however, it would be advantageous to process at a single reaction temperature in order to decrease the operational complexity. To this end, SRNL and the customer selected three processing temperatures to determine the effects of temperature on the reaction kinetics and TPB destruction efficiency. The temperatures utilized were $35^{\circ} \mathrm{C}, 50{ }^{\circ} \mathrm{C}$, and $65^{\circ} \mathrm{C}$. These temperatures were thought to be theoretically obtainable in the actual facility, and the $30^{\circ} \mathrm{C}$ range was considered broad enough to provide a reasonable indication of temperature effects.

For this experiment, three "new" reaction vessels were assembled. Each vessel consisted of a stainless steel bottom; $\sim 4.75$ " diameter and 6" tall with a $\sim 1 / 2$ " lip. Mated to the stainless steel bottom was a glass hemispherical dome with several penetrations. The penetrations were used for the stirring shaft, the chemical delivery, a $\mathrm{pH}$ probe (see Figure 10).

A set of baffles was incorporated in the stainless steel bottom. The baffles and the agitation paddles were designed to match the Froude number; a dimensionless number related to mixing (see Appendix A).

Figure 10. Picture of One of the Designed Reactor Components

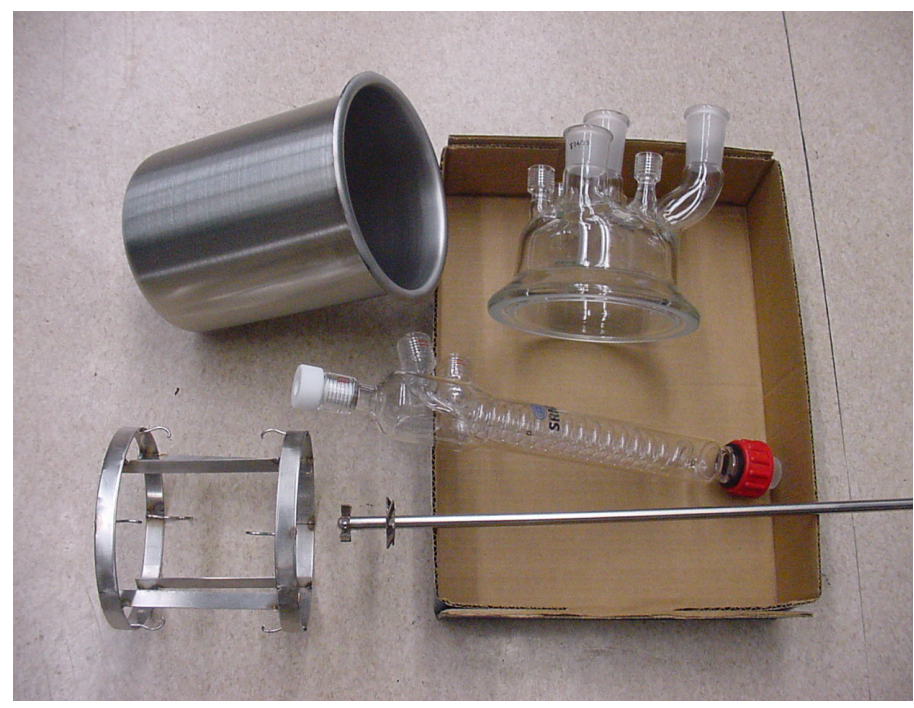


The vessel was designed to utilize $500 \mathrm{~mL}$ of Tank $48 \mathrm{H}$ slurry in each reaction, and contained enough volume to accommodate the additional $\mathrm{pH}$ adjustment acid and added $\mathrm{H}_{2} \mathrm{O}_{2}$. The vessel dimensions were also designed to fit inside a controlled temperature bath. For this work, a Thermo-Haake Model P1-B5 was used which is capable of sustaining temperatures beyond $75^{\circ} \mathrm{C}$.

Three bottles of $500 \mathrm{~mL}$ of slurry were generated according to the recipe (Table 1). The slurries were adjusted with $50 \mathrm{wt} \%(10.4 \mathrm{M})$ nitric acid to a final $\mathrm{pH}$ of 11 . The slurries were used without further changes. To each vessel, the copper catalyst in the form of $\mathrm{Cu}\left(\mathrm{NO}_{3}\right)_{2} \bullet 2.5 \mathrm{H}_{2} \mathrm{O}$ was added, with a targeted concentration of added copper $(\mathrm{Cu})$ as $500 \mathrm{mg} / \mathrm{L}$. Active temperature control was provided by the thermal baths. One reaction was conducted at a constant $35^{\circ} \mathrm{C}$, the second was conducted at a constant $50{ }^{\circ} \mathrm{C}$, and the third was conducted at a constant $65^{\circ} \mathrm{C}$. All three reactions were conducted at the same time to facilitate sample timing.

Hydrogen peroxide was added at the rates used in the 2004 work, after scaling for volume differences, $0.2 \mathrm{~mL} /$ hour.

Over time, the filtrate samples started with a dark orange and lightened over time. The slurry in the reaction vessel changed color from brown, to a slightly more green-brown.

Each test operated approximately 15 days. Filtrate samples were pulled initially at one per day, and towards the end of the test, once every 1-2 days. Samples were not pulled over the weekends. A total of $13\left(65^{\circ} \mathrm{C}\right.$ test $)$ or $14\left(35\right.$ or $50{ }^{\circ} \mathrm{C}$ tests $)$ samples were removed for analysis by ICPES. From the ICPES results, the boron, potassium, copper, sodium, and titanium results were examined. Results from each test were compared to establish potential differences in reactivity.

\subsubsection{Soluble Boron Results}

As in previous experiments, the boron concentration in solution was measured as an indicator of TPB destruction. After the start of the $\mathrm{H}_{2} \mathrm{O}_{2}$ addition the boron in the filtrate samples increased over time. See Figure 11.

The reaction was halted after 372 hours, and the extent of boron dissolution associated with the acid hydrolysis and the peroxide oxidation reaction was calculated using the same methodology as in Section 3.1.1 (see Table 6). 
SRNL-STI-2012-00342

Revision 1

Table 6. Total TPB Destruction from Final Boron Results at Varying Temperatures

\begin{tabular}{|c|c|c|c|c|c|c|c|c|}
\hline \multicolumn{3}{|c|}{ Destruction by Acid } & \multicolumn{3}{c|}{ Destruction by $\mathrm{H}_{2} \mathrm{O}_{2}$} & \multicolumn{3}{c|}{ Total Destruction } \\
\hline $35{ }^{\circ} \mathrm{C}$ & $50^{\circ} \mathrm{C}$ & $65{ }^{\circ} \mathrm{C}$ & $35{ }^{\circ} \mathrm{C}$ & $50{ }^{\circ} \mathrm{C}$ & $65{ }^{\circ} \mathrm{C}$ & $35{ }^{\circ} \mathrm{C}$ & $50{ }^{\circ} \mathrm{C}$ & $65{ }^{\circ} \mathrm{C}$ \\
\hline $15.1-18.5 \%$ & $15.7-19.2 \%$ & $21.6-26.5 \%$ & $24.3-34.1 \%$ & $64.2-82.7 \%$ & $57.6-76.4 \%$ & $41.4-50.6 \%$ & $81.8-100 \%$ & $82.0-100 \%$ \\
\hline
\end{tabular}

Figure 11. Boron Concentration Comparison at Varying Temperatures

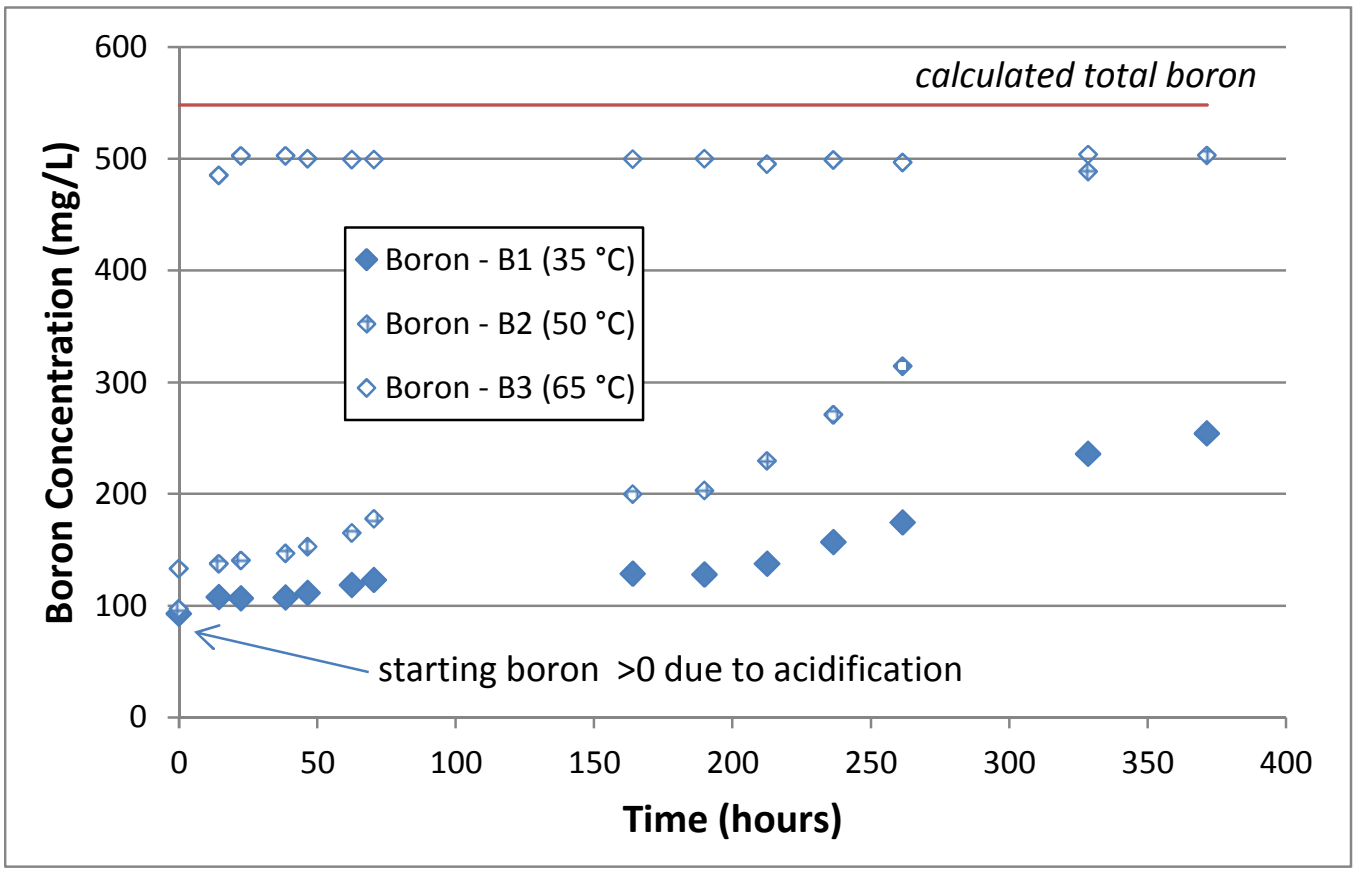

While all three reactions provided approximately the same TPB destruction from $\mathrm{pH}$ adjustment (which is to be expected as the $\mathrm{pH}$ adjustment occurred at room temperature), there were large differences in the level of TPB destruction resulting from the $\mathrm{H}_{2} \mathrm{O}_{2}$ aided reaction. By the end of the test period, the $35^{\circ} \mathrm{C}$ test indicated less than $50 \%$ TPB destruction. The $50{ }^{\circ} \mathrm{C}$ test reached total TPB destruction by the final sample, and the $65^{\circ} \mathrm{C}$ test provided total TPB destruction in 1 day.

It is curious to note that the boron filtrate results plateau at $\sim 90 \%$ of the theoretical values. It is possible that the plateau is a function of incomplete dissolution (low solubility) of all the boron compounds liberated from the destruction of TPB.

\subsubsection{Soluble Potassium Results}

After the start of the $\mathrm{H}_{2} \mathrm{O}_{2}$ addition the potassium in the filtrate samples increased over time. See Figure 12. 
Figure 12. Potassium Concentration Comparison at Varying Temperatures

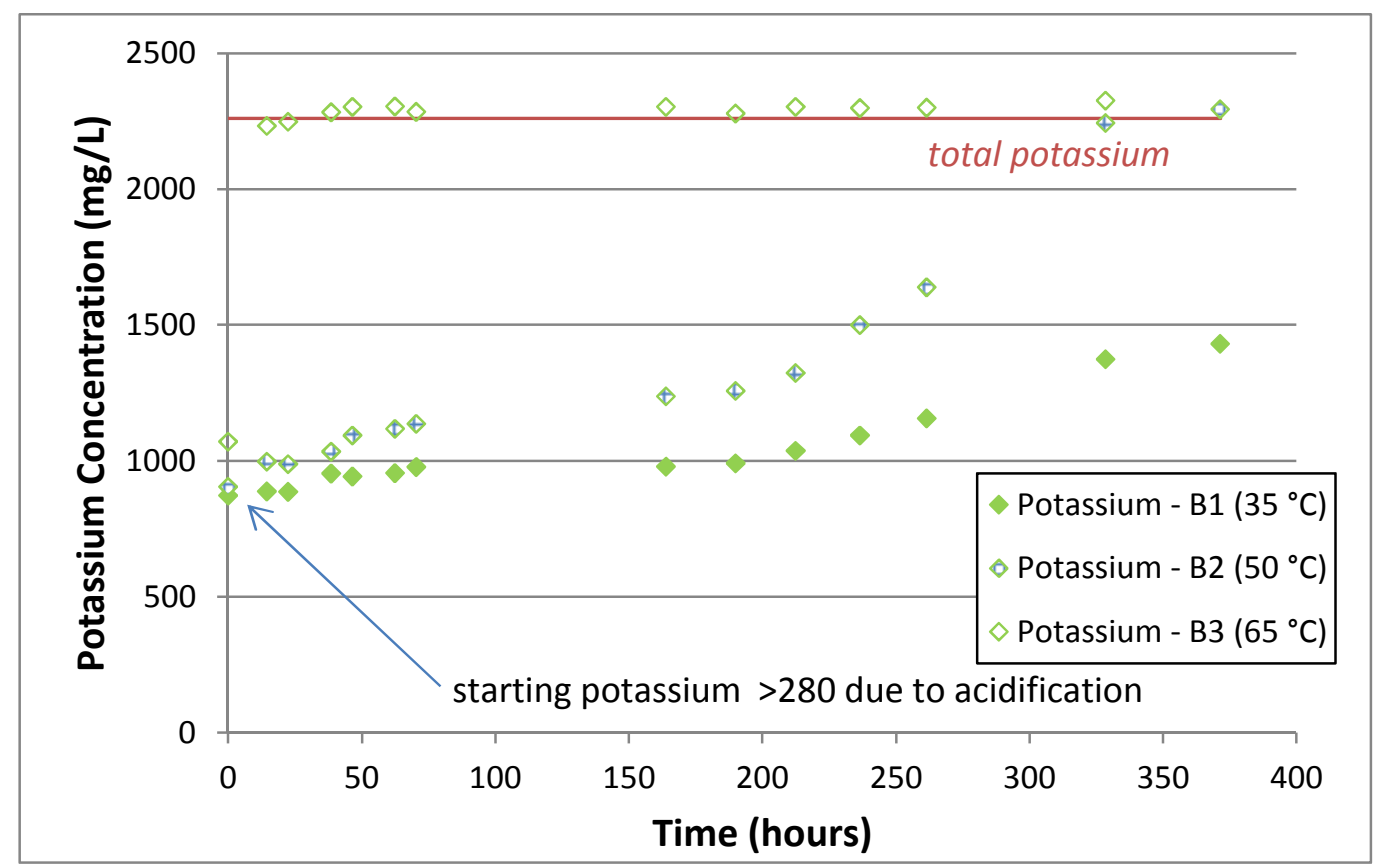

The reaction was halted after 372 hours, and the extent of potassium dissolution associated with the acid hydrolysis and peroxide oxidation reactions was calculated using the same methodology as in Section 3.1.1 (Table 7).

Table 7. Total TPB Destruction from Potassium Results at Varying Temperatures

\begin{tabular}{|c|c|c|c|c|c|c|c|c|}
\hline \multicolumn{3}{|c|}{ Destruction by Acid } & \multicolumn{3}{c|}{ Destruction by $\mathrm{H}_{2} \mathrm{O}_{2}$} & \multicolumn{3}{c|}{ Total Destruction } \\
\hline $35{ }^{\circ} \mathrm{C}$ & $50^{\circ} \mathrm{C}$ & $65{ }^{\circ} \mathrm{C}$ & $35{ }^{\circ} \mathrm{C}$ & $50{ }^{\circ} \mathrm{C}$ & $65{ }^{\circ} \mathrm{C}$ & $35{ }^{\circ} \mathrm{C}$ & $50{ }^{\circ} \mathrm{C}$ & $65{ }^{\circ} \mathrm{C}$ \\
\hline $25.3-34.0 \%$ & $26.7-35.7 \%$ & $34.1-44.8 \%$ & $19.6-36.4 \%$ & $57.1-81.8 \%$ & $50.0-75.6 \%$ & $50.5-64.8 \%$ & $89.2-112 \%$ & $90.6-114 \%$ \\
\hline
\end{tabular}

The potassium results show the same temperature-related trends as the boron results and provide for the same conclusion. 


\subsubsection{Soluble Copper Results}

After the start of the $\mathrm{H}_{2} \mathrm{O}_{2}$ addition the copper in the filtrate samples slowly increased over time. See Figure 13.

The data indicates that most of the copper remains in an insoluble form. The highest reaction temperature resulted in faster increase in soluble copper concentration but all reactions approached the same value of $\sim 100 \mathrm{mg} / \mathrm{L}$ which is also equivalent to the copper solubility observed in the earlier ambient temperature test (see Figure 4). This data suggests a similar reaction sequence.

\section{Figure 13. Soluble Copper Concentration Comparison at Varying Temperatures}

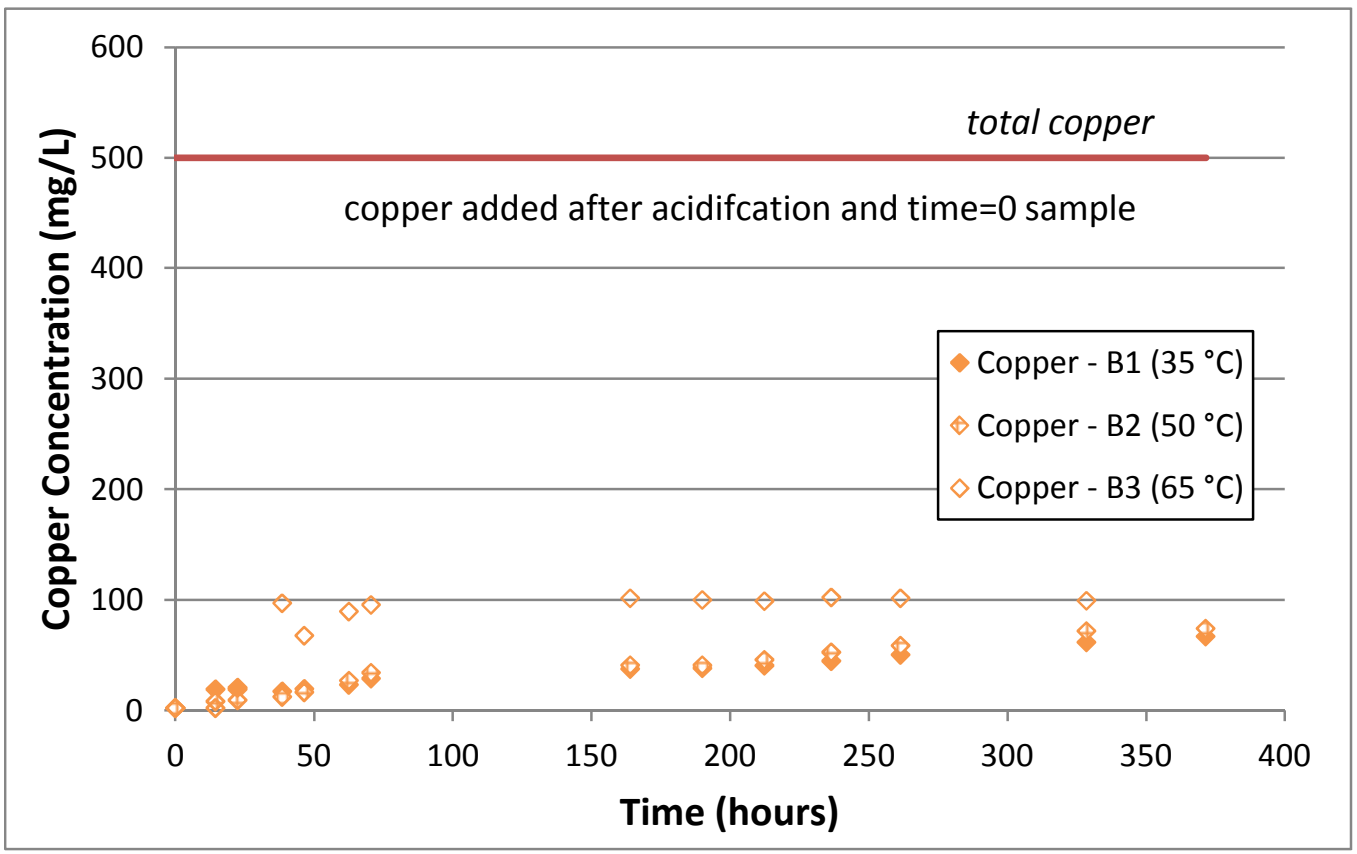

\subsubsection{Soluble Titanium Results}

The titanium in solution is monitored for the reasons outlined in Section 3.1.4. See Figure 14.

The titanium data indicates that the temperature range does have a moderate, but not immediate effect on the titanium leaching into solution. In each reaction, the titanium concentration towards the end of the experiment reached about double $(\sim 20 \mathrm{mg} / \mathrm{L})$ the concentration of the room temperature equivalent experiment. There is no effective difference between the $35 / 50 / 65^{\circ} \mathrm{C}$ temperatures at the end of the experiment. 
Figure 14. Titanium Concentration Comparison at Varying Temperatures

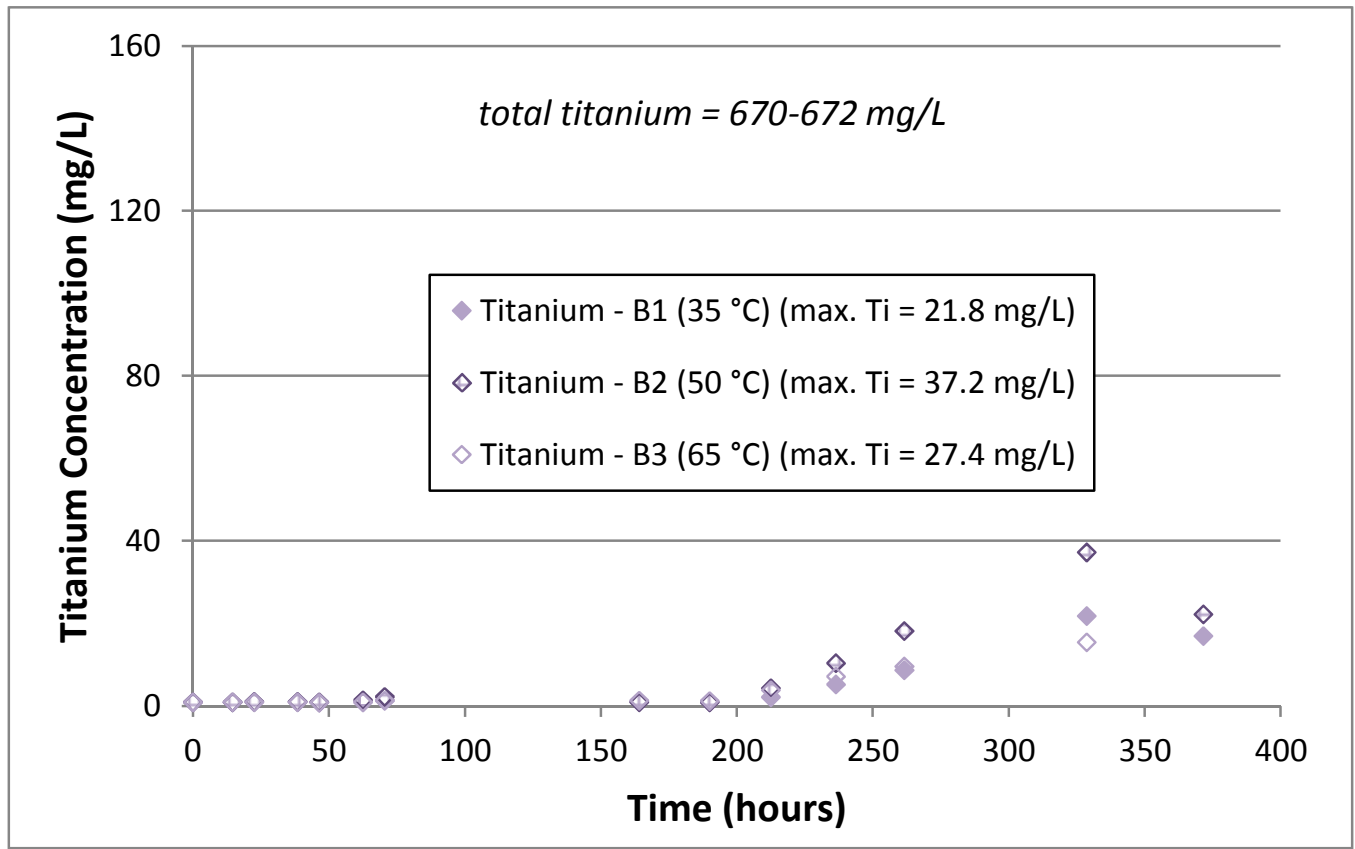

This data seems to suggest that the undesired reaction with MST is accelerating at a later point in the reaction, regardless of the reaction temperature in this range.

\subsubsection{Analysis of Residual Slurry After Reaction}

After each reaction was complete, the residues were isolated after reaction. The amount of recovered material is somewhat dependent on the efficiency of slurry removal (varying amounts of solids were caked on the upper parts of the reactor, or difficult to remove).

From each bottle of residual slurry, well-mixed (in an attempt to ensure homogeneity) duplicate samples were analyzed via HPLC, ${ }^{\text {a }}$ VOA and SVOA. However, due to the elapsed time from the end of the reaction $\left(\sim 1140\right.$ hours for the 35 and $50{ }^{\circ} \mathrm{C}$ reactions, and $\sim 1180$ hours for the $65^{\circ} \mathrm{C}$ reaction), and the time of sampling, a filtered sample of the residual slurry were also analyzed via ICPES as a check to see if the reaction had

\footnotetext{
${ }^{a}$ SRNL modified the HPLC protocols as discussed in Appendix B in an attempt to lower the detection limits for the phenylboron compounds to $2-3 \mathrm{mg} / \mathrm{L}$. The lower detection limits were not generally achieved for the complex slurry composition.
} 
proceeded further. The results of the ICPES analyses are listed in Table 8. The results for the four important analytes $(\mathrm{B}, \mathrm{K}, \mathrm{Cu}, \mathrm{Ti})$ are given next to the chronologically previous sample results. These results are corrected for dilution using sodium concentration for normalization.

There are no statistically significant differences in the boron and potassium results between the two sample sets for any of the reactions. As boron and potassium are indicators of the extent of TPB destruction, this indicates us that the destruction reaction essentially did not proceed further in the time interval between the last sample and the check sample.

Table 8. ICPES Samples (mg/L) at Varying Temperatures

\begin{tabular}{|c|c|c|c|}
\hline Reaction & Analyte & $\begin{array}{c}\text { Final Filtrate } \\
\text { Result }\end{array}$ & $\begin{array}{c}\text { End of Reaction Period } \\
\text { Sample Result }\end{array}$ \\
\hline \multirow{3}{*}{$35{ }^{\circ} \mathrm{C}$} & $\mathrm{B}$ & 273 & 254 \\
\cline { 2 - 4 } & $\mathrm{K}$ & 1456 & 1429 \\
\cline { 2 - 4 } & $\mathrm{Cu}$ & 80.7 & 66.5 \\
\cline { 2 - 4 } & $\mathrm{Ti}$ & 8.37 & 17.0 \\
\hline \multirow{3}{*}{$50{ }^{\circ} \mathrm{C}$} & $\mathrm{B}$ & 534 & 503 \\
\cline { 2 - 4 } & $\mathrm{K}$ & 2256 & 2292 \\
\cline { 2 - 4 } & $\mathrm{Cu}$ & 93.9 & 73.5 \\
\cline { 2 - 4 } & $\mathrm{Ti}$ & 22.5 & 22.2 \\
\hline \multirow{3}{*}{$65{ }^{\circ} \mathrm{C}$} & $\mathrm{B}$ & 573 & 504 \\
\cline { 2 - 4 } & $\mathrm{K}$ & 2283 & 2324 \\
\cline { 2 - 4 } & $\mathrm{Cu}$ & 108 & 98.7 \\
\cline { 2 - 4 } & $\mathrm{Ti}$ & 27.4 & 15.5 \\
\hline
\end{tabular}

The analytical uncertainty is $10 \%$ for each result.

As no additional destruction occurred, there is a valid comparison between the ICPES and HPLC results. Table 9 lists the HPLC results.

Table 9. HPLC Results from Residual Slurry After Reaction Analyses (mg/L) at Varying Temperatures

\begin{tabular}{|c|c|c|c|c|c|c|}
\hline Reaction & TPB & 3PB & 2PB & 1PB & Phenol & \% Destruction \\
\hline $35^{\circ} \mathrm{C}$ & $7460(0.19 \%)$ & $<100$ & $<100$ & $<100$ & $<100$ & $50.7-50.9 \%$ \\
\hline $50^{\circ} \mathrm{C}$ & $16(0.00 \%)$ & $<10$ & $<10$ & $<10$ & $<10$ & $99.9-99.9 \%$ \\
\hline $65{ }^{\circ} \mathrm{C}$ & $<10$ & $<10$ & $<10$ & $<10$ & $<10$ & $>99.9 \%$ \\
\hline
\end{tabular}

The value in parentheses is the \%relative standard deviation (\%RSD). The "\% Destruction" column is the calculated percent destruction. The value is based on the 
mass of TPB added to the simulant slurries and calculation of the mass of TPB in the residual slurry after reaction, after correcting for the mass of samples removed from the system during the reactions.

The residual slurry after reaction was also analyzed using VOA and SVOA. These two analytical methods are used to discern the presence of volatile or semi-volatile organic species. See Tables 10, 11, and 12. The values in parentheses are the \%RSD.

In the results column, values that are shaded indicate only one measured value with the other being a detection limit result. In this case, the values in parentheses are the analytical uncertainties. In the analyte column, shaded cells indicate the presence of that analyte is doubtful due to chemical conditions or contaminants. The "total organic residuals" are the sum of all the mid-range values of the detected analytes, less benzene and the analytes that are declared to be from contaminants. These results are not normalized to the starting volumes.

Only the detection of benzene is anticipated from the VOA analysis. Due to the type of oxidation chemistry is unlikely that any other organic compound with a high enough volatility would be created in this type of reaction.

There is very little benzene left in solution by time of sampling. Benzene is highly volatile and the reactions were maintained at higher than room temperature for extended time periods (the duration of the experiments).

Table 10. VOA and SVOA Results for $35^{\circ} \mathrm{C}$ Reaction

\begin{tabular}{|c|c|}
\hline Analyte & Result (mg/L) \\
\hline benzene & $0.765(2.77 \%)$ \\
\hline biphenyl & $1650(12.9 \%)$ \\
\hline nitrobenzene & $97.5(3.63 \%)$ \\
\hline p-terphenyl & $87.0(1.63 \%)$ \\
\hline triphenylboroxin & $46.0(6.15 \%)$ \\
\hline diisooctyl adipate & $34.4-51.6$ \\
\hline 4-nitro, 1,1-biphenyl & $16.5(30.0 \%)$ \\
\hline 7-nitro-6H-dibenzo [b d]pyran-6-one & $13.6-20.4$ \\
\hline ethanedioic acid dimethylester & $10.4-15.6$ \\
\hline o-phenylene benzeneboronate & $10.1(13.4 \%)$ \\
\hline o-terphenyl & $8.35(0.85 \%)$ \\
\hline m-terphenyl & $7.75(0.91 \%)$ \\
\hline 4-hydroxy-4-nitro-biphenyl & $3.04-4.56$ \\
\hline Total organic residuals & 1957 \\
\hline
\end{tabular}


Table 11. VOA and SVOA Results for $50{ }^{\circ} \mathrm{C}$ Reaction

\begin{tabular}{|c|c|}
\hline Analyte & Result (mg/L) \\
\hline benzene & $0.12(11.8 \%)$ \\
\hline biphenyl & $940(6.02 \%)$ \\
\hline p-terphenyl & $38.5(5.51 \%)$ \\
\hline o-terphenyl & $11.5(6.15 \%)$ \\
\hline diisooctyl adipate & $10.5(60.6 \%)$ \\
\hline 2-phenoxy, 1,1-biphenyl & $4.5(6.29 \%)$ \\
\hline 2-phenyl-4H-1,3,2-benzodioxaborin-4-one & $2.75(33.5 \%)$ \\
\hline diphenylamine & $1.8(7.86 \%)$ \\
\hline 4-nitro-N-phenyl-benzenamine & $1.75(4.04 \%)$ \\
\hline 1,1,2,1,4,1-quaterphenyl & $1.6(8.84 \%)$ \\
\hline Total organic residuals & 1002 \\
\hline
\end{tabular}

Table 12. VOA and SVOA Results for $65^{\circ} \mathrm{C}$ Reaction

\begin{tabular}{|c|c|}
\hline Analyte & Result (mg/L) \\
\hline benzene & $<0.05$ \\
\hline biphenyl & $92(27.7 \%)$ \\
\hline [1,1-biphenyl]-3-amine & $91(1.55 \%)$ \\
\hline diphenyl ether & $64.5(1.10 \%)$ \\
\hline p-terphenyl & $31.5(33.7 \%)$ \\
\hline m-terphenyl & $14.4-21.6$ \\
\hline diisooctyl adipate & $16.5(21.4 \%)$ \\
\hline 2-phenoxy, 1,1-biphenyl & $13(0.00 \%)$ \\
\hline o-terphenyl & $9.25(2.29 \%)$ \\
\hline 2-nitro-N-(4-nitrophenyl)-benzenamine & $5.65(6.26 \%)$ \\
\hline 1,2-diphenoxybenzene & $5.45(3.89 \%)$ \\
\hline 1,1-oxybis(4-phenoxybenzene) & $5.50(36.0 \%)$ \\
\hline 1,1,4,1,4,1,4,1-quaterphenyl & $3.12-4.68$ \\
\hline 2,4-dinitro-N-phenylbenzenamine & $2.72-4.08$ \\
\hline diphenylamine & $2.15(3.29 \%)$ \\
\hline 2-nitro-N-(2-nitrophenyl)-benzenamine & $2.10(13.5 \%)$ \\
\hline azobenene & $2.16-3.24$ \\
\hline (4-nitrophenyl)diphenylamine & $1.30(32.6 \%)$ \\
\hline 4-phenyl-1,1,2,1-terphenyl & 1.04-1.56 \\
\hline 1,1,2,1,2,1-quaterphenyl & $1.04-1.56$ \\
\hline Total organic residuals & 354 \\
\hline
\end{tabular}


The diisooctyl adipate is a known plasticizer and is likely a leachate from contact with a plastic surface.

Increased reaction temperatures resulted in greater proportions of organic compound destruction. Of the residual organics remaining in the residual material, biphenyl is the most concentrated. Given that this material has been noted as a reaction byproduct previously, ${ }^{4}$ the presence in these reactions is not surprising. While biphenyl readily sublimes under the reaction conditions (as evidenced by formation of biphenyl on the glass reactor head), there is no evidence that the biphenyl is exiting the system entirely since it is visibly apparent that the biphenyl is not depositing in the ambient temperature tubing lines leading to the GCs. For example, while all the reactions produced visible quantities of biphenyl on the glass reactor dome, the $65^{\circ} \mathrm{C}$ reaction provided the least quantity of biphenyl by the end of the reaction, with the $35^{\circ} \mathrm{C}$ reaction providing the most. It is assumed that the higher temperature reaction is destroying the biphenyl more effectively. Considering that biphenyl fouling may be an issue in the real facility, efficient destruction of biphenyl is an important consideration. However, the biphenyl is refluxing into the slurry during the laboratory work due to the liquid condensation on the hemispherical vessel lids exposed to ambient air flow in the hood. The relative amount of biphenyl reflux in these experiments may differ appreciably from that experienced by the demister equipment in the actual process facility.

With respect to the other analytes remaining in the residual slurry after reaction, they are almost all partially degraded or functionalized aryl compounds. It is very difficult to locate any trend in these analytes.

\subsubsection{Conclusion}

Not surprisingly, increasing the process temperature significantly enhances the CCPO reaction kinetics. At $35^{\circ} \mathrm{C}$ complete TPB destruction was not achieved in the time-frame of the test (approximately 350 hours), whereas the $50{ }^{\circ} \mathrm{C}$ reaction achieved total TPB destruction by the end of the test, and the $65{ }^{\circ} \mathrm{C}$ test achieved complete destruction in $\sim 1$ day. Furthermore, higher temperatures generate smaller quantities of residual organics, and in particular, biphenyl and amines.

Compared to the room temperature tests (Section 3.1), the lower destruction efficiency of the $35^{\circ} \mathrm{C}$ test is due to the shortened time frame of the experiment. The room temperature tests have similar destruction efficiencies as the $35^{\circ} \mathrm{C}$ test, at the similar times.

Not only do the ICPES boron and potassium data indicate excellent agreement in regards to predicting the level of TPB destruction, the HPLC results are also internally consistent. 
As such, there is confidence that using all three methods to determine the TPB destruction levels result in reasonable destruction efficiency. However, the reader should recall that the destruction efficiency, as defined for this investigation, equates to the destruction of TPB. At this time it has not been possible to close the carbon balance due to the lack of off-gas data and other data (carbonate, IC-anions). It is considered possible that the majority of the organic carbon is leaving the system as carbon dioxide and benzene. It has not currently been determined if the concentration of benzene in the offgas will be acceptable in terms of environmental emissions and vapor space flammability in the reaction vessel.

The higher temperatures do not affect the copper concentrations in the filtrate. Presumably this is because the copper solubility is not a strong function of temperature within the range of these tests.

Higher temperature does have a moderate, but not immediate effect on the extent of titanium leaching from the MST. The unexplained increase in titanium occurred in all three tests.

\subsection{Demonstration\#1}

Part of the documented work scope involves duplicating the 2004 work. DEMO 1 is the initial attempt to duplicate those results.

This experiment used the same reaction vessel and temperature control as described in Section 3.3. Other experimental details were as described in previous Sections, except for those changes subsequently listed.

(1) The vessel was attached to a gas chromatograph (GC), which enabled the concentration of the following gaseous species to be tracked: $\mathrm{CO}_{2}, \mathrm{~N}_{2} \mathrm{O}, \mathrm{O}_{2}, \mathrm{~N}_{2}$, and light organics (benzene). The GC actively analyzed the contents of the reactor headspace during the entire reaction every 15 minutes, including during $\mathrm{pH}$ adjustment.

(2) $\mathrm{A} \mathrm{pH}$ probe was inserted into the reaction solution to facilitate $\mathrm{pH}$ adjustment in the reactor. The probe was calibrated prior to its use.

A bottle of $500 \mathrm{~mL}$ of slurry was generated according to the recipe (see Table 1). The $\mathrm{pH}$ of the slurry was adjusted (in the reaction vessel) with $50 \mathrm{wt} \%(10.4 \mathrm{M})$ nitric acid to a final $\mathrm{pH}$ of 11 . The $\mathrm{pH}$ adjustment resulted in $\sim 600 \mathrm{~mL}$ of slurry. During the acid addition it was observed that the stainless steel needles used for acid addition suffered from excessive corrosion. No evidence of ingrowth of steel leachates into the solution was detected, but nonetheless the acid delivery method was modified to avoid the use of stainless steel delivery needles. 
It was noted that the "prototypical mixing" is in fact very poor compared to the reactions performed in poly bottles with a magnetic stirrer. The agitation was insufficient to prevent a semi-stable floating solids mass. This poor agitation may affect the overall reaction efficiency. Also, since the rheology of real waste is known to differ from the simulated slurries, this behavior may lead to experimental offsets in similar tests.

Copper catalyst in the form of $\mathrm{Cu}\left(\mathrm{NO}_{3}\right)_{2} \bullet 2.5 \mathrm{H}_{2} \mathrm{O}$ (to the targeted amount of $500 \mathrm{mg} / \mathrm{L}$ copper) was added to the reaction vessel. Active temperature control was provided by the thermal bath. The initial temperature was set to $35^{\circ} \mathrm{C}$. At approximately 144,264 , and 336 hours into the test, the operating temperature was raised to $45^{\circ} \mathrm{C}, 55^{\circ} \mathrm{C}$, and $75^{\circ} \mathrm{C}$, respectively. The total duration of the test was 497 hours. This temperature profile matches that of the 2004 work, with the exception that the initial room temperature phase of $\sim 2$ weeks was omitted. Given the lack of reactivity at $35^{\circ} \mathrm{C}$ in the 2004 work, it was anticipated that removing the room temperature step would have little impact on overall reactivity. (Note, in the 2004 experiment, the copper concentration was increased after one week at $35^{\circ} \mathrm{C}$ to a value of $467 \mathrm{mg} / \mathrm{L}$ with relatively slow reaction occurring as noted by one filtrate sample analysis and then the temperature was increased to $45{ }^{\circ} \mathrm{C}$.)

Hydrogen peroxide was added at the rates used in the 2004 work, after scaling for volume differences; $0.2 \mathrm{~mL} /$ hour.

The test ran for approximately 21 days. Filtrate samples were removed once per day. A total of 23 samples were removed for analysis by ICPES. From the ICPES results, the boron, potassium, copper, sodium, and titanium soluble concentrations were examined. Results from each test were compared to establish potential differences in reactivity.

\subsubsection{Soluble Boron Results}

As in previous experiments, the concentration of soluble boron was used as an indicator of the extent of TPB destruction. After the start of the $\mathrm{H}_{2} \mathrm{O}_{2}$ addition the boron in the filtrate samples increased over time. See Figure 15.

The reaction was halted after 497 hours, and the extent of boron dissolution associated with the acid hydrolysis and peroxide oxidation reactions was calculated using the same methodology as in Section 3.1.1 (see Table 13). The final data point at $\mathrm{t}=708$ hours is from the confirmation sample from the residual slurry after reaction (see Section 3.4.5) and is not used in the percent destruction calculation. 
Figure 15. Boron Concentration Results for Demonstration 1

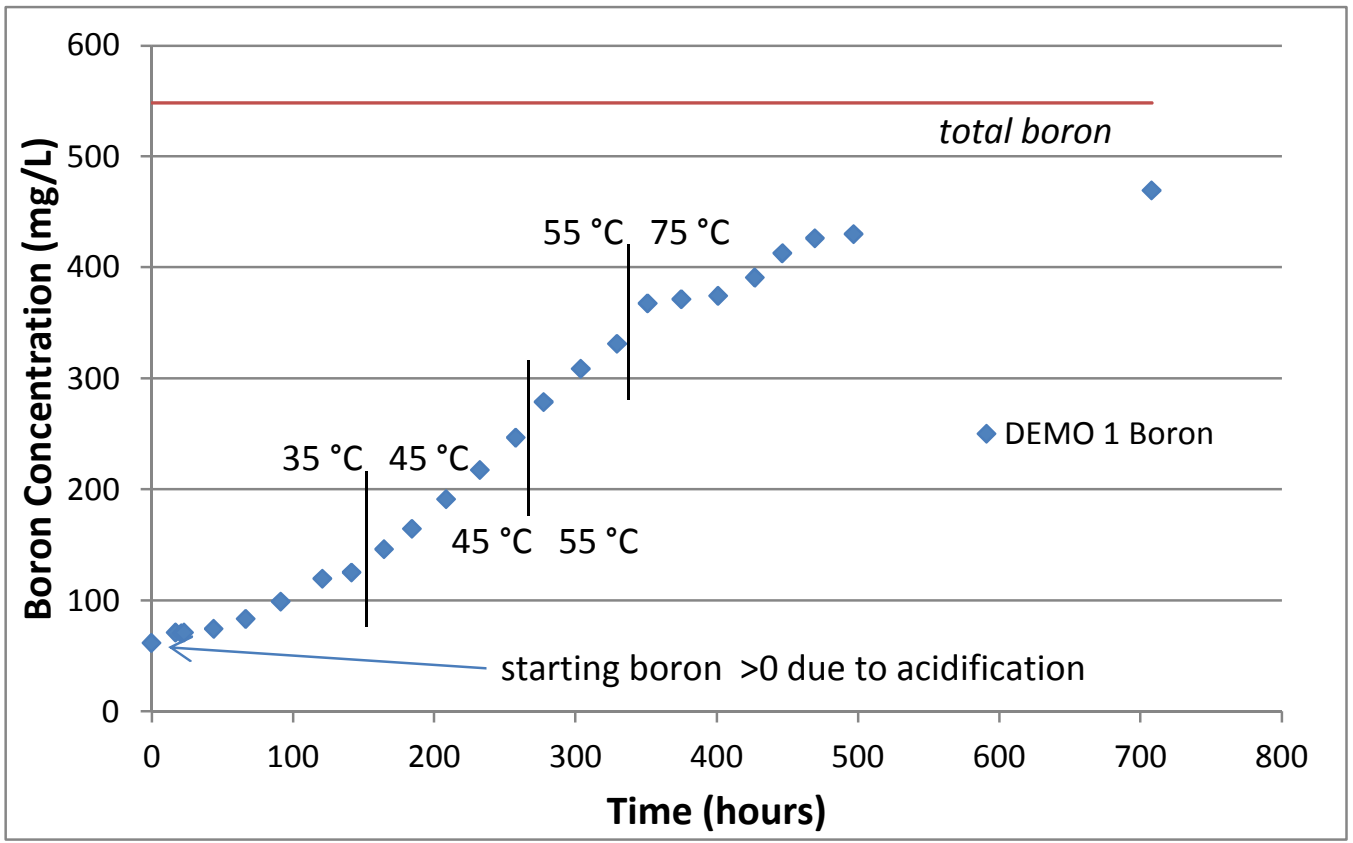

Table 13. Total TPB Destruction from Final Boron Results for Demonstration 1

\begin{tabular}{|c|c|c|}
\hline Destruction by Acid & Destruction by $\mathrm{H}_{2} \mathrm{O}_{2}$ & Total Destruction \\
\hline $10.1-12.4 \%$ & $59.0-74.8 \%$ & $70.3-85.9 \%$ \\
\hline
\end{tabular}

The decline in reactivity in DEMO 1 is counter to expectations from previous data sets. At this time causes for the lack of reactivity at 55 and $75^{\circ} \mathrm{C}$ have not been established, though there is no reason to think that temperatures above $45^{\circ} \mathrm{C}$ are detrimental.

\subsubsection{Soluble Potassium Results}

As in previous experiments, the concentration of soluble potassium was used as an indicator of TPB destruction. After the start of the $\mathrm{H}_{2} \mathrm{O}_{2}$ addition the potassium in the filtrate samples increased over time. See Figure 16.

From the potassium data, the same trends found in the boron data are observed, including the temperature dependencies. The extent of destruction is closer to complete from the potassium data (as usual, the potassium data shows a higher extent of destruction than the boron data), and within the analytical uncertainty of showing $100 \%$ destruction. 
The reaction was halted after 497 hours, and the extent of potassium dissolution associated with the acid hydrolysis and the peroxide oxidation reaction was calculated using the same methodology as in Section 3.1.1 (see Table 14). The final data point at $\mathrm{t}=708$ hours is from the confirmation sample from the residual slurry after reaction (see Section 3.4.5) and is not used in the percent destruction calculation.

Table 14. Total TPB Destruction from Potassium Results for Demonstration 1

\begin{tabular}{|c|c|c|}
\hline Destruction by Acid & Destruction by $\mathrm{H}_{2} \mathrm{O}_{2}$ & Total Destruction \\
\hline $19.5-26.9 \%$ & $60.3-83.4 \%$ & $85.7-108 \%$ \\
\hline
\end{tabular}

Figure 16. Potassium Concentration Results for Demonstration 1

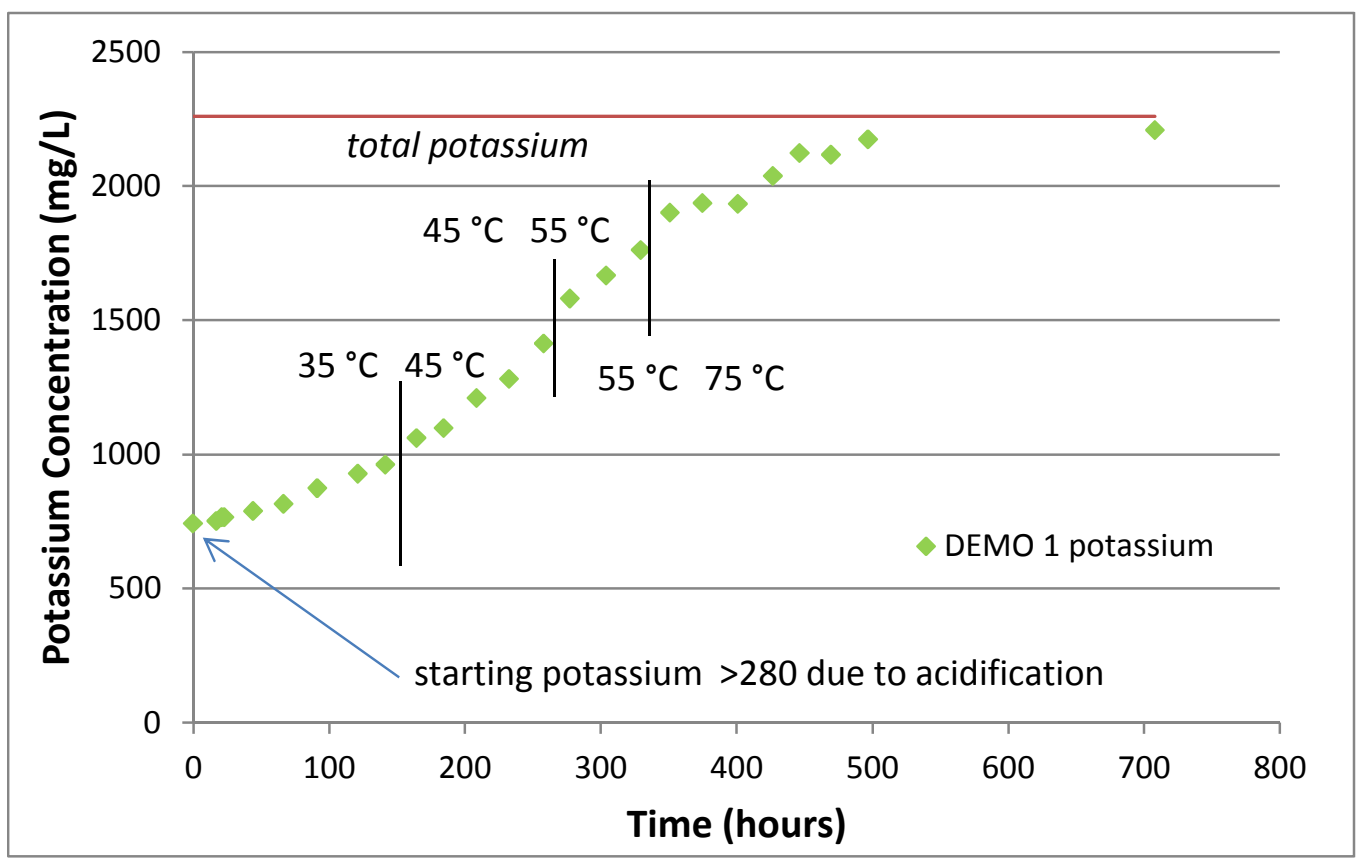




\subsubsection{Soluble Copper Results}

Copper concentrations are tracked in the filtrate for the reasons outlined in Section 3.1.3. After the start of the $\mathrm{H}_{2} \mathrm{O}_{2}$ addition the copper in the filtrate samples slowly increased over time. See Figure 17.

DEMO 1 shows unique time-dependent copper soluble concentrations in comparison to the aforementioned tests. Previous tests all exhibited a relatively slow increase in copper soluble concentrations, reaching a maximum of $\sim 100 \mathrm{mg} / \mathrm{L}$. DEMO 1, however, indicates a more rapid rate of copper dissolution and higher maximum copper concentration. The maximum concentration is subsequently followed by a decline in soluble concentrations after the slurry is heated to $75^{\circ} \mathrm{C}$ eventually reaching $\sim 60 \%$ of the peak concentration, but still leveling off at $\sim$ twice as high as other reactions. Even the confirmation sample, which had long since cooled to room temperature, showed a higher filtrate concentration than the other reactions. Even more significant is that the boron and copper behavior both show a distinct change in behavior at the time the temperature was increased from $55^{\circ} \mathrm{C}$ to $75^{\circ} \mathrm{C}$ (see Figure 18).

Figure 17. Soluble Copper Concentration Results for DEMO 1

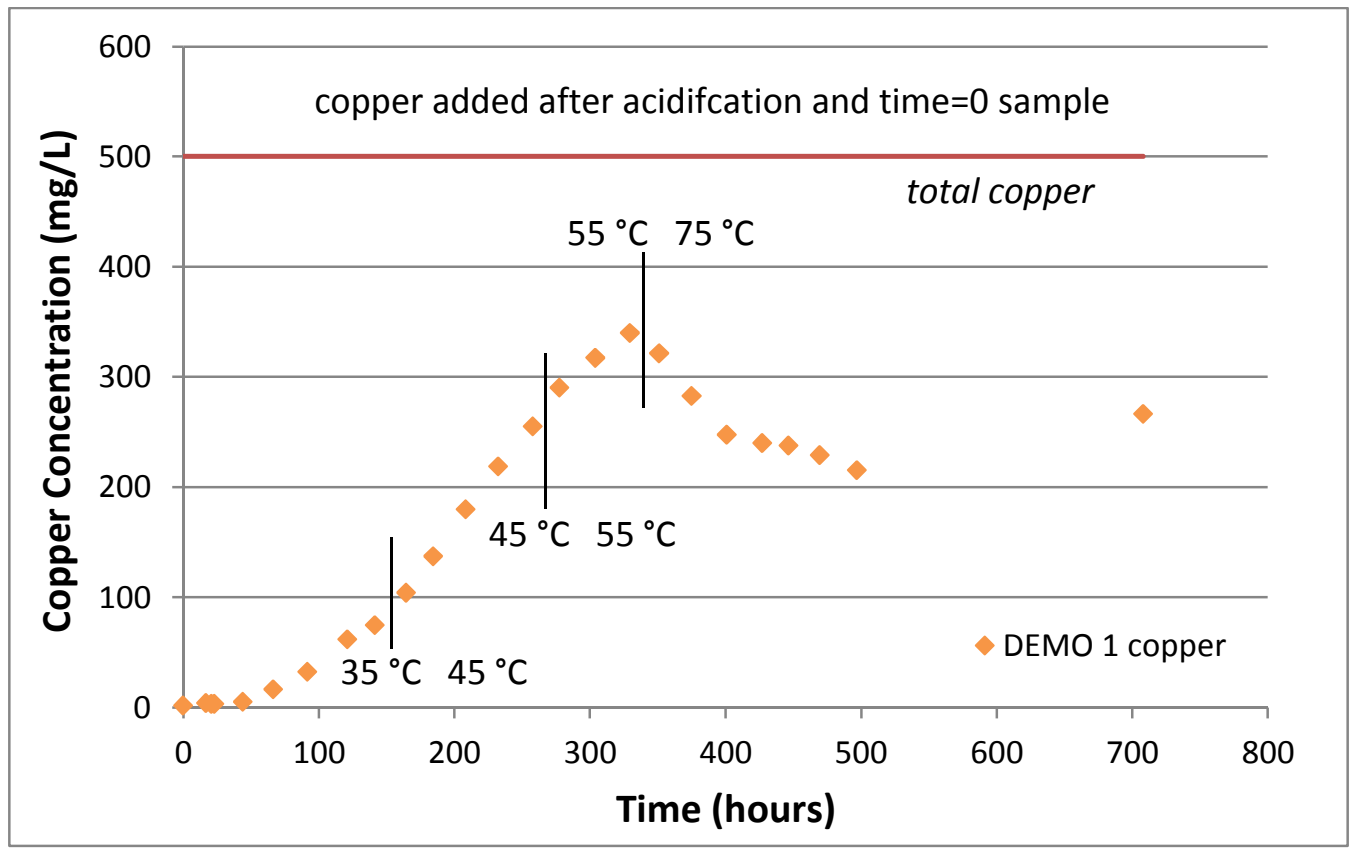


At the point of temperature change from 55 to $75^{\circ} \mathrm{C}$, the rate of destruction (slope of the line) from the boron data shows a distinct negative impact, as opposed to the intuitive positive impact that was anticipated. At the same time, the copper sharply declines to $\sim 60 \%$ of its peak concentration. Both of these behaviors are unique in the tests to date.

\section{Figure 18. Soluble Boron and Copper Concentration Behavior Correlation for DEMO 1}

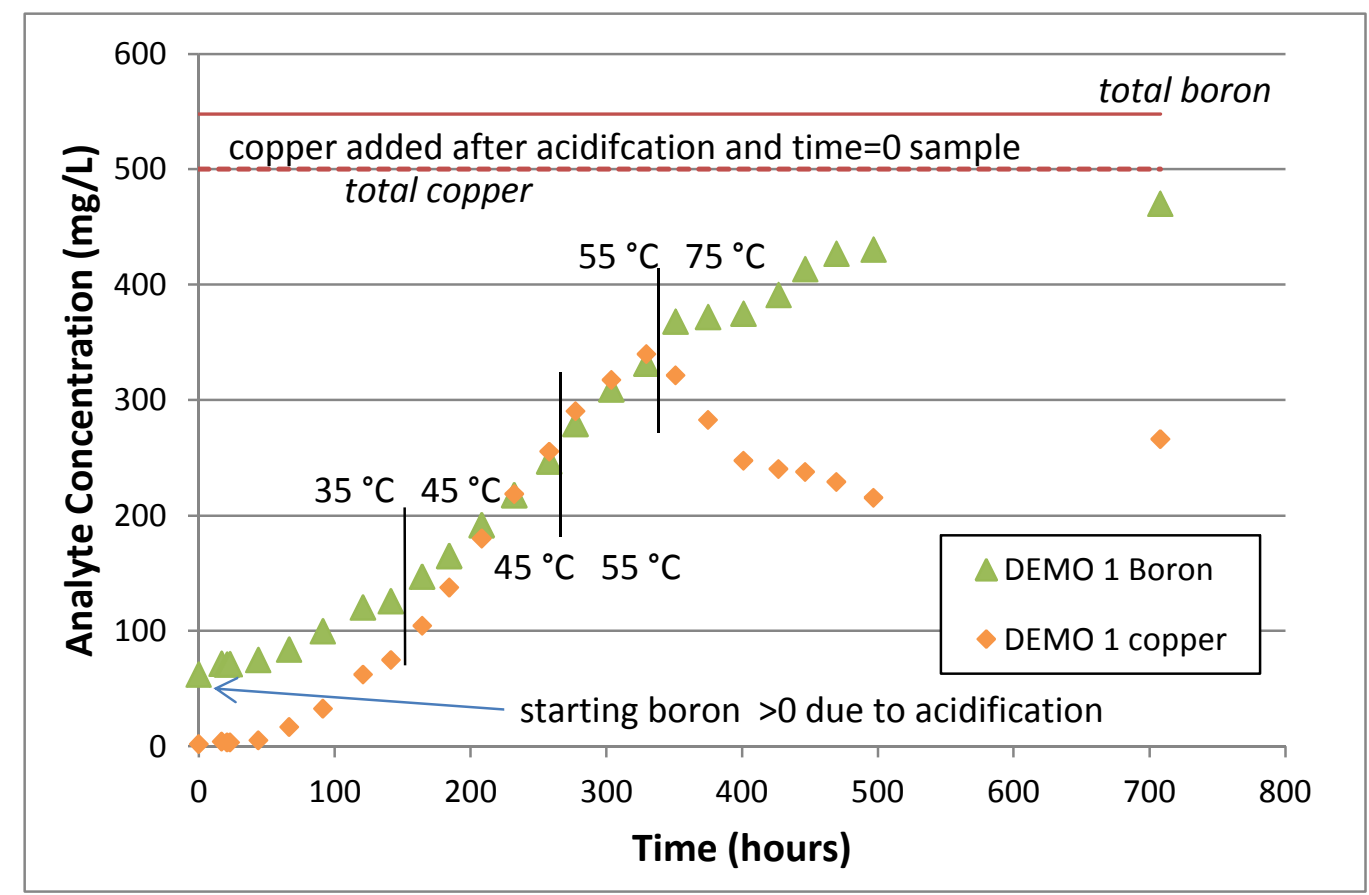

\subsubsection{Soluble Titanium Results}

The titanium concentration in solution is monitored for the reasons outlined in Section 3.1.4. See Figure 19.

The titanium data indicates no significant thermally induced changes in the soluble concentration of titanium. At all four reaction temperatures, the titanium concentrations were below $5 \mathrm{mg} / \mathrm{L}$. In addition, although it cannot be discerned on Figure 19, the 
titanium levels drop to below detection limits $(1.2 \mathrm{mg} / \mathrm{L})$ at the same time the boron and copper concentrations decrease (i.e., at the time the temperature was increased from $55^{\circ} \mathrm{C}$ to $75^{\circ} \mathrm{C}$ ).

Figure 19. Titanium Concentration Results for Demonstration 1

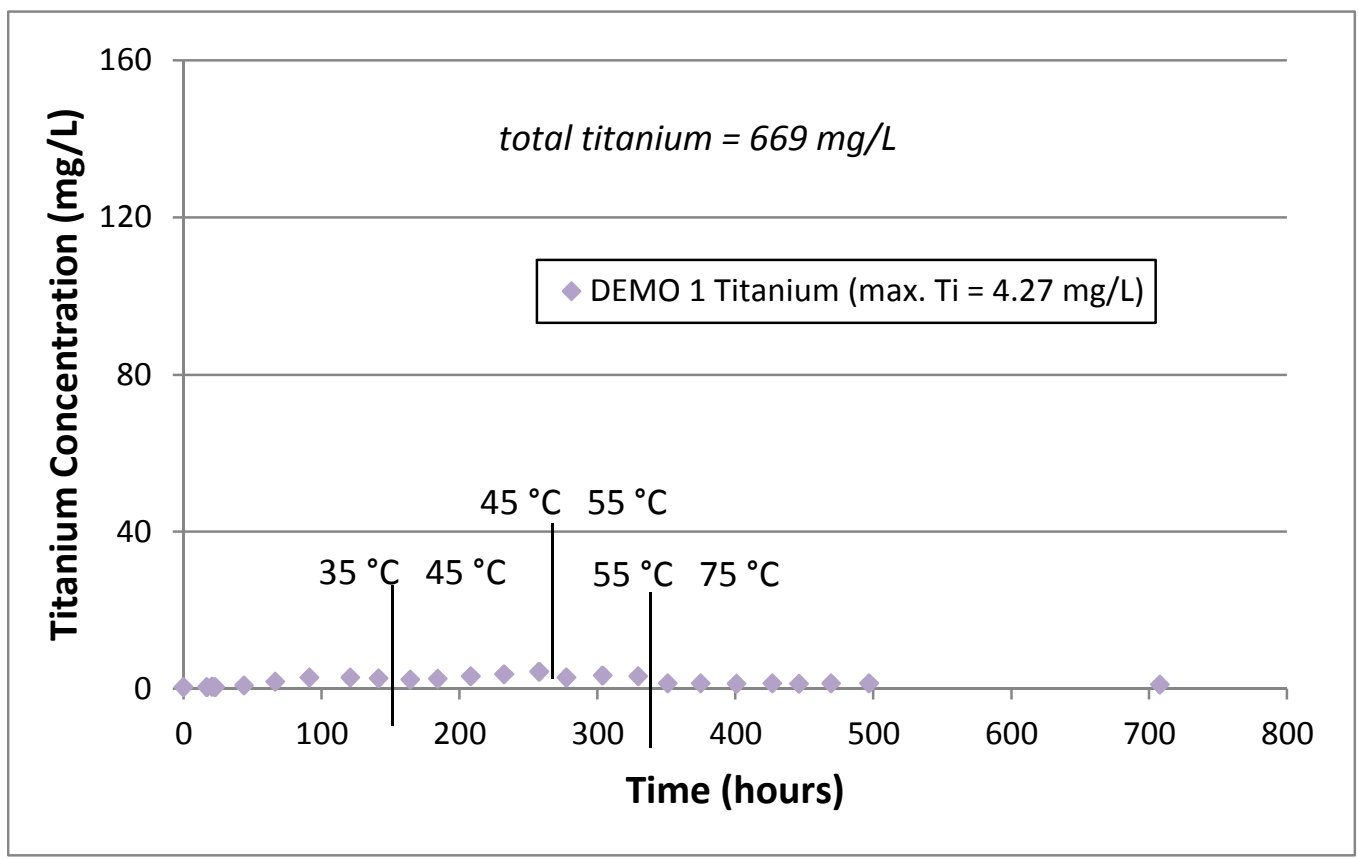

\subsubsection{Analysis of Residual Slurry After Reaction}

After DEMO 1 was complete, the remaining reactor bottom was removed. The amount of recovered material is somewhat dependent on the efficiency of slurry removal (some solids were caked on the upper parts of the reactor or difficult to remove).

Well-mixed duplicate samples of the reactor bottom were analyzed via HPLC, VOA and SVOA. However, due to the elapsed time from the end of the reaction ( 211 hours), and the time of sampling, a filtered sample of the bottom was analyzed via ICPES as a check to see if the reaction had proceeded further. The results of the ICPES analyses are listed in Table 15. These results are corrected for dilution as normal. 
There are no statistically significant differences in the boron and potassium results between the two sample sets for any of the reactions. This is indicative of no further TPB destruction occurring in the time interval between the last sample and the check sample.

Table 15. ICPES Check Samples for Demonstration $1(\mathrm{mg} / \mathrm{L})$

\begin{tabular}{|c|c|c|}
\hline Analyte & $\begin{array}{c}\text { Final Filtrate } \\
\text { Result }\end{array}$ & $\begin{array}{c}\text { End of Reaction Period } \\
\text { Sample Result }\end{array}$ \\
\hline $\mathrm{B}$ & 469.8 & 430.4 \\
\hline $\mathrm{K}$ & 2207 & 2173 \\
\hline $\mathrm{Cu}$ & 266.2 & 215.2 \\
\hline $\mathrm{Ti}$ & 0.936 & 1.248 \\
\hline
\end{tabular}

The analytical uncertainty is $10 \%$ for each result.

As no additional destruction occurred, a valid comparison between the ICPES and HPLC results exists. Table 16 lists the HPLC results.

\section{Table 16. HPLC Results from Residual Slurry After Reaction Analysis (mg/L) for Demonstration 1}

\begin{tabular}{|c|c|c|c|c|c|}
\hline TPB & 3PB & 2PB & 1PB & Phenol & \% Destruction \\
\hline $2420(1.17 \%)$ & $<10$ & $<10$ & $<10$ & $<10$ & $84.0-84.4 \%$ \\
\hline
\end{tabular}

The value in parentheses is the \%RSD. The "\% Destruction" column is the calculated percent destruction. The value is based on the mass of TPB added to the simulant slurries and calculation of the mass of TPB in the residual material, after correcting for the mass of samples removed from the system during the reactions.

Finally, samples of the residual slurry after reaction were analyzed using VOA and SVOA. See Table 17. The values in parentheses are the \%RSD. In the results column, values that are shaded indicate only one measured value with the other being a detection limit result. In this case, the values in parentheses are the analytical uncertainties. The "total organic residuals" are the sum of all the mid-range values of the detected analytes, less benzene. These results are not normalized to the beginning volumes.

Of the residual organics remaining in the reactor residuals, biphenyl is the most concentrated. Given that this material has been noted as a reaction byproduct before, the presence in these reactions is not surprising. 
With respect to the other analytes left in the residual slurry after reaction, they are almost all partially degraded or functionalized aryl compounds.

Table 17. VOA and SVOA Results for Demonstration 1

\begin{tabular}{|c|c|}
\hline Analyte & Result (mg/L) \\
\hline benzene & $0.20(0.00 \%)$ \\
\hline biphenyl & $760(81.9 \%)$ \\
\hline p-terphenyl & $40.0(28.3 \%)$ \\
\hline 2-nitrophenol & $30.5(67.2 \%)$ \\
\hline nitrobenzene & $32.8-49.2$ \\
\hline phenol & $6.72-10.1$ \\
\hline 4-nitrobiphenyl & $5.92-8.88$ \\
\hline o-phenylene benzeneboronate & $3.2-4.8$ \\
\hline o-terphenyl & $2.72-4.08$ \\
\hline m-terphenyl & $2.8(0.00 \%)$ \\
\hline Total organic residuals & 898 \\
\hline
\end{tabular}

\subsubsection{Gas Chromatography Results}

During the entire life of DEMO 1, including the $\mathrm{pH}$ adjustment, the off-gas composition was monitored using GC. This enables tracking of important off-gas species such as benzene and $\mathrm{CO}_{2}$ which can potentially provide information on reaction rates. During the $\mathrm{pH}$ adjustment, benzene is produced from hydrolysis of the TPB, while $\mathrm{CO}_{2}$ is from the acid attack on the carbonate in the slurry. During CCPO activity, benzene is less likely to be formed, and $\mathrm{CO}_{2}$ production is from the total degradation of organic compounds.

The major off-gas components are benzene and $\mathrm{CO}_{2}$. The presence of benzene and $\mathrm{CO}_{2}$ are associated with $\mathrm{pH}$ adjustment of the slurry and chemical oxidation of the organic compounds (both gases are evolved throughout the reaction). See Figure 20. 
Figure 20. Gas Release Rates for DEMO 1

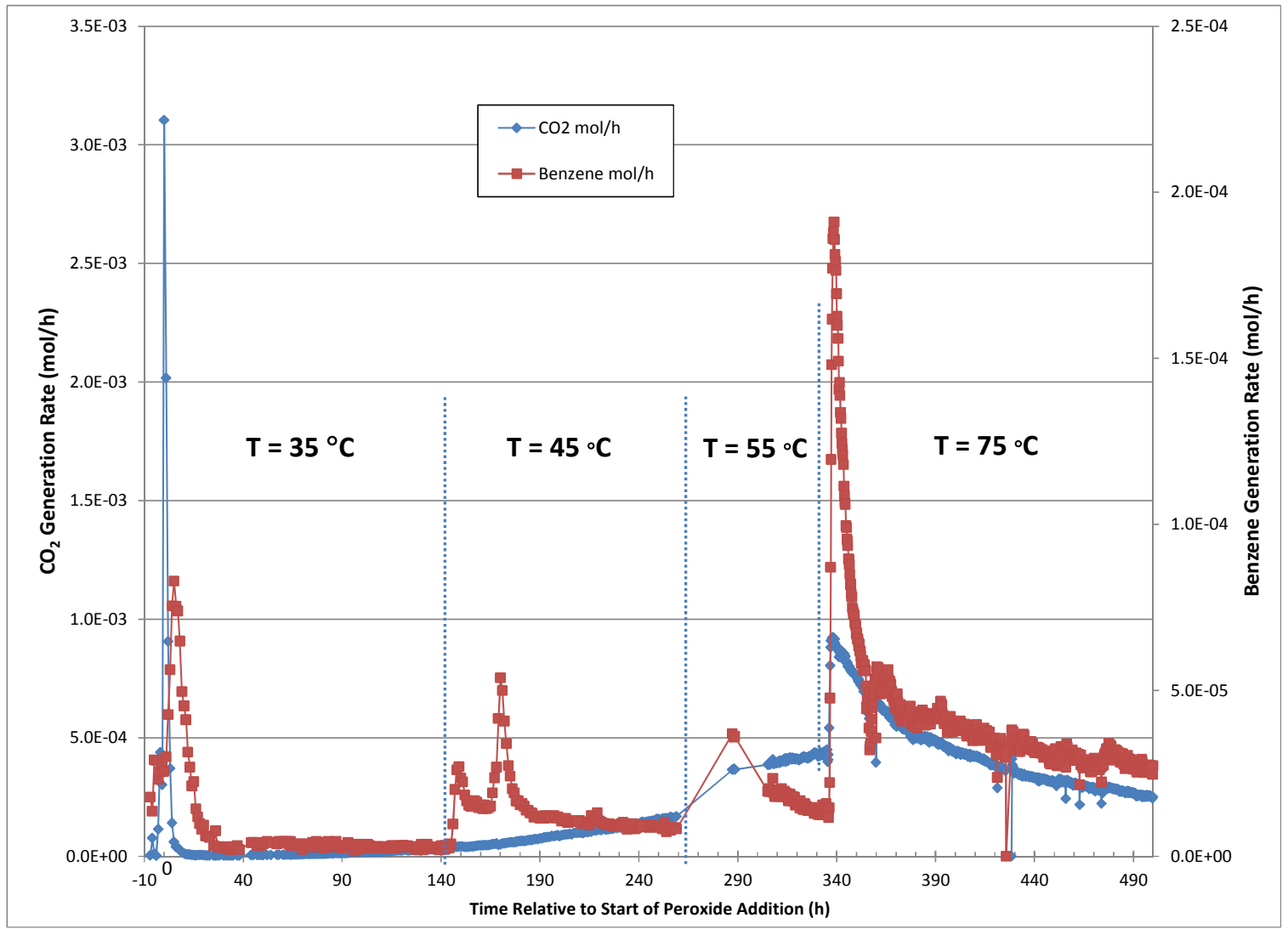

The generation rates of benzene and carbon dioxide are clearly affected by the changes in temperature. At each temperature increase, a corresponding increase in benzene and carbon dioxide gas is observed. The $\mathrm{CO}_{2}$ gas release can be due to two factors decreased solubility as the temperature increases, and increases in generation from the decomposition reactions. The initial spikes in $\mathrm{CO}_{2}$ concentration must be due to the $\mathrm{pH}$ adjustment process, and are more clearly shown in Figure 21.

Figure 21 shows the gas generation from the initiation of GC monitoring to 13 hours into the reaction. The $\mathrm{H}_{2} \mathrm{O}_{2}$ addition and temperature increase to $35^{\circ} \mathrm{C}$ started at time $=0$. The $\mathrm{pH}$ adjustment occurred before time $=0$, and is indicated by the shaded area in Figure 21. 
Figure 21. Gas Release near Time $=0$

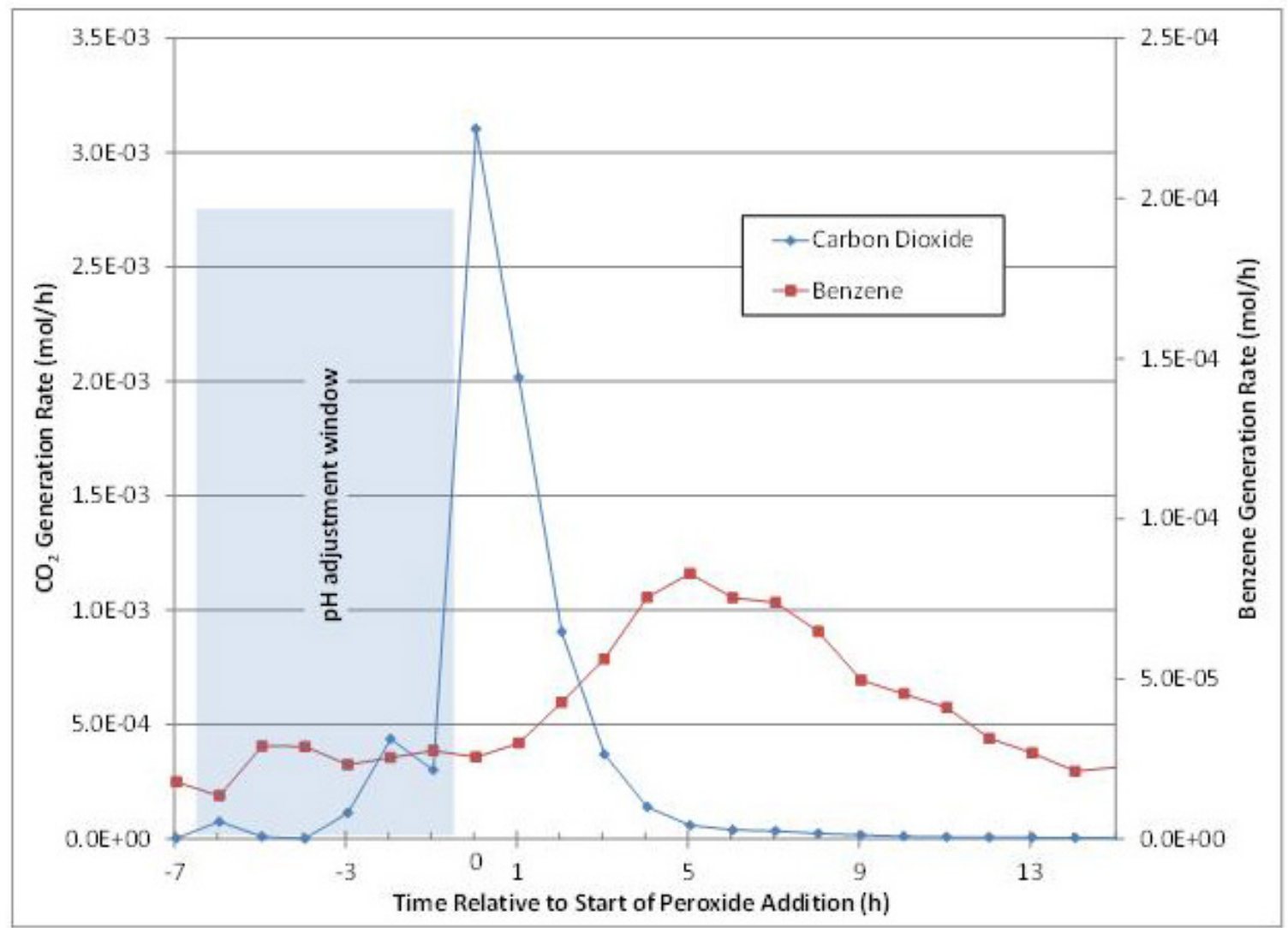

Several important points can be drawn from this graph.

- $\mathrm{CO}_{2}$ evolution occurs slowly about 4 hours after acid addition is commenced (presumed due to acid-carbonate reaction) and then rapidly increases as the $\mathrm{pH}$ adjustment continues. The acid-carbonate reaction continues after the acid is no longer added.

- Even though the benzene is assumed to be produced during acid hydrolysis it is not released until after the almost concurrent increase to reaction temperature and addition of peroxide. Previous work indicates a correlation between temperature increases and increased release of benzene. ${ }^{20}$

- Since such a small amount of peroxide is added in the first hours $(0.2 \mathrm{~mL} /$ hour $)$ it is more likely that the benzene release is associated with increase in temperature. 
- Increased temperature can have two potential effects; increased benzene volatility or decreased gas solubility.

There are complications in further analyzing the off-gas concentrations. Firstly, because acidification occurs in the reactor (as opposed to the 2004 work), it is impossible to deconvolute $\mathrm{CO}_{2}$ generated from acidification of carbonate in the simulant, and $\mathrm{CO}_{2}$ generated from organic oxidation. This is because degassing of the $\mathrm{CO}_{2}$ is not immediate and takes place over time. Later tests that employ a more measured acidification provide some clarification. See Section 3.16.

In the case of benzene, it is not possible to deconvolute benzene generated during acidification or during the $\mathrm{H}_{2} \mathrm{O}_{2}$ aided destruction. Furthermore, any generated benzene may be degassed from solution, or oxidized as part of a chemical reaction. Finally, as part of the simulant recipe, for each reaction, $44 \mu \mathrm{L}$ of benzene ( 0.000495 moles) is added to the simulant after the acidification, but before the addition of the $\mathrm{H}_{2} \mathrm{O}_{2}$.

In the case of $\mathrm{CO}_{2}$, it is difficult to determine from the graph if this was generated during acidification versus $\mathrm{H}_{2} \mathrm{O}_{2}$ aided destruction, other than to assume that as time progresses the $\mathrm{CO}_{2}$ produced is more likely to be from organic destruction than the acidification. Furthermore, any generated $\mathrm{CO}_{2}$ may be degassed from solution, or oxidized as part of a chemical reaction.

It is possible to use the GC data in attempt to determine a mass balance for DEMO 1. To do this, it is necessary to determine the moles of benzene and $\mathrm{CO}_{2}$ available in the simulant slurry before $\mathrm{pH}$ addition, and compare this against the moles of benzene and $\mathrm{CO}_{2}$ remaining in the residual slurry after reaction at the end of the reaction.

Figure 22 shows the cumulative amount of benzene and $\mathrm{CO}_{2}$ detected over the life of the experiment. The graph is also broken into the four different temperature blocks.

From this graph several key points can be determined.

- There is a noticeable temperature effect. Increased temperatures generate more $\mathrm{CO}_{2}$ and benzene. Whether this is from degassing or from generation is impossible to say.

- The amount of benzene produced by the end of the reaction is 0.0117 moles $(0.914$ grams).

- The amount of $\mathrm{CO}_{2}$ produced by the end of the reaction is 0.119 moles. 
Figure 22. Cumulative Off-gas Release in Demonstration 1

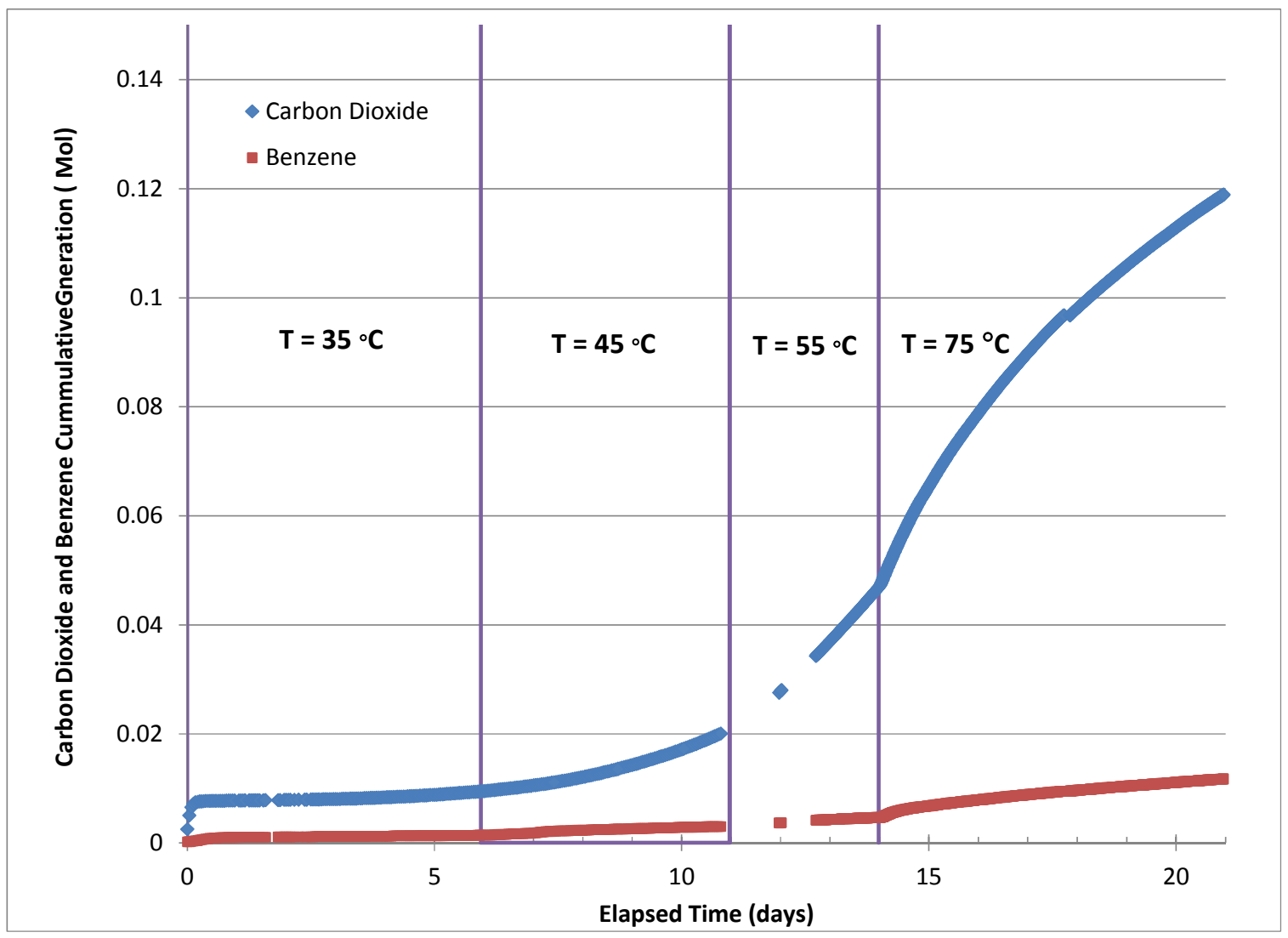

With respect to benzene, from the HPLC and VOA measurements, 0.00474 moles of TPB remains in the residual slurry after reaction as TPB (as well as a trivial amount of benzene detected from VOA). Each mole of TPB can convert to 4 moles of benzene, for a maximum possible remaining inventory of 0.114 moles of $\mathrm{CO}_{2}{ }^{\mathrm{b}}$

With respect to $\mathrm{CO}_{2}$, a sample of the DEMO 1 residual material was analyzed by TIC/TOC. The TIC (total inorganic carbon - assumed to be carbonate ${ }^{18,19}$ ) result indicated that 0.098 moles of carbonate remained in the reactor residuals.

From the reactor residuals, SVOA analysis provided a result of $898 \mathrm{mg} / \mathrm{L}$ of residual organics, the bulk of which is in the form of biphenyl. For the sake of simplicity, if it is assumed that all of this is biphenyl, this converts to a maximum possible remaining inventory of 0.0438 moles of $\mathrm{CO}_{2}$.

\footnotetext{
${ }^{\mathrm{b}}$ For the moment, the initial added quantities of biphenyl and phenol will be ignored for the sake of clarity.
} 
Against these observations, the initial inventory of benzene was calculated. Each $500 \mathrm{~mL}$ of simulant slurry has a maximum benzene inventory of 0.12 moles (this includes the $44 \mu \mathrm{L}$ of benzene added just before time $=0$ ). The GC measured only 0.0117 moles of benzene over the life of the reaction and so it can be concluded that $\sim 9.7 \%$ of the potential benzene inventory left the system as benzene. Ideally, no benzene should leave the system.

The inventory of carbonate was calculated. Each slurry starts with 0.290 moles of carbonate. This serves as a possible inventory for an equimolar amount of $\mathrm{CO}_{2}$, as any decrease in the carbonate concentration in the slurry must be due to the $\mathrm{pH}$ adjustment (carbonate $\rightarrow \mathrm{CO}_{2}$ ).

For DEMO 1 the starting carbonate amount is 0.290 moles, and by the end of the reaction, the amount left over is 0.098 moles. Therefore, the difference, 0.192 moles, was lost from $\mathrm{pH}$ adjustment. This carbonate was converted to $\mathrm{CO}_{2}$ and left the system.

The slurry used in DEMO 1, as generated, also contained 0.0300 moles of TPB. Under ideal conditions, if all of the phenyl groups in the TPB were converted into $\mathrm{CO}_{2}$, this would allow for a maximum $\mathrm{CO}_{2}$ generation of 0.72 moles of $\mathrm{CO}_{2}$.

It is possible to calculate the amount of $\mathrm{CO}_{2}$ that was actually created during DEMO 1. The maximum possible amount is 0.72 moles. To this value must be added the $\mathrm{CO}_{2}$ that was produced from the conversion of carbonate to $\mathrm{CO}_{2}$ which occurred during the $\mathrm{pH}$ adjustment, or 0.192 moles, for a total of 0.912 moles. From this total, the known remainder in the reactor residuals must be subtracted:

- 0.114 moles from the residual TPB (HPLC)

- 0.0438 moles from the residual other organics (SVOA)

- 0.069 moles from the benzene that the GC measured

This gives a calculated amount of created $\mathrm{CO}_{2}$ of 0.658 moles. ${ }^{\mathrm{c}}$ The remaining carbonate is not subtracted since this material should not be further converted to $\mathrm{CO}_{2}$ through the action of the CCPO.

The GC only detected 0.119 moles, or $\sim 17 \%$ of the calculated $\mathrm{CO}_{2}$ produced.

Potential losses from the system due to leaks are being investigated to account for the differential.

\footnotetext{
${ }^{c}$ Again, this is intended as a rough measurement. The production of oxalate and formate results would affect this value.
} 


\subsection{7 pH Monitoring}

$\mathrm{pH}$ was monitored during the reaction (see Figure 23).

The chemical reactions appear to drive towards a final $\mathrm{pH}$ of about 9. SRNL is currently considering the possible reasons for this result.

Figure 23. pH Readings for Demonstration 1

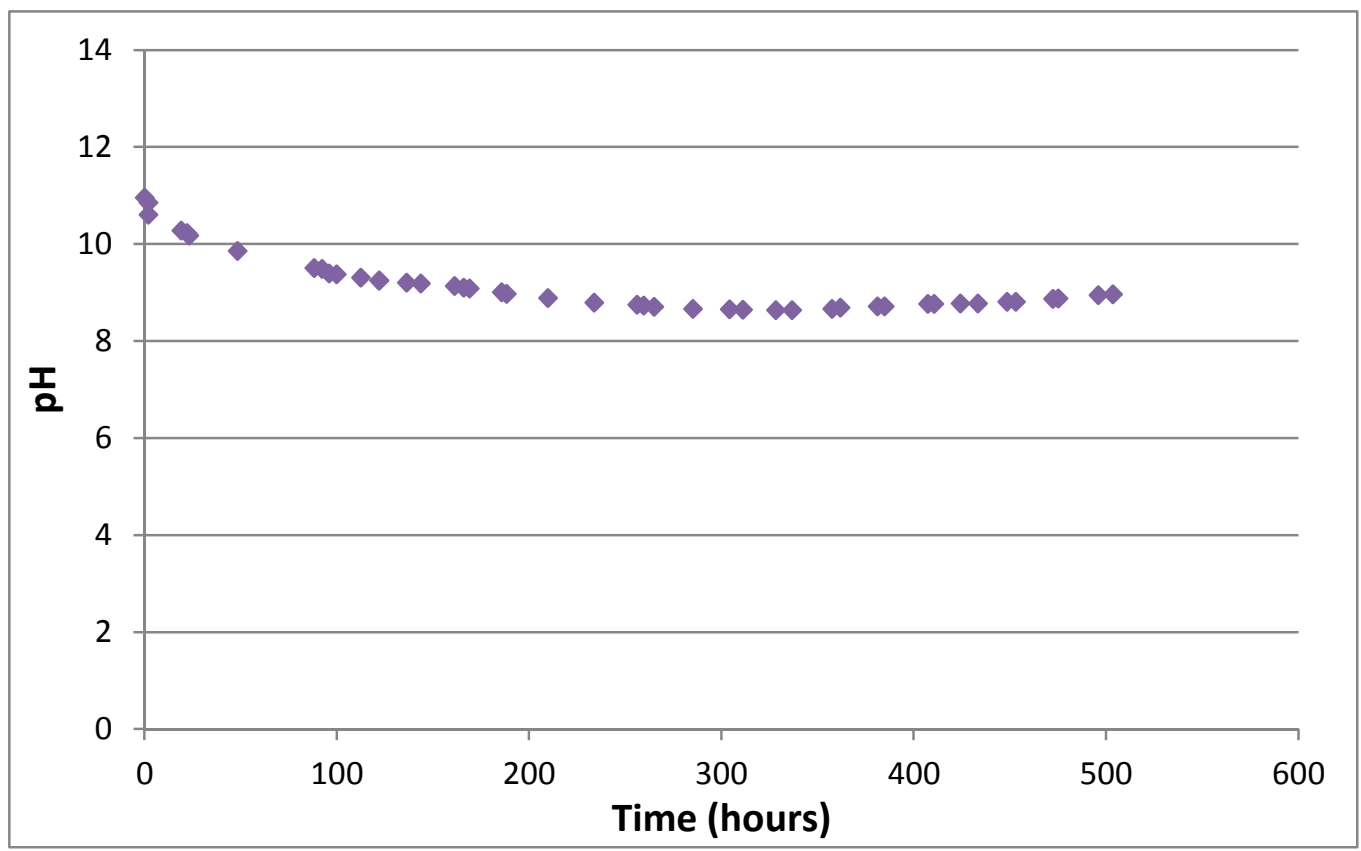

\subsubsection{IC-Anions Data}

The fate of the various anions in the simulant was also evaluated. While most anions in the simulant slurry are likely unaffected by the reaction chemistry, it is known that the concentrations of certain anions, such as nitrite, oxalate or formate, may change during processing. In previous work, ${ }^{8}$ a number of reaction samples were examined to establish the effects on these types of anions. See Table 18.

There was no formate or oxalate added to the salt simulant, so the appearance of those species is significant and must be generated as part of the CCPO reaction. 
SRNL-STI-2012-00342

Revision 1

Table 18. IC-Anions Concentration Results for DEMO 1 Samples (mg/L)

\begin{tabular}{|c|c|}
\hline Analyte & Result (mg/L) \\
\hline fluoride & $<100$ \\
\hline formate & 601 \\
\hline chloride & 303 \\
\hline nitrite & 22300 \\
\hline bromide & $<500$ \\
\hline nitrate & 107000 \\
\hline phosphate & 113 \\
\hline sulfate & 247 \\
\hline oxalate & 3200 \\
\hline
\end{tabular}

The analytical uncertainty for each IC-Anions sample is $10 \%$.

Using the highest measured values for both anions, the amount of carbon sequestered in those materials that came from benzene can be estimated. $255.7 \mathrm{mg} / \mathrm{L}$ of formate translates to 0.00907 moles of benzene. $1742 \mathrm{mg} / \mathrm{L}$ of oxalate translates to 0.024 moles of benzene. Together, these two anions account for $\sim 20.5 \%$ of the potential benzene inventory.

\subsubsection{Conclusion}

DEMO 1 did not lead to complete destruction. However, the ICPES data indicates some unique behavior. Boron and potassium indicate a decline in the rate of TPB destruction at the point of the temperature increase to $75^{\circ} \mathrm{C}$, and copper and titanium show a decline in concentration during the same temperature transition. It seems unlikely that these observations are coincidental. SRNL believes that at $75^{\circ} \mathrm{C}$, the rate of autodecomposition of the $\mathrm{H}_{2} \mathrm{O}_{2}$ may become severe enough that it is essentially depleted from the reaction. In the absence of the $\mathrm{H}_{2} \mathrm{O}_{2}$ (and subsequent chemical oxidation of TPB) the rate of ingrowth of soluble boron and potassium would decrease.

With respect to the copper, this test resulted in copper filtrate concentrations much higher than previous tests. The method of addition was the same in all cases, and potential causes of the higher copper concentration for this particular reaction have not been determined.

There was no significant effect on the titanium. Concentrations started low, and stayed low during the entire lifetime of the test. 


\subsection{Comparison of Demonstration 1 and the 2004 Final Test}

In the 2004 report, ${ }^{4}$ SRNL provided the results from two tests designed to prove the efficacy of $\mathrm{H}_{2} \mathrm{O}_{2}$ aided organic destruction. In that report, the reaction which was conducted at $\mathrm{pH} 11$ is the most relevant to the current work. The current work for DEMO 1 was conducted very similarly to the 2004 work as an attempt to repeat it. However, there were three differences.

- The simulant slurry was not $\mathrm{pH}$ adjusted in the same manner. The 2004 test used samples from earlier tests with a composite slurry initial $\mathrm{pH}$ of 11 . Hence, the initial slurry processing history differed.

- The current work used $50 \mathrm{wt} \% \mathrm{H}_{2} \mathrm{O}_{2}$ instead of $30 \mathrm{wt} \%$. Volume additions were not corrected for the difference There were no anticipated negative processing effects in using a higher peroxide concentration, and $50 \mathrm{wt} \% \mathrm{H}_{2} \mathrm{O}_{2}$ should ultimately reduce the final waste volume.

- The current test simulated the 2004 test procedure that followed addition of $467 \mathrm{mg} / \mathrm{L}$ copper catalyst since prior to this point no significant reactivity was observed. As such a one week reaction period at room temperature, and four days at $35^{\circ} \mathrm{C}$ (both with a lesser $24 \mathrm{mg} / \mathrm{L}$ added copper catalyst) were omitted from the current test procedure.

At the end of the 2004 reaction, the report ${ }^{4}$ claimed $95 \%$ of the TPB had decomposed as determined by boron in solution. By the potassium result, $100 \%$ (111\% as reported) of the TPB had decomposed.

Table 19 shows the comparison of the final slurry analyses. The residual TPB and other organics in the reactor residuals corroborate the lower extent of reaction for the current test (DEMO 1). Factors associated with the reduced destruction efficiencies for the verification test have not been conclusively identified. 
Table 19. Comparison of 2004 and Demonstration 1

\begin{tabular}{|c|c|c|}
\hline Analyte & 2004 Result & Current Result \\
\hline TPB destruction - B & $95 \%$ & $78.1 \%$ \\
\hline TPB destruction - K & $111 \%$ & $95.1 \%$ \\
\hline TPB & $<10$ & $2420 \mathrm{mg} / \mathrm{L}$ \\
\hline 3PB & $<10$ & $<10$ \\
\hline 2PB & $<10$ & $<10$ \\
\hline 1PB & $<10$ & $<10$ \\
\hline Phenol & $<10$ & $<10$ \\
\hline TIC & $2760 \mathrm{mg} / \mathrm{L}$ & $1870 \mathrm{mg} / \mathrm{L}$ \\
\hline TOC & $1160 \mathrm{mg} / \mathrm{L}$ & $1150 \mathrm{mg} / \mathrm{L}$ \\
\hline $\begin{array}{c}\text { Total residual SVOA } \\
\text { organics }\end{array}$ & $16 \mathrm{mg} / \mathrm{L}$ & $898 \mathrm{mg} / \mathrm{L}$ \\
\hline Final $\mathrm{pH}$ & 9.6 & 8.96 \\
\hline \multicolumn{2}{|c}{}
\end{tabular}

The off-gas measurements from the two reactions can also be compared (Figure 24). Note that $\mathrm{CO}_{2}$ was not measured in the 2004 test.

The benzene in both reactions shows the same general trends - a spike in gas released to the $\mathrm{GC}$ at each temperature increase, although in the 2004 test the increase at $45{ }^{\circ} \mathrm{C}$ is rather small. In DEMO 1, the initial release of benzene occurs after the $\mathrm{pH}$ adjustment; $\mathrm{pH}$ adjustment was not required in the 2004 work since the simulant was already $\mathrm{pH}$ adjusted. 
Figure 24. Comparison of 2004 pH11 Test and Demonstration 1

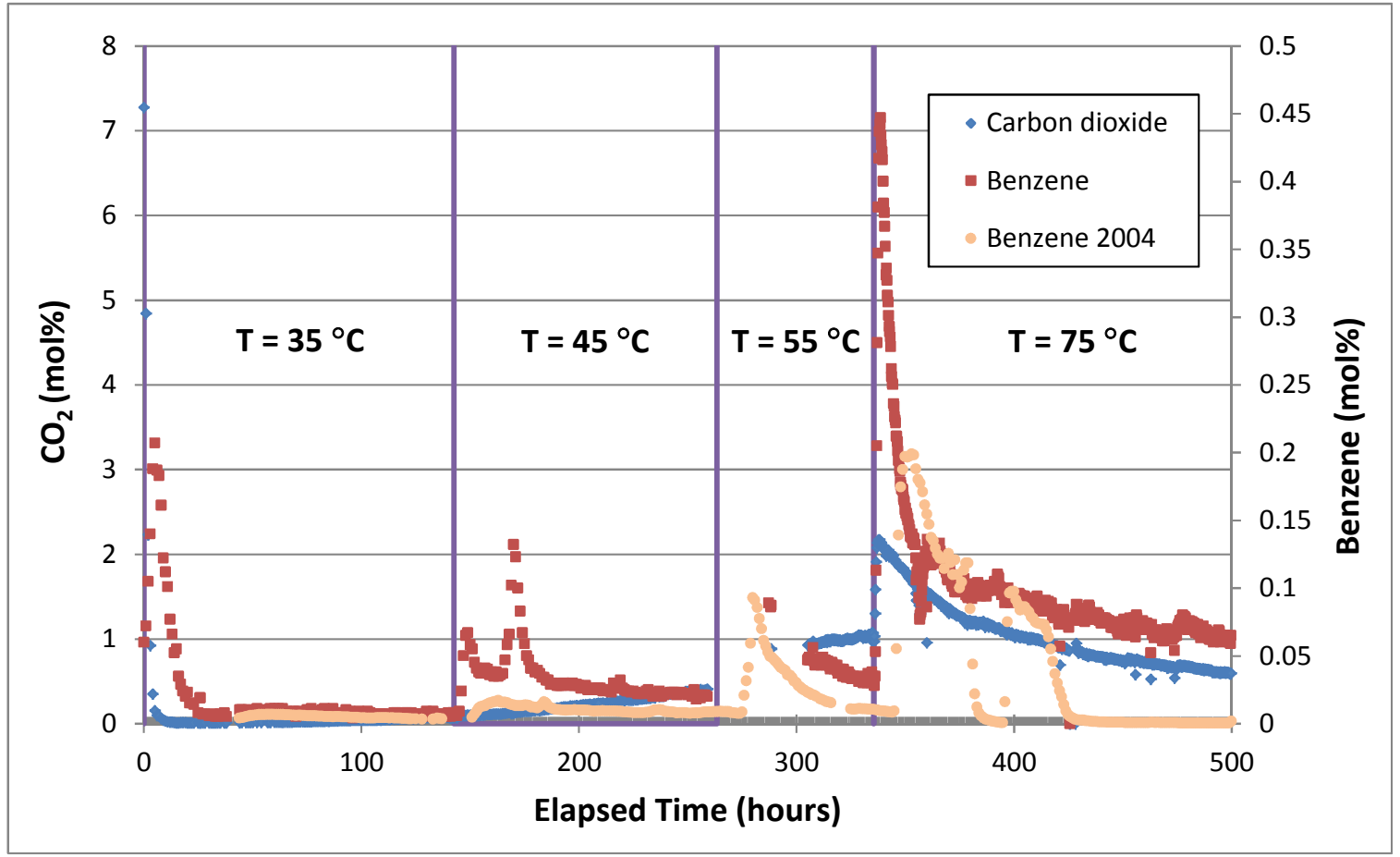

It is also possible to compare the 2004 and current work with respect to boron and potassium results though the 2004 work has a sparse data set in comparison to the current data. Figure 25 shows the boron results from the current work, converted into \%Destruction values on the y-axis. The two relevant data points from 2004 are also in the figure. The 2004 data is not volume normalized due to the lack of sodium data in those analyses. Furthermore, the method of calculating the \%Destruction varies slightly between the 2004 and the current work. Thus the 2004 data points should be considered to have uncertainties larger than just their analytical uncertainty $(10 \%)$. 
Figure 25. Comparison of the \%Destruction by Boron Results in the 2004 and Current Work

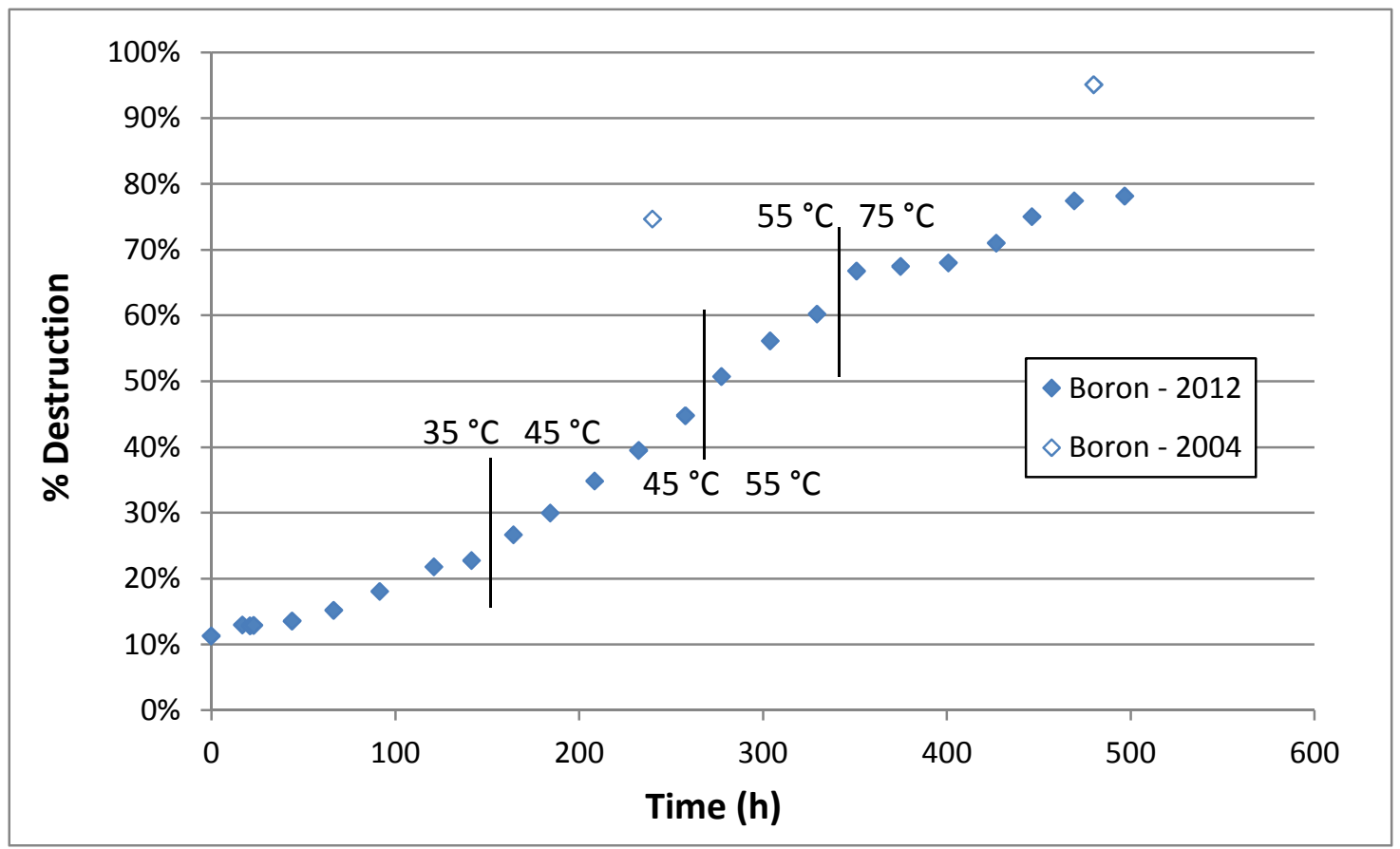

The same exercise can be performed with the potassium data. See Figure 26.

Figure 26. Comparison of the \%Destruction by Potassium Results in the 2004 and Current Work

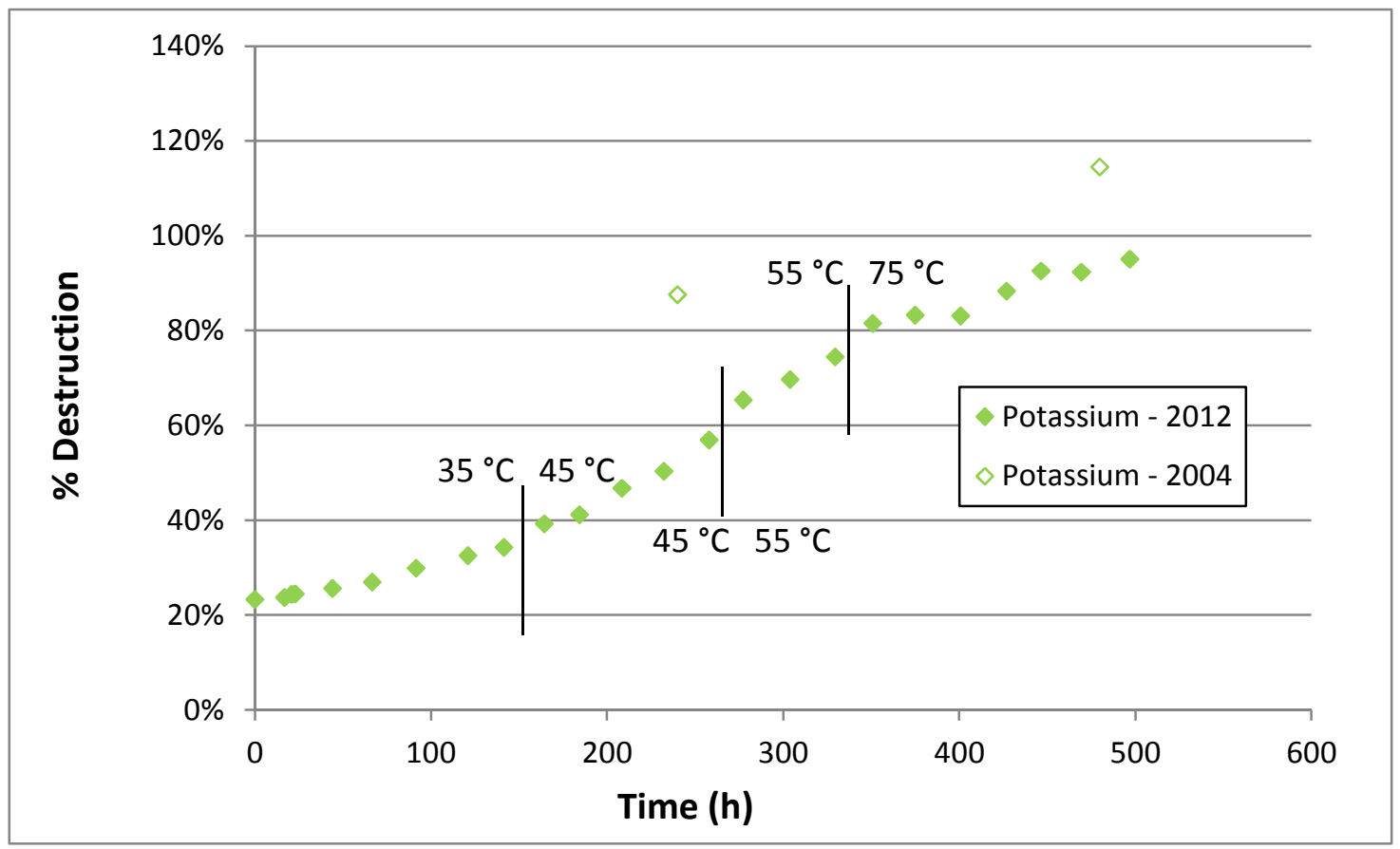


Both sets of data show an offset between the 2004 and the current work. The offset between the appropriate comparison points averages $\sim 28 \%$ (flat percent, not a percentage of the values), with the 2004 data being uniformly higher. From an inspection of 2004 data points that fall outside the time window of the current work (room temperature data), it appears that the 2004 work started at a higher \%Destruction than the current work. In other words, the 2004 work had a "head start" in the total destruction. ${ }^{\mathrm{d}}$

\subsection{Effect of Lower pH Conditions}

Prior tests discussed in this report have been conducted at $\mathrm{pH} 11$. This is due to a legacy restriction of operating in-situ in Tank $48 \mathrm{H}$, where corrosion of the carbon steel tanks would have been a concern. The strike tanks in Building 241-96H are made of stainless steel and the $\mathrm{pH}$ requirements are less restrictive. Thus, as part of the process optimization strategy the effects of utilizing $\mathrm{pH} 7$ and 9 were investigated.

A pair of new tests (also referred to as "Test 1b" and "Test 1c") were assembled using the same general conditions as previous tests except SRNL and the customer selected two new $\mathrm{pH}$ parameters ( $\mathrm{pH} 7$ for Test $1 \mathrm{c}$ and $\mathrm{pH} 9$ for Test $1 \mathrm{~b}$ ) to use in an experiment to determine the effects of starting $\mathrm{pH}$ on the extent of reaction. The same reaction vessels as detailed previously were used (see Sections 3.3 and 3.4).

Two bottles of $500 \mathrm{~mL}$ of slurry were generated according to the recipe, and poured into separate vessels. One slurry was adjusted with $50 \mathrm{wt} \%(10.4 \mathrm{M})$ nitric acid to a final $\mathrm{pH}$ of 9 . The second slurry was adjusted to a $\mathrm{pH}$ of 7 . To the bottle, the copper catalyst was added in the form of $\mathrm{Cu}\left(\mathrm{NO}_{3}\right)_{2} \bullet 2.5 \mathrm{H}_{2} \mathrm{O}$, with a target copper concentration of $500 \mathrm{mg} / \mathrm{L}$. Active temperature control was provided by the thermal baths. Both reactions were conducted at a constant $50{ }^{\circ} \mathrm{C}$. Both reactions were conducted at the same time to facilitate sample timing. Due to a procedural error, the addition of the $44 \mu \mathrm{L}$ of benzene was omitted in these two experiments.

Hydrogen peroxide was added at the rates used in the 2004 work, after scaling for volume differences, $0.2 \mathrm{~mL} /$ hour.

Each test continued approximately 20 days. Filtrate samples were removed once per day. A total of 19 samples were removed for analysis by ICPES.

\footnotetext{
${ }^{\mathrm{d}}$ The 2004 work actually occurred at $75^{\circ} \mathrm{C}$ for a longer time period (453 hours) than the current work (161 hours). However, the 2004 work removed the "final" sample after only 168 hours. No further chemical samples were removed for the 2004 work even though the temperature was maintained.
} 


\subsubsection{Soluble Boron Results}

After the start of the $\mathrm{H}_{2} \mathrm{O}_{2}$ addition the boron in the filtrate samples increased over time. See Figure 27.

\section{Figure 27. Boron Concentration Comparison between pH 7 and 9 Reactions}

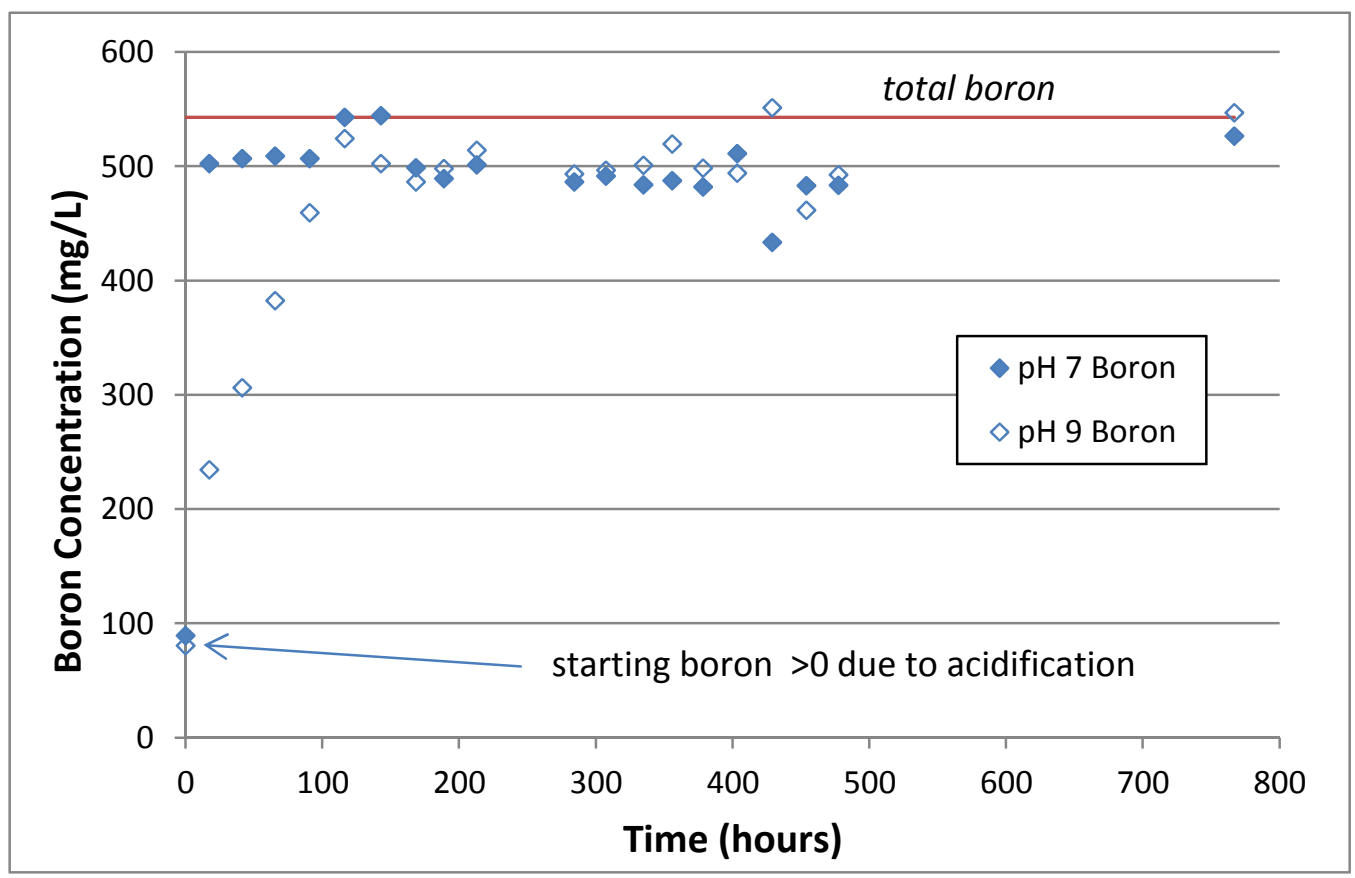

The reaction was halted after 478 hours, and the extent of boron dissolution associated with the acid hydrolysis and peroxide oxidation reactions was calculated using the same methodology as in Section 3.1.1 (see Table 20). The final data point at $\mathrm{t}=767$ hours is from the confirmation sample from the residual slurry after reaction (see Section 3.5.5) and is not used in the percent destruction calculation.

Table 20. Total TPB Destruction from Final Boron Results for Initial pH of 7 and 9

\begin{tabular}{|cc|cc|cc|}
\hline \multicolumn{2}{|c|}{ Destruction by Acid } & \multicolumn{2}{c|}{ Destruction by $\mathrm{H}_{2} \mathrm{O}_{2}$} & \multicolumn{2}{c|}{ Total Destruction } \\
\hline $\mathrm{pH} 7$ & $\mathrm{pH} \mathrm{9}$ & $\mathrm{pH} \mathrm{7}$ & $\mathrm{pH} \mathrm{9}$ & $\mathrm{pH} \mathrm{7}$ & $\mathrm{pH} \mathrm{9}$ \\
\hline $14.9-18.2 \%$ & $13.3-16.2 \%$ & $64.4-82.7 \%$ & $66.8-85.1 \%$ & $81.1-99.2 \%$ & $81.6-100 \%$ \\
\hline
\end{tabular}

At $\mathrm{pH} 7$ and $\mathrm{pH} 9$ complete TPB destruction (per boron soluble concentrations) was achieved after approximately 1 and 5 days, respectively. The increased destruction 
kinetics at $\mathrm{pH} 7$ cannot be directly attributed to the $\mathrm{pH}$ adjustment since both reactions produced a typical amount of destruction for that step. Rather, the addition of the copper and increased temperature initiated a rapid chemical degradation. Even though the reactions have not technically liberated $100 \%$ of the boron into solution, the fact that both reactions plateau at the same point (average of $91-95 \%$ destruction) yields confidence that all of the TPB has been degraded.

\subsubsection{Soluble Potassium Results}

As in previous experiments, the potassium in solution was measured as an indicator of organic destruction. After the start of the $\mathrm{H}_{2} \mathrm{O}_{2}$ addition the potassium in the filtrate samples increased over time. See Figure 28.

From the potassium data, the same trends are found in the boron data, including the evidence of a much faster reaction at $\mathrm{pH} 7$.

The reaction was halted after 478 hours, and the extent of potassium dissolution associated with the acid hydrolysis and peroxide oxidation reactions was calculated using the same methodology as in Section 3.1.1 (see Table 21). The final data point at $t=767$ hours is from the confirmation sample from the residual slurry after reaction (see Section 3.4.5) and is not used in the percent destruction calculation.

Table 21. Total TPB Destruction from Potassium Results for Initial pH of 7 and 9

\begin{tabular}{|c|c|cc|cc|}
\hline \multicolumn{2}{|c|}{ Destruction by Acid } & \multicolumn{2}{c|}{ Destruction by $\mathrm{H}_{2} \mathrm{O}_{2}$} & \multicolumn{2}{c|}{ Total Destruction } \\
\hline $\mathrm{pH} \mathrm{7}$ & $\mathrm{pH} \mathrm{9}$ & $\mathrm{pH} \mathrm{7}$ & $\mathrm{pH} \mathrm{9}$ & $\mathrm{pH} \mathrm{7}$ & $\mathrm{pH} \mathrm{9}$ \\
\hline $39.4-51.3 \%$ & $31.8-42.0 \%$ & $64.3-94.5 \%$ & $56.1-82.2 \%$ & $111-139 \%$ & $94.1-118 \%$ \\
\hline
\end{tabular}


Figure 28. Potassium Concentrations for the pH 7 and 9 Reactions

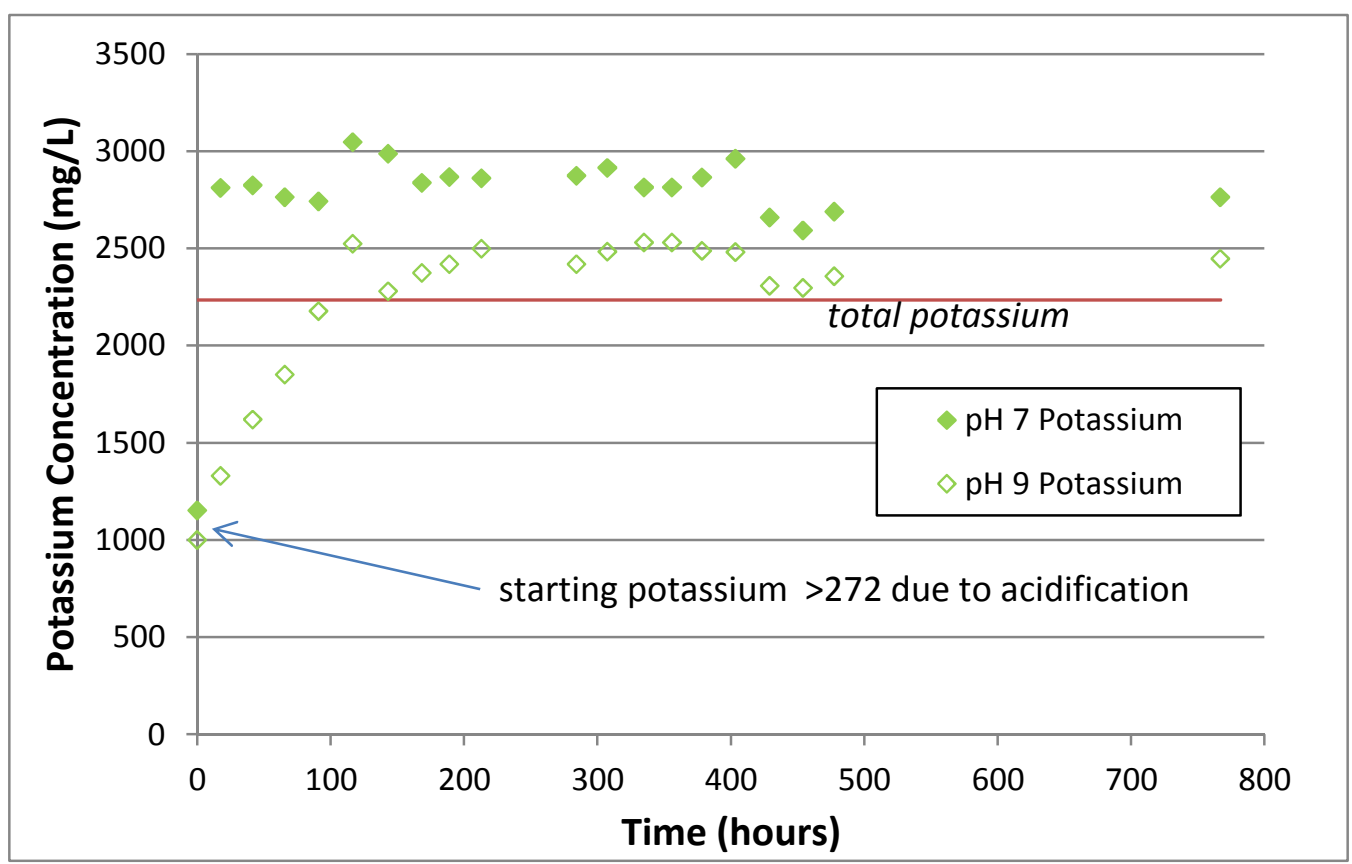

While the $\mathrm{pH} 9$ reaction potassium concentration is slightly high by the end $(112 \%$ destruction), it is within the sum of the analytical uncertainties of the two ICPES results required to derive the final percentage destruction. The $\mathrm{pH} 7$ reaction is outside the analytical uncertainty sums. Initially, the reason for the high potassium values in the $\mathrm{pH}$ 7 reaction could not be determined. After further examination of the log sheets, and the $\mathrm{pH}$ data (see Section 3.5.6 below) it was determined that no later than 19 hours into the reaction the $\mathrm{pH}$ probe began giving readings that were anomalously high. The probe was removed at $\sim 94$ hours into the reaction and it was determined that the probe was physically damaged by excessive contact with the agitator shaft, which resulted in a hole being abraded into the inner shaft of the $\mathrm{pH}$ probe. $\mathrm{pH}$ probes typically contain a solution of $\mathrm{KCl}$. Once a hole was made in the probe, the $\mathrm{KCl}$ would be free to leak into the reaction vessel. Assuming the anomalously high $\mathrm{pH}$ readings indicate the time of damage and leaking, then this happened at some point between 3 and 19 hours into the reaction (overnight). This early leak of potassium would then be reflected in all further samples, which was the observation made in the reaction sample results. Therefore, SRNL believes that the $\mathrm{pH} 7$ high potassium reaction results are a reflection of the $\mathrm{pH}$ probe failure, but still indicate complete TPB destruction. 


\subsubsection{Soluble Copper Results}

The copper concentrations in the filtrate were monitored for the reasons outlined in Section 3.1.3. After the start of the $\mathrm{H}_{2} \mathrm{O}_{2}$ addition the copper in the filtrate samples slowly increased over time. See Figure 29.

These two reactions provide the same approximate results as for the previous reactions (other than DEMO 1). Copper solubility averages $\sim 100 \mathrm{mg} / \mathrm{L}$ over the duration of the experiment, after a gradual ramp up to those concentrations. Processing at $\mathrm{pH} 9$ appears to provide slightly higher copper concentrations throughout the tests.

Figure 29. Soluble Copper Concentration Results for pH 7 and 9 Reactions

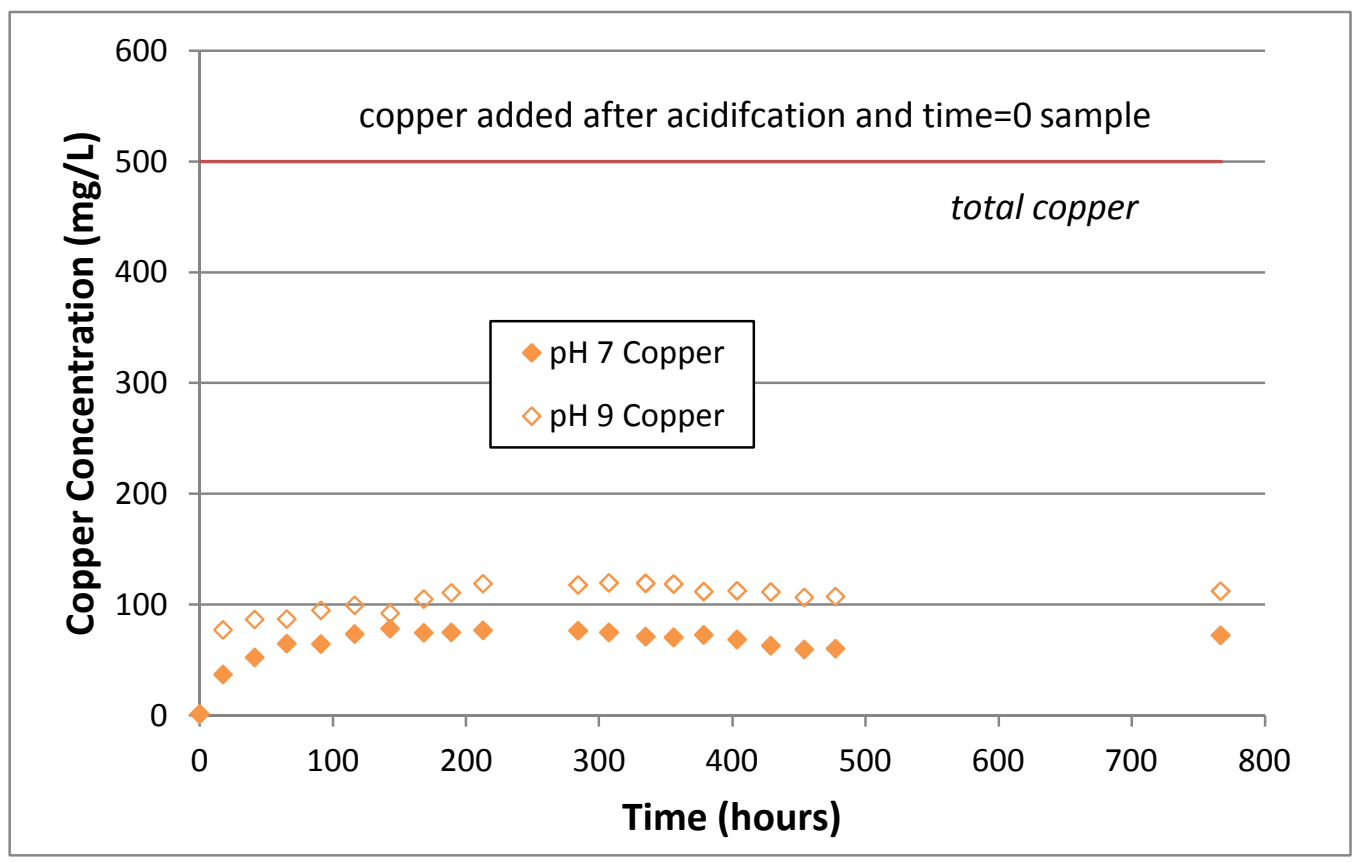

\subsubsection{Soluble Titanium Results}

The titanium concentration in solution is monitored for the reasons outlined in Section 3.1.4. See Figure 30.

The titanium data indicates that the $\mathrm{pH}$ difference has a virtually negligible effect on the titanium concentration. In all cases, the titanium concentrations were below $10 \mathrm{mg} / \mathrm{L}$. 
Figure 30. Titanium Concentration Results for pH 7 and 9 Experiments

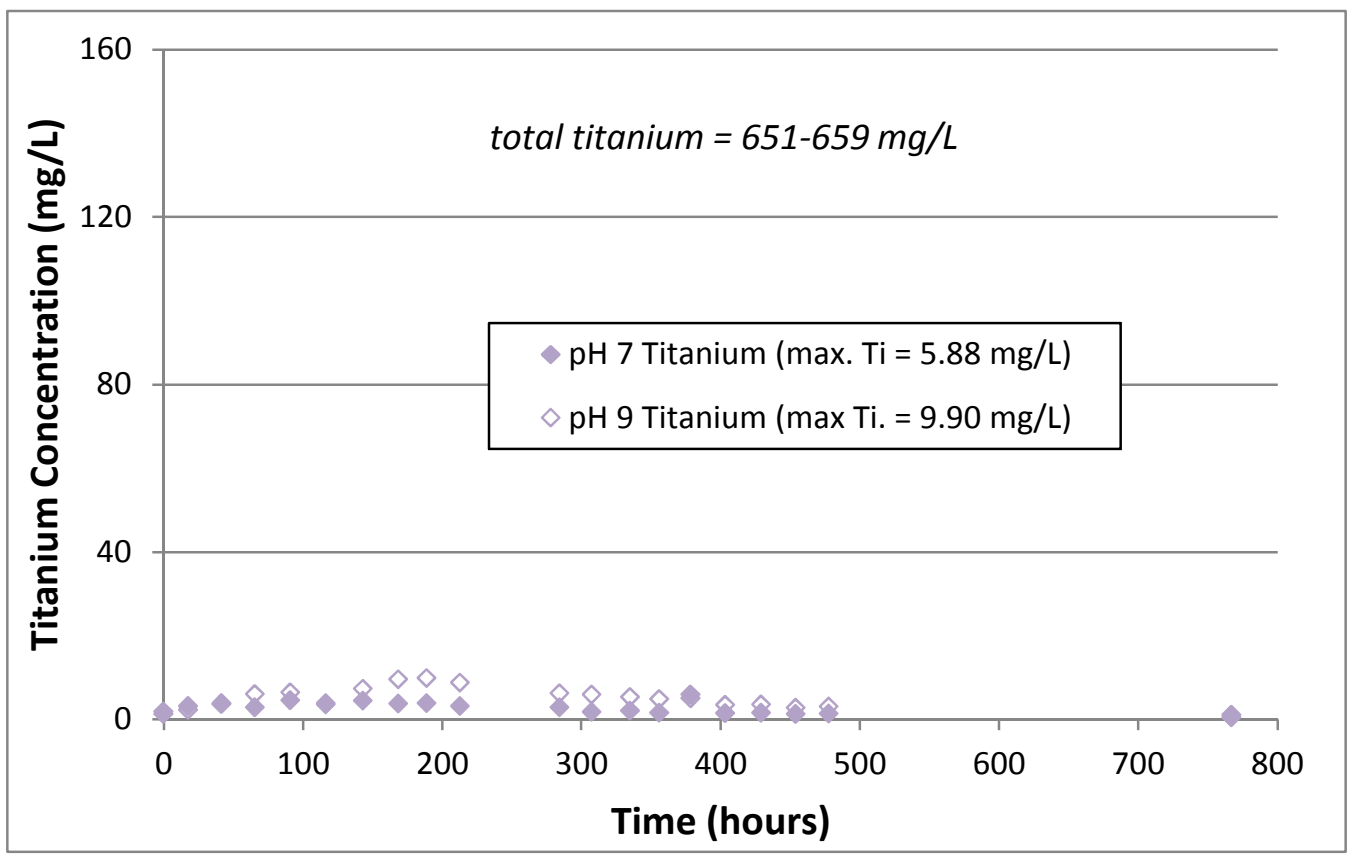

\subsubsection{Analysis of Residual Slurry After Reaction}

After the $\mathrm{pH} 7$ and 9 reactions were complete, the residual slurry after reaction was removed. The amount of recovered material is dependent on the efficiency of slurry removal (some solids were caked on the upper parts of the reactor or difficult to remove).

From the bottle of residual slurry after reaction, well-mixed (in an attempt to ensure homogeneity) duplicate samples were analyzed via HPLC, VOA and SVOA. However, due to the elapsed time from the end of the reaction ( $\sim 290$ hours), and the time of sampling, a filtered sample of the residual slurry after reaction was also analyzed via ICPES as a check to see if the reaction had proceeded further. The results of the ICPES analyses are listed in Table 22 . The results for the four important analytes $(\mathrm{B}, \mathrm{K}, \mathrm{Cu}, \mathrm{Ti})$ are given next to the chronologically previous sample results. These results are corrected for dilution as normal.

There are no statistically significant differences in the boron and potassium results between the two sample sets for any of the reactions. 
Table 22. ICPES Check Samples (mg/L) for Varying Initial pH Reactions

\begin{tabular}{|c|c|c|c|}
\hline Reaction & Analyte & $\begin{array}{c}\text { Final Filtrate } \\
\text { Result }\end{array}$ & $\begin{array}{c}\text { End of Reaction Period } \\
\text { Sample Result }\end{array}$ \\
\hline \multirow{3}{*}{ pH 7 } & $\mathrm{B}$ & 526.2 & 483.3 \\
\cline { 2 - 4 } & $\mathrm{K}$ & 2762 & 2688 \\
\cline { 2 - 4 } & $\mathrm{Cu}$ & 71.95 & 60.20 \\
\cline { 2 - 4 } & $\mathrm{Ti}$ & $<0.49$ & 1.33 \\
\hline \multirow{3}{*}{$\mathrm{pH} \mathrm{9}$} & $\mathrm{B}$ & 546.7 & 492.5 \\
\cline { 2 - 4 } & $\mathrm{K}$ & 2446 & 2355 \\
\cline { 2 - 4 } & $\mathrm{Cu}$ & 111.8 & 106.8 \\
\cline { 2 - 4 } & $\mathrm{Ti}$ & 1.06 & 2.99 \\
\hline
\end{tabular}

The analytical uncertainty is $10 \%$ for each result.

As there is no detectable additional destruction occurring, a valid comparison existed between the ICPES and HPLC results. Table 23 lists the HPLC results.

Table 23. HPLC Results from Residual Slurry After Reaction Analyses (mg/L)

\begin{tabular}{|c|c|c|c|c|c|c|}
\hline Reaction & TPB & 3PB & 2PB & 1PB & Phenol & \% Destruction \\
\hline pH 7 & $<10$ & $<10$ & $<10$ & $<10$ & $<10$ & $>99.9 \%$ \\
\hline pH 9 & $<10$ & $<10$ & $<10$ & $<10$ & $<10$ & $>99.9 \%$ \\
\hline
\end{tabular}

The "\% Destruction" column is the calculated percent destruction. The value is based on the mass of TPB added to the simulant slurries and calculation of the mass of TPB in the residual slurry after reaction, after correcting for the mass of samples removed from the system during the reactions.

Given the very rapid destruction indicated by the boron and potassium data, less than detectable levels of all the HPLC analytes were anticipated.

Samples of the residual slurry after reaction was analyzed using VOA and SVOA (see Tables 24 and 25). The values in parentheses are the \%RSD. In the results column, values that are shaded indicate only one measured value with the other being a detection limit result. In this case, the values in parentheses are the analytical uncertainties. In the analyte column, shaded cells indicate the presence of that analyte is doubtful due to chemical conditions or contaminants. The "total organic residuals" are the sum of all the mid-range values of the detected analytes, less benzene and the analytes that are declared to be from contaminants. The "total organic residuals" are the sum of all the detected 
analytes, less benzene and the analytes that are declared to be from contaminants. These results are not normalized to the beginning volumes.

Table 24. VOA and SVOA Results for pH 7 Reaction

\begin{tabular}{|c|c|}
\hline Analyte & Result (mg/L) \\
\hline benzene & $<0.05$ \\
\hline biphenyl & $195(39.9 \%)$ \\
\hline 2,4-dinitro-N-phenylbenzeneamine & $45.5(82.4 \%)$ \\
\cline { 1 - 2 } 2-nitro-N-4-nitrophenylbenzeneamine & $42.4-63.6$ \\
\cline { 1 - 2 } 2-methyl-4,6-diphenylpyridine & $29.6-44.4$ \\
\hline 1,2-ditrobenzene & $34(0.00 \%)$ \\
\hline 1,2-dinitrobenzene & $27.2-40.8$ \\
\hline N, N-diphenylbenzeneamine & $29.7(126 \%)$ \\
\hline diisooctyladipate & $19.2-28.8$ \\
\hline diphenylamine & $20.00(7.07 \%)$ \\
\hline p-terphenyl & $19.0(22.3 \%)$ \\
\hline o-terphenyl & $17(0.00 \%)$ \\
\hline 2,3,4-trinitrodiphenylamine & $10.2(66.6 \%)$ \\
\hline 4-nitro-N-phenylbenzeneamine & $5.25(25.6 \%)$ \\
\hline Diphenyl(2-pyridyl)methanol & $5.05(4.20 \%)$ \\
\hline diphenyl ether & $4.90(11.5 \%)$ \\
\hline 2-nitro-N-phenylbenzenamine & $3.15(2.25 \%)$ \\
\hline azobenzene & $1.92-2.88$ \\
\hline 1,1,2,1,4,1-quaterphenyl & $2.00(28.3 \%)$ \\
\hline Total organic residuals & 518 \\
\hline &
\end{tabular}

Of the residual organics left in the residual slurry after reaction, biphenyl is the most concentrated and the presence of a fair concentration of various amines is noted. Considering that biphenyl fouling, or amine deposition may be an issue in the real facility, efficient destruction of these compounds are an important consideration.

It appears that driving the starting $\mathrm{pH}$ to below 11 provides superior biphenyl destruction. In the thermal reactions (Section 3.3.3), the $50{ }^{\circ} \mathrm{C}$ test $(\mathrm{pH} 11)$ gave a final biphenyl concentration of $940 \mathrm{mg} / \mathrm{L}$. The equivalent $\mathrm{pH} 9$ reaction gave $29 \mathrm{mg} / \mathrm{L}$ and the equivalent $\mathrm{pH} 7$ reaction gave $195 \mathrm{mg} / \mathrm{L}$. It may be that a starting $\mathrm{pH}$ of 9 is the ideal starting point to minimize residual biphenyl though this result will require verification.

As for the other analytes left in the reactor residuals, they are almost all partially degraded or functionalized aryl compounds. It is very difficult to define any trend in 
these analytes, other than to note that the $\mathrm{pH} 7$ reaction gave about $2.5 \times$ the amount of residuals compared to the $\mathrm{pH}$ reaction.

Table 25. VOA and SVOA Results for pH 9 Reaction

\begin{tabular}{|c|c|}
\hline Analyte & Result (mg/L) \\
\hline benzene & $<0.05$ \\
\hline 4-methyl-3-hexanol & $35.2-52.8$ \\
\hline 3-aminobiphenyl & $30.4-45.6$ \\
\hline$[1,1]$ biphenyl-3-amine & $25.6-38.4$ \\
\hline biphenyl & $29.0(19.5 \%)$ \\
\hline p-terphenyl & $26(27.2 \%)$ \\
\hline m-terphenyl & 13.6-20.4 \\
\hline o-terphenyl & $10.1(12.6 \%)$ \\
\hline diphenyl ether & $8.25(19.7 \%)$ \\
\hline 2,4-dinitro-N-phenylbenzeneamine & $8.20(5.17 \%)$ \\
\hline 2-nitro-N-(2-nitrophenylbenzeneamine) & $5.95(3.57 \%)$ \\
\hline diphenylamine & 4.4-6.6 \\
\hline 2-phenoxybiphenyl & $4.08-6.12$ \\
\hline $\mathrm{N}, \mathrm{N}$-diphenylbenzeneamine & $3.52-5.28$ \\
\hline 2-phenoxy, 1,1-biphenyl & $3.52-5.28$ \\
\hline 4-methyl-1-heptanol & $3.12-4.68$ \\
\hline 2,3,4-trinitrodiphenylamine & $2.32-3.48$ \\
\hline 4-nitro-N-(4-nitrophenyl)bezeneamine & $2.16-3.24$ \\
\hline (4-nitrophenyl)diphenylamine & $1.92-2.88$ \\
\hline 4-nitro-N-phenylbenzeneamine & $1.12-1.68$ \\
\hline 1,1,2,1,4,1-quaterphenyl & $0.68-1.02$ \\
\hline Total organic residuals & 199 \\
\hline
\end{tabular}

\subsection{6 pH Monitoring}

$\mathrm{pH}$ was monitored during the reaction (see Figure 31).

As with DEMO 1, the $\mathrm{pH}$ in both reactions trended towards a final $\mathrm{pH}$ of 9 - from both high and lower initial $\mathrm{pH}$ values.

As late as 19 hours into the $\mathrm{pH} 7$ reaction, the $\mathrm{pH}$ probe readings increased suddenly to 10 and higher. This was unanticipated behavior given previous results, and upon replacing the probe at 94 hours, it was observed that the $\mathrm{pH}$ probe had been physically 
damaged by contact with the agitator (see Section 3.5.2). After replacing the $\mathrm{pH}$ probe, the readings returned to what was considered typical.

Figure 31. pH Readings for Lower pH Reactions

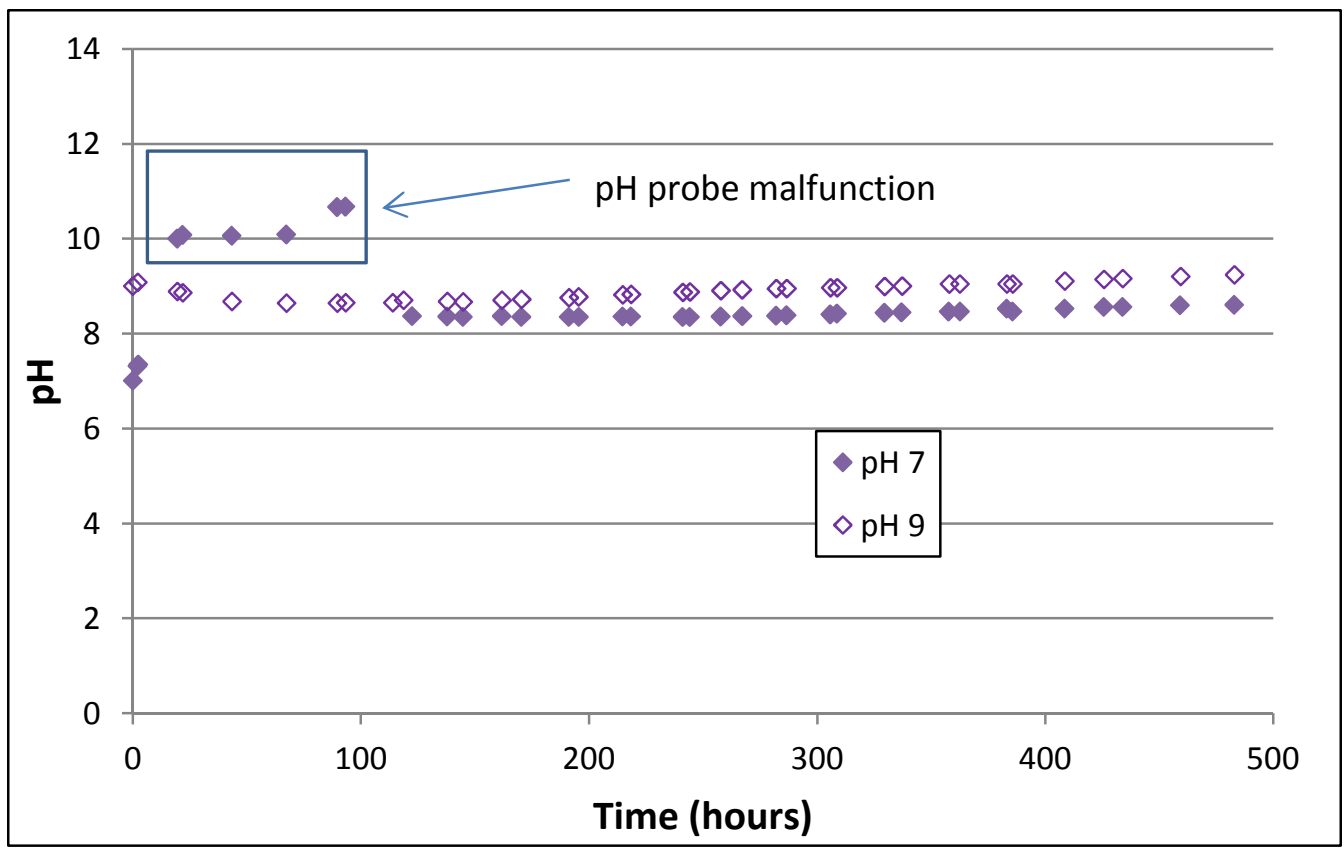

\subsubsection{Conclusion}

The $\mathrm{pH} 7$ and 9 experiments both gave rapid and complete destruction of the KTPB slurries. By the end of the reactions, there were no traces of organic materials by HPLC, and SVOA analysis indicated only small quantities of the partially degraded or functionalized aryl compounds, which are more than likely due to the $\mathrm{pH}$ adjustment process. The $\mathrm{pH} 7$ reaction resulted in larger quantities of residuals so from this perspective, the $\mathrm{pH} 9$ starting $\mathrm{pH}$ is preferential.

For both reactions, the destruction was complete in a significantly shorter time-frame than would be required to add a stoichiometric amount of $\mathrm{H}_{2} \mathrm{O}_{2}$ at the $0.2 \mathrm{~mL} / \mathrm{h}$ addition rate. For the $\mathrm{pH} 7$ reaction, $<5 \mathrm{~mL}$ of $\mathrm{H}_{2} \mathrm{O}_{2}$ had been added by the time of complete destruction, and for the $\mathrm{pH}$ experiment, $<24 \mathrm{~mL}$. This makes it quite likely that hydrolysis (TPB to benzene) is the dominant initial reaction mechanism.

With respect to the copper, once again only $20 \%$ of the added copper was present in a soluble form. There was no significant effect on the titanium. Concentrations started low, and stayed low during the entire lifetime. 


\subsection{DEMONSTRATION 2}

The TTQAP for this work calls for formal demonstrations after DEMO 1, although by this point, all the reactions use the same equipment and methodology for each test. Therefore, the title "DEMONSTRATION" implies no further differences from a "test".

This experiment used the same reaction vessel and temperature control (at $50^{\circ} \mathrm{C}$ ) as described in Section 3.4. Other experimental details were as described in previous sections. It was noted that the "prototypical mixing" is in fact, very poor compared to reactions performed in poly bottles with a magnetic stirrer. The agitation was insufficient to prevent a semi-stable floating solids mass. This may affect the overall reaction efficiency.

Hydrogen peroxide was added at $0.4 \mathrm{~mL} /$ hour $(2 \times)$.

The test continued for approximately 20 days. Filtrate samples were pulled one per day. A total of 22 samples were removed for analysis by ICPES. From the ICPES results, boron, potassium, copper, sodium, and titanium concentrations were examined. Results from each test were compared to establish potential differences in reactivity.

\subsubsection{Soluble Boron Results}

After the start of the $\mathrm{H}_{2} \mathrm{O}_{2}$ addition the boron in the filtrate samples increased over time. See Figure 32.

Figure 32. Boron Concentration Results for Demonstration 2

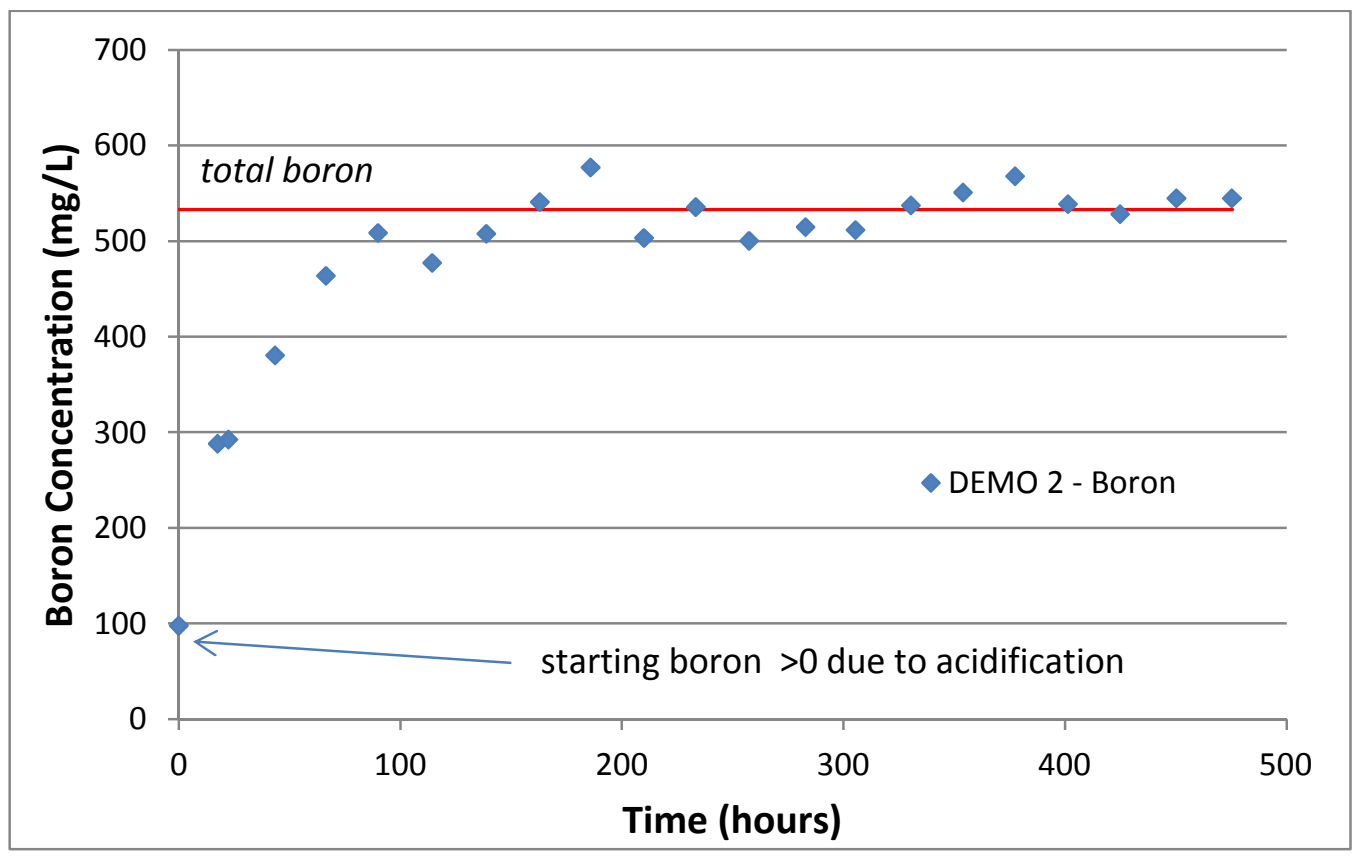


The reaction was halted after 476 hours, and the extent of boron dissolution associated with the acid hydrolysis and the peroxide oxidation reaction was calculated using the same methodology as in Section 3.1.1 (see Table 26). A final data point at $t=937$ hours from the confirmation sample from the residual slurry after reaction (see Section 3.6.5) is not shown for clarity and is not used in the percent destruction calculation.

Table 26. Total TPB Destruction from Final Boron Results: Demonstration 2

\begin{tabular}{|c|c|c|}
\hline Destruction by Acid & Destruction by $\mathrm{H}_{2} \mathrm{O}_{2}$ & Total Destruction \\
\hline $16.4-20.1 \%$ & $73.5-94.3 \%$ & $91.9-112 \%$ \\
\hline
\end{tabular}

By 90 hours the TPB destruction was complete. This is comparable, though slightly faster, than the most equivalent previous reaction (see Section 3.5.1, $\mathrm{pH} 9$ reaction).

\subsubsection{Soluble Potassium Results}

After the start of the $\mathrm{H}_{2} \mathrm{O}_{2}$ addition the potassium in the filtrate samples increased over time. See Figure 33.

Figure 33. Potassium Concentration Results for Demonstration 2

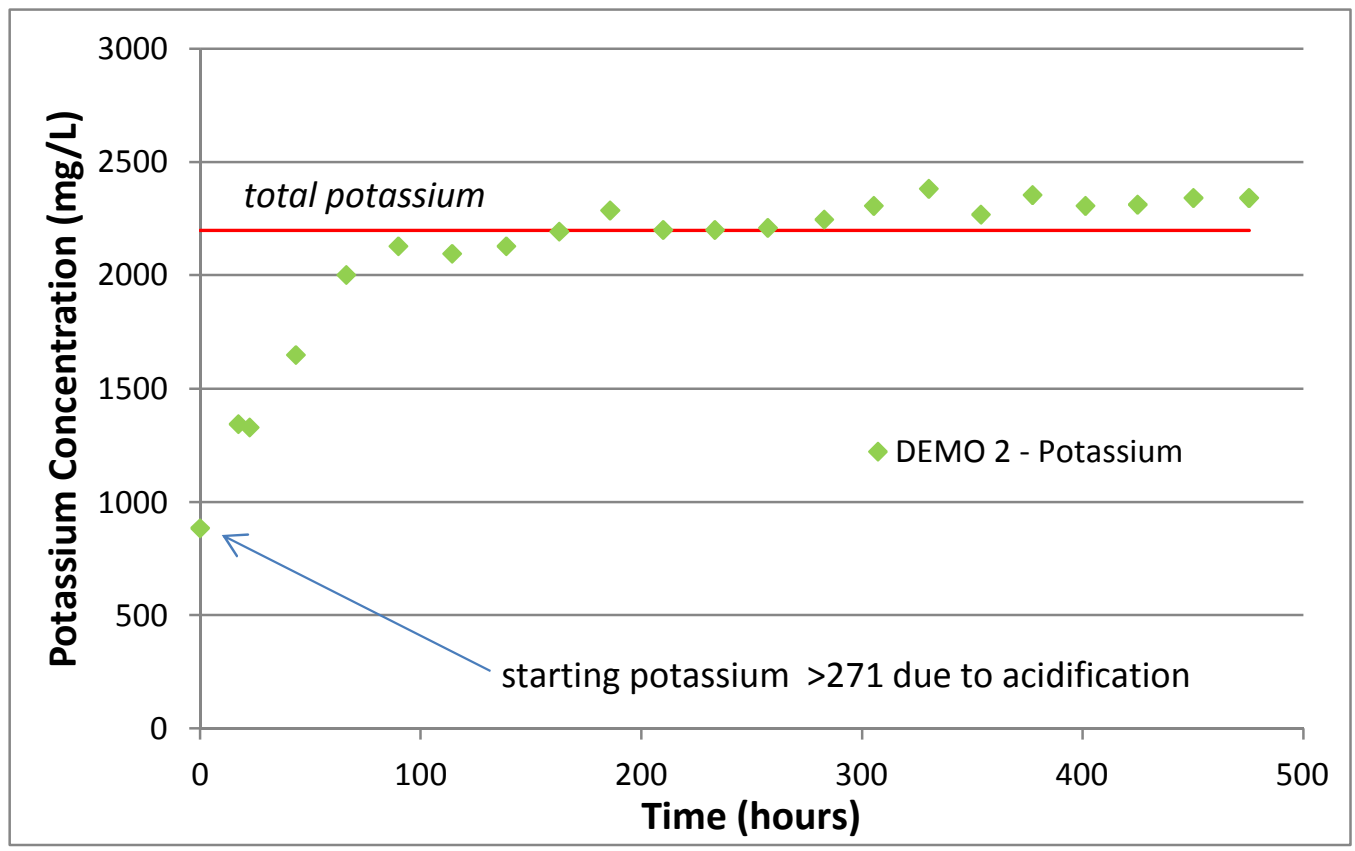


The reaction was halted after 476 hours, and the extent of potassium dissolution associated with the acid hydrolysis and the peroxide oxidation reaction was calculated using the same methodology as in Section 3.1.1 (see Table 27). The final data point at $\mathrm{t}=$ 937 hours is from the confirmation sample from the residual slurry after reaction (see Section 3.6.5) and is not used in the \%destruction calculation.

\section{Table 27. Total TPB Destruction from Potassium Results: Demonstration 2}

\begin{tabular}{|c|c|c|}
\hline Destruction by Acid & Destruction by $\mathrm{H}_{2} \mathrm{O}_{2}$ & Total Destruction \\
\hline $27.2-36.4 \%$ & $63.7-88.7 \%$ & $95.3-120 \%$ \\
\hline
\end{tabular}

As with the boron data, the destruction appeared complete after $\sim 90$ hours.

\subsubsection{Soluble Copper Results}

After the start of the $\mathrm{H}_{2} \mathrm{O}_{2}$ addition the copper in the filtrate samples quickly increased near the reaction start, then remained stable. See Figure 34.

Figure 34. Soluble Copper Concentration Results for Demonstration 2

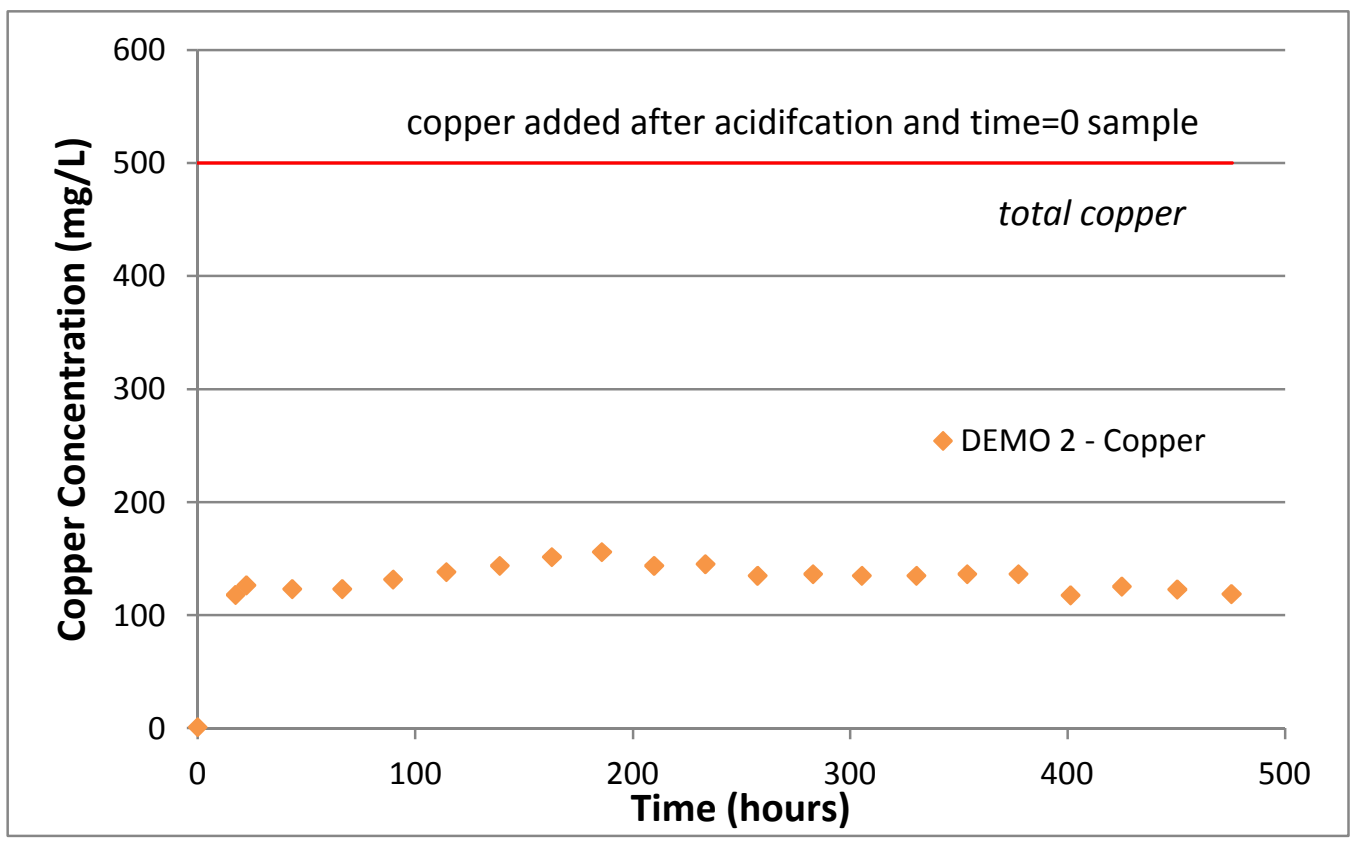

The copper results show a fairly similar pattern to most of the previous tests, although slightly higher in magnitude. 
SRNL-STI-2012-00342

Revision 1

\subsubsection{Soluble Titanium Results}

The titanium in solution is monitored for the reasons outlined in Section 3.1.4 (see Figure $35)$.

The titanium results are very typical, with a maximum of $\sim 20 \mathrm{mg} / \mathrm{L}$. The data shows a slow decline from the peak value.

Figure 35. Titanium Concentration Results for Demonstration 2

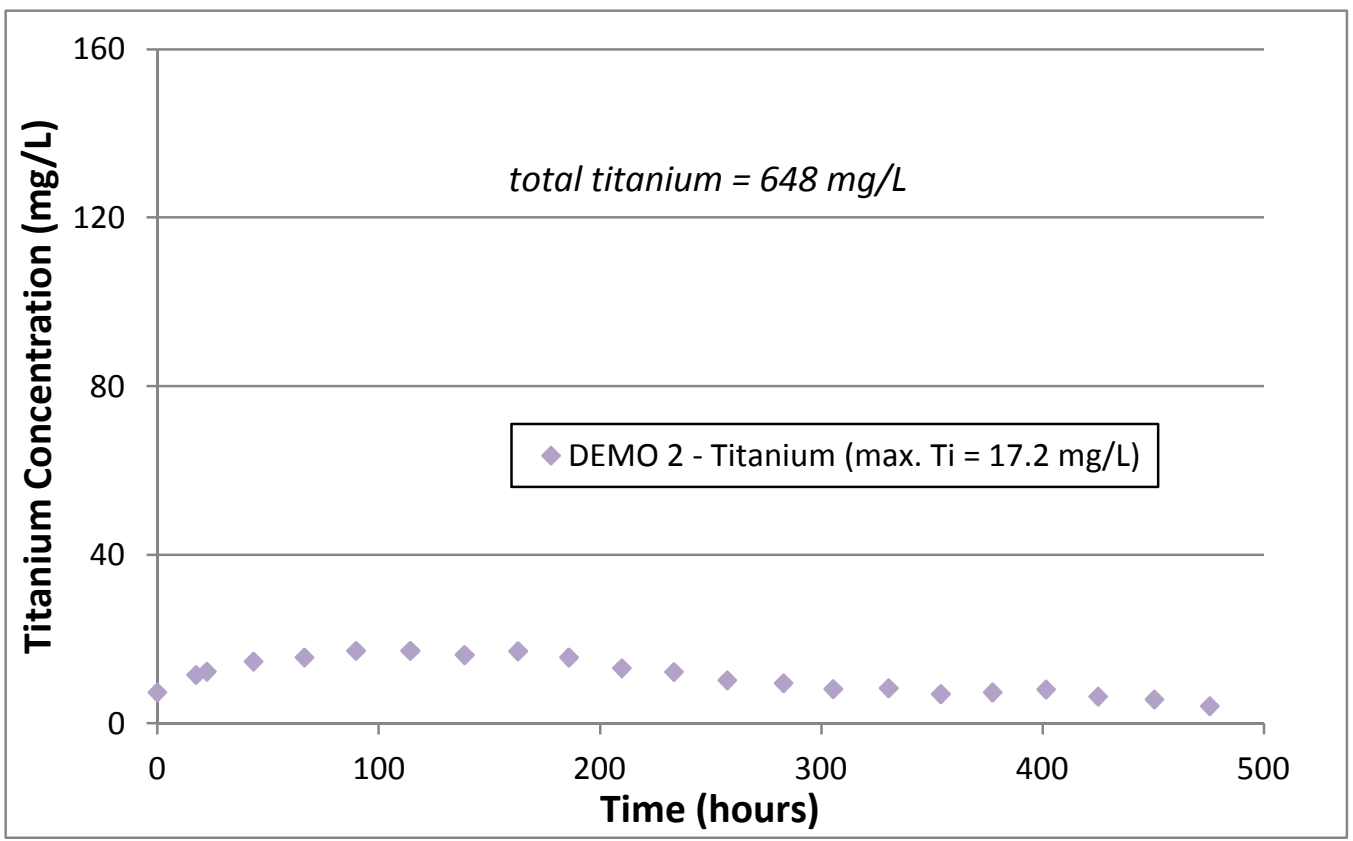

\subsubsection{Analysis of Residual Slurry After Reaction}

After the reaction was complete, the residual slurry after reaction was removed. The amount of recovered material is somewhat dependent on the efficiency of slurry removal (some solids were caked on the upper parts of the reactor or difficult to remove).

From the bottle of residual slurry after reaction, well-mixed (in an attempt to ensure homogeneity) duplicate samples were analyzed via HPLC, VOA and SVOA. However, due to the elapsed time from the end of the reaction ( $\sim 62$ hours), and the time of sampling, a filtered sample of the residual material was also analyzed via ICPES as a check to see if the reaction had proceeded further. The results of the ICPES analyses are 
listed in Table 28. The results for the four important analytes $(\mathrm{B}, \mathrm{K}, \mathrm{Cu}, \mathrm{Ti})$ are given next to the chronologically previous sample results. These results are corrected for dilution as normal.

There are no statistically significant differences in the boron and potassium results between the two sample sets for any of the reactions. The titanium results showed a drop in titanium soluble concentrations, which is consistent with the trend displayed in previous titanium data.

Table 28. ICPES Check Samples (mg/L) for Demonstration 2

\begin{tabular}{|c|c|c|}
\hline Analyte & $\begin{array}{c}\text { Final Filtrate } \\
\text { Result }\end{array}$ & $\begin{array}{c}\text { End of Reaction Period } \\
\text { Sample Result }\end{array}$ \\
\hline $\mathrm{B}$ & 513.9 & 544.5 \\
\hline $\mathrm{K}$ & 2294 & 2341 \\
\hline $\mathrm{Cu}$ & 102.8 & 118.4 \\
\hline $\mathrm{Ti}$ & $<1.54$ & 4.02 \\
\hline
\end{tabular}

The analytical uncertainty is $10 \%$ for each result.

As there is no evidence for additional destruction, a valid comparison between the ICPES and HPLC results exists. Table 29 lists the HPLC results.

Table 29. HPLC Results from Residual Slurry After Reaction Analyses (mg/L) for Demonstration 2

\begin{tabular}{|c|c|c|c|c|c|}
\hline TPB & 3PB & 2PB & 1PB & Phenol & \% Destruction \\
\hline$<4$ & $<4$ & $<4$ & $<4$ & $<4$ & $>99.9 \%$ \\
\hline
\end{tabular}

The "\% Destruction" column is the calculated percent destruction. The value is based on the mass of TPB added to the simulant slurries and calculation of the mass of TPB in the residual slurry after reaction, after correcting for the mass of samples removed from the system during the reactions.

While previous results have a HPLC detection limit of $10 \mathrm{mg} / \mathrm{L}$, the analyst had been investigating methods to further improve the detection limit. This work resulted in a decrease of the detection limit to $4 \mathrm{mg} / \mathrm{L}$ (see Appendix B).

Given the very rapid destruction indicated by the boron and potassium data, less than detectable concentrations of all the HPLC analytes were anticipated after almost 500 hours of CCPO processing. 
Samples of the residual slurry after reaction were analyzed using VOA and SVOA. See Table 30. The values in parentheses are the \%RSD. In the results column, values that are shaded indicate only one measured value with the other being a detection limit result. In this case, the values in parentheses are the analytical uncertainties. In the analyte column, shaded cells indicate the presence of that analyte is doubtful due to chemical conditions or contaminants. The "total organic residuals" are the sum of all the mid-range values of the detected analytes, less benzene and the analytes that are declared to be from contaminants. These results are not normalized to the beginning volumes.

Table 30. VOA and SVOA Results for Demonstration 2

\begin{tabular}{|c|c|}
\hline Analyte & Result (mg/L) \\
\hline benzene & $<0.05$ \\
\hline biphenyl & $16.0(35.4 \%)$ \\
\hline [1,1-biphenyl]-3-amine & $30.4-45.6$ \\
\hline diisooctyl adipate & $35.5(41.8 \%)$ \\
\hline p-terphenyl & $8.85(7.19 \%)$ \\
\hline m-terphenyl & $4.96-7.44$ \\
\hline diphenyl amine & $4.05(40.2 \%)$ \\
\hline o-terphenyl & $3.35(52.8 \%)$ \\
\hline diphenyl ether & $2.55(41.6 \%)$ \\
\hline 2-phenoxy-1,1-biphenyl & $1.44-2.16$ \\
\hline 2-nitro-N-(2-nitrophenyl)benzeneamine & $1.2-1.8$ \\
\hline N, N diphenylbenzeneamine & $0.8-1.2$ \\
\hline Total organic residuals & 83.3 \\
\hline
\end{tabular}

The diisooctyl adipate is a known plasticizer and is more than likely leachate from contact with a plastic surface.

As for the other analytes left in the residual slurry after reaction, they are almost all partially degraded or functionalized aryl compounds. It is very difficult to locate any trend in these analytes. It is interesting to note that the number and total amounts of these materials are less than seen in previous tests.

\subsubsection{Gas Chromatography Results}

For the duration of the experiment, including the $\mathrm{pH}$ adjustment, the off-gas composition was monitored using GC. This enabled the important off-gas species such as benzene and $\mathrm{CO}_{2}$ to be tracked which can help determine how the organics are being broken down. See Figure 36. 
All the concerns listed in regards to the GC data in Section 3.4.6 also pertain here. First, because of in-reactor acidification (as opposed to the 2004 work), it is impossible to deconvolute $\mathrm{CO}_{2}$ generated from acidification of carbonate in the simulant, and $\mathrm{CO}_{2}$ generated from organic oxidation. This is because degassing of the $\mathrm{CO}_{2}$ is not immediate and takes place over time. Second, the reactor vessel cannot be made gastight (the physical design has penetrations that cannot be completely sealed) and leaks are probable.

Figure 36. Gas Release Rates for Demonstration 2

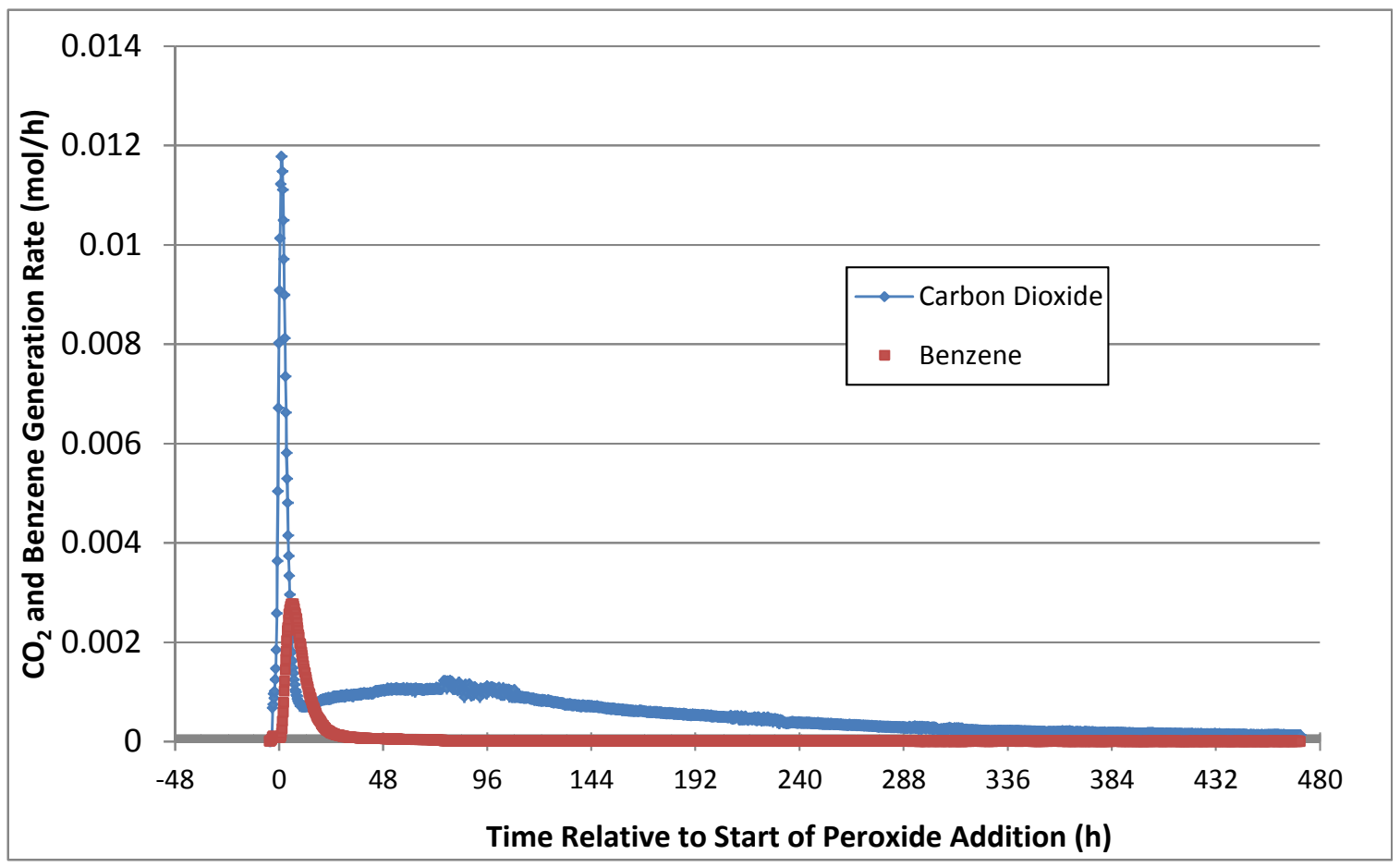

The major off-gas components are benzene and $\mathrm{CO}_{2}$. The benzene and $\mathrm{CO}_{2}$ are from the $\mathrm{pH}$ adjustment of the slurry, as well as degradation of organics (the presence of these two gases was observed throughout the reaction).

The initial spikes in gas generation must be due to the $\mathrm{pH}$ adjustment process, and a closer inspection of the data set shows the same general behavior as observed for DEMO 1 - the benzene and $\mathrm{CO}_{2}$ generation spikes closely follow the $\mathrm{pH}$ adjustment and then taper off quickly (Figure 37).

In the case of benzene, again, it is not possible to deconvolute benzene generated during acidification or during the $\mathrm{H}_{2} \mathrm{O}_{2}$ addition. However, it is possible to confidently state that 
the initial benzene spike is from $\mathrm{pH}$ adjustment, and the decline in generation rate from the GC data indicates that any benzene, if generated, is being consumed in the reactor.

Figure 37. Close In View of Gas Release Data for Demonstration 2

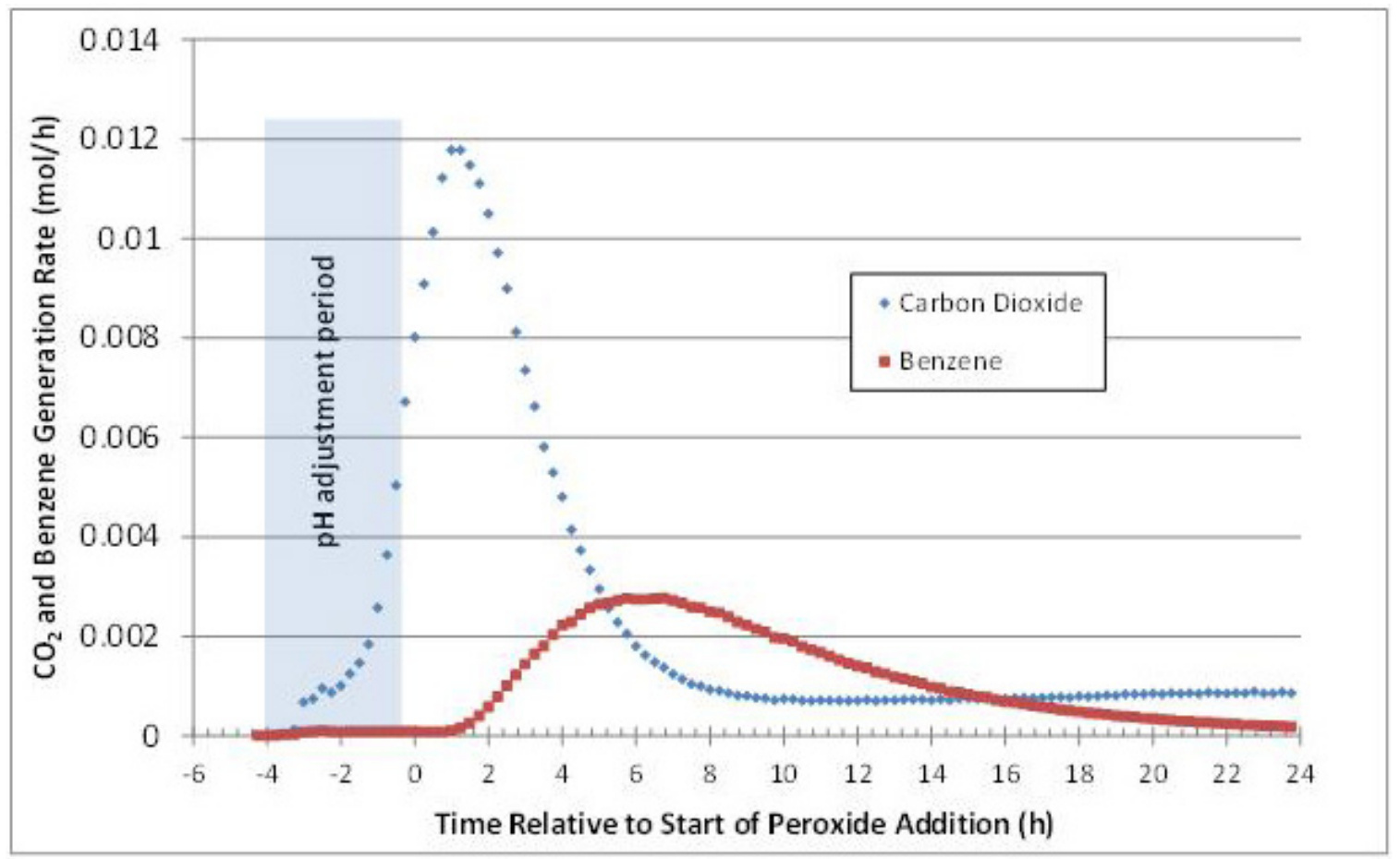

Several important points can be drawn from this graph.

- $\mathrm{CO}_{2}$ evolution occurs slowly about 1 hour after acid addition is commenced (presumed due to acid-carbonate reaction) and then rapidly increases as the $\mathrm{pH}$ adjustment continues. The acid-carbonate reaction continues after the acid is no longer added.

- Even though the benzene is assumed to be produced during acid hydrolysis it is not released until after the almost concurrent increase to reaction temperature and addition of peroxide. Previous work indicates a correlation between temperature increases and increased release of benzene. ${ }^{20}$

- Since such a small amount of peroxide is added in the first hours $(0.4 \mathrm{~mL} / \mathrm{hour})$ it is more likely that the benzene release is associated with increase in temperature. 
- Increased temperature can have two potential effects; increased benzene volatility or decreased gas solubility.

The GC data can be used in attempt to determine a mass balance for DEMO 2. To do this, the moles of benzene and $\mathrm{CO}_{2}$ available in the simulant slurry before $\mathrm{pH}$ addition must be determined, and compared against the moles of benzene and $\mathrm{CO}_{2}$ remaining in the residual slurry at the end of the reaction.

Figure 35 shows the cumulative amount of benzene and $\mathrm{CO}_{2}$ detected over the life of the experiment.

Figure 38. Cumulative Off-gas Release in Demonstration 2

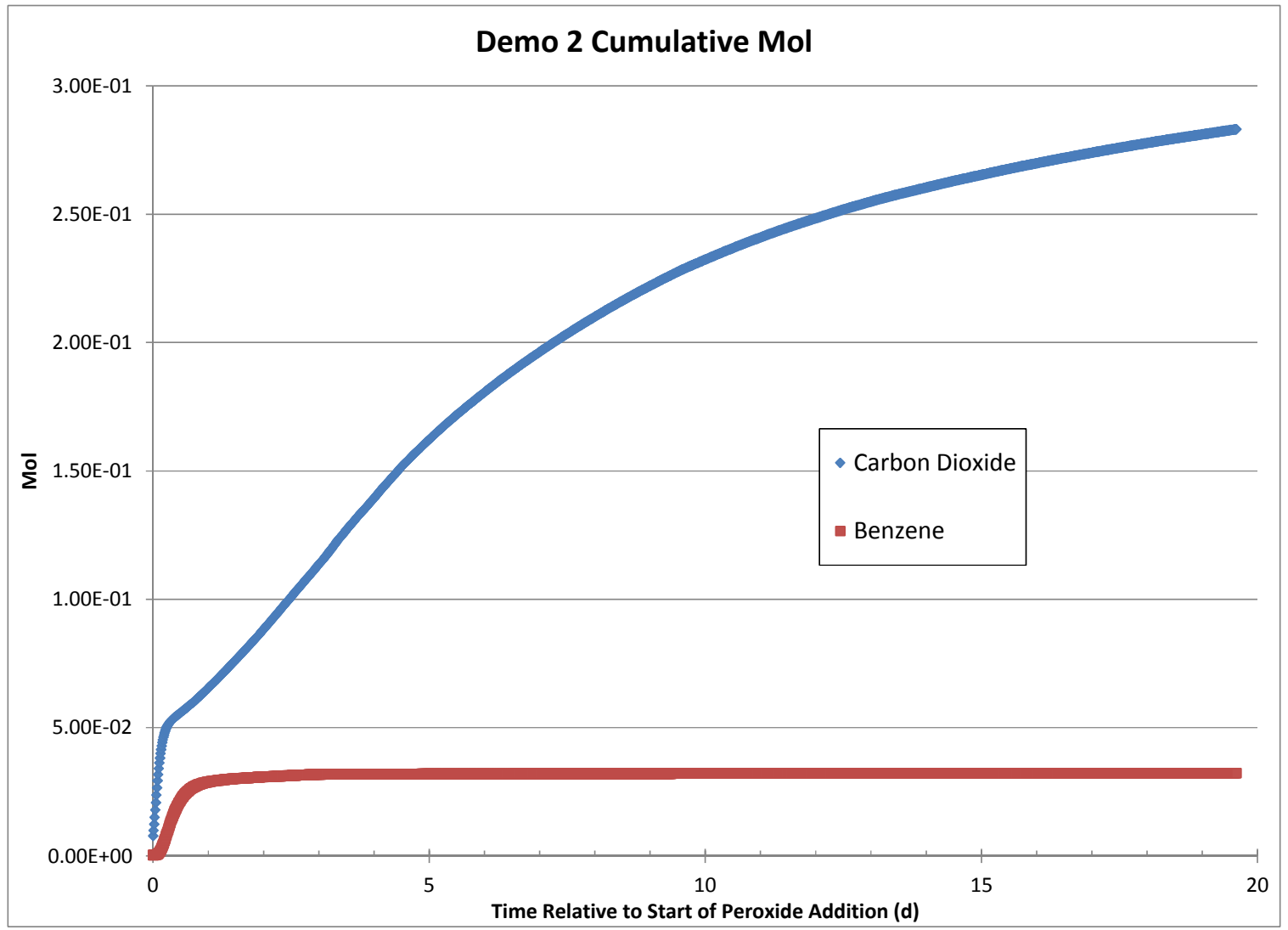

From this graph several key points can be determined.

- The amount of benzene produced by the end of the reaction is 0.032 moles. 
- The amount of $\mathrm{CO}_{2}$ produced by the end of the reaction is 0.283 moles with no apparent precipitous drop off in production.

- The majority of the observed benzene is generated in the first 5 hours of testing.

With respect to benzene, from the HPLC and VOA measurements, $\sim 0$ moles of TPB remain in the reactor bottoms as TPB which means there is no reservoir of benzene (which for the sake of this calculation, we assume therefore no $\mathrm{CO}_{2}$ ) from that material. ${ }^{\mathrm{e}}$

With respect to $\mathrm{CO}_{2}$, a sample of the DEMO 2 residuals was analyzed by TIC/TOC. The TIC (total inorganic carbon - assumed to be carbonate ${ }^{18,19}$ ) result indicated that 0.172 moles of carbonate remained in the reactor residuals.

From the residual slurry after reaction, SVOA analysis provided a result of $83 \mathrm{mg} / \mathrm{L}$ of residual organics, the bulk of which is in the form of biphenyl. For the sake of simplicity, if it is assumed all of this is biphenyl, this converts to a maximum possible remaining inventory of 0.00481 moles of $\mathrm{CO}_{2}$.

Against these observations, the initial inventory of benzene was calculated. Each $500 \mathrm{~mL}$ of simulant slurry has maximum benzene inventory of 0.12 moles (this includes the $44 \mu \mathrm{L}$ of benzene added just before time $=0$ ). The $\mathrm{GC}$ measured only 0.032 moles of benzene over the life of the reaction and as such it can be concluded that only $\sim 26.7 \%$ of the potential benzene inventory left the system as benzene. Ideally, no benzene should leave the system.

The inventory of carbonate was calculated. Each slurry starts with 0.290 moles of carbonate. This serves as a possible inventory for an equimolar amount of $\mathrm{CO}_{2}$, as any decrease in the carbonate concentration in the slurry must be due to the $\mathrm{pH}$ adjustment (carbonate $\rightarrow \mathrm{CO}_{2}$ ).

For DEMO 2 the starting carbonate amount is 0.290 moles, and by the end of the reaction, the amount remaining is 0.172 moles. Therefore, the difference, 0.118 moles, was lost from $\mathrm{pH}$ adjustment. This carbonate was converted to $\mathrm{CO}_{2}$ and left the system.

The slurry used in DEMO 2, as generated, also contained 0.0300 moles of TPB. Under ideal conditions, if all of the phenyl groups in the TPB were converted into $\mathrm{CO}_{2}$, this would allow for a maximum $\mathrm{CO}_{2}$ generation of 0.72 moles of $\mathrm{CO}_{2}$.

Now it is possible to calculate the amount of $\mathrm{CO}_{2}$ that was actually created during DEMO 2. The maximum possible amount is 0.72 moles. To this value is added the $\mathrm{CO}_{2}$ that was produced from the conversion of carbonate to $\mathrm{CO}_{2}$ which occurred during the

\footnotetext{
${ }^{\mathrm{e}}$ For the moment, the initial added quantities of biphenyl and phenol will be ignored for the sake of clarity.
} 
$\mathrm{pH}$ adjustment, or 0.118 moles, for a total of 0.838 moles. From this total the known remainders in the residual slurry after reaction are subtracted:

- $\sim 0$ moles from the residual TPB (HPLC)

- 0.00481 moles from the residual other organics (SVOA)

- 0.192 moles from the benzene that the GC measured

- 0.0146 moles remaining as oxalate (see Section 3.6.7, below)

This gives a calculated amount of generated $\mathrm{CO}_{2}$ of 0.620 moles. ${ }^{\mathrm{f}}$ The remaining carbonate is not subtracted as this material should not be further converted to $\mathrm{CO}_{2}$ through the action of the CCPO.

The GC only detected 0.283 moles, or $\sim 45 \%$ of the calculated $\mathrm{CO}_{2}$ produced.

Potential losses from the system due to leaks are being investigated to account for the differential.

\subsubsection{IC-Anions Data}

The fate of the various anions in the simulant was also evaluated. While most anions in the simulant slurry are likely unaffected by the reaction chemistry, it is known that the concentrations of certain anions, such as nitrite, oxalate or formate, may change during processing, In previous work, ${ }^{8}$ a number of reaction samples were examined to establish the effects on these types of anions.

As part of DEMO 2, the slurry was sampled at 0, 17.5, 22.5, 43.5 and 475.5 hours into the reaction. These samples were subjected to IC-Anions analysis. The results are in Table 31 and have been dilution corrected in the same manner as the ICPES data.

There was no formate or oxalate added to the salt simulant, so the appearance of those species is significant. It appears that the formate is initially generated though finally consumed whereas the concentration of oxalate increases throughout the test.

\footnotetext{
${ }^{\mathrm{f}}$ Again, this is intended as a rough measurement. The production of oxalate and formate results would affect this value.
} 
Table 31. IC-Anions Concentration Results for DEMO 2 Samples (mg/L)

\begin{tabular}{|c|c|c|c|c|c|}
\hline & \multicolumn{5}{|c|}{ Time (hours) } \\
\hline analyte & $\mathbf{0}$ & $\mathbf{1 7 . 5}$ & $\mathbf{2 2 . 5}$ & $\mathbf{4 3 . 5}$ & $\mathbf{4 7 5 . 5}$ \\
\hline fluoride & $<100$ & $<98.9$ & $<97.8$ & $<91.6$ & $<136$ \\
\hline formate & $<100$ & 101.8 & 144.7 & 255.7 & $<136$ \\
\hline chloride & 167 & 164 & 163 & 157 & 242 \\
\hline nitrite & 14000 & 13545 & 13199 & 12371 & 10522 \\
\hline bromide & $<500$ & $<494$ & $<489$ & $<458$ & $<681$ \\
\hline nitrate & 121000 & 119635 & 118300 & 112710 & 137478 \\
\hline phosphate & 174 & 199 & $<207$ & $<236$ & $<362$ \\
\hline sulfate & 183 & 175 & 174 & 165 & 221 \\
\hline oxalate & $<100$ & 229 & 310 & 539 & 1742 \\
\hline
\end{tabular}

The analytical uncertainty for each IC-Anions sample is $10 \%$.

Using the maximum measured values for both anions, the amount of carbon sequestered in those materials that came from benzene can be estimated. $255.7 \mathrm{mg} / \mathrm{L}$ of formate translates to 0.00385 moles of benzene. $1742 \mathrm{mg} / \mathrm{L}$ of oxalate translates to 0.013 moles of benzene. Together, these two anions account for $\sim 14.4 \%$ of the potential benzene inventory.

There is a moderately statistically significant decline in nitrite, which is not surprising as nitrite can be oxidized to nitrate.

There are also statistically significant increases in chloride and sulfate which is not anticipated. In principle, these anion concentrations should remain constant since no chemicals are added during the tests that incorporate these species.

\subsection{8 pH Monitoring}

pH was monitored during the reaction. See Figure 39.

The chemical reactions appear to drive towards a final $\mathrm{pH}$ of about 9 , which is not surprising given previous reaction results. 
Figure 39. pH Readings for Demonstration 2

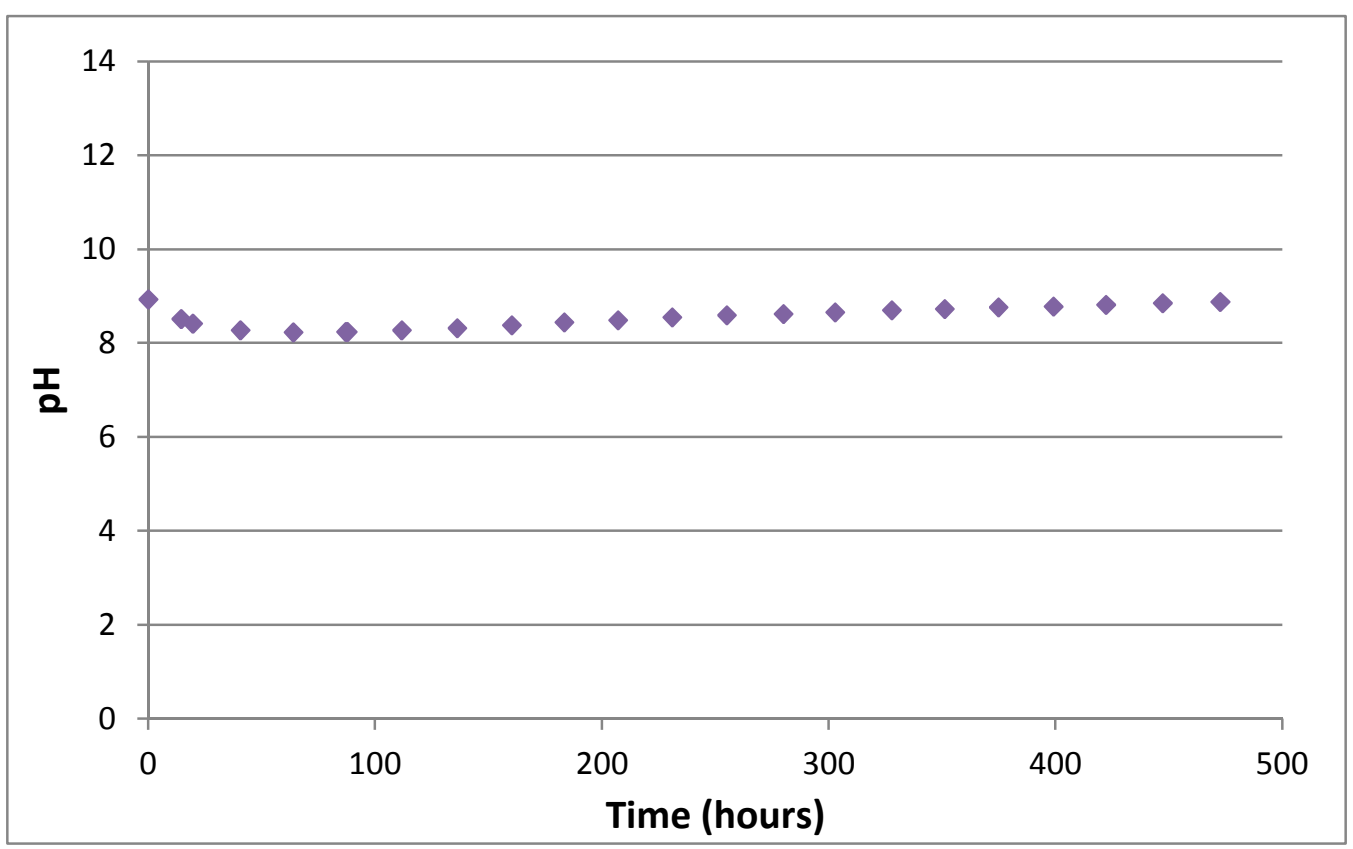

\subsubsection{Conclusion}

DEMO 2 showed complete destruction within 4 days, which is comparable, if not slightly faster than the closest comparable reaction (see Section 3.5.5, the $\mathrm{pH} 9$ reaction). Furthermore, there is only a small fraction of measurable $(<1 \%)$ residual organic material left in the reactor at the end. This is less than half the amount residual material left in the reactor for the closest comparable reaction. The difference between these two reactions is the rate of $\mathrm{H}_{2} \mathrm{O}_{2}$ addition. This indicates that the increased $\mathrm{H}_{2} \mathrm{O}_{2}$ addition in DEMO 2 is beneficial. Furthermore, the increased $\mathrm{H}_{2} \mathrm{O}_{2}$ delivery does not appear to effect the copper concentrations, although it does provide for slightly elevated titanium concentrations.

The researchers were able to detect $\sim 45 \%$ of the produced $\mathrm{CO}_{2}$ via GC. It may be possible in the future to detect a higher percentage of the produced $\mathrm{CO}_{2}$ through the use of reactors with better sealed penetrations.

\subsection{Further Examination of $\mathrm{H}_{2} \underline{\mathrm{O}}_{2}$ Addition Rates}

While previous tests examined the effects of a ten-fold increase in the $\mathrm{H}_{2} \mathrm{O}_{2}$ addition rate conducted at room temperature (see Section 3.2), SRNL performed a subsequent test at five-fold $(5 \times)$ the nominal peroxide addition rate. This test is also identified as "Test $2 \mathrm{a}$ ". 
This experiment used the same reaction vessel and temperature control $\left(50^{\circ} \mathrm{C}\right)$ as described in Section 3.5. Other experimental details were as described in previous sections, except as noted below. It was noted that the "prototypical mixing" is in fact, very poor compared to reactions performed in poly bottles with a magnetic stirrer. The agitation was insufficient to prevent a semi-stable floating solids mass. This may have effects in the overall reaction efficiency.

Hydrogen peroxide was added at $1 \mathrm{~mL} /$ hour $(5 \times)$.

The test operated approximately 20 days. Filtrate samples were taken once per day. A total of 22 samples were removed for analysis by ICPES.

\subsubsection{Soluble Boron Results}

After the start of the $\mathrm{H}_{2} \mathrm{O}_{2}$ addition the boron in the filtrate samples increased over time. See Figure 37. In the figure the data from related tests are also included to show the effect of varying rates of $\mathrm{H}_{2} \mathrm{O}_{2}$ addition.

The reaction was halted after 472 hours, and the extent of boron dissolution associated with the acid hydrolysis and the peroxide oxidation reaction was calculated using the same methodology as in Section 3.1.1 (see Table 32). A final data point at $t=957$ hours from the confirmation sample from the residual slurry after reaction (see Section 3.6.5) is not shown for clarity, and is not used in the percent destruction calculation.

\section{Table 32. Total TPB Destruction from Final Boron Results: $5 \times$ Peroxide Addition Rate}

\begin{tabular}{|c|c|c|c|c|c|c|c|c|}
\hline \multicolumn{3}{|c|}{ Destruction by Acid } & \multicolumn{3}{c|}{ Destruction by $\mathrm{H}_{2} \mathrm{O}_{2}$} & \multicolumn{3}{c|}{ Total Destruction } \\
\hline $1 \mathrm{xH}_{2} \mathrm{O}_{2}$ & $2 \mathrm{xH}_{2} \mathrm{O}_{2}$ & $5 \mathrm{xH}_{2} \mathrm{O}_{2}$ & $1 \mathrm{xH}_{2} \mathrm{O}_{2}$ & $2 \mathrm{xH}_{2} \mathrm{O}_{2}$ & $5 \mathrm{xH}_{2} \mathrm{O}_{2}$ & $1 \mathrm{xH}_{2} \mathrm{O}_{2}$ & $2 \mathrm{xH}_{2} \mathrm{O}_{2}$ & $5 \mathrm{xH}_{2} \mathrm{O}_{2}$ \\
\hline $13.3-16.2 \%$ & $16.4-20.1 \%$ & $12.5-15.3 \%$ & $66.8-85.1 \%$ & $73.5-94.3 \%$ & $69.4-88.1 \%$ & $81.6-100 \%$ & $91.9-112 \%$ & $83.4-102 \%$ \\
\hline
\end{tabular}

By $\sim 100$ hours the TPB destruction is complete. This is comparable to the most equivalent previous reactions (see Section 3.5.1, $\mathrm{pH} 9$ reaction and Section 3.6.1). As this test and the previously mentioned two tests form a series with only one variation $\left(\mathrm{H}_{2} \mathrm{O}_{2}\right.$ addition rate), it is possible to plot them against each other (see Figure 38$)$ to determine the effect of $\mathrm{H}_{2} \mathrm{O}_{2}$ addition rates.

The " $5 \times \mathrm{H}_{2} \mathrm{O}_{2}$ " reaction is the one described in this section. The " $2 \times \mathrm{H}_{2} \mathrm{O}_{2}$ " is DEMO 2, and the " $1 \times \mathrm{H}_{2} \mathrm{O}_{2}$ " is the $\mathrm{pH} 9$ experiment from Section 3.5.1. All three reactions were conducted at $50{ }^{\circ} \mathrm{C}$, starting at $\mathrm{pH} 9$, with $500 \mathrm{mg} / \mathrm{L}$ of copper. 
The differences in the boron data are fairly small. All three reactions appear to go to completion by $\sim 100$ hours. The " $5 \times$ " appears to be slightly faster than the " $2 \times$ ", which is slightly faster than the " $1 \times$ " reaction, but the differences are small and sometimes statistically insignificant.

Figure 40. Boron Concentration Results Comparison at Varying Peroxide Addition Rates

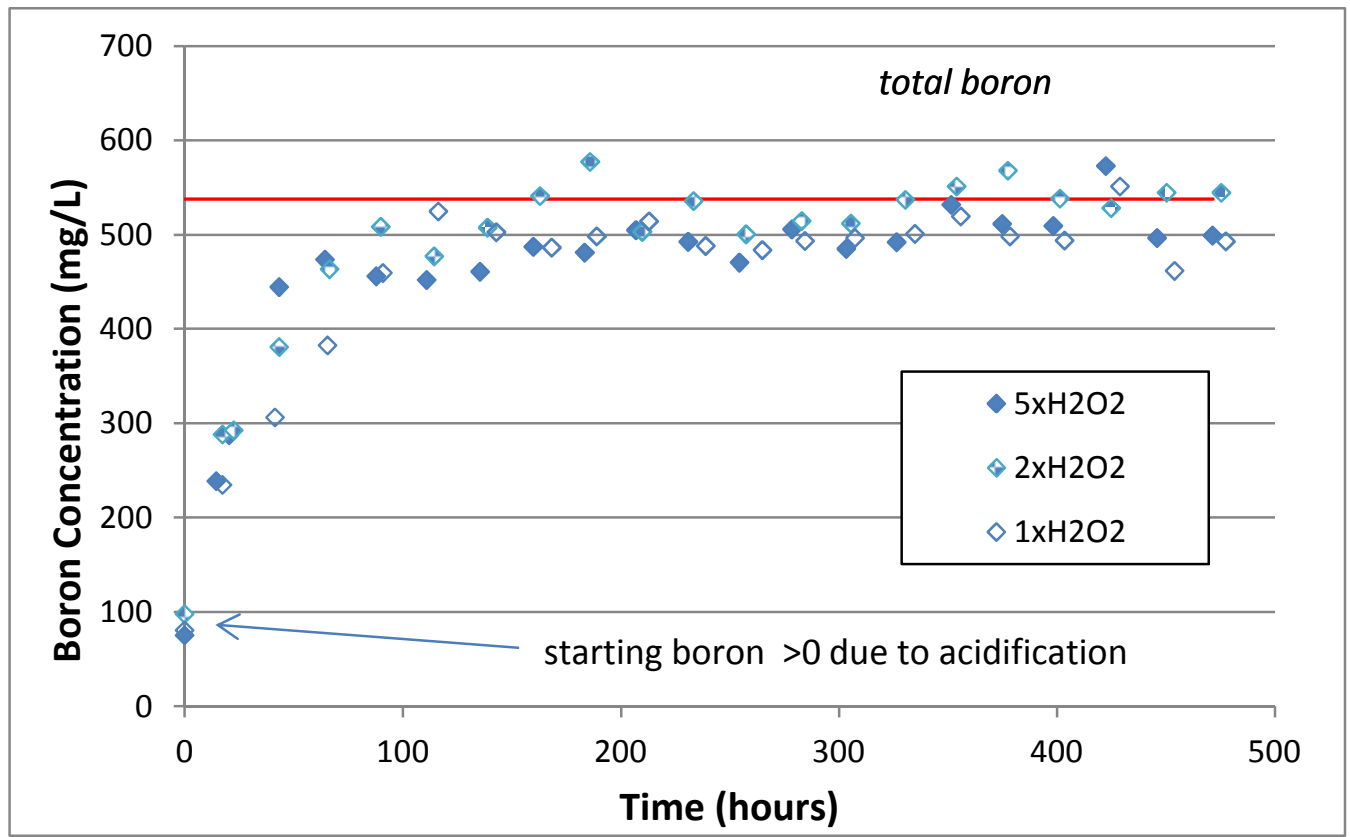

\subsubsection{Soluble Potassium Results}

After the start of the $\mathrm{H}_{2} \mathrm{O}_{2}$ addition the potassium in the filtrate samples increased over time (see Figure 41). In the figure data from related tests is also included to show the effect of varying rates of $\mathrm{H}_{2} \mathrm{O}_{2}$ addition.

The reaction was halted after 472 hours, and the extent of potassium dissolution associated with the acid hydrolysis and the peroxide oxidation reaction was calculated using the same methodology as in Section 3.1.1 (see Table 33). The final data point at $\mathrm{t}=957$ hours is from the confirmation sample from the residual slurry after reaction (see Section 3.7.5) and is not used in the percent destruction calculation. 
Figure 41. Potassium Concentration Results Comparison at Varying Peroxide Addition Rates

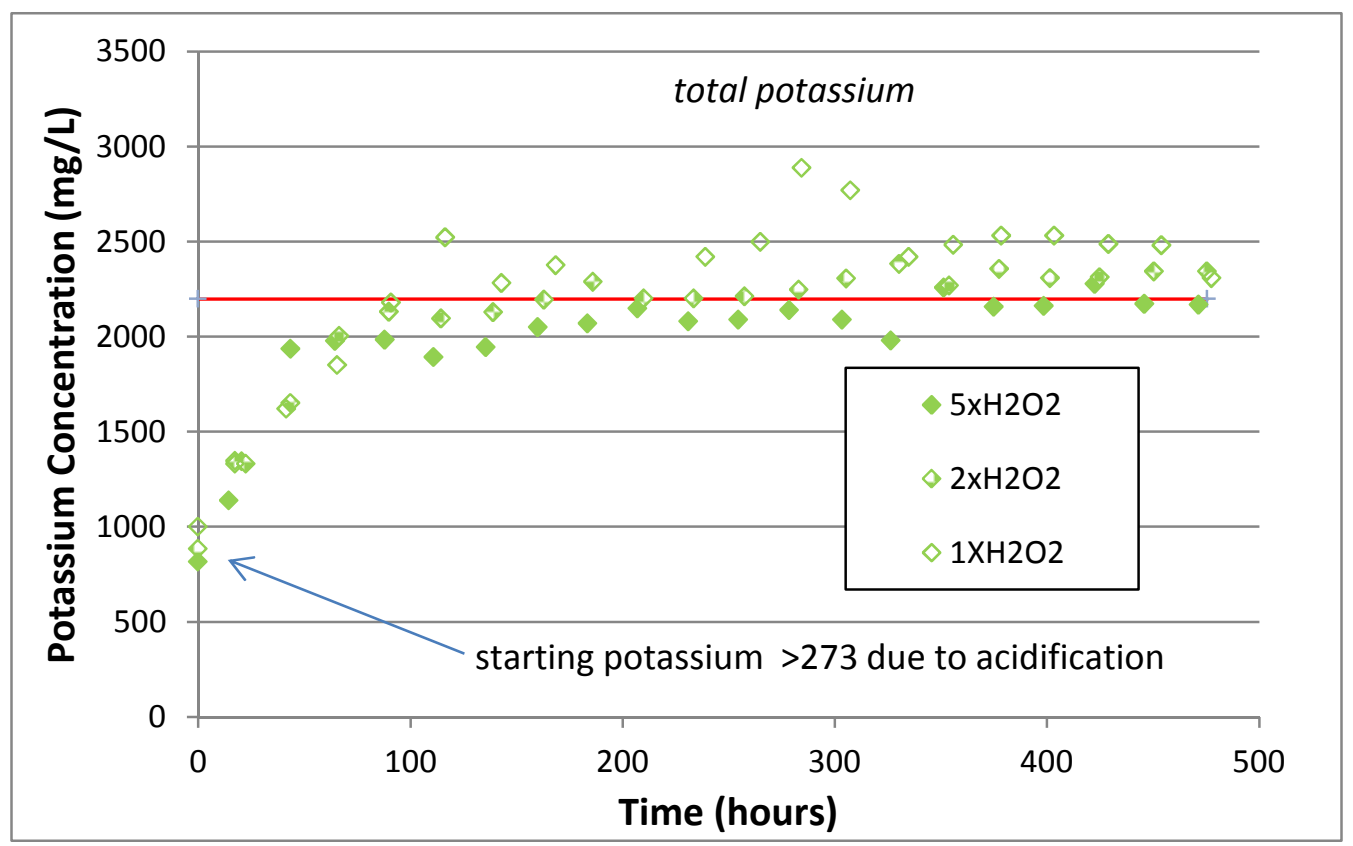

Table 33. Total TPB Destruction from Potassium Results at $5 \times$ Peroxide Addition Rate

\begin{tabular}{|c|c|c|c|c|c|c|c|c|}
\hline \multicolumn{3}{|c|}{ Destruction by Acid } & \multicolumn{3}{c|}{ Destruction by $\mathrm{H}_{2} \mathrm{O}_{2}$} & \multicolumn{3}{c|}{ Total Destruction } \\
\hline $1 \mathrm{xH}_{2} \mathrm{O}_{2}$ & $2 \mathrm{xH}_{2} \mathrm{O}_{2}$ & $5 \mathrm{xH}_{2} \mathrm{O}_{2}$ & $1 \mathrm{xH}_{2} \mathrm{O}_{2}$ & $2 \mathrm{xH}_{2} \mathrm{O}_{2}$ & $5 \mathrm{xH}_{2} \mathrm{O}_{2}$ & $1 \mathrm{xH}_{2} \mathrm{O}_{2}$ & $2 \mathrm{xH}_{2} \mathrm{O}_{2}$ & $5 \mathrm{xH}_{2} \mathrm{O}_{2}$ \\
\hline $31.8-42.0 \%$ & $27.2-36.4 \%$ & $23.7-32.1 \%$ & $56.1-82.2 \%$ & $63.7-88.7 \%$ & $57.6-81.5 \%$ & $94.1-118 \%$ & $95.3-120 \%$ & $86.3-109 \%$ \\
\hline
\end{tabular}

As with the boron data, the TPB destruction is complete by $\sim 100$ hours.

\subsubsection{Soluble Copper Results}

After the start of the $\mathrm{H}_{2} \mathrm{O}_{2}$ addition the copper in the filtrate samples quickly increased near the start of the reaction, then slowly decreased. See Figure 42. 
Figure 42. Soluble Copper Concentration Results for Increased $\mathrm{H}_{2} \mathrm{O}_{2}$ Addition

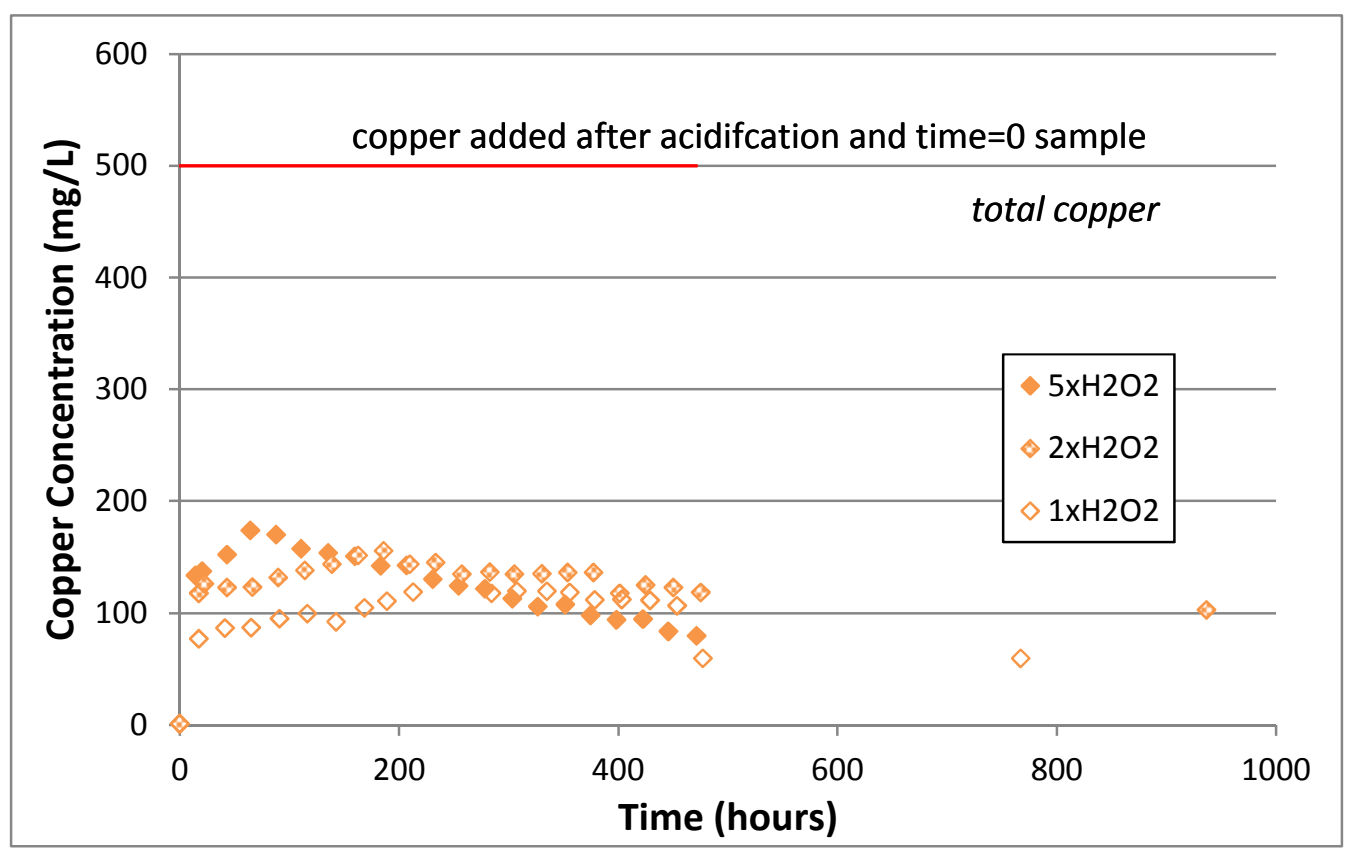

The copper results show a fairly similar pattern to the previous tests (DEMO 2), although slightly higher in magnitude. Between the three data sets there is some variation. Higher $\mathrm{H}_{2} \mathrm{O}_{2}$ delivery appears to generate higher initial copper concentrations, but lower concentrates towards the end.

It is interesting to note that despite increased dilution for this experiment the copper concentration at the end of the experiment is equivalent to that observed for DEMO 2.

\subsubsection{Soluble Titanium Results}

The titanium concentration in solution is monitored for the reasons outlined in Section 3.1.4. See Figure 43.

There is a clear trend that higher delivery rates generate higher titanium concentrations during the test, but soluble Ti declines towards the end of the test period. The peak occurs with a maximum concentration of $\sim 60 \mathrm{mg} / \mathrm{L}$, similar to the experiments with $10 \times$ 
peroxide addition rate (Section 3.2.4). However, unlike that previous test, the titanium declines to levels more typical by the end of the test; $\sim 10 \mathrm{mg} / \mathrm{L}$.

Under these test conditions, it appears that additional $\mathrm{H}_{2} \mathrm{O}_{2}$ is reacting with MST to temporarily bring titanium into solution.

\section{Figure 43. Titanium Concentration Results for Increased $\mathrm{H}_{2} \mathrm{O}_{2}$ Addition}

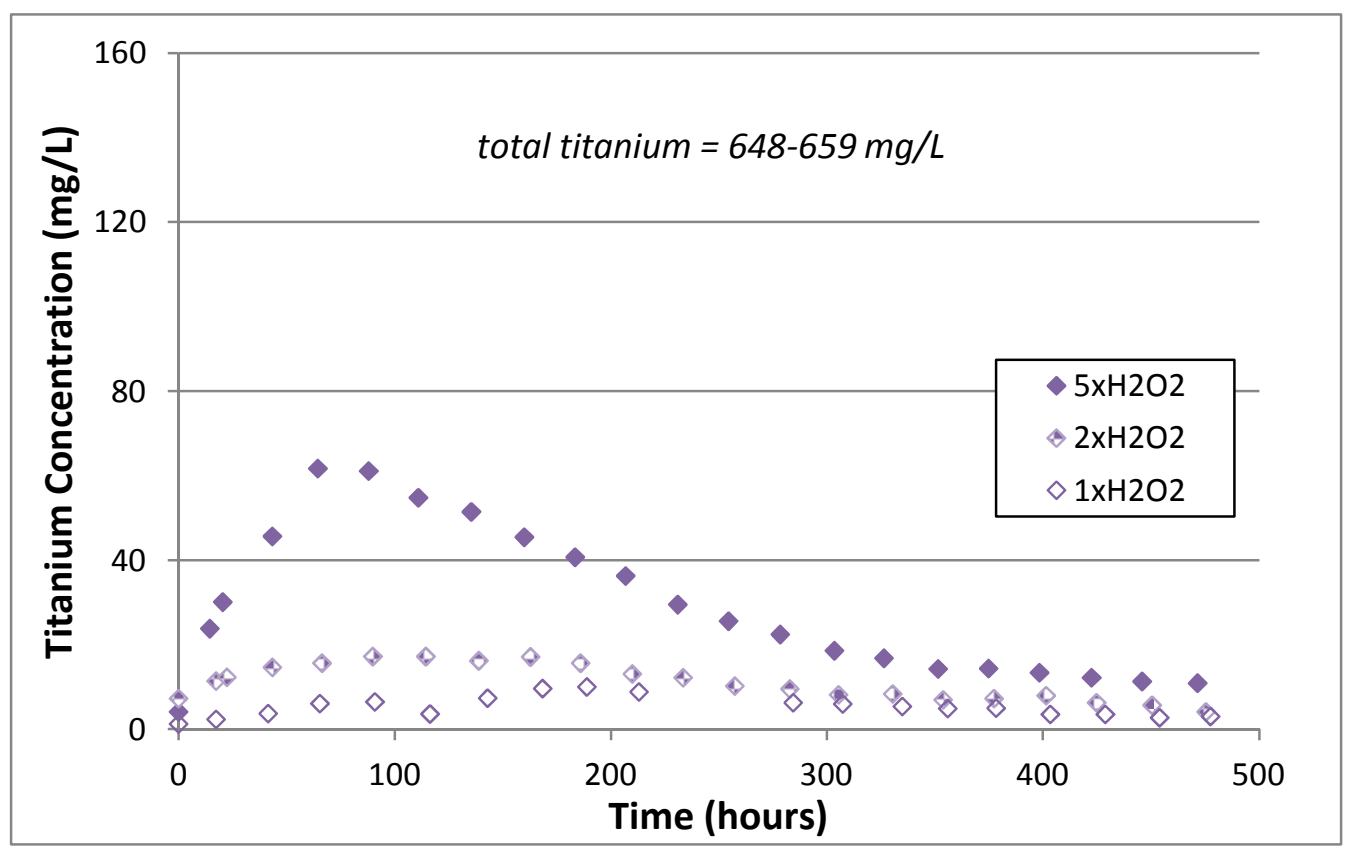

\subsubsection{Analysis of Residual Slurry After Reaction}

After the reaction was complete, the residual post-reaction slurry was removed. The amount of recovered material is dependent on the efficiency of slurry removal since some solids were caked on the upper parts of the reactor or difficult to remove.

From the bottle of bottoms, well-mixed (in an attempt to ensure homogeneity) duplicate samples were analyzed via HPLC, VOA and SVOA. However, due to the elapsed time from the end of the reaction ( $\sim 486$ hours), and the time of sampling, a filtered sample of the reactor residuals was also analyzed via ICPES to determine if the reaction had proceeded further. The results of the ICPES analyses are listed in Table 34. The results for the four analytes $(\mathrm{B}, \mathrm{K}, \mathrm{Cu}, \mathrm{Ti})$ are given next to the chronologically previous sample results. These results are corrected for dilution using sodium. 
Table 34. ICPES Check Samples for Test 2a (mg/L)

\begin{tabular}{|c|c|c|}
\hline Analyte & $\begin{array}{c}\text { Final Filtrate } \\
\text { Result } \\
(\mathrm{t}=471.5 \text { hours })\end{array}$ & $\begin{array}{c}\text { End of Reaction Period } \\
\text { Sample Result } \\
(\mathrm{t}=957 \text { hours })\end{array}$ \\
\hline $\mathrm{B}$ & 469.1 & 498.6 \\
\hline $\mathrm{K}$ & 2079 & 2166 \\
\hline $\mathrm{Cu}$ & 66.90 & 79.24 \\
\hline $\mathrm{Ti}$ & $<1.93$ & 10.83 \\
\hline
\end{tabular}

The analytical uncertainty is $10 \%$ for each result.

There are no statistically significant differences in the boron and potassium results between the two sample sets for any of the reactions. The titanium results showed a drop, which is consistent with the trend displayed in previous titanium data.

As there is no detectable additional destruction occurring, a valid comparison existed between the ICPES and HPLC results. Table 35 lists the HPLC results.

Table 35. HPLC Results from Residual Slurry After Reaction Analyses for Test 2a $(\mathrm{mg} / \mathrm{L})$

\begin{tabular}{|c|c|c|c|c|c|}
\hline TPB & 3PB & 2PB & 1PB & Phenol & \% Destruction \\
\hline$<4$ & $<4$ & $<4$ & $<10$ & $<4$ & $>99.9 \%$ \\
\hline
\end{tabular}

The "\% Destruction" column is the calculated percent destruction. The value is based on the mass of TPB added to the simulant slurries and calculation of the mass of TPB in the residual slurry after reaction, after correcting for the mass of samples removed from the system during the reactions.

Given the very rapid destruction indicated by the boron and potassium data, less than detectable concentrations of all the HPLC analytes were anticipated.

In addition to the residual slurry after reaction samples, two slurry samples were also removed at 207 and 304 hours. These two samples were analyzed by HPLC and the results are listed in Table 36. 
SRNL-STI-2012-00342

Revision 1

Table 36. HPLC Results from Time $=207,304$ Hour Slurry Samples for Test 2a $(\mathrm{mg} / \mathrm{L})$

\begin{tabular}{|c|c|c|c|c|c|c|}
\hline Sample & TPB & 3PB & 2PB & 1PB & Phenol & \% Destruction \\
\hline 207 hour & $<10$ & $<10$ & $<10$ & $<10$ & $<10$ & $>99.9 \%$ \\
\hline 304 hour & $<10$ & $<10$ & $<10$ & $<10$ & $<10$ & $>99.9 \%$ \\
\hline
\end{tabular}

The $\%$ Destruction values in Table 36 were calculated in a different manner than other examples of this type. In this case, as the mass of the entire slurry (the reaction is ongoing) cannot be determined, it is necessary to use the starting TPB concentration (gravimetrically determined) and the TPB concentration at the sample time (by HPLC) to determine the \% Destruction.

These two HPLC measurements also corroborate the boron and potassium data indicating complete destruction as early as 189 hours.

Samples of the reactor bottoms were analyzed using VOA and SVOA (see Table 37). The values in parentheses are the \%RSD. In the analyte column, shaded cells indicate the presence of that analyte is doubtful due to chemical conditions or contaminants. The "total organic residuals" are the sum of all the mid-range values of the detected analytes, less benzene and the analytes that are declared to be from contaminants. The concentrations are the measured values and are not normalized to the beginning volumes.

Table 37. VOA and SVOA Results for Test $2 \mathrm{a}\left(5 \times \mathrm{H}_{2} \mathrm{O}_{2}\right)$

\begin{tabular}{|c|c|}
\hline Analyte & Result (mg/L) \\
\hline Benzene & $<0.05$ \\
\hline diisooctyl adipate & $35.5(41.8 \%)$ \\
\hline p-terphenyl & $2.20(32.1 \%)$ \\
\hline m-terphenyl & $2.60(81.6 \%)$ \\
\hline Biphenyl & $1.65(4.29 \%)$ \\
\hline o-terphenyl & $1.30(32.6 \%)$ \\
\hline Total organic residuals & 7.75 \\
\hline
\end{tabular}

Unlike all previous reactions, there are very few compounds left in the reactor bottoms. The diisooctyl adipate is a known plasticizer and is more than likely leachate from contact with a plastic surface such as the bottle that contained the slurry prior to the experiment or from the analytical method equipment. 


\subsection{6 pH Monitoring}

$\mathrm{pH}$ was monitored during the reaction. See Figure 44.

Again, the $\mathrm{pH}$ values remain at $\sim \mathrm{pH} 9$ for the duration of the reaction. There is no apparent effect of varying the $\mathrm{H}_{2} \mathrm{O}_{2}$ additional rates on the resulting $\mathrm{pH}$.

Figure 44. pH Readings for Effects of $\mathrm{H}_{2} \mathrm{O}_{2}$ Addition Rates

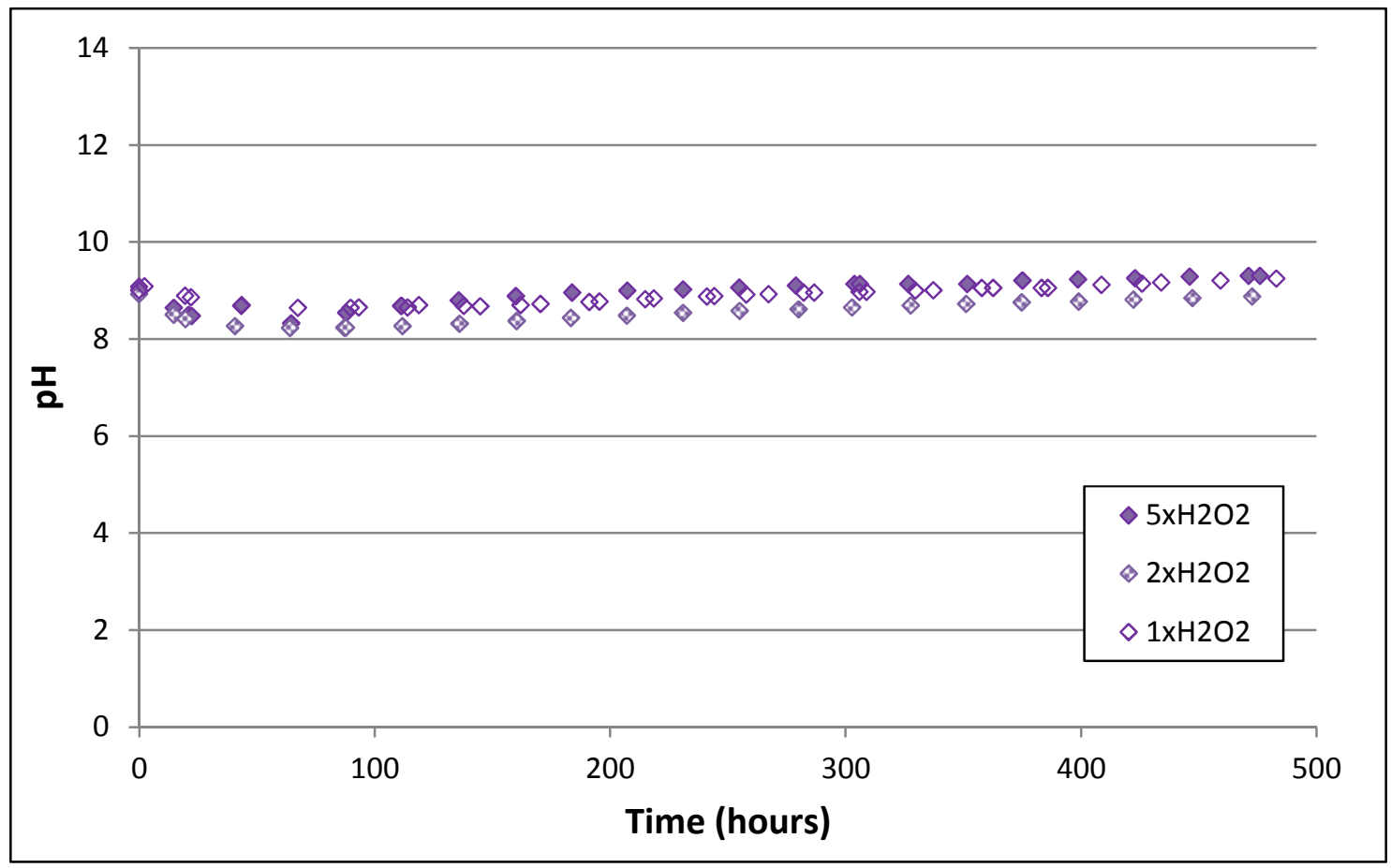

\subsubsection{Conclusion}

Test $2 \mathrm{a}$ showed complete destruction within 4 days. It appears that the increased $\mathrm{H}_{2} \mathrm{O}_{2}$ delivery $(5 \times$ nominal rates) did not provide a further decrease in time required to reach complete TPB destruction. However it is clear that the increased $\mathrm{H}_{2} \mathrm{O}_{2}$ did provide a reduction in the residual organic materials in the residual slurry though this is off-set by the volume increase associated with higher $\mathrm{H}_{2} \mathrm{O}_{2}$ addition rates.

The additional $\mathrm{H}_{2} \mathrm{O}_{2}$ did not increase the final copper soluble concentrations. 
The titanium data suggests that while increased rates of $\mathrm{H}_{2} \mathrm{O}_{2}$ addition can lead to elevated MST leaching, the titanium does not remain soluble. This reaction provided the highest titanium values in solution, but this maximum was not sustained, and the titanium values declined to $\sim 11 \mathrm{mg} / \mathrm{L}$ by the end of the reaction, indicating precipitation to a less soluble titanium compound.

\subsection{Effect of Lower Copper Concentrations}

The prior reactions discussed in this report all used $500 \mathrm{mg} / \mathrm{L}$ of copper. Given that previous results in this document reveal that the $500 \mathrm{mg} / \mathrm{L}$ of copper is not completely dissolved into the caustic slurry, there is the potential to reduce the amount of added copper while still retaining rapid and complete destruction. Lower copper additions are desired for processing at DWPF.

For this set of experiments 0,250 and $100 \mathrm{mg} / \mathrm{L}$ of copper were investigated. These are referred to as "Test $2 \mathrm{c}$ ", "Test $2 \mathrm{~g}$ " and "Test $2 \mathrm{~b}$ " respectively. The $0 \mathrm{mg} / \mathrm{L}$ concentration was conducted to confirm the beneficial role of copper as a catalyst as well as to examine the baseline contribution to reaction by the trace copper concentration $(<1 \mathrm{mg} / \mathrm{L})$ in the sludge component of the slurry. The other two concentrations were used to explore the efficiencies of copper concentrations $<500 \mathrm{mg} / \mathrm{L}$.

These experiments used the same reaction vessels and temperature controls $\left(50^{\circ} \mathrm{C}\right)$ as described in Section 3.5. Other experimental details were as described in previous sections, except where noted below. It was noted that the "prototypical mixing" is in fact, very poor compared to reactions performed in poly bottles with a magnetic stirrer. The agitation was not sufficient enough to prevent a semi-stable floating solids mass. This may have effects in the overall reaction efficiency.

Hydrogen peroxide was added at $0.2 \mathrm{~mL} /$ hour.

Each test continued for approximately 20-21 days. Filtrate samples were pulled one per day. From all reactions, a total of 21-22 samples were removed for analysis by ICPES.

\subsubsection{Soluble Boron Results}

After the start of the $\mathrm{H}_{2} \mathrm{O}_{2}$ addition the boron in the filtrate samples increased over time (see Figure 45). The three reactions of this sequence are displayed on the same graph, with the results from the comparable $500 \mathrm{mg} / \mathrm{L}$ copper test (Section 3.5.1, pH 9 reaction) also shown. 


\section{Figure 45. Boron Concentration Comparison From Low Copper Reactions}

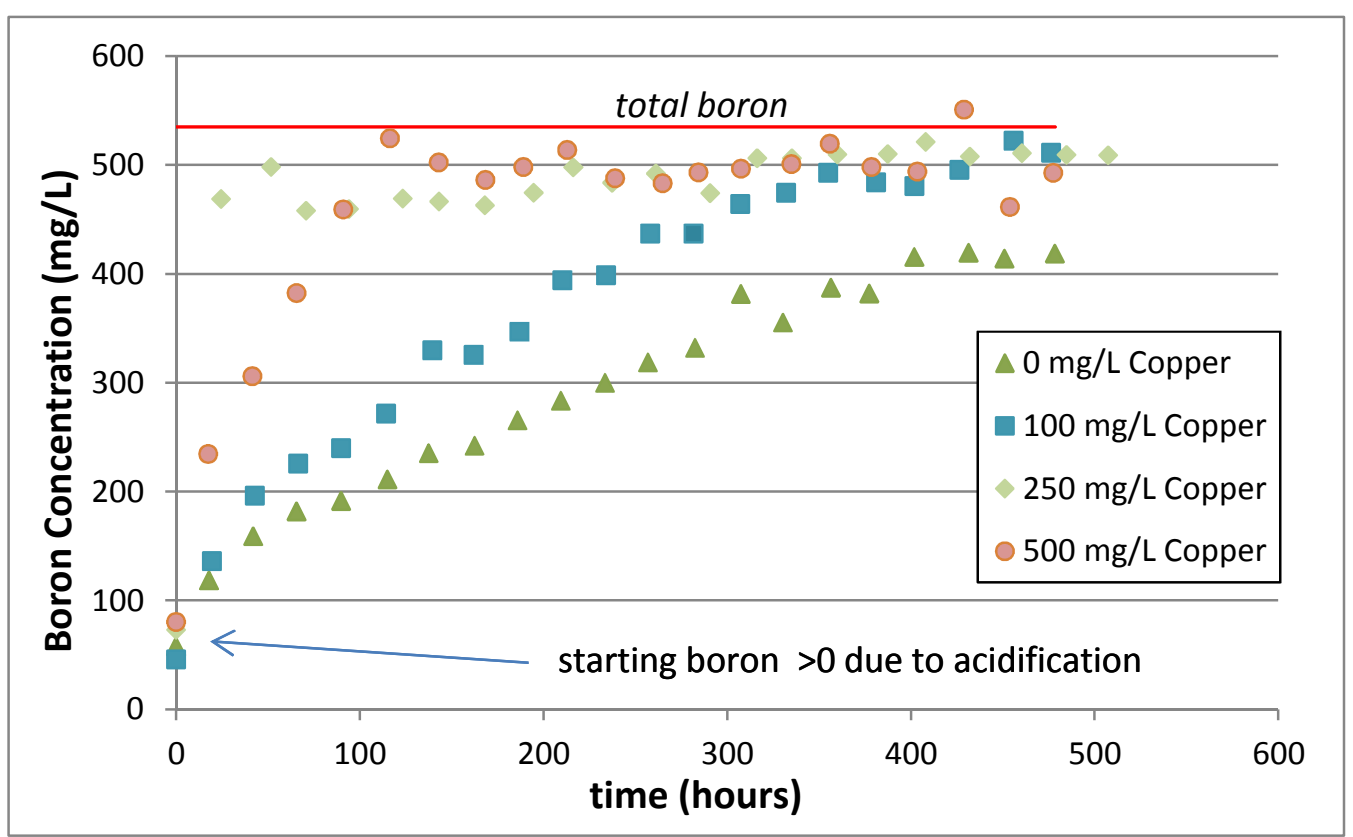

The correlation is very clear; copper concentrations $>100 \mathrm{mg} / \mathrm{L}$ provide higher reaction rates, although it appears that the $500 \mathrm{mg} / \mathrm{L}$ test provides a slower rate of destruction than the $250 \mathrm{mg} / \mathrm{L}$ test. It is interesting to note, however, that the destruction of TPB proceeds (though not to completion in the 480 hour test time-frame) without any addition of copper catalyst.

The reactions were halted after $\sim 480-510$ hours, and the extent of boron dissolution associated with the acid hydrolysis and the peroxide oxidation reaction was calculated using the same methodology as in Section 3.1.1 (see Table 38). A final data point at $\mathrm{t}=793$ hours from the confirmation sample from the residual slurry after reaction (see Section 3.8.5) is not shown for clarity and is not used in the percent destruction calculation. 
Table 38. Total TPB Destruction from Final Boron Results

\begin{tabular}{|c|c|c|c|}
\hline \multicolumn{5}{|c|}{ Destruction by Acid } \\
\hline $0 \mathrm{mg} / \mathrm{L} \mathrm{Cu}$ & $100 \mathrm{mg} / \mathrm{L} \mathrm{Cu}$ & $250 \mathrm{mg} / \mathrm{L} \mathrm{Cu}$ & $500 \mathrm{mg} / \mathrm{L} \mathrm{Cu}$ \\
\hline $9.8-11.9 \%$ & $7.6-9.3 \%$ & $12.3-15.0 \%$ & $13.3-16.2 \%$ \\
\hline \multicolumn{4}{|c|}{ Destruction by $\mathrm{H}_{2} \mathrm{O}_{2}$} \\
\hline $0 \mathrm{mg} / \mathrm{L} \mathrm{Cu}$ & $100 \mathrm{mg} / \mathrm{L} \mathrm{Cu}$ & $250 \mathrm{mg} / \mathrm{L} \mathrm{Cu}$ & $500 \mathrm{mg} / \mathrm{L} \mathrm{Cu}$ \\
\hline $59.5-75.3 \%$ & $77.1-96.2 \%$ & $72.0-91.2 \%$ & $66.8-85.1 \%$ \\
\hline \multicolumn{4}{|c|}{ Total Destruction } \\
\hline $0 \mathrm{mg} / \mathrm{L} \mathrm{Cu}$ & $100 \mathrm{mg} / \mathrm{L} \mathrm{Cu}$ & $250 \mathrm{mg} / \mathrm{L} \mathrm{Cu}$ & $500 \mathrm{mg} / \mathrm{L} \mathrm{Cu}$ \\
\hline $70.4-86.0 \%$ & $85.6-105 \%$ & $85.7-105 \%$ & $81.6-100 \%$ \\
\hline
\end{tabular}

One data set $(0 \mathrm{mg} / \mathrm{L} \mathrm{Cu})$ showed incomplete destruction. Clearly, $0 \mathrm{mg} / \mathrm{L}$ of copper is insufficient to achieve a rapid cycle time.

\subsubsection{Soluble Potassium Results}

After the start of the $\mathrm{H}_{2} \mathrm{O}_{2}$ addition the potassium in the filtrate samples increased over time. See Figure 46.

From the potassium data, the same trends found in the boron data are observed, including the evidence of a much faster reaction at higher copper concentrations.

Figure 46. Potassium Concentration Comparison from Low Copper Reactions

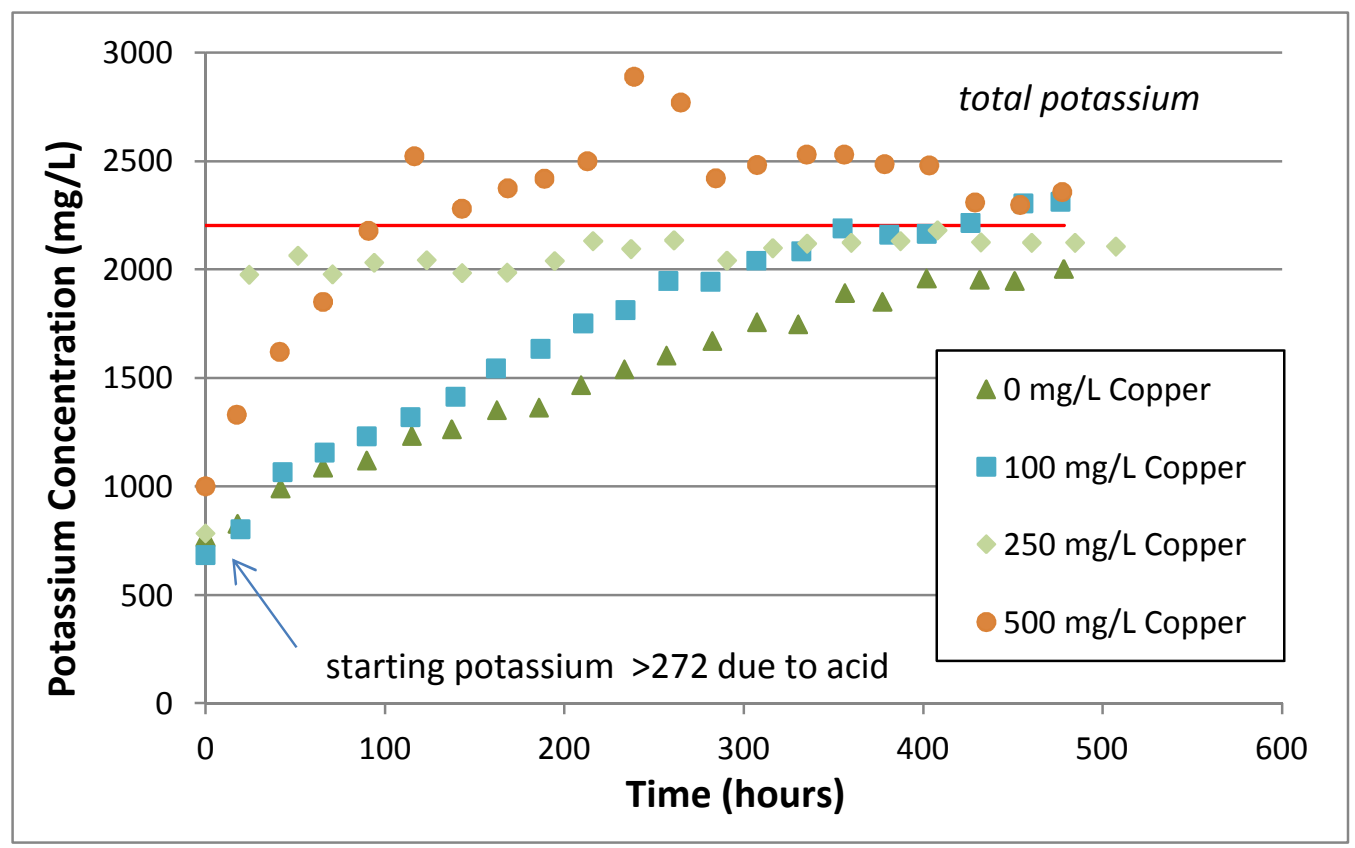


The reactions were halted after $\sim 480-510$ hours, and the extent of potassium dissolution associated with the acid hydrolysis and peroxide oxidation reactions were calculated using the same methodology as in Section 3.1.1. See Table 39. A final data point at $\mathrm{t}=793$ hours from the confirmation sample from the residual slurry after reaction (see Section 3.8.5) is not shown for clarity and is not used in the percent destruction calculation.

Table 39. Total TPB Destruction from Potassium Results

\begin{tabular}{|c|c|c|c|}
\hline \multicolumn{5}{|c|}{ Destruction by Acid } \\
\hline $0 \mathrm{mg} / \mathrm{L} \mathrm{Cu}$ & $100 \mathrm{mg} / \mathrm{L} \mathrm{Cu}$ & $250 \mathrm{mg} / \mathrm{L} \mathrm{Cu}$ & $500 \mathrm{mg} / \mathrm{L} \mathrm{Cu}$ \\
\hline $21.6-29.5 \%$ & $17.6-24.7 \%$ & $22.4-30.5 \%$ & $31.8-42.0 \%$ \\
\hline \multicolumn{4}{|c|}{ Destruction by $\mathrm{H}_{2} \mathrm{O}_{2}$} \\
\hline $0 \mathrm{mg} / \mathrm{L} \mathrm{Cu}$ & $100 \mathrm{mg} / \mathrm{L} \mathrm{Cu}$ & $250 \mathrm{mg} / \mathrm{L} \mathrm{Cu}$ & $500 \mathrm{mg} / \mathrm{L} \mathrm{Cu}$ \\
\hline $52.9-75.1 \%$ & $71.5-96.4 \%$ & $57.0-80.3 \%$ & $56.1-82.2 \%$ \\
\hline \multicolumn{4}{|c|}{ Total Destruction } \\
\hline $0 \mathrm{mg} / \mathrm{L} \mathrm{Cu}$ & $100 \mathrm{mg} / \mathrm{L} \mathrm{Cu}$ & $250 \mathrm{mg} / \mathrm{L} \mathrm{Cu}$ & $500 \mathrm{mg} / \mathrm{L} \mathrm{Cu}$ \\
\hline $79.2-100 \%$ & $93.2-117 \%$ & $84.2-106 \%$ & $94.1-118 \%$ \\
\hline
\end{tabular}

The trends in the potassium data match the trends in the boron data.

\subsubsection{Soluble Copper Results}

After the start of the $\mathrm{H}_{2} \mathrm{O}_{2}$ addition the copper in the filtrate samples slowly increased over time (see Figure 47). The figure only shows the copper data from the 100, 250 and $500 \mathrm{mg} / \mathrm{L}$ reactions, as there were less than detectable concentrations of copper in the $0 \mathrm{mg} / \mathrm{L}$ reaction. 
SRNL-STI-2012-00342

Revision 1

Figure 47. Soluble Copper Concentration Results for Low Copper Reactions

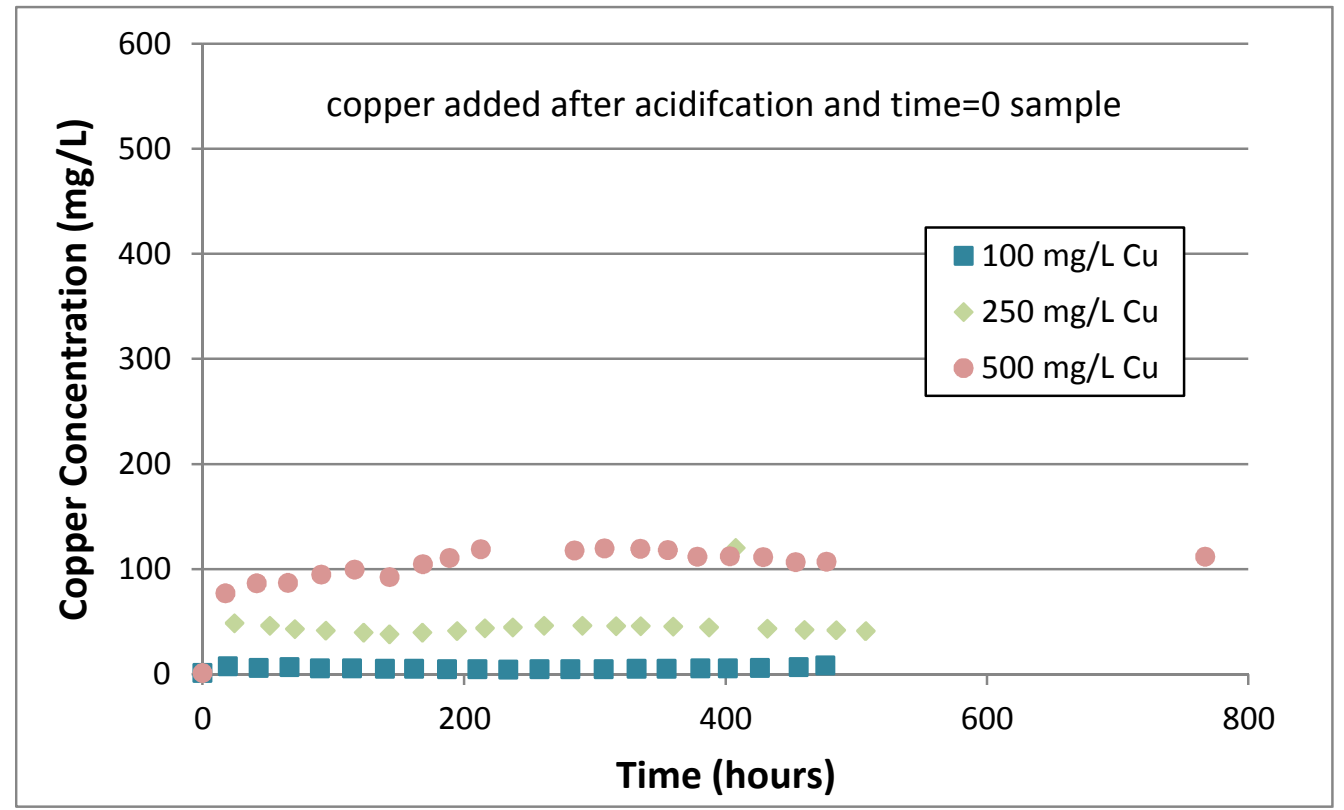

In previous reactions which added copper to $500 \mathrm{mg} / \mathrm{L}$, the filtrates typically contained $\sim 100 \mathrm{mg} / \mathrm{L}$ by the end of the test (about $20 \%$ of the added copper). In the reaction with $250 \mathrm{mg} / \mathrm{L}$ of added copper, only $\sim 50 \mathrm{mg} / \mathrm{L}$ remained soluble (about $20 \%$ of the added copper). With copper added to only $100 \mathrm{mg} / \mathrm{L}$, an even smaller fraction $(<10 \%)$ of the copper dissolved. SRNL is unsure for the reason for this at this time.

\subsubsection{Soluble Titanium Results}

Soluble titanium is monitored for the reasons outlined in Section 3.1.4 (see Figure 48). In all cases, the titanium concentration was below $30 \mathrm{mg} / \mathrm{L}$. Perhaps of some significance is the apparent trend that lower copper concentrations lead to higher titanium concentrations. There is, however, no intuitively obvious connection between the presence of copper and the titanium concentration. SRNL surmises that in the presence of less catalyst, the competing reaction of peroxide with other species - such as MST - becomes more favored. 
Figure 48. Titanium Concentration Results for Low Copper Experiments

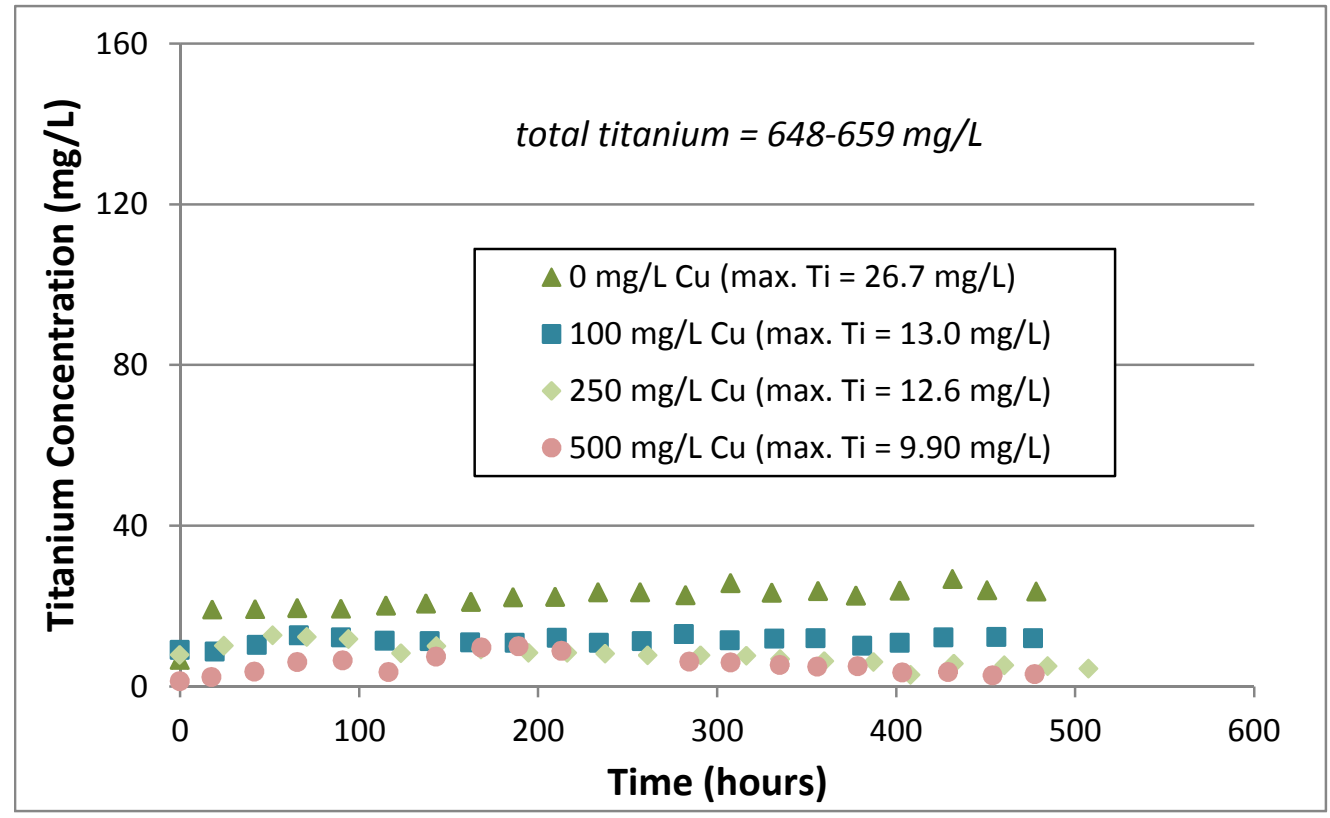

\subsubsection{Analysis of Residual Slurry After Reaction}

After the low copper reactions were complete, the reactor residuals were removed. The amount of recovered material is dependent on the efficiency of slurry removal since some solids were caked on the upper parts of the reactor or difficult to remove.

From the bottle of residual slurry after reaction, well-mixed (in an attempt to ensure homogeneity) duplicate samples were analyzed via HPLC, VOA and SVOA. However, due to the elapsed time from the end of the reaction ( $\sim 315$ hours), and the time of sampling, a filtered sample of the residuals from Tests $2 \mathrm{~b}$ and $2 \mathrm{c}$ were also analyzed via ICPES as a check to see if the reaction had proceeded further. SRNL did not analyze samples from Test $2 \mathrm{~g}$ as by that time the researchers had confidence in the lack of further reactions after the end of an experiment. The results of the ICPES analyses are listed in Table 40. The results for the four analytes $(\mathrm{B}, \mathrm{K}, \mathrm{Cu}, \mathrm{Ti})$ are given next to the chronologically previous sample results. These results are corrected for dilution using Na.

There are no statistically significant differences in the boron and potassium results between the two sample sets for any of the reactions. 
Table 40. ICPES Check Samples (mg/L) for Varying Amounts of Added Copper

\begin{tabular}{|c|c|c|c|}
\hline \multirow{2}{*}{ Reaction } & Analyte & $\begin{array}{c}\text { Final Filtrate } \\
\text { Result }\end{array}$ & $\begin{array}{c}\text { End of Reaction Period } \\
\text { Sample Result }\end{array}$ \\
\hline \multirow{3}{*}{$0 \mathrm{mg} / \mathrm{L} \mathrm{Cu}$} & $\mathrm{B}$ & 422.8 & 418.4 \\
\cline { 2 - 4 } & $\mathrm{K}$ & 2076 & 2002 \\
\cline { 2 - 4 } & $\mathrm{Cu}$ & $<0.86$ & $<0.86$ \\
\cline { 2 - 4 } & $\mathrm{Ti}$ & 18.56 & 23.62 \\
\hline \multirow{3}{*}{$100 \mathrm{mg} / \mathrm{L} \mathrm{Cu}$} & $\mathrm{B}$ & 497.0 & 511.0 \\
\cline { 2 - 4 } & $\mathrm{K}$ & 2193 & 2311 \\
\cline { 2 - 4 } & $\mathrm{Cu}$ & 6.51 & 7.95 \\
\cline { 2 - 4 } & $\mathrm{Ti}$ & 4.06 & 11.87 \\
\hline
\end{tabular}

The analytical uncertainty is $10 \%$ for each result.

As there is no detectable additional destruction occurring, a valid comparison existed between the ICPES and HPLC results. Table 41 lists the HPLC results.

Table 41. HPLC Results from Residual Slurry After Reaction Analyses (mg/L) for Lesser Amounts of Added Copper

\begin{tabular}{|c|c|c|c|c|c|c|}
\hline Reaction & TPB & 3PB & 2PB & 1PB & Phenol & \% Destruction \\
\hline $0 \mathrm{mg} / \mathrm{L} \mathrm{Cu}$ & $2585(0.82 \%)$ & 12 & $<10$ & $<10$ & 33 & $84.6-84.8 \%$ \\
\hline $100 \mathrm{mg} / \mathrm{L} \mathrm{Cu}$ & $245(2.89 \%)$ & $<10$ & $<10$ & $<10$ & $<10$ & $98.4-98.5 \%$ \\
\hline $250 \mathrm{mg} / \mathrm{L} \mathrm{Cu}$ & $<4$ & $<4$ & $<4$ & $<4$ & $<4$ & $>99.97 \%$ \\
\hline $500 \mathrm{mg} / \mathrm{L} \mathrm{Cu}$ & $<10$ & $<10$ & $<10$ & $<10$ & $<10$ & $>99.9 \%$ \\
\hline
\end{tabular}

The value in parentheses is the \%RSD. The "\% Destruction" column is the calculated percent destruction. The value is based on the mass of TPB added to the simulant slurries and calculation of the mass of TPB in the reactor residuals, after correcting for the mass of samples removed from the system during the reactions.

The HPLC results corroborate the boron and potassium data. While the $100 \mathrm{mg} / \mathrm{L} \mathrm{Cu}$ reaction is close to complete after 480 hours of processing, the $0 \mathrm{mg} / \mathrm{L}$ copper test indicates the need for additional reaction time.

Samples of the residual slurry after reaction were analyzed using VOA and SVOA. See Tables 42-44. The values in parentheses are the \%RSD. In the results column, values that are shaded indicate only one measured value with the other being a detection limit result. In this case, the values in parentheses are the analytical uncertainties. In the analyte column, shaded cells indicate the presence of that analyte is doubtful due to chemical conditions or contaminants. The "total organic residuals" are the sum of all the mid- 
range values of the detected analytes, less benzene and the analytes that are considered to be from contaminants.

Table 42. VOA and SVOA Results for $0 \mathrm{mg} / \mathrm{L} \mathrm{Cu}$ Reactions

\begin{tabular}{|c|c|}
\hline Analyte & Result (mg/L) \\
\hline benzene & $0.20(0.00 \%)$ \\
\hline biphenyl & $301(9.87 \%)$ \\
\hline benzophenone & $47.4(136 \%)$ \\
\hline p-terphenyl & $21.5(23.0 \%)$ \\
\hline diisooctyl adipate & $18.5(3.82 \%)$ \\
\hline o-terphenyl & $3.70(7.64 \%)$ \\
\hline m-terphenyl & $3.15(6.73 \%)$ \\
\hline 4-nitro-1,1-biphenyl & $1.28-1.92$ \\
\hline 3-nitrophenol & $0.88-1.32$ \\
\hline Total organic residuals & 380 \\
\hline
\end{tabular}

Table 43. VOA and SVOA Results for $100 \mathrm{mg} / \mathrm{L} \mathrm{Cu}$ Reaction

\begin{tabular}{|c|c|}
\hline Analyte & Result (mg/L) \\
\hline benzene & $0.0975(3.63 \%)$ \\
\hline biphenyl & $51.0(80.4 \%)$ \\
\hline p-terphenyl & $24.4(60.1 \%)$ \\
\hline diisooctyl adipate & $17.0(49.9 \%)$ \\
\hline o-terphenyl & $3.85(38.6 \%)$ \\
\hline m-terphenyl & $1.84-2.76$ \\
\hline diphenyl ether & $1.04-1.56$ \\
\hline Total organic residuals & 82.9 \\
\hline
\end{tabular}


Table 44. VOA and SVOA Results for $250 \mathrm{mg} / \mathrm{L} \mathrm{Cu}$ Reaction

\begin{tabular}{|c|c|}
\hline Analyte & Result (mg/L) \\
\hline [1,1-biphenyl]-3-amine & $94.0(9.03 \%)$ \\
\hline biphenyl & $36.0(11.8 \%)$ \\
\hline terphenyl & $15.0(28.3 \%)$ \\
\hline diphenylamine & $9.50(7.44 \%)$ \\
\hline N,N-diphenylbenzeneamine & $8.00-12.0$ \\
\hline 2-methyl-1-buten-3-yne & $6.96-10.4$ \\
\hline diisooctyl adipate & $8.10(19.2 \%)$ \\
\hline diphenyl ether & $7.90(2.70 \%)$ \\
\hline 2-nitro-N-(2-nitrophenyl)benzeneamine & $5.30(8.00 \%)$ \\
\hline 6-methoxybenzofuroxan & $3.04-4.56$ \\
\hline 2,4-dinitro-N-phenylbenzeneamine & $2.80-4.20$ \\
\hline triphenylmethane & $2.00-3.00$ \\
\hline diphenyl(2-pyridyl)methanol & $1.28-1.92$ \\
\hline dimethyldiphenyldihydrodipyrrolopyridin & $1.12-1.68$ \\
\hline 3-pentene-1-yne & $6.40-9.6$ \\
\hline 1-pyrenecarboxaldehyde hydrazone & $5.60-8.40$ \\
\hline 2-nitro-N-(4-nitrophenyl)benzeneamine & $2.40-3.60$ \\
\hline butanal & $0.068(1.05 \%)$ \\
\hline acetone & $0.590(14.4 \%)$ \\
\hline Total organic residuals & 218 \\
\hline
\end{tabular}

These three sets of results can be compared against the $\mathrm{pH} 9$ reaction result of $199 \mathrm{mg} / \mathrm{L}$ (section 3.5.1).

Of the residual organics left in the residual slurry after reaction, biphenyl or a biphenyl derivative are the most concentrated. The $100 \mathrm{mg} / \mathrm{L}$ added $\mathrm{Cu}$ reaction gave the least amount of residual organics (not counting phenylborates), while the $0 \mathrm{mg} / \mathrm{L}$ gave the most. The 250 and $500 \mathrm{mg} / \mathrm{L}$ reactions gave comparable amounts. This could imply that $100 \mathrm{mg} / \mathrm{L}$ of added copper may be superior to $250-500 \mathrm{mg} / \mathrm{L}$ in terms of minimizing the organic residuals. However, there is a complex equilibrium occurring from CCPO destruction. As the phenylborates are being destroyed, this will generate other residual organic compounds. These compounds are also destroyed during the CCPO reaction. Given the variety of residual compounds that are detected, it is impossible to determine any sort of preference or comparative rate of destruction. 


\subsection{6 pH Monitoring}

$\mathrm{pH}$ was monitored during the reactions. See Figure 49. In addition to the three experiments described in this Section, the $500 \mathrm{mg} / \mathrm{L}$ copper test (see Section 3.5.1, pH 9 reaction) is also shown.

Again, the $\mathrm{pH}$ values remain at $\sim \mathrm{pH} 9$ throughout the life of the reaction. The varying concentrations of copper do not affect the change in $\mathrm{pH}$ of the reactions.

Figure 49. pH Readings for Tests $2 \mathrm{~b}, 2 \mathrm{c}$ and $2 \mathrm{~g}$.

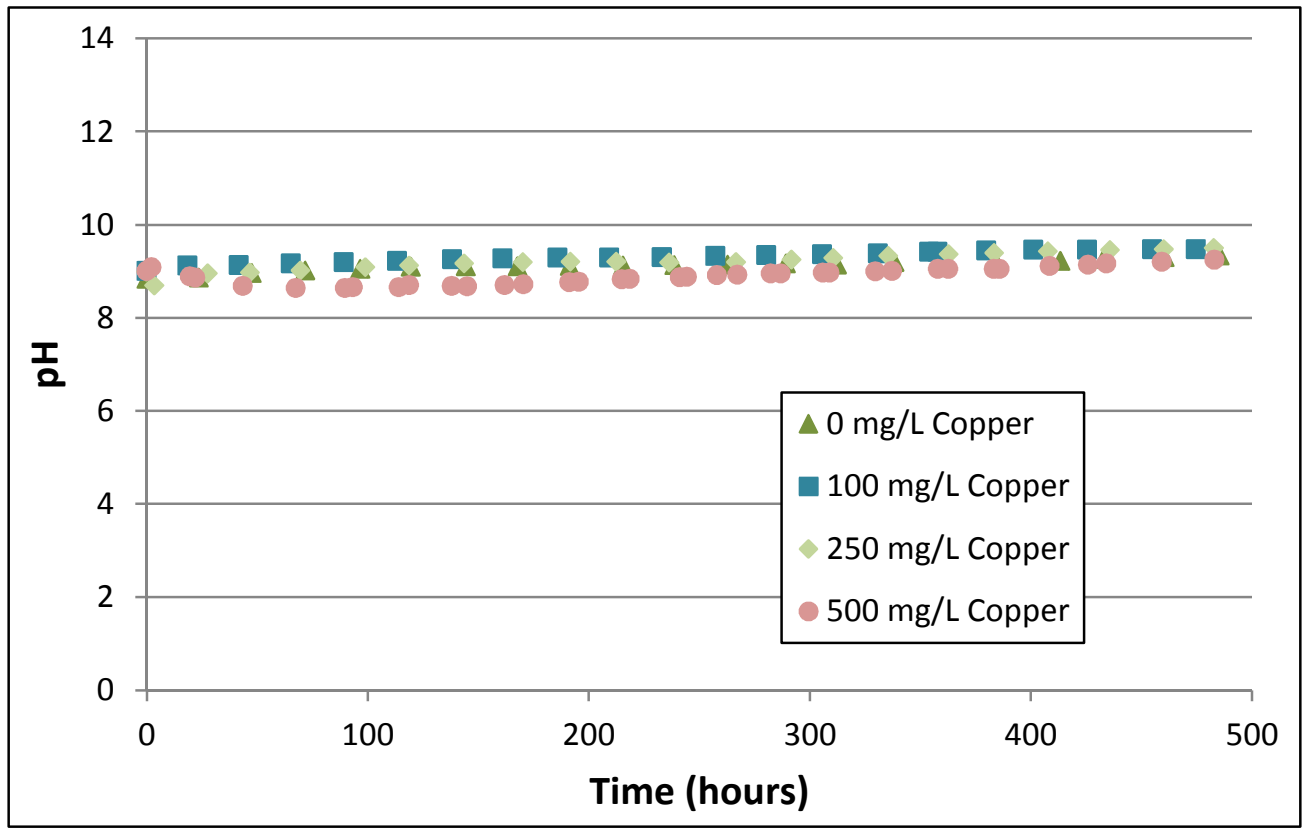

\subsubsection{Conclusion}

While lower concentrations of copper are desirable to reduce impacts at DWPF, lowering the copper to $100 \mathrm{mg} / \mathrm{L}$ or lower detrimentally affects the rate of TPB destruction. Lowering the copper to $250 \mathrm{mg} / \mathrm{L}$ gives approximately the same destruction rate (or slightly higher than) the $500 \mathrm{mg} / \mathrm{L}$ equivalent. On the other hand, the $100 \mathrm{mg} / \mathrm{L}$ test gave incomplete destruction, but also the lowest concentrations of residual organics (not counting the undestroyed phenylborates).

The copper concentration added appears to affect the proportion of soluble titanium. The data sets tentatively suggest that excess amounts of $\mathrm{H}_{2} \mathrm{O}_{2}$ will leach titanium into solution if insufficient copper is present to catalyze the desired reaction. The excess $\mathrm{H}_{2} \mathrm{O}_{2}$ may either occur as a function of increasing the $\mathrm{H}_{2} \mathrm{O}_{2}$ addition rate (see Section 3.7.3) or by reducing the amount of added copper. For the latter, reduced copper catalyst is assumed 
to decrease the formation of hydroxyl radicals that would be utilized in the oxidation of organic compounds thus making more $\mathrm{H}_{2} \mathrm{O}_{2}$ available for interaction with MST.

\subsection{Further Effects of Reaction Temperatures}

Previous work examined the effects of varying the reaction temperature (section 3.3). Since these original experiments, the researchers desired to see if the rapid TPB destruction that occurred at $\mathrm{pH} 7$ and $50{ }^{\circ} \mathrm{C}$ (see the $\mathrm{pH} 7$ reaction, Test 1c, Section 3.6) also occurred at temperatures below $50{ }^{\circ} \mathrm{C}$. Operating at lower temperature is advantageous for the full scale process.

This experiment (referred to as "Test $2 \mathrm{f}$ ") used the same reaction vessels and temperature control (water bath) as described in Section 3.5, $\mathrm{pH} 7$ reaction, except the operating temperature was $45^{\circ} \mathrm{C}$. Other experimental details were as described in previous sections, except where noted below. It was noted that the "prototypical mixing" is in fact, very poor compared to reactions performed in poly bottles with a magnetic stirrer. The agitation was not sufficient enough to prevent a semi-stable floating solids mass. This may have effects in the overall TPB destruction.

Hydrogen peroxide was added at $0.2 \mathrm{~mL} /$ hour.

Each test continued for approximately 20-22 days. Filtrate samples were pulled one per day. From all reactions, a total of 20-22 samples were removed for analysis by ICPES.

\subsubsection{Soluble Boron Results}

As in previous experiments, the boron concentration in solution was measured as an indicator of TPB destruction. After the start of the $\mathrm{H}_{2} \mathrm{O}_{2}$ addition the boron in the filtrate samples increased over time. See Figure 50. The appropriate comparison data from section 3.5 (Test 1c) is included.

The reaction was halted after 507 hours, and the extent of boron dissolution associated with the acid hydrolysis and the peroxide oxidation reaction was calculated using the same methodology as in Section 3.1.1 (see Table 45). 
SRNL-STI-2012-00342

Revision 1

Table 45. Total TPB Destruction from Final Boron Results at Varying Temperatures

\begin{tabular}{|c|c|c|c|c|c|}
\hline \multicolumn{2}{|c|}{ Destruction by Acid } & \multicolumn{2}{c|}{ Destruction by $\mathrm{H}_{2} \mathrm{O}_{2}$} & \multicolumn{2}{c|}{ Total Destruction } \\
\hline $45{ }^{\circ} \mathrm{C}$ & $50{ }^{\circ} \mathrm{C}$ & $45{ }^{\circ} \mathrm{C}$ & $50{ }^{\circ} \mathrm{C}$ & $45{ }^{\circ} \mathrm{C}$ & $50{ }^{\circ} \mathrm{C}$ \\
\hline $8.6-10.6 \%$ & $14.9-18.2 \%$ & $72.7-91.1 \%$ & $64.4-82.7 \%$ & $82.3-101 \%$ & $81.1-99.2 \%$ \\
\hline
\end{tabular}

Both reactions provided the same total destruction.

Figure 50. Boron Concentration Comparison at Varying Temperatures

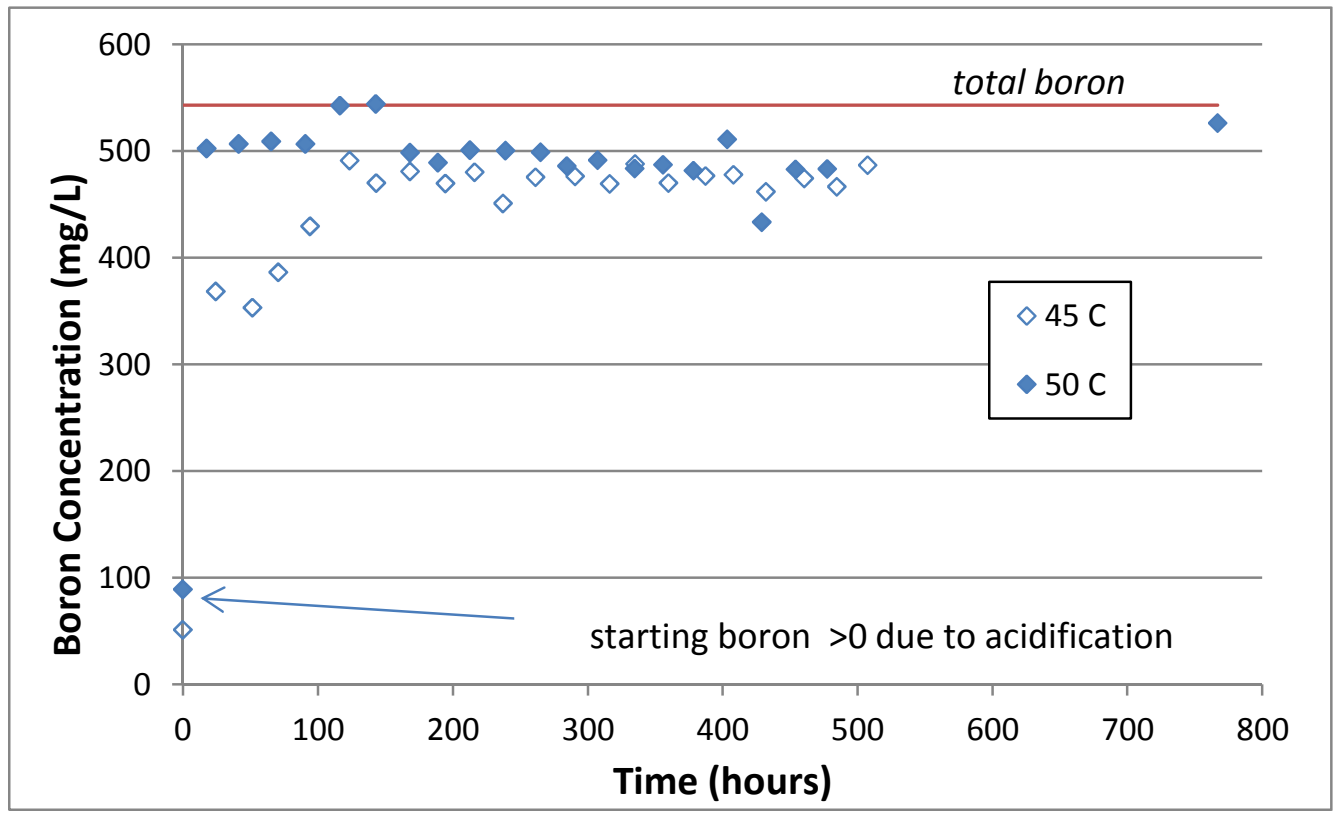

The $50{ }^{\circ} \mathrm{C}$ test (Test $1 \mathrm{c}$ ) proceeded faster than the $45{ }^{\circ} \mathrm{C}$ test (Test $2 \mathrm{f}$ ), and provided complete destruction $\sim 100$ hours before the $45^{\circ} \mathrm{C}$ test.

Even though the reactions have not technically liberated $100 \%$ of the boron into solution, the fact that both reactions plateau at the same point (average of 91-95\% destruction) yields confidence that all of the TPB has been degraded.

\subsubsection{Soluble Potassium Results}

After the start of the $\mathrm{H}_{2} \mathrm{O}_{2}$ addition, the potassium in the filtrate samples increased over time. See Figure 51. The appropriate comparison data from section 3.5 (Test 1c) is included. 


\section{Figure 51. Potassium Concentration Comparison at Varying Temperatures}

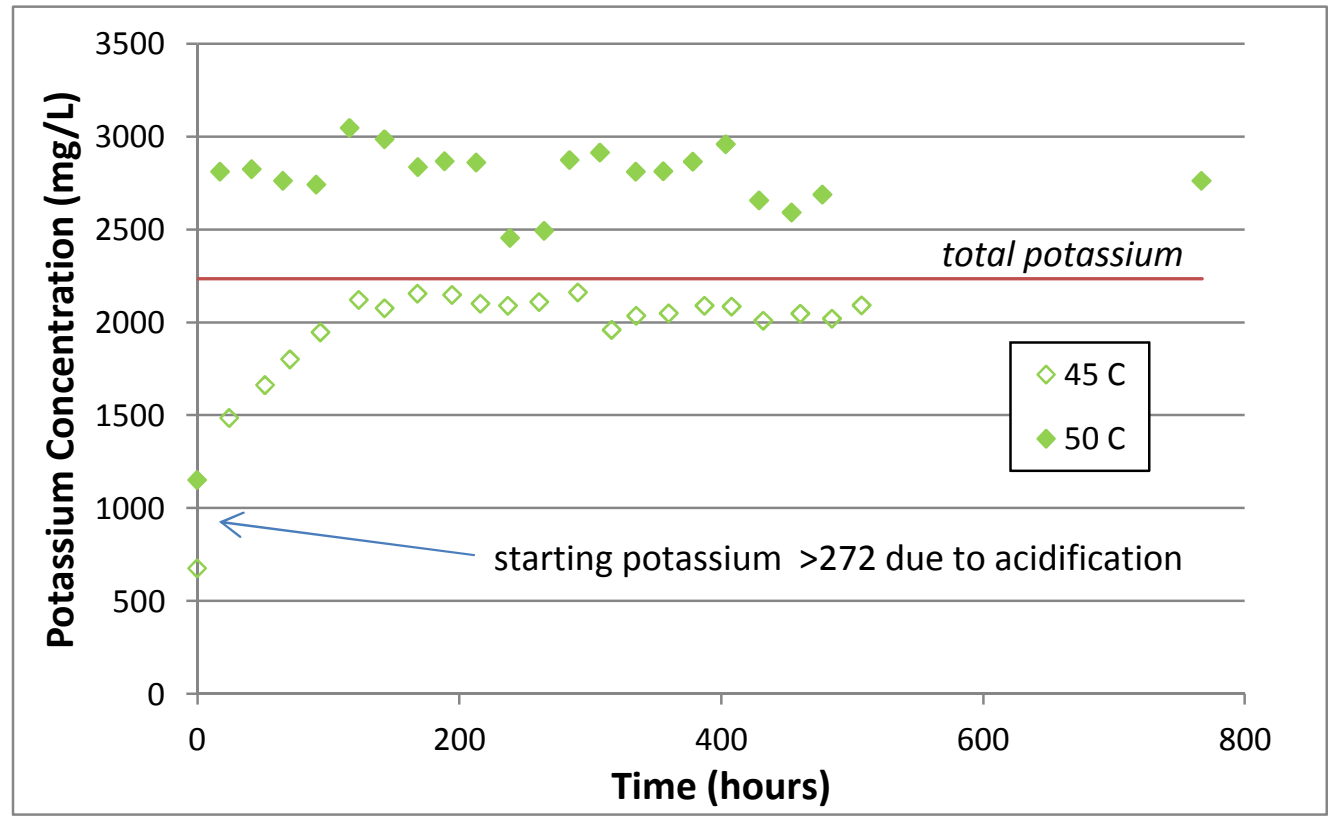

The reaction was halted after 507 hours, and the extent of potassium dissolution associated with the acid hydrolysis and peroxide oxidation reactions was calculated using the same methodology as in Section 3.1.1 (Table 46). As previously noted, the potassium data for the $50{ }^{\circ} \mathrm{C}$ test (Test 1c) is biased high due to the $\mathrm{pH}$ probe leak described previously.

Table 46. Total TPB Destruction from Potassium Results at Varying Temperatures

\begin{tabular}{|c|c|c|c|c|c|}
\hline \multicolumn{2}{|c|}{ Destruction by Acid } & \multicolumn{2}{c|}{ Destruction by $\mathrm{H}_{2} \mathrm{O}_{2}$} & \multicolumn{2}{c|}{ Total Destruction } \\
\hline $45{ }^{\circ} \mathrm{C}$ & $50{ }^{\circ} \mathrm{C}$ & $45{ }^{\circ} \mathrm{C}$ & $50{ }^{\circ} \mathrm{C}$ & $45{ }^{\circ} \mathrm{C}$ & $50{ }^{\circ} \mathrm{C}$ \\
\hline $17.5-24.5 \%$ & $39.4-51.3 \%$ & $62.3-85.2 \%$ & $64.3-94.5 \%$ & $83.9-106 \%$ & $111-139 \%$ \\
\hline
\end{tabular}

The potassium results show the same temperature-related trends as the boron results and provide for the same conclusion.

\subsubsection{Soluble Copper Results}

After the start of the $\mathrm{H}_{2} \mathrm{O}_{2}$ addition the copper in the filtrate samples slowly increased over time. See Figure 52. The appropriate comparison data from section 3.5 (Test 1c) is included. 
The data indicate that most of the copper remains in an insoluble form. Both reactions approached the same value of $\sim 100 \mathrm{mg} / \mathrm{L}$ which is also equivalent to the copper solubility observed in the earlier ambient temperature test (see Figure 4). These data suggest a similar reaction sequence.

Figure 52. Soluble Copper Concentration Comparison at Varying Temperatures

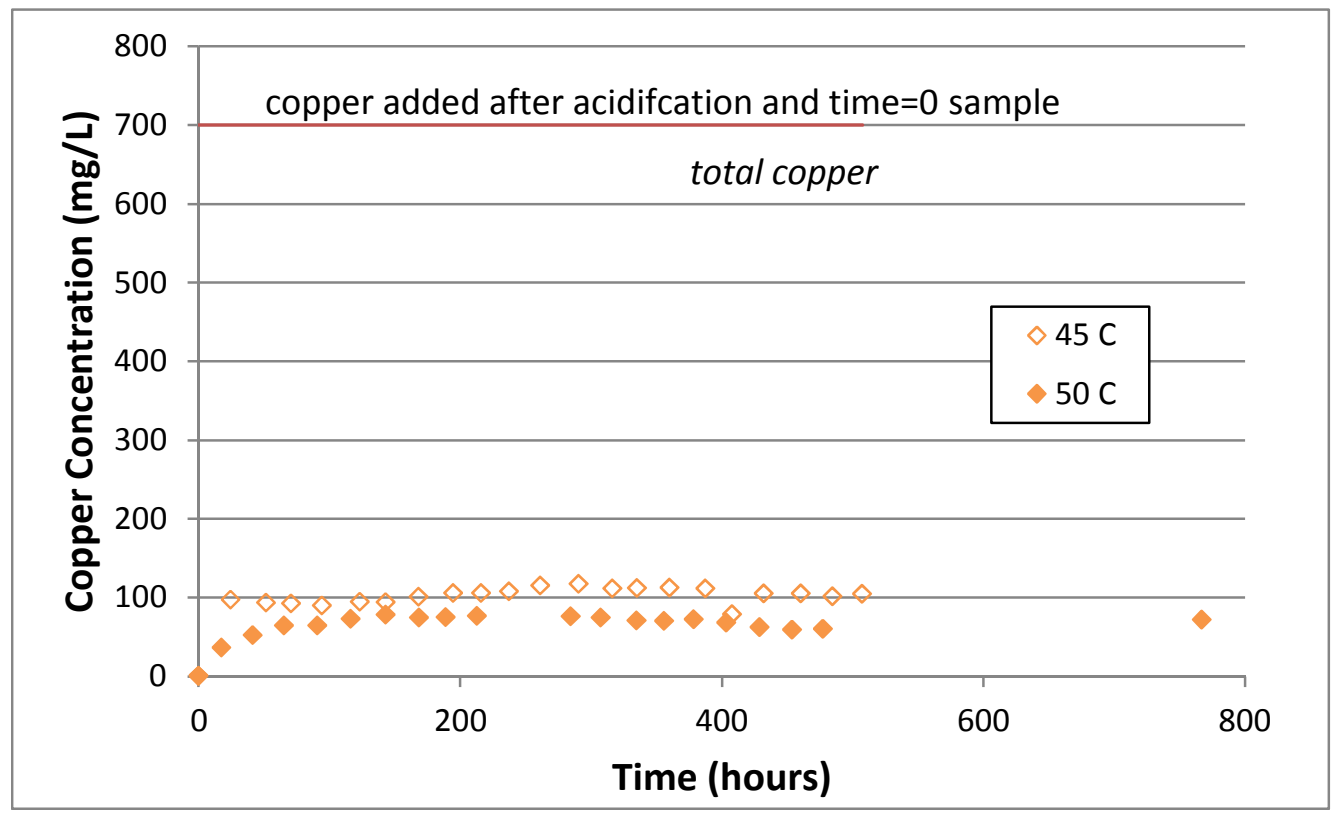

\subsubsection{Soluble Titanium Results}

The titanium in solution is monitored for the reasons outlined in Section 3.1.4. See Figure 53. The appropriate comparison data from section 3.5 (Test 1c) is included.

The titanium data indicate that the temperature range does have some effect on the titanium leaching into solution.

The previous investigation into the effect of temperature on titanium in solution (Section 3.3.4) showed different behavior in terms of temperature effect (none discernible) and timing of leaching (no leaching until halfway into the tests). The difference between these two sets of tests makes it problematic to draw an overall conclusion. Intuitively, one would expect that lower temperatures to reduce the rate of $\mathrm{H}_{2} \mathrm{O}_{2}$ consumption from the $\mathrm{CCPO}$ reaction, and thus could leave more $\mathrm{H}_{2} \mathrm{O}_{2}$ available for titanium leaching from MST. However, given that SRNL has noted a strong effect of copper concentration on 
titanium results (Section 3.9.4), there is probably no simple temperature-titanium relationship.

\section{Figure 53. Titanium Concentration Comparison at Varying Temperatures}

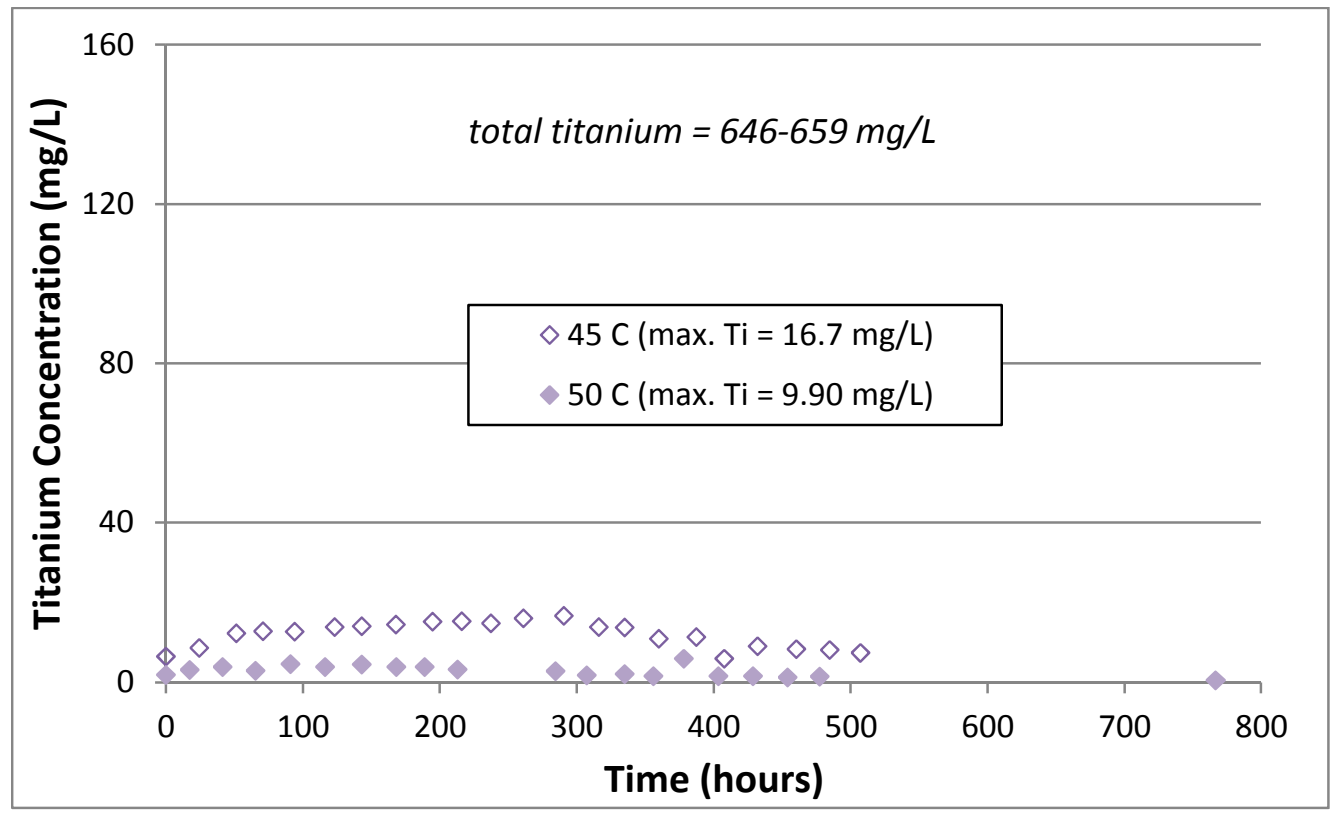

\subsubsection{Analysis of Residual Slurry After Reaction}

After each reaction was complete, the residues were isolated from each of the residual slurry after reaction. The amount of recovered material is dependent on the efficiency of slurry removal as varying amounts of solids were caked on the upper parts of the reactor, or difficult to remove.

From each bottle of residual slurry after reaction, well-mixed (in an attempt to ensure homogeneity) duplicate samples were analyzed via HPLC, ${ }^{\mathrm{g}}$ VOA and SVOA. Table 47 lists the HPLC results. The appropriate comparison data from section $3.5\left(50{ }^{\circ} \mathrm{C}\right.$, test $\left.1 \mathrm{c}\right)$ is included.

\footnotetext{
${ }^{g}$ SRNL modified the HPLC protocols as discussed in Appendix B in an attempt to lower the detection limits for the phenylboron compounds to $2-3 \mathrm{mg} / \mathrm{L}$. The lower detection limits were not generally achieved for the complex slurry composition.
} 
SRNL-STI-2012-00342

Revision 1

Table 47. HPLC Results from Residual Slurry After Reaction Analyses (mg/L) at Varying Temperatures

\begin{tabular}{|c|c|c|c|c|c|c|}
\hline Reaction & TPB & 3PB & 2PB & 1PB & Phenol & \% Destruction \\
\hline $45^{\circ} \mathrm{C}$ & $18(10 \%)$ & $<4$ & $<8$ & $<4$ & $<4$ & $99.86-99.87 \%$ \\
\hline $50^{\circ} \mathrm{C}$ & $16(0.00 \%)$ & $<10$ & $<10$ & $<10$ & $<10$ & $99.9-99.9 \%$ \\
\hline
\end{tabular}

The value in parentheses is the percent relative standard deviation $(\% \mathrm{RSD})$ for the $50{ }^{\circ} \mathrm{C}$ test. For the $45^{\circ} \mathrm{C}$ test, the value in parenthesis is the analytical uncertainty, as this is a single value. The "\% Destruction" column is the calculated percent destruction. The value is based on the mass of TPB added to the simulant slurries and calculation of the mass of TPB in the reactor residuals, after correcting for the mass of samples removed from the system during the reactions.

The residual slurry after reaction was also analyzed using VOA and SVOA. These two analytical methods are used to discern the presence of volatile or semi-volatile organic species. See Table 48. The values in parentheses are the \%RSD.

In the results column, values that are shaded indicate only one measured value with the other being a detection limit result. In this case, the values in parentheses are the analytical uncertainties. In the analyte column, shaded cells indicate the presence of that analyte is doubtful due to chemical conditions or contaminants. The "total organic residuals" are the sum of all the mid-range values of the detected analytes, less benzene and the analytes that are declared to be from contaminants. These results are not normalized to the starting volumes.

Only the detection of benzene is anticipated from the VOA analysis. Due to the type of oxidation chemistry is unlikely that any other organic compound with a high enough volatility would be created in this type of reaction.

There is very little benzene left in solution by time of sampling. Benzene is highly volatile and the reactions were maintained at higher than room temperature for extended time periods (the duration of the experiments). 
Table 48. VOA and SVOA Results for $45^{\circ} \mathrm{C}$ Reaction

\begin{tabular}{|c|c|}
\hline Analyte & Result (mg/L) \\
\hline [1,1-biphenyl]-3-amine & $76.5(0.92 \%)$ \\
\hline dimethyldiphenyldihydrodipyrrolopyridin & $59.0(24.0 \%)$ \\
\hline biphenyl & $86.5(4.09 \%)$ \\
\hline terphenyl & $33.5(27.4 \%)$ \\
\hline diphenyl ether & $31.0(4.56 \%)$ \\
\hline 2-nitro-N-nitrophenylbenzeneamine & $9.6-14.4$ \\
\hline Nitro-N-(nitrophenyl)benzeneamine & $10.4-15.6$ \\
\hline diphenylamine & $9.90(2.15 \%)$ \\
\hline quaterphenyl & $3.36-5.04$ \\
\hline 5-nitro-2-furfuryl alcohol & $4.08-6.12$ \\
\hline 4-benzylbiphenyl & $3.04-4.56$ \\
\hline 4-nitro-N-phenylbenzeneamine & $2.80(10.1 \%)$ \\
\hline diisooctyl adipate & $1.9(0.00 \%)$ \\
\hline azobenzene & $2.70(0.00 \%)$ \\
\hline 2-phenoxybiphenyl & $2.10(26.9 \%)$ \\
\hline diphenyl-(2-pyridyl)methanol & $1.20-1.80$ \\
\hline N, N-diphenylbenzeneamine & $0.88-1.32$ \\
\hline triphenylamine & $0.80-1.20$ \\
\hline 1,1-oxybis-4-phenoxybenzene & $0.80-1.20$ \\
\hline 1-pyrenecarboxaldehyde hydrazone & $6.4-9.6$ \\
\hline 5-nitro-2-furanmethanol & $5.52-8.28$ \\
\hline 4-methyl-1-heptanol & $3.76-5.64$ \\
\hline 2,3,4-trinitrodiphenylamine & $2.00-3.00$ \\
\hline butanal & $0.20(4.56 \%)$ \\
\hline isopropanol & $4.70(3.01 \%)$ \\
\hline acetone & $10.5(6.72 \%)$ \\
\hline Total organic residuals & 371 \\
\hline & \\
\hline &
\end{tabular}

The diisooctyl adipate is a known plasticizer and is likely a leachate from contact with a plastic surface. Of the residual organics remaining in the reactor, biphenyl or biphenyl derivatives are the most concentrated.

With respect to the other analytes remaining in the residual slurry after reaction, they are almost all partially degraded or functionalized aryl compounds. It is very difficult to locate any trend in these analytes. 
Increased reaction temperatures under these conditions resulted in greater concentrations of organic compound destruction (Test $1 \mathrm{c}$, the $50{ }^{\circ} \mathrm{C}$ reaction, generated $518 \mathrm{mg} / \mathrm{L}$ of residual organics). Given the large analytical uncertainties and the experimental variances, the different results between the two tests may not be significant.

The previous tests (Section 3.3.5) had showed the clear trend of higher temperatures leading to smaller amounts of residual organics, although these occurred at a different $\mathrm{pH}$ (11).

\subsection{6 pH Monitoring}

The $\mathrm{pH}$ was monitored during the reaction. See Figure 54.

All of the $\mathrm{pH}$ values trend towards at $\sim \mathrm{pH} 9$ for the duration of the reaction.

Figure 54. pH Readings for Varying Peroxide Addition Rates

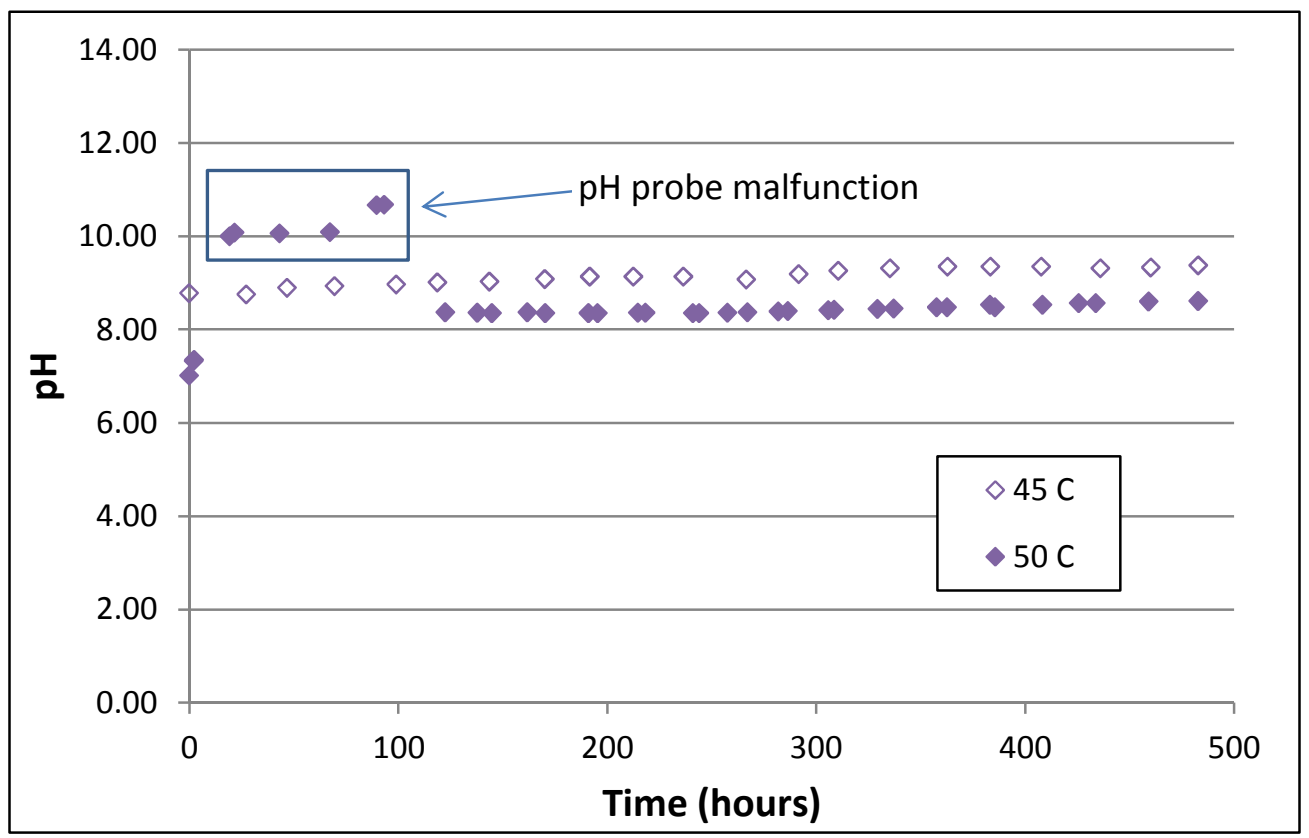

\subsubsection{Conclusion}

As with the previous temperature effect tests, it is noted that higher temperatures deliver faster TPB destruction. Higher temperatures under these reaction conditions also generated a higher concentration of residual organics. The degree and rate of TPB destruction between $45^{\circ} \mathrm{C}$ and $50{ }^{\circ} \mathrm{C}$ is comparable. 
The higher temperatures do not affect the copper concentrations in the filtrate. Presumably this is because the copper solubility is not primarily a function of temperature, but the form of the copper species being relatively insoluble in the alkaline simulant

\subsection{Further Effects of $\mathrm{H}_{2} \underline{\mathrm{O}}_{2}$ Addition Rates at Lower Copper Additions}

Previous tests examined the effects of a ten-fold increase in the $\mathrm{H}_{2} \mathrm{O}_{2}$ addition rate conducted at room temperature (see Section 3.2), as well as the effects of going to a fivefold increase (section 3.7). From subsequent tests, SRNL can derive further information on the effects of changing the $\mathrm{H}_{2} \mathrm{O}_{2}$ delivery rates.

This experiment (referred to as "Test $3 b^{\prime}$ ") used the same reaction vessel and temperature control $\left(50^{\circ} \mathrm{C}\right)$ as described in Section 3.5, with the exception that the added copper was targeted to $250 \mathrm{mg} / \mathrm{L}$. Other experimental details were as described in previous sections, except where as noted below. It was noted that the "prototypical mixing" is in fact, very poor compared to reactions performed in poly bottles with a magnetic stirrer. The agitation was insufficient to prevent a semi-stable floating solids mass. This may have effects in the overall reaction efficiency.

Hydrogen peroxide was added at $0.4 \mathrm{~mL} /$ hour $(2 \times)$.

The test continued for approximately 21 days. Filtrate samples were taken once per day. A total of 21 samples were removed for analysis by ICPES. As a comparison point, this reaction was compared against $2 \mathrm{~g}$ (section 3.8 ) which operated under similar conditions except for a $\mathrm{H}_{2} \mathrm{O}_{2}$ delivery rate of $0.2 \mathrm{~mL} /$ hour.

\subsubsection{Soluble Boron Results}

After the start of the $\mathrm{H}_{2} \mathrm{O}_{2}$ addition the boron in the filtrate samples increased over time. See Figure 55. In the figure the data from a related test (" $1 \mathrm{xH}_{2} \mathrm{O}_{2}$ ", Test $2 \mathrm{~g}$, section 3.8) are also included to show the effect of varying rates of $\mathrm{H}_{2} \mathrm{O}_{2}$ addition.

The reaction was halted after 475 hours, and the extent of boron dissolution associated with the acid hydrolysis and the peroxide oxidation reaction was calculated using the same methodology as in Section 3.1.1 (see Table 49). 
SRNL-STI-2012-00342

Revision 1

Table 49. Total TPB Destruction from Final Boron Results for Varying Peroxide Addition Rates

\begin{tabular}{|c|c|c|c|c|c|}
\hline \multicolumn{2}{|c|}{ Destruction by Acid } & \multicolumn{2}{c|}{ Destruction by $\mathrm{H}_{2} \mathrm{O}_{2}$} & \multicolumn{2}{c|}{ Total Destruction } \\
\hline $1 \times \mathrm{H}_{2} \mathrm{O}_{2}$ & $2 \times \mathrm{H}_{2} \mathrm{O}_{2}$ & $1 \times \mathrm{H}_{2} \mathrm{O}_{2}$ & $2 \times \mathrm{H}_{2} \mathrm{O}_{2}$ & $1 \times \mathrm{H}_{2} \mathrm{O}_{2}$ & $2 \times \mathrm{H}_{2} \mathrm{O}_{2}$ \\
\hline $12.3-15.0 \%$ & $11.2-13.7 \%$ & $72.0-91.2 \%$ & $76.8-96.8 \%$ & $85.7-105 \%$ & $89.3-109 \%$ \\
\hline
\end{tabular}

By $\sim 111$ hours the TPB destruction is approximately complete. This is somewhat slower compared to the most equivalent previous reaction (Test $2 \mathrm{~g}$ ), which appeared to complete in about half the time. The previous comparisons (Section 3.7) also seem to indicate that the rate of reaction is not strongly correlated to the rate of $\mathrm{H}_{2} \mathrm{O}_{2}$ addition, under the tested conditions.

Figure 55. Boron Concentration Results Comparison at Varying Peroxide Addition Rates

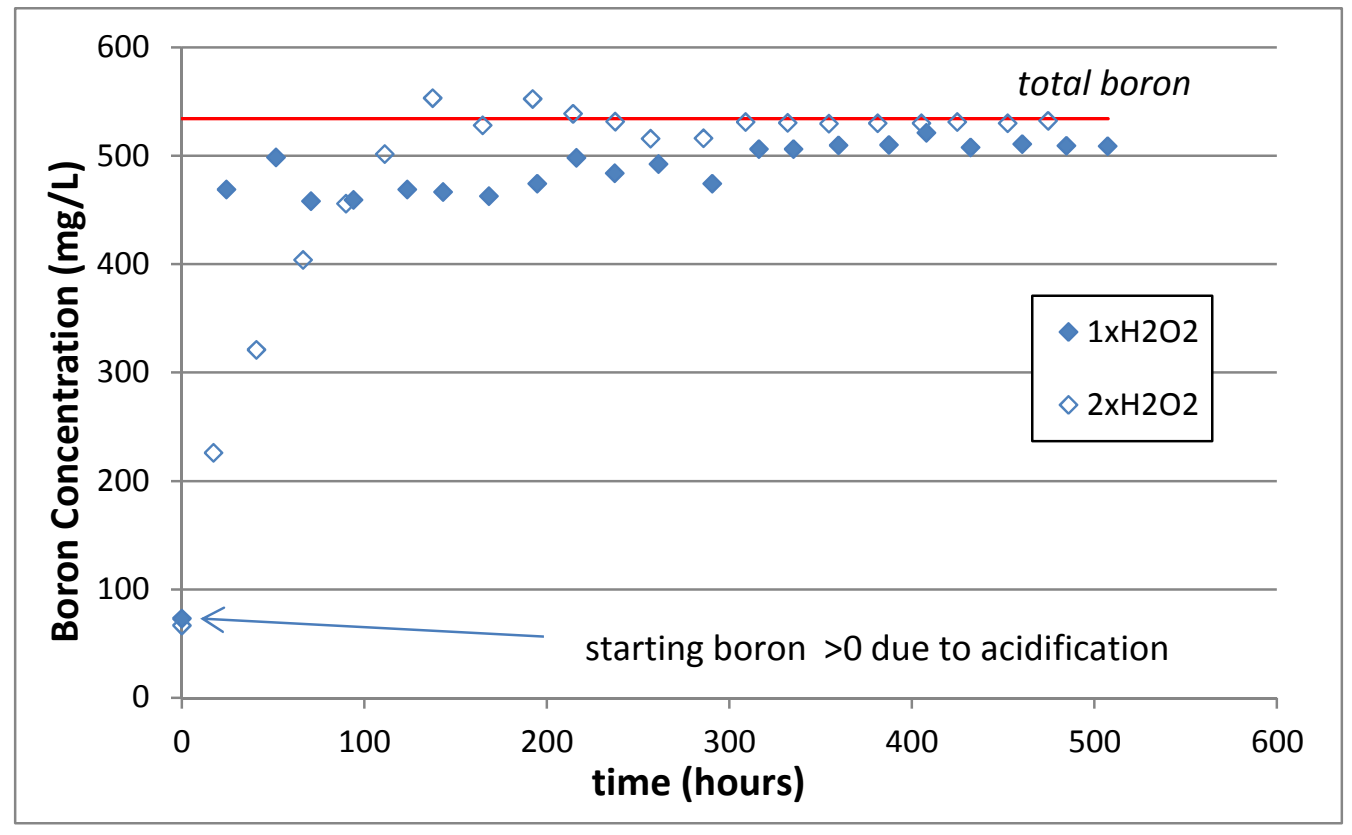

\subsubsection{Soluble Potassium Results}

After the start of the $\mathrm{H}_{2} \mathrm{O}_{2}$ addition the potassium in the filtrate samples increased over time (see Figure 56). In the figure data from related tests is also included to show the effect of varying rates of $\mathrm{H}_{2} \mathrm{O}_{2}$ addition. 
The reaction was halted after 475 hours, and the extent of potassium dissolution associated with the acid hydrolysis and the peroxide oxidation reaction was calculated using the same methodology as in Section 3.1.1 (see Table 50).

Figure 56. Potassium Concentration Results Comparison at Varying Peroxide Addition Rates

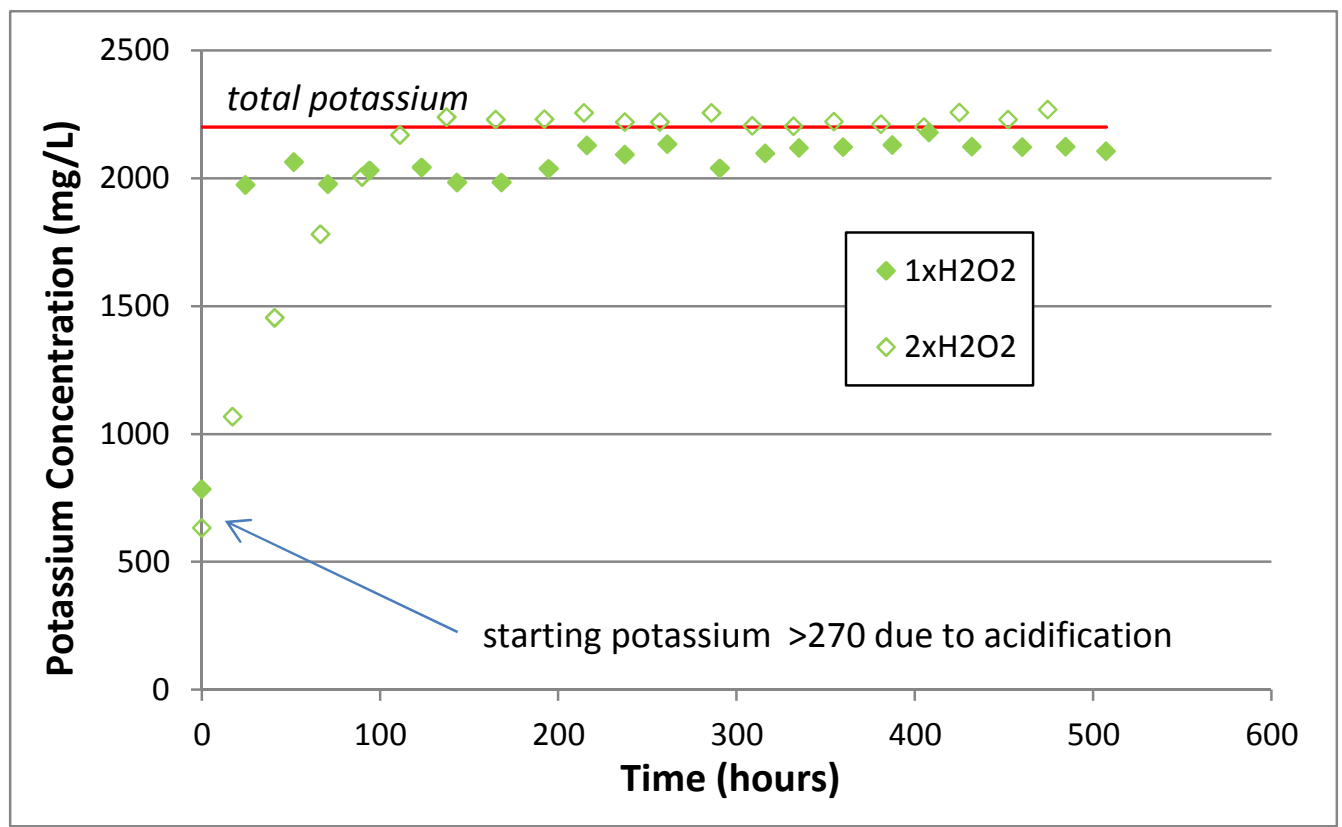

Table 50. Total TPB Destruction from Potassium Results at Varying Peroxide Addition Rates

\begin{tabular}{|c|c|c|c|c|c|}
\hline \multicolumn{2}{|c|}{ Destruction by Acid } & \multicolumn{2}{c|}{ Destruction by $\mathrm{H}_{2} \mathrm{O}_{2}$} & \multicolumn{2}{c|}{ Total Destruction } \\
\hline $1 \times \mathrm{H}_{2} \mathrm{O}_{2}$ & $2 \times \mathrm{H}_{2} \mathrm{O}_{2}$ & $1 \times \mathrm{H}_{2} \mathrm{O}_{2}$ & $2 \times \mathrm{H}_{2} \mathrm{O}_{2}$ & $1 \times \mathrm{H}_{2} \mathrm{O}_{2}$ & $2 \times \mathrm{H}_{2} \mathrm{O}_{2}$ \\
\hline $22.4 \%-30.5 \%$ & $15.4-21.9 \%$ & $57.0-80.3 \%$ & $70.7-94.7 \%$ & $84.2-106 \%$ & $89.8-113 \%$ \\
\hline
\end{tabular}

As with the boron data, the TPB destruction is complete by $\sim 110$ hours.

As with the boron data, while both reactions easily reached completion, the $2 \mathrm{xH}_{2} \mathrm{O}_{2}$ test took $\sim 2 \mathrm{x}$ as long to do so. 


\subsubsection{Soluble Copper Results}

After the start of the $\mathrm{H}_{2} \mathrm{O}_{2}$ addition the copper in the filtrate samples quickly increased near the start of the reaction, then slowly decreased. See Figure 57.

\section{Figure 57. Soluble Copper Concentration Results for Varying Peroxide Addition Rates}

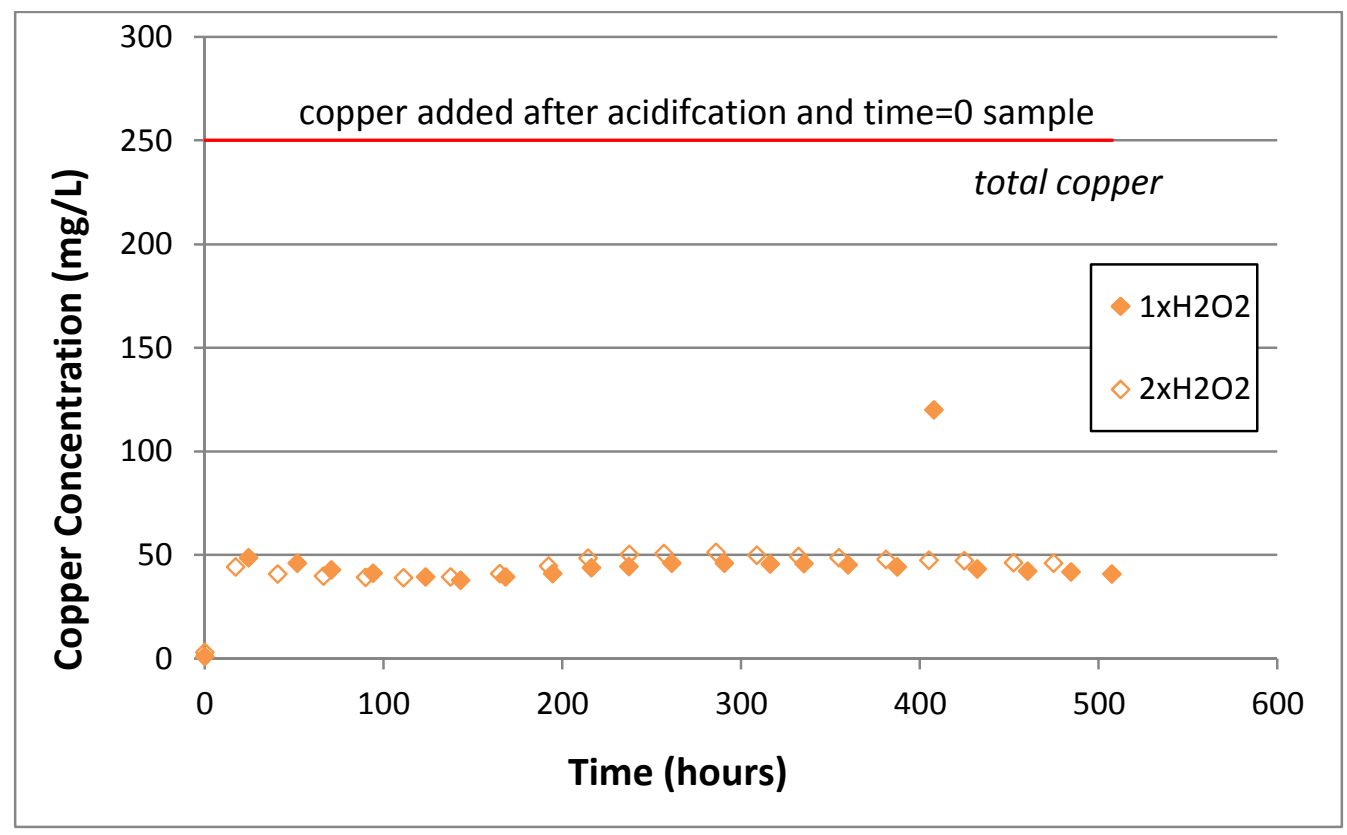

The copper results show no effective differences between the two comparable tests.

\subsubsection{Soluble Titanium Results}

The titanium concentration in solution is monitored for the reasons outlined in Section 3.1.4. See Figure 58.

The results between the two tests indicate a trend towards higher $\mathrm{H}_{2} \mathrm{O}_{2}$ delivery rates provided higher initial titanium into solution. 
Figure 58. Titanium Concentration Results for Varying Peroxide Addition Rates

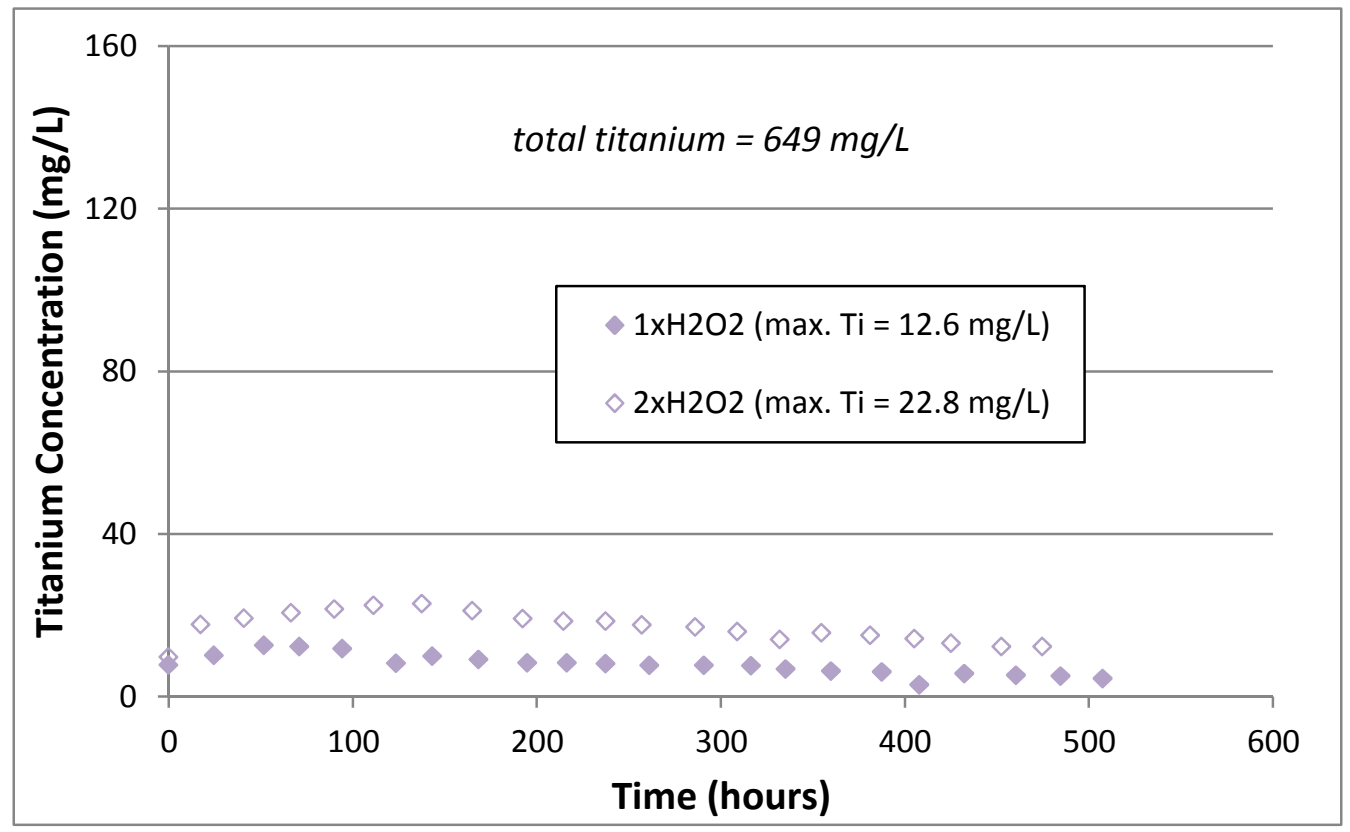

\subsubsection{Analysis of Residual Slurry After Reaction}

After the reaction was complete, the residual slurry after reaction were removed. The amount of recovered material is dependent on the efficiency of slurry removal.

From the bottle of residual slurry after reaction, well-mixed (in an attempt to ensure homogeneity) duplicate samples were analyzed via HPLC, VOA and SVOA. Table 51 lists the HPLC results, along with the comparable data (Test $2 \mathrm{~g}$ ) from Section 3.8. 
SRNL-STI-2012-00342

Revision 1

Table 51. HPLC Results from Residual Slurry After Reaction Analyses for Varying Peroxide Addition Rates

\begin{tabular}{|c|c|c|c|c|c|c|}
\hline Reaction & TPB & 3PB & 2PB & 1PB & Phenol & \% Destruction \\
\hline $1 \times \mathrm{H}_{2} \mathrm{O}_{2}$ & $<4$ & $<4$ & $<4$ & $<4$ & $<4$ & $>99.97 \%$ \\
\hline $2 \times \mathrm{H}_{2} \mathrm{O}_{2}$ & $<4$ & $<4$ & $<4$ & $<4$ & $<4$ & $>99.97 \%$ \\
\hline
\end{tabular}

The "\% Destruction" column is the calculated percent destruction. The value is based on the mass of TPB added to the simulant slurries and calculation of the mass of TPB in the residual slurry after reaction, after correcting for the mass of samples removed from the system during the reactions.

Given the very rapid destruction indicated by the boron and potassium data, less than detectable concentrations of all the HPLC analytes were anticipated.

Samples of the residual slurry after reaction were analyzed using VOA and SVOA (see Table 52). The values in parentheses are the \%RSD. In the results column, values that are shaded indicate only one measured value with the other being a detection limit result. In this case, the values in parentheses are the analytical uncertainties. In the analyte column, shaded cells indicate the presence of that analyte is doubtful due to chemical conditions or contaminants. The "total organic residuals" are the sum of all the midrange values of the detected analytes, less benzene and the analytes that are declared to be from contaminants. These results are not normalized to the beginning volumes.

Table 52. VOA and SVOA Results for Test 3b

\begin{tabular}{|c|c|}
\hline Analyte & Result (mg/L) \\
\hline terphenyl & $65.0(28.3 \%)$ \\
\hline biphenyl & $58.0(21.9 \%)$ \\
\hline 5-nitro-2-furanmethanol & $21.5(3.29 \%)$ \\
\hline diisooctyl adipate & $19.5(3.63 \%)$ \\
\hline quaterphenyl & $13.6-20.4$ \\
\hline diphenyl ether & $3.40(23.2 \%)$ \\
\hline 2-nitrophenol & $12.8-19.2$ \\
\hline benzoic acid & $5.84-8.76$ \\
\hline [1,1]-biphenyl-2-amine & $2.16-3.24$ \\
\hline N-pentylidene-1butanamine & $1.92-2.88$ \\
\hline 2-phenoxy-1,1-biphenyl & $1.52-2.28$ \\
\hline triphenylmethane & $1.12-1.68$ \\
\hline butanal & $0.27(0.00 \%)$ \\
\hline Total organic residuals & 181 \\
\hline
\end{tabular}


The diisooctyl adipate is a known plasticizer and is more than likely leachate from contact with a plastic surface such as the bottle than contained the slurry prior to the experiment or from the analytical method equipment.

The increased $\mathrm{H}_{2} \mathrm{O}_{2}$ delivery in this reaction (Test $3 \mathrm{~b}$ ) provided approximately the same concentration of residual organics as in the comparable test (Test $2 \mathrm{~g}, 217 \mathrm{mg} / \mathrm{L}$ ). Given the small difference it is difficult to declare whether the incremental change in $\mathrm{H}_{2} \mathrm{O}_{2}$ delivery provided for superior results.

\subsection{6 pH Monitoring}

The $\mathrm{pH}$ was monitored during the reaction. See Figure 59.

All of the $\mathrm{pH}$ values remain at $\sim \mathrm{pH} 9$ for the duration of the reaction.

Figure 59. pH Readings for Varying Peroxide Addition Rates

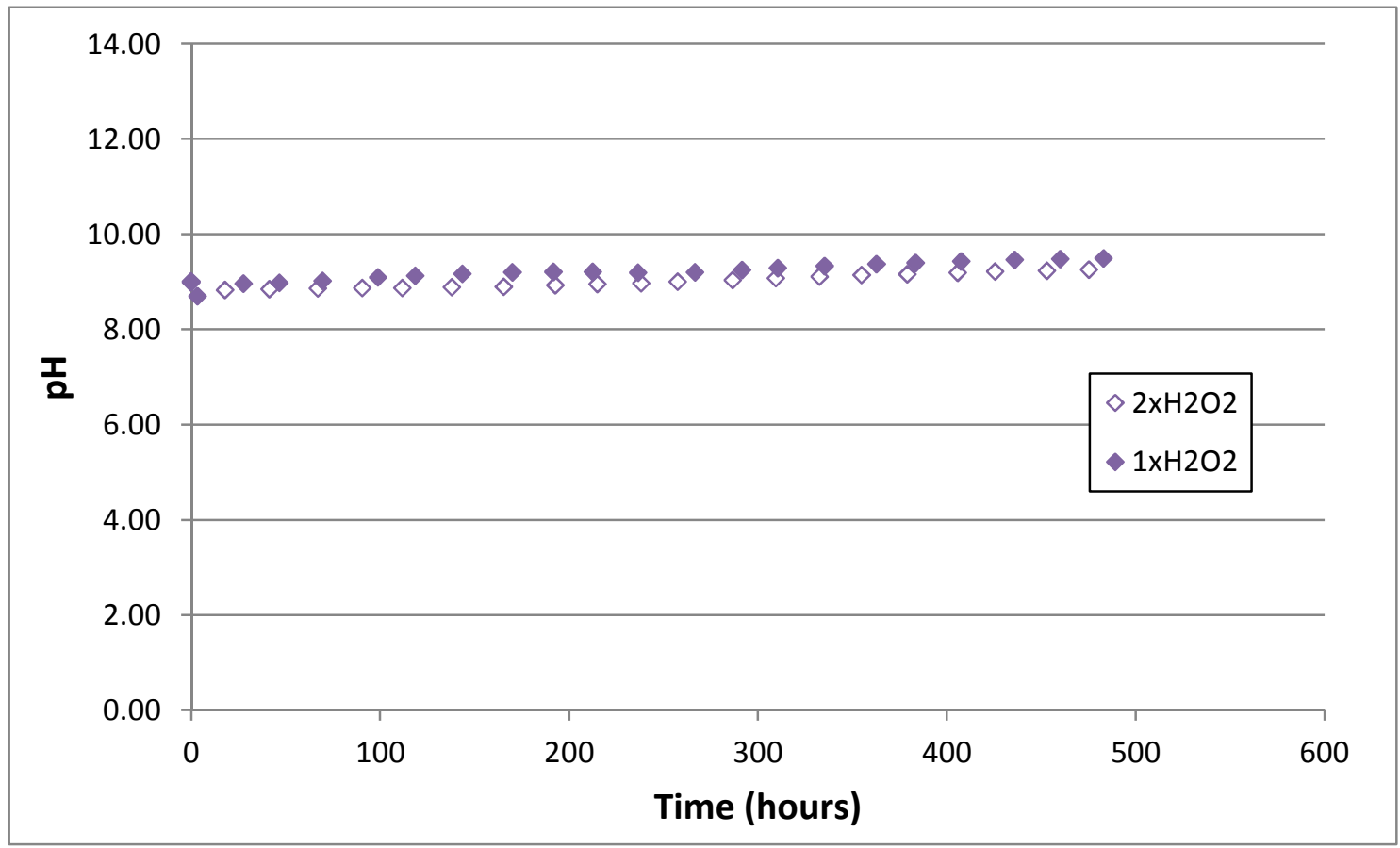




\subsubsection{Conclusion}

Test $3 \mathrm{~b}$ showed complete TPB destruction within 5 days. It appears that the increased $\mathrm{H}_{2} \mathrm{O}_{2}$ delivery ( $2 \times$ nominal rates) did not provide an improvement in time required to reach complete TPB destruction, compared to a similar test $(2 \mathrm{~g})$ that used a $1 \times$ nominal rate. It is also difficult to declare that Test $3 b$ provided a reduction in the residual organics concentration.

The additional $\mathrm{H}_{2} \mathrm{O}_{2}$ did not increase the final copper soluble concentrations.

The titanium data suggests that under the test conditions, increased rates of $\mathrm{H}_{2} \mathrm{O}_{2}$ addition can lead to reduced MST leaching. It may be that with the reduced copper loading ( $250 \mathrm{mg} / \mathrm{L}$ ) compared to most other tests, the increased $\mathrm{H}_{2} \mathrm{O}_{2}$ delivery does not provide benefits other than slightly reduced levels of titanium in solution.

\subsection{Duplicate Reaction of $\mathrm{pH} 9$ Test}

In section 3.5, SRNL performed a test at lower $\mathrm{pH}$ conditions of 9. At a customer request, SRNL performed a duplicate test (referred to as "Test $2 \mathrm{~d}$ "), with the same conditions as outlined in section 3.5 for the $\mathrm{pH} 9$ test. This test was performed to ensure that this reaction could be performed in a reproducible manner.

This experiment (referred to as "Test 2d") used the same reaction vessel and temperature control $\left(50^{\circ} \mathrm{C}\right)$ as described in the $\mathrm{pH} 9$ test in Section 3.5. Other experimental details were as described in previous sections, except where as noted below. It was noted that the "prototypical mixing" is in fact, very poor compared to reactions performed in poly bottles with a magnetic stirrer. The agitation was insufficient to prevent a semi-stable floating solids mass. This may have effects in the overall reaction efficiency.

Hydrogen peroxide was added at $0.2 \mathrm{~mL} /$ hour $(1 \times)$.

The test operated approximately 22 days. Filtrate samples were taken once per day. A total of 22 samples were removed for analysis by ICPES.

\subsubsection{Soluble Boron Results}

After the start of the $\mathrm{H}_{2} \mathrm{O}_{2}$ addition the boron in the filtrate samples increased over time. See Figure 60. "Original" refers to the original pH 9 test outlined in section 3.5. "Duplicate" is the new test described in this section. 


\section{Figure 60. Boron Concentration Comparison between Duplicate pH 9 Tests}

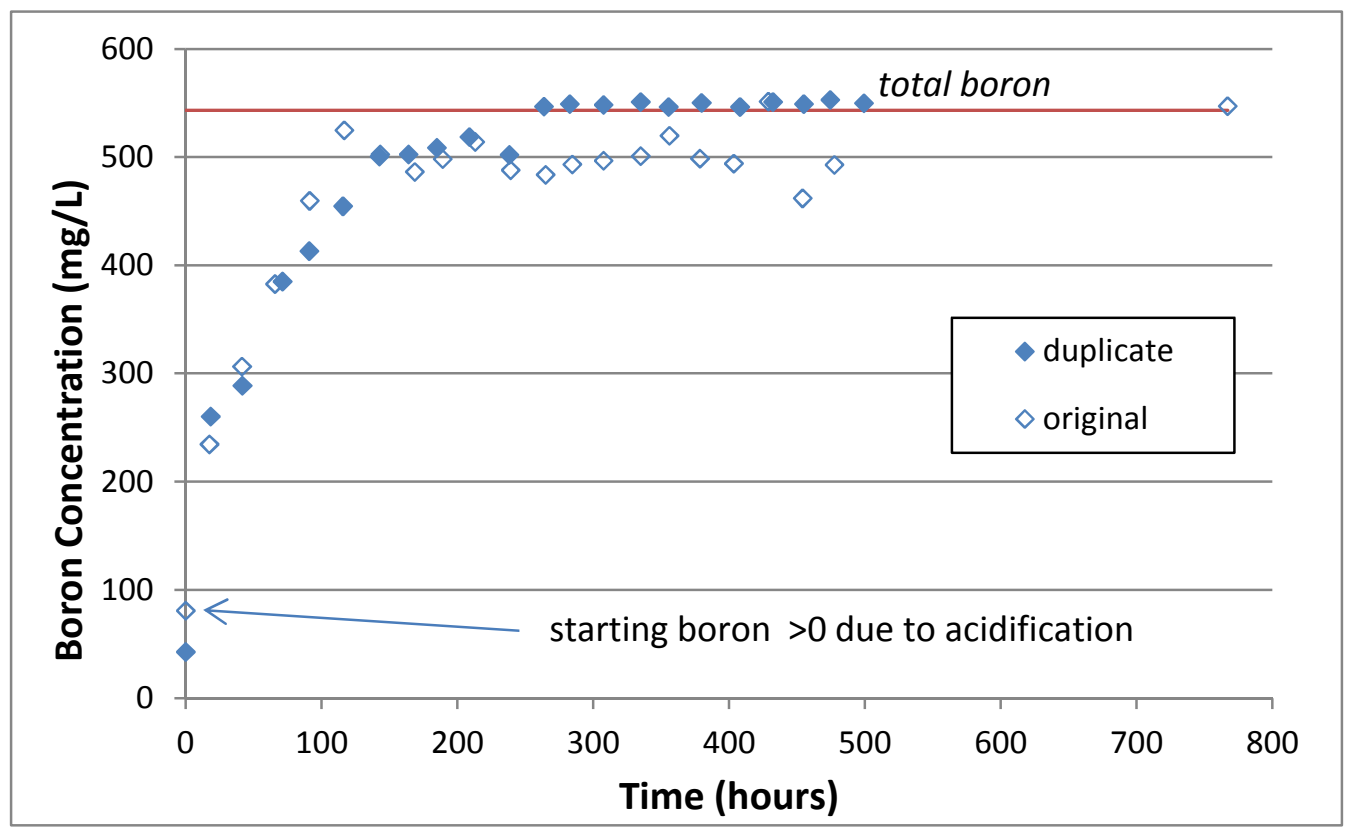

The reaction was halted after 499 hours, and the extent of boron dissolution associated with the acid hydrolysis and peroxide oxidation reactions was calculated using the same methodology as in Section 3.1.1 (see Table 53).

Table 53. Total TPB Destruction from Final Boron Results between Duplicate pH 9 Tests

\begin{tabular}{|c|c|c|c|c|c|}
\hline \multicolumn{2}{|c|}{ Destruction by Acid } & \multicolumn{2}{c|}{ Destruction by $\mathrm{H}_{2} \mathrm{O}_{2}$} & \multicolumn{2}{c|}{ Total Destruction } \\
\hline original & duplicate & original & duplicate & original & duplicate \\
\hline $14.9-18.2 \%$ & $7.1-8.7 \%$ & $64.4-82.7 \%$ & $84.7-105 \%$ & $81.1-99.2 \%$ & $92.6-113 \%$ \\
\hline
\end{tabular}

The boron data shows that the duplicate reaction provided a lesser degree of destruction during $\mathrm{pH}$ adjustment, but a higher degree of CCPO destruction.

\subsubsection{Soluble Potassium Results}

As in previous experiments, the potassium in solution was measured as an indicator of organic destruction. After the start of the $\mathrm{H}_{2} \mathrm{O}_{2}$ addition the potassium in the filtrate samples increased over time. See Figure 54. 
The reaction was halted after 499 hours, and the extent of potassium dissolution associated with the acid hydrolysis and peroxide oxidation reactions was calculated using the same methodology as in Section 3.1.1 (see Table 54).

Table 54. Total TPB Destruction from Final Potassium Results between Duplicate pH 9 Tests

\begin{tabular}{|c|c|c|c|c|c|}
\hline \multicolumn{2}{|c|}{ Destruction by Acid } & \multicolumn{2}{c|}{ Destruction by $\mathrm{H}_{2} \mathrm{O}_{2}$} & \multicolumn{2}{c|}{ Total Destruction } \\
\hline original & duplicate & original & duplicate & original & duplicate \\
\hline $39.4-51.3 \%$ & $15.8-22.5 \%$ & $64.3-94.5 \%$ & $75.9-101 \%$ & $111-139 \%$ & $95.5-120 \%$ \\
\hline
\end{tabular}

Figure 61. Potassium Concentration Comparison Between Duplicate pH 9 Tests

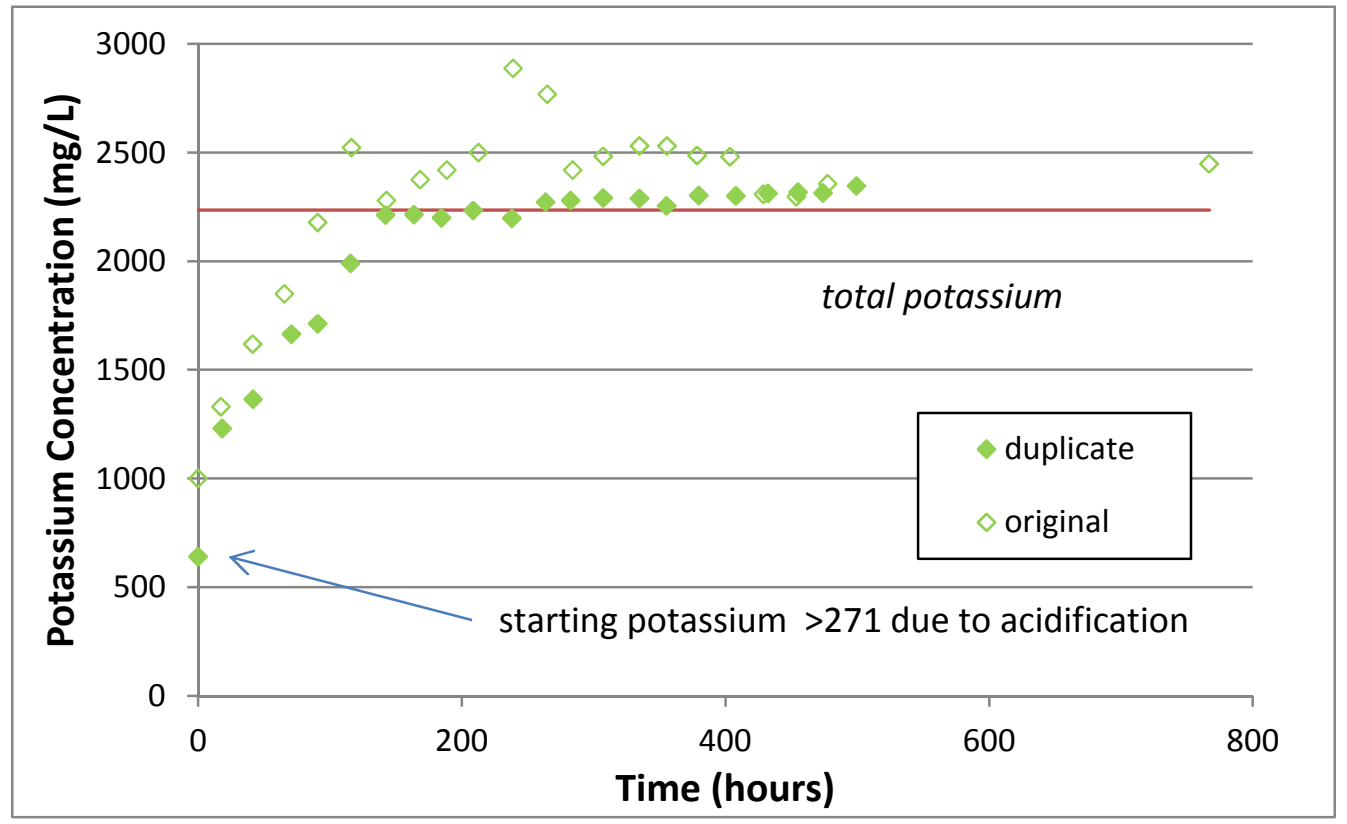

The potassium data appear to indicate a slightly faster completion time for the original test, probably due to the greater extent of destruction during the $\mathrm{pH}$ adjustment. 


\subsubsection{Soluble Copper Results}

The copper concentrations in the filtrate were monitored for the reasons outlined in Section 3.1.3. After the start of the $\mathrm{H}_{2} \mathrm{O}_{2}$ addition the copper in the filtrate samples slowly increased over time. See Figure 62.

These two reactions provide the same approximate results. Copper solubility averages $\sim 100 \mathrm{mg} / \mathrm{L}$ over the duration of the experiment, after a gradual ramp up to those concentrations.

Figure 62. Soluble Copper Concentration Comparison between Duplicate pH 9 Tests

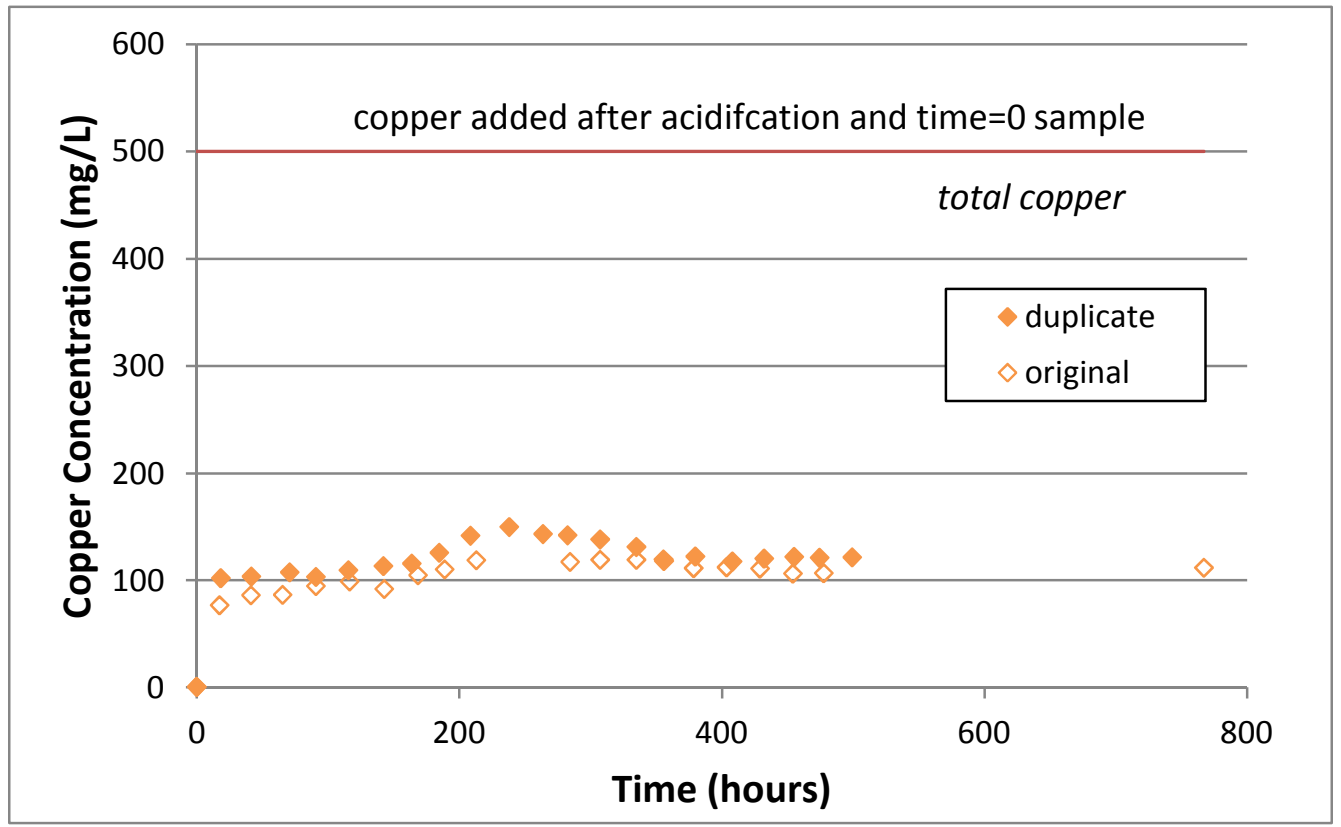

\subsubsection{Soluble Titanium Results}

The titanium concentration in solution is monitored for the reasons outlined in Section 3.1.4. See Figure 63.

The titanium data indicate that the duplicate reaction showed slightly higher titanium values for most of the test, but not greatly so. In all cases, the titanium concentrations were below $20 \mathrm{mg} / \mathrm{L}$. 


\section{Figure 63. Titanium Concentration Comparison between Duplicate pH 9 Tests}

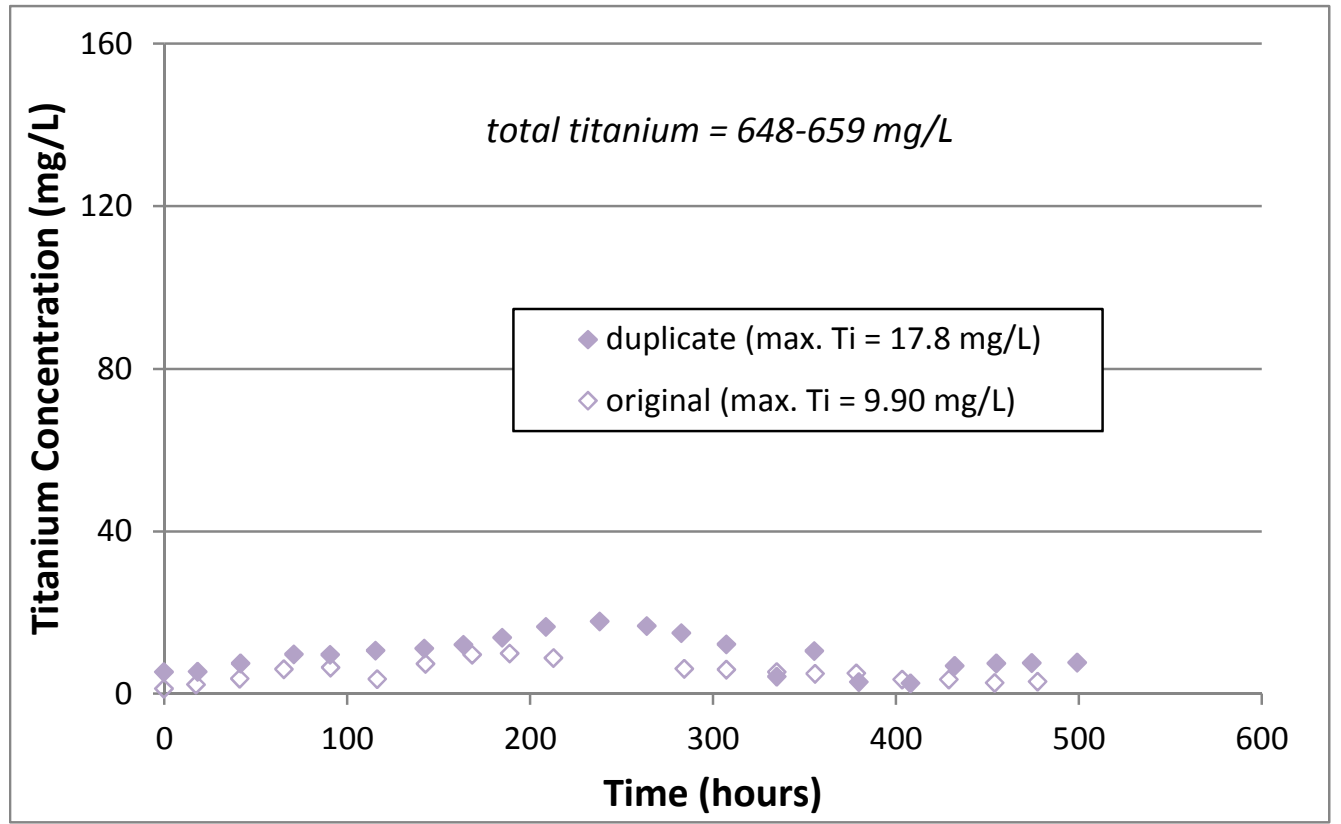

\subsubsection{Analysis of Residual Slurry After Reaction}

After the reaction was complete, the reactor bottom was removed. The amount of recovered material is dependent on the efficiency of slurry removal.

From the bottle of reactor residuals, well-mixed (in an attempt to ensure homogeneity) duplicate samples were analyzed via HPLC, VOA and SVOA. Table 55 lists the HPLC results.

Table 55. HPLC Results from Residual Slurry After Reaction Analyses (mg/L)

\begin{tabular}{|c|c|c|c|c|c|c|}
\hline Reaction & TPB & 3PB & 2PB & 1PB & Phenol & \% Destruction \\
\hline original & $<10$ & $<10$ & $<10$ & $<10$ & $<10$ & $>99.9 \%$ \\
\hline duplicate & $<4$ & $<4$ & $<4$ & $<4$ & $<4$ & $>99.97 \%$ \\
\hline
\end{tabular}

The "\% Destruction" column is the calculated percent destruction. The value is based on the mass of TPB added to the simulant slurries and calculation of the mass of TPB in the residual slurry after reaction, after correcting for the mass of samples removed from the system during the reactions.

Given the very rapid destruction indicated by the boron and potassium data, less than detectable levels of all the HPLC analytes were anticipated. 
Samples of the residual slurry after reaction were analyzed using VOA and SVOA (see Table 56). The values in parentheses are the \%RSD. In the results column, values that are shaded indicate only one measured value with the other being a detection limit result. In this case, the values in parentheses are the analytical uncertainties. In the analyte column, shaded cells indicate the presence of that analyte is doubtful due to chemical conditions or contaminants. The "total organic residuals" are the sum of all the midrange values of the detected analytes, less benzene and the analytes that are declared to be from contaminants. The "total organic residuals" are the sum of all the detected analytes, less benzene and the analytes that are considered to be from contaminants. These results are not normalized to the beginning volumes.

Table 56. VOA and SVOA Results for Test 2d

\begin{tabular}{|c|c|}
\hline Analyte & Result (mg/L) \\
\hline [1,1-biphenyl]-3-amine & $24.0(5.89 \%)$ \\
\hline dimethyldiphenyldihydrodipyrrolopyridin & $44.5(7.95 \%)$ \\
\hline biphenyl & $19.0(22.3 \%)$ \\
\hline terphenyl & $9.5(52.1 \%)$ \\
\hline diphenyl ether & $8.4(8.42 \%)$ \\
\hline diphenylamine & $2.6(8.32 \%)$ \\
\hline 2-nitro-N-(4-nitrophenyl)benzeneamine & $4.24-6.36$ \\
\hline diisooctyl adipate & $13(0.00 \%)$ \\
\hline 1,2-dintrobenzene & $1.6-2.4$ \\
\hline 4-benzylbiphenyl & $0.96-1.44$ \\
\hline N, N-diphenylbenzeneamine & $2.3(67.6 \%)$ \\
\hline 5-nitro-2-furanmethanol & $11.2(23.5 \%)$ \\
\hline 2,4-dinitro-N-phenyl-benzeneamine & $2.72-4.08$ \\
\hline butanal & $0.10(12.3 \%)$ \\
\hline acetone & $1.1(0.00 \%)$ \\
\hline Total organic residuals & 135 \\
\hline
\end{tabular}

As for the other analytes left in the residual slurry after reaction, they are almost all partially degraded or functionalized aryl compounds. It is very difficult to define any trend in these analytes.

The original $\mathrm{pH} 9$ test detailed in section 3.5 .5 gave $199 \mathrm{mg} / \mathrm{L}$ of residual organics, compared to the current result of $135 \mathrm{mg} / \mathrm{L}$. The residual organics results for the two tests are comparable, with the difference attributable to the limits of test reproducibility. 


\subsection{6 pH Monitoring}

$\mathrm{pH}$ was monitored during the reaction (see Figure 64).

As with the original $\mathrm{pH} 9$ test, the $\mathrm{pH}$ in both reactions trended towards a final $\mathrm{pH}$ of $\sim 9$.

Figure 64. pH Readings between Duplicate pH 9 Tests

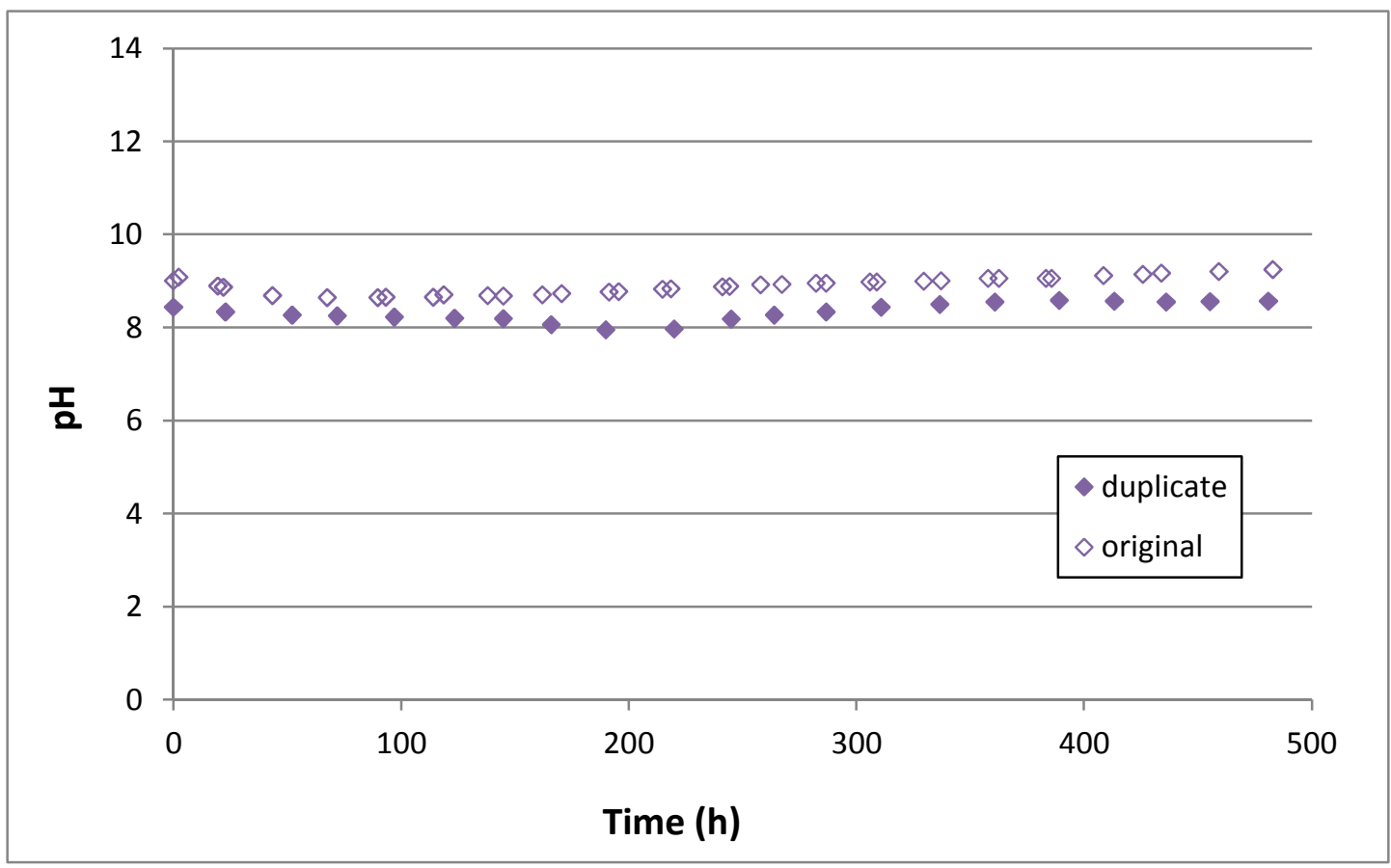

\subsubsection{Conclusion}

Both the original and duplicate $\mathrm{pH} 9$ tests provide approximately similar results, with TPB destruction completion times of 5-6 days, leaving 135-199 mg/L of residual organics after $\sim 20$ days.

\subsection{Duplicate Reaction of $\mathrm{pH} 7$ Test}

Section 3.5 discusses the test performed at lower $\mathrm{pH}$ conditions of 7. At a customer request, SRNL performed a new test (referred to as "Test 2e"), with the same conditions as outlined in Section 3.5 for the $\mathrm{pH} 7$ test.

This experiments (referred to as "Test 2e") used the same reaction vessel and temperature control $\left(50^{\circ} \mathrm{C}\right)$ as described in the $\mathrm{pH} 7$ test in Section 3.5. Other experimental details were as described in previous sections, except where as noted below. It was noted that the "prototypical mixing" is in fact, very poor compared to reactions performed in poly 
bottles with a magnetic stirrer. The agitation was insufficient to prevent a semi-stable floating solids mass. This may have effects in the overall reaction efficiency.

Hydrogen peroxide was added at $0.2 \mathrm{~mL} /$ hour $(1 \times)$.

The test continued for approximately 22 days. Filtrate samples were taken once per day. A total of 22 samples were removed for analysis by ICPES.

\subsubsection{Soluble Boron Results}

After the start of the $\mathrm{H}_{2} \mathrm{O}_{2}$ addition the boron in the filtrate samples increased over time. See Figure 65. "Original" refers to the original pH 7 test outlined in Section 3.5. "Duplicate" is the new test described in this section.

\section{Figure 65. Boron Concentration Comparison between Duplicate pH 7 Tests}

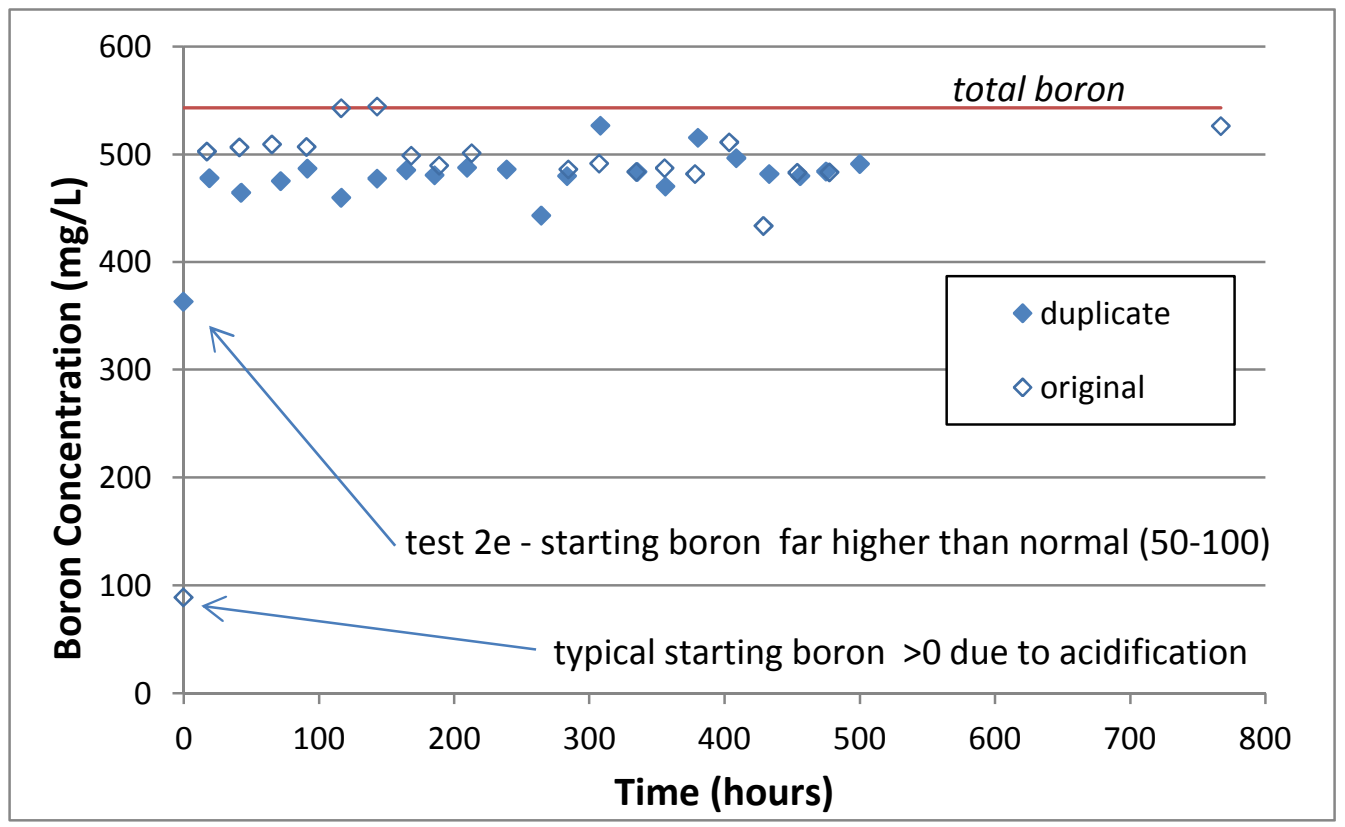

The reaction was halted after 500 hours, and the extent of boron dissolution associated with the acid hydrolysis and peroxide oxidation reactions were calculated using the same methodology as in Section 3.1.1 (see Table 57). 
SRNL-STI-2012-00342

Revision 1

\section{Table 57. Total TPB Destruction from Final Boron Results between Duplicate pH 7 Tests}

\begin{tabular}{|c|c|c|c|c|c|}
\hline \multicolumn{2}{|c|}{ Destruction by Acid } & \multicolumn{2}{c|}{ Destruction by $\mathrm{H}_{2} \mathrm{O}_{2}$} & \multicolumn{2}{c|}{ Total Destruction } \\
\hline original & duplicate & original & duplicate & original & duplicate \\
\hline $14.9-18.2 \%$ & $62.2-76.1 \%$ & $64.4-82.7 \%$ & $12.8-36.0 \%$ & $81.1-99.2 \%$ & $84.2-103 \%$ \\
\hline
\end{tabular}

The duplicate reaction shows a much higher destruction from $\mathrm{pH}$ adjustment than any other test, including the original experiment. There are no experimental observations to explain this, and SRNL is uncertain of the reason.

\subsubsection{Soluble Potassium Results}

As in previous experiments, the potassium in solution was measured as an indicator of organic destruction. After the start of the $\mathrm{H}_{2} \mathrm{O}_{2}$ addition the potassium in the filtrate samples increased over time. See Figure 66.

Figure 66. Potassium Concentration Comparison between Duplicate pH 7 Tests

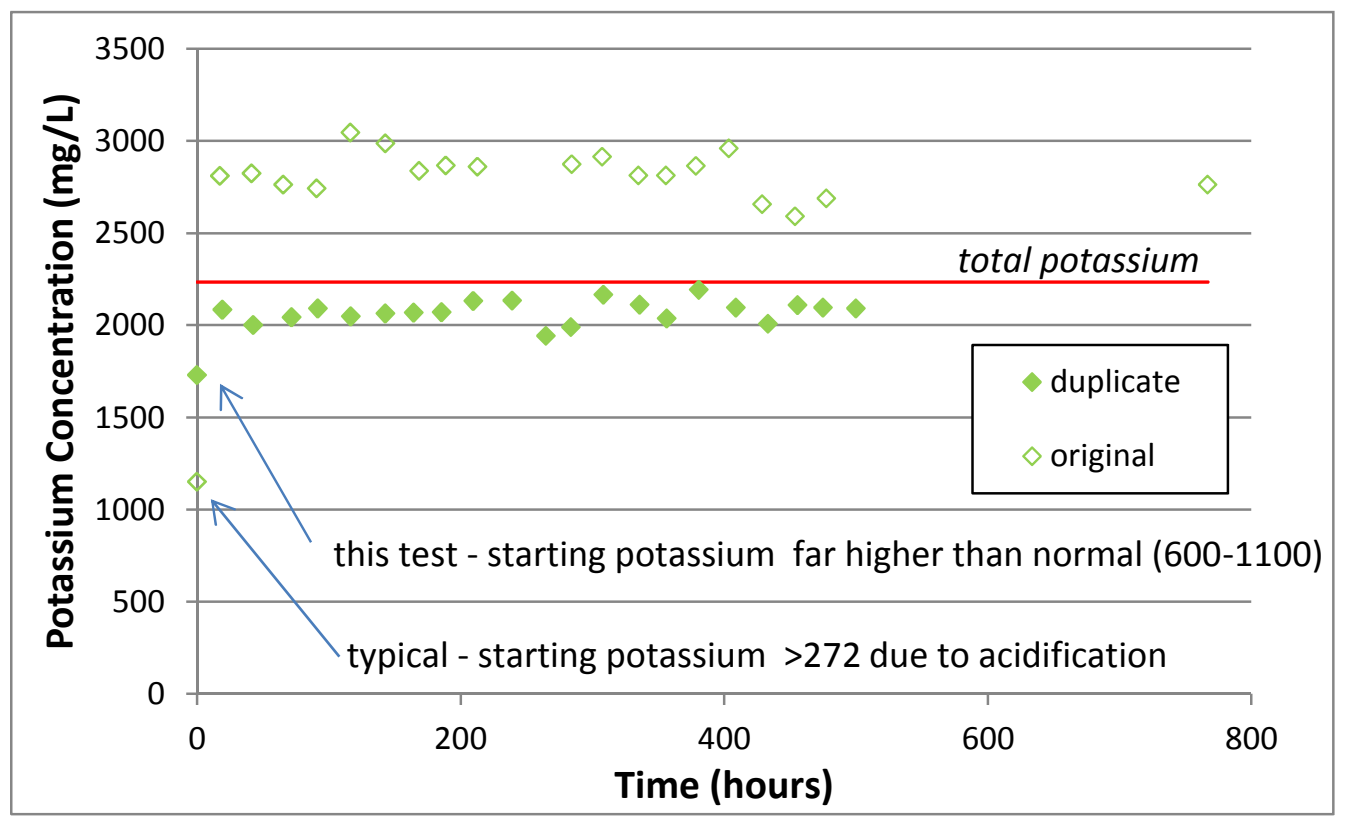

The potassium data indicate the same highly increased destruction as a function of the $\mathrm{pH}$ adjustment. 
In the original experiment, the $\mathrm{pH}$ probe broke during operations, which presumably caused an influx of potassium-containing solution, which in turn biased the potassium results high (see Section 3.5.2).

The reaction was halted after 500 hours, and the extent of potassium dissolution associated with the acid hydrolysis and peroxide oxidation reactions were calculated using the same methodology as in Section 3.1.1 (see Table 58).

Table 58. Total TPB Destruction from Final Potassium Results between Duplicate pH 7 Tests

\begin{tabular}{|c|c|c|c|c|c|}
\hline \multicolumn{2}{|c|}{ Destruction by Acid } & \multicolumn{2}{c|}{ Destruction by $\mathrm{H}_{2} \mathrm{O}_{2}$} & \multicolumn{2}{c|}{ Total Destruction } \\
\hline original & duplicate & original & duplicate & original & duplicate \\
\hline $39.4-51.3 \%$ & $68.1-86.3 \%$ & $64.3-94.5 \%$ & $4.7-33.3 \%$ & $111-139 \%$ & $85.2-107 \%$ \\
\hline
\end{tabular}

\subsubsection{Soluble Copper Results}

The copper concentrations in the filtrate were monitored for the reasons outlined in Section 3.1.3. After the start of the $\mathrm{H}_{2} \mathrm{O}_{2}$ addition the copper in the filtrate samples slowly increased over time. See Figure 67.

These two reactions provide the same approximate results. Copper solubility averages $\sim 80 \mathrm{mg} / \mathrm{L}$ over the main body of the experiment. 
SRNL-STI-2012-00342

Revision 1

Figure 67. Soluble Copper Concentration Comparison between Duplicate pH 7 Tests

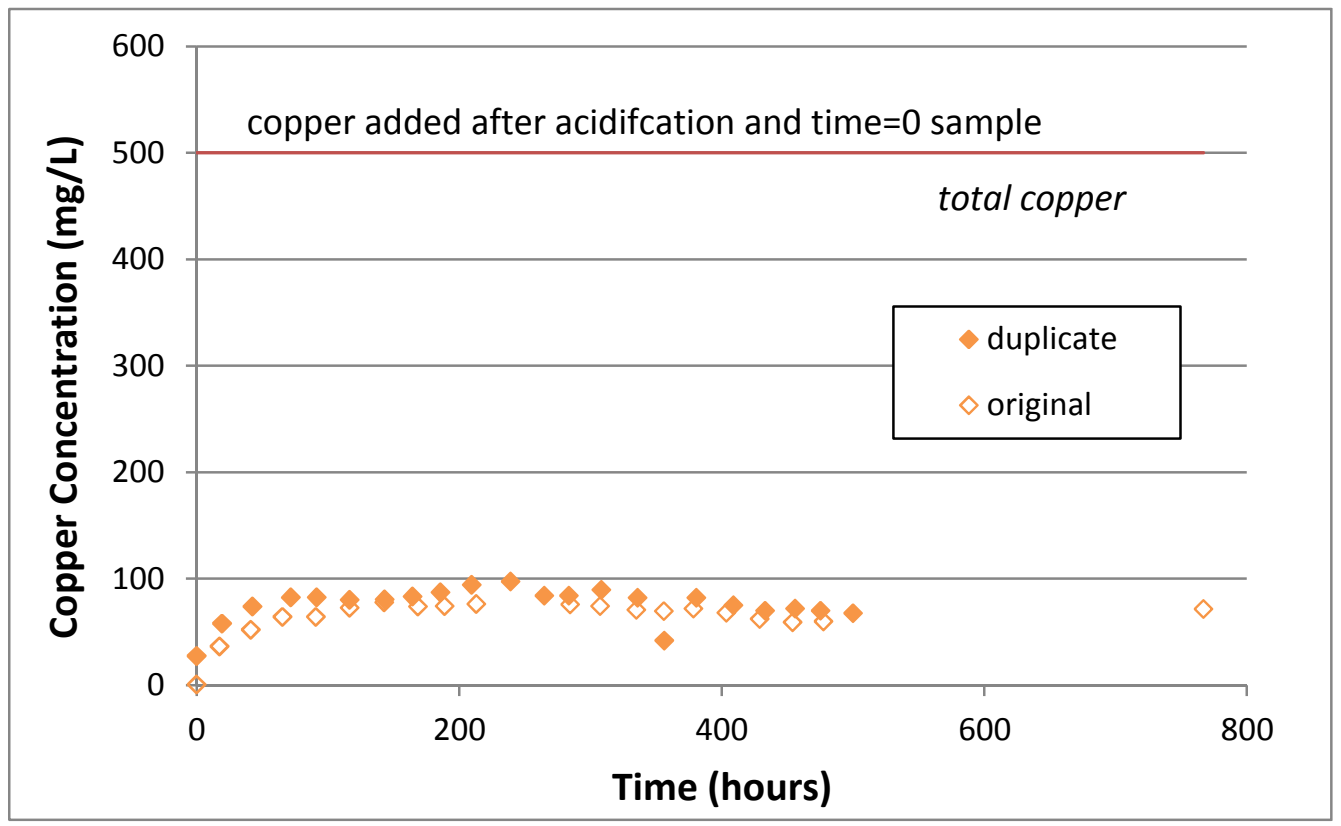

\subsubsection{Soluble Titanium Results}

The titanium concentration in solution is monitored for the reasons outlined in Section 3.1.4. See Figure 68.

The titanium data indicate that the duplicate reaction showed slightly higher titanium values for most of the test, but not greatly so. In all cases, the titanium concentrations were below $10 \mathrm{mg} / \mathrm{L}$. 


\section{Figure 68. Titanium Concentration Comparison between Duplicate pH 7 Tests}

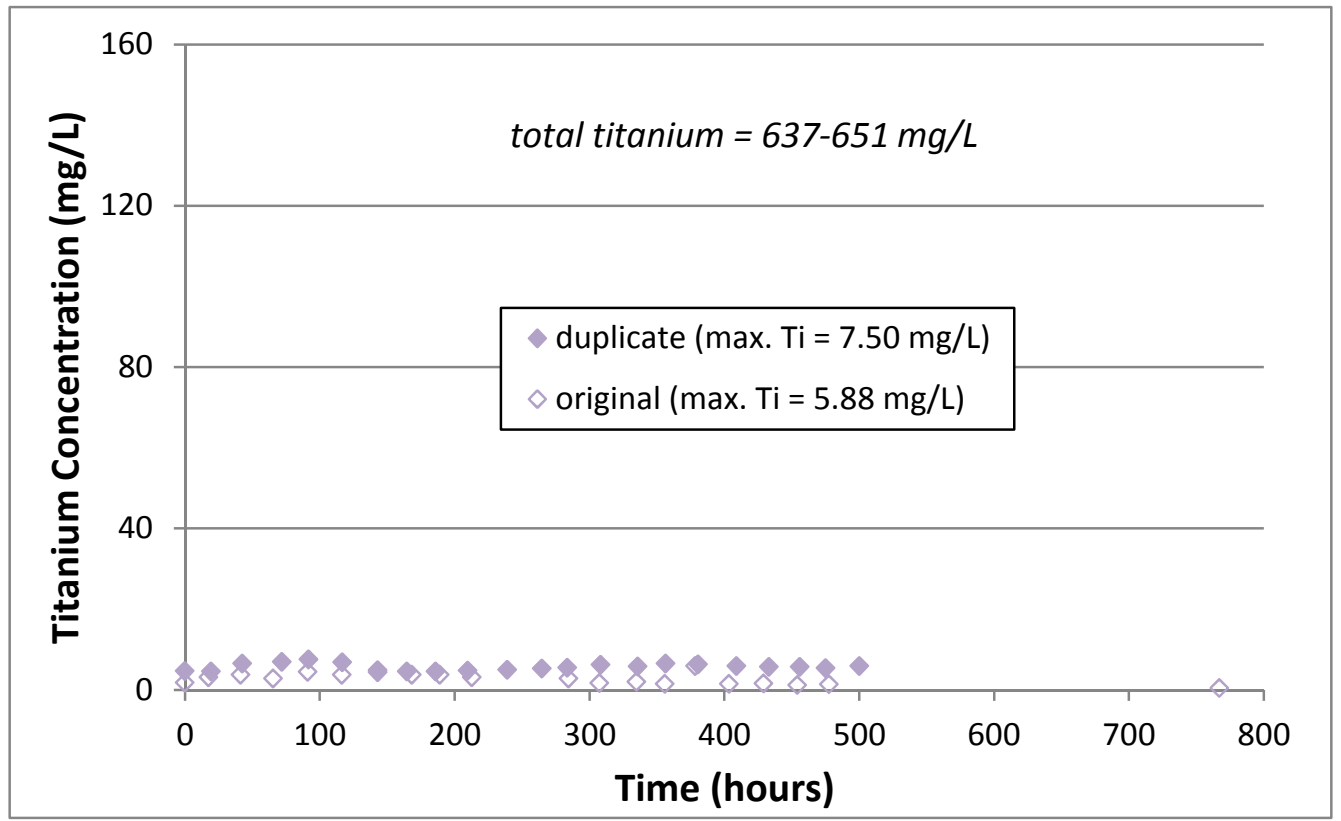

\subsubsection{Analysis of Residual Slurry After Reaction}

After the reaction was complete, the reactor bottom was removed. The amount of recovered material is dependent on the efficiency of slurry removal.

From the bottle of residual slurry after reaction, well-mixed (in an attempt to ensure homogeneity) duplicate samples were analyzed via HPLC, VOA and SVOA. Table 59 lists the HPLC results.

Table 59. HPLC Results from Residual Slurry After Reaction Analyses (mg/L)

\begin{tabular}{|c|c|c|c|c|c|c|}
\hline Reaction & TPB & 3PB & 2PB & 1PB & Phenol & \% Destruction \\
\hline original & $<10$ & $<10$ & $<10$ & $<10$ & $<10$ & $>99.9 \%$ \\
\hline duplicate & $<4$ & $<4$ & $<8$ & $<4$ & $<4$ & $>99.97 \%$ \\
\hline
\end{tabular}

The "\% Destruction" column is the calculated percent destruction. The value is based on the mass of TPB added to the simulant slurries and calculation of the mass of TPB in the residual slurry after reaction, after correcting for the mass of samples removed from the system during the reactions.

Given the very rapid destruction indicated by the boron and potassium data, less than detectable levels of all the HPLC analytes were anticipated. 
Samples of the residual slurry after reaction were analyzed using VOA and SVOA (see Table 60 ). The values in parentheses are the \%RSD. In the results column, values that are shaded indicate only one measured value with the other being a detection limit result. In this case, the values in parentheses are the analytical uncertainties. In the analyte column, shaded cells indicate the presence of that analyte is doubtful due to chemical conditions or contaminants. The "total organic residuals" are the sum of all the midrange values of the detected analytes, less benzene and the analytes that are declared to be from contaminants. The "total organic residuals" are the sum of all the detected analytes, less benzene and the analytes that are declared to be from contaminants. These results are not normalized to the beginning volumes.

Table 60. VOA and SVOA Results for Test 2e

\begin{tabular}{|c|c|}
\hline Analyte & Result (mg/L) \\
\hline biphenyl & $51.0(8.32 \%)$ \\
\hline dimethyldiphenyldihydrodipyrrolopyridine & $23.4(112 \%)$ \\
\hline 2-nitro-N-(4-nitrophenyl)benzeneamine & $35.5(9.96 \%)$ \\
\hline 2,4-dinitro-N-phenyl-benzeneamine & $51.5(26.1 \%)$ \\
\hline $\mathrm{N}, \mathrm{N}$-diphenylbenzeneamine & $29.0(0.00 \%)$ \\
\hline diphenylamine & $26.0(5.44 \%)$ \\
\hline 5-nitro-2-furanal alcohol & $21.0(13.5 \%)$ \\
\hline diisooctyl adipate & $13.0(21.8 \%)$ \\
\hline terphenyl & $13.0(10.9 \%)$ \\
\hline 2,3,4 trinitrodiphenylamine & $14.1(10.6 \%)$ \\
\hline diphenyl(2-pyridyl)methanol & $4.1(6.90 \%)$ \\
\hline 4-nitro-N-phenyl-benzeneamine & $4.6(45.1 \%)$ \\
\hline diphenyl ether & $3.3(8.57 \%)$ \\
\hline aminohydroxyoxadiazolecarboxamidine & $2.16-3.24$ \\
\hline 2-nitro-N-phenyl-benzeneamine & $2.05(3.45 \%)$ \\
\hline (4-nitrophenyl)diphenylamine & $5.20(95.2 \%)$ \\
\hline 3-methylbut-2-yl isophthalic acid & $1.28-1.92$ \\
\hline benzyl biphenyl & $1.04-1.56$ \\
\hline [1,1-biphenyl]-3-amine & $19.2-28.8$ \\
\hline ethanoic acid dimethyl ester & $5.68-8.52$ \\
\hline 4-benzyl biphenyl & $4.08-6.12$ \\
\hline Total organic residuals & 326 \\
\hline
\end{tabular}


Most of the analytes are biphenyl derivatives or partially degraded or functionalized aryl compounds. It is very difficult to define any trend in these analytes.

The original $\mathrm{pH} 7$ test (Test 1c) detailed in Section 3.6 .5 yielded $518 \mathrm{mg} / \mathrm{L}$ of residual organics, compared to the current result (Test 2e) of $326 \mathrm{mg} / \mathrm{L}$. The residual organics results for the two tests are comparable, with the difference probably attributable to the limits of test reproducibility.

\subsection{6 pH Monitoring}

$\mathrm{pH}$ was monitored during the reaction (see Figure 69).

As with the original $\mathrm{pH} 7$ test, the $\mathrm{pH}$ in both reactions trended towards a final $\mathrm{pH}$ of $\sim 9$.

\section{Figure 69. pH Readings between Duplicate pH 7 Tests}

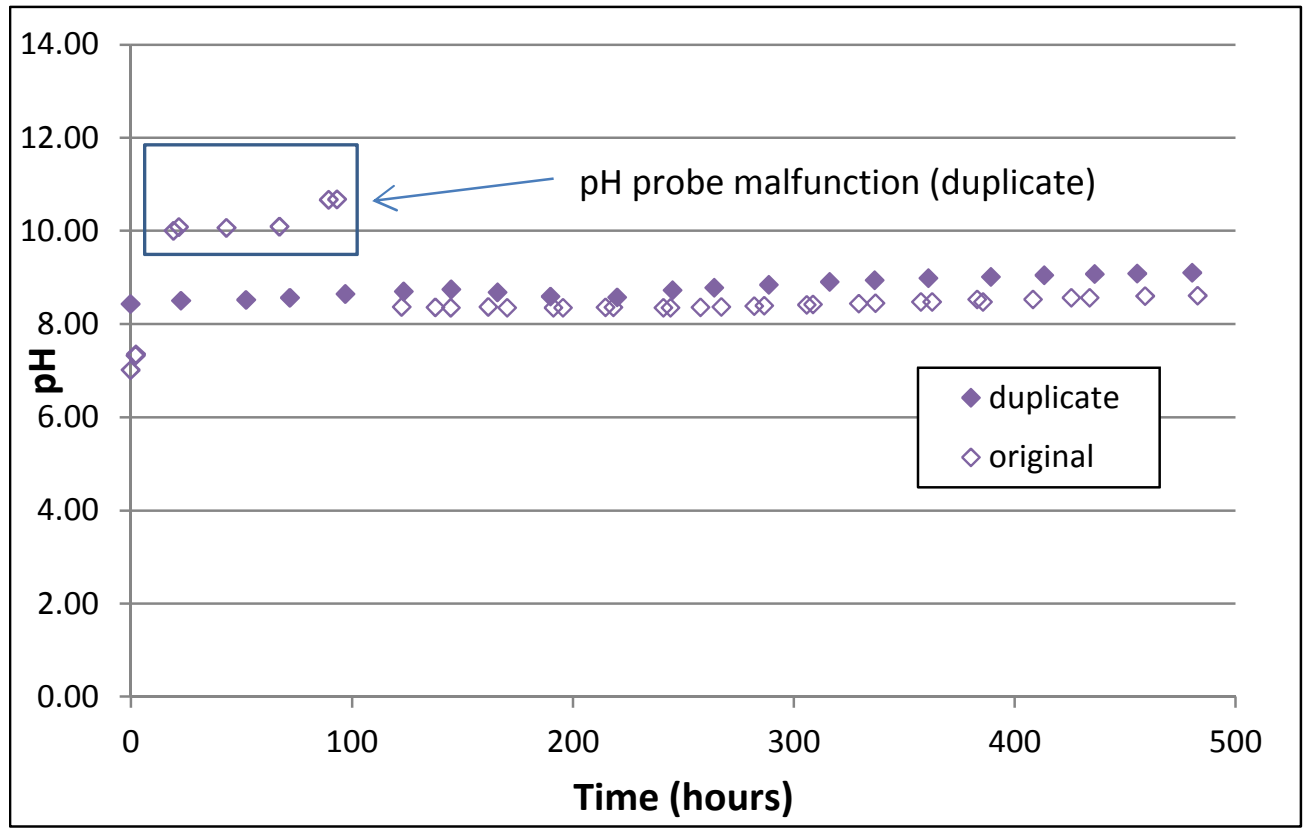

\subsubsection{Conclusion}

Both the original and duplicate $\mathrm{pH} 7$ tests provide approximately similar results, with TPB destruction completion times of $\sim 1$ day, leaving $326-518 \mathrm{mg} / \mathrm{L}$ of residual organics after $\sim 22$ days. 


\subsection{Replicate Reactions of DEMONSTRATION 2}

The previously performed DEMO 2 (Section 3.6) provided positive results (complete destruction in $\sim 4$ days) as well as one of the least amounts of residual organic concentrations $(83.3 \mathrm{mg} / \mathrm{L})$. The reaction conditions for DEMO 2 were also found to provide excellent overall results, so it was decided that several further tests should be performed using the same set of reaction conditions.

These experiments (referred to as "DEMO 3", "Test 3c", and "DEMO 4") used the same reaction vessels and temperature control $\left(50^{\circ} \mathrm{C}\right)$ as described in Section 3.6. Test $3 \mathrm{c}$ operated for $\sim 96$ hours. DEMO 4 operated for $\sim 215$ hours, while DEMO 3 operated for $\sim 480$ hours. By running some of these tests for different durations, this allowed SRNL to determine the time-dependence of TPB and residual organic destruction. Other experimental details were as described in previous sections, except where as noted below. It was noted that the "prototypical mixing" is in fact, very poor compared to reactions performed in poly bottles with a magnetic stirrer. The agitation was insufficient to prevent a semi-stable floating solids mass. This may have effects in the overall reaction efficiency.

Hydrogen peroxide was added at $0.4 \mathrm{~mL} /$ hour $(2 \times)$.

The tests continued for approximately 4-21 days. Filtrate samples were taken once per day. A total of 4-21 samples, depending on the test were removed for analysis by ICPES.

\subsubsection{Soluble Boron Results}

After the start of the $\mathrm{H}_{2} \mathrm{O}_{2}$ addition the boron in the filtrate samples increased over time or all experiments. See Figure 70. 
Figure 70. Boron Concentration Comparison between Replicates of DEMO 2

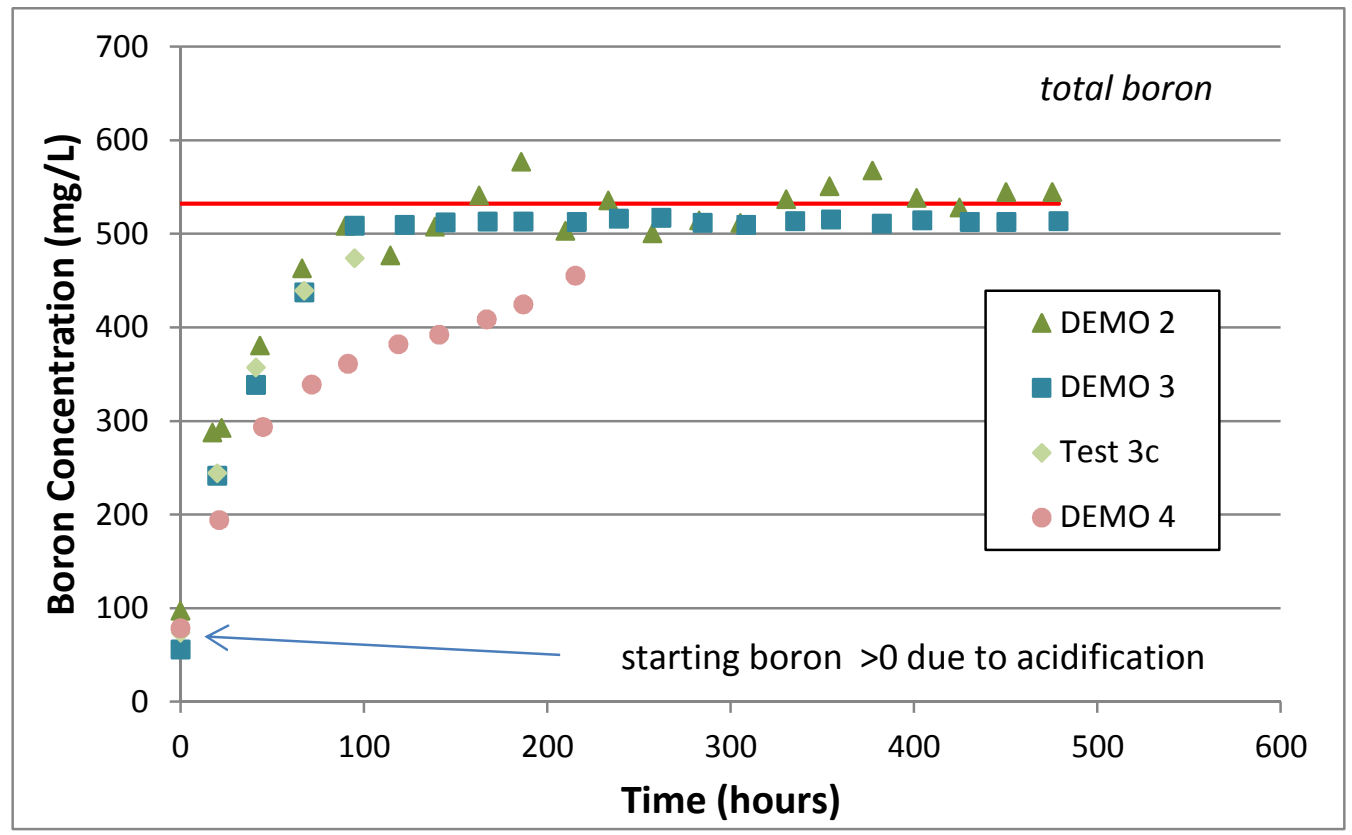

After each reaction was halted the extent of boron dissolution associated with the acid hydrolysis and peroxide oxidation reactions was calculated using the same methodology as in Section 3.1.1 (see Table 61).

\section{Table 61. Total TPB Destruction from Final Boron Results between DEMO 2} Replicate Reactions

\begin{tabular}{|c|c|c|c|}
\hline \multicolumn{4}{|c|}{ Destruction by Acid } \\
\hline DEMO 2 & DEMO 3 & test 3c & DEMO 4 \\
\hline $16.4-20.1 \%$ & $9.4-11.5 \%$ & $12.4-15.1 \%$ & $13.3-16.2 \%$ \\
\hline \multicolumn{4}{|c|}{ Destruction by $\mathrm{H}_{2} \mathrm{O}_{2}$} \\
\hline DEMO 2 & DEMO 3 & test 3c & DEMO 4 \\
\hline $73.5-94.3 \%$ & $76.2-95.7 \%$ & $66.0-83.9 \%$ & $62.1-79.5 \%$ \\
\hline \multicolumn{4}{|c|}{ Total Destruction } \\
\hline DEMO 2 & DEMO 3 & test 3c & DEMO 4 \\
\hline $91.9-112 \%$ & $86.6-106 \%$ & $79.8-97.6 \%$ & $77.0-94.13 \%$ \\
\hline
\end{tabular}

With the notable exception of DEMO 4, the other replicate reactions exhibited excellent agreement. DEMO 4 was not complete by the end time of $\sim 215$ hours, which is far longer than typical. 


\subsubsection{Soluble Potassium Results}

As in previous experiments, the potassium in solution was measured as an indicator of organic destruction. After the start of the $\mathrm{H}_{2} \mathrm{O}_{2}$ addition the potassium in the filtrate samples increased over time. See Figure 71.

Figure 71. Potassium Concentration Comparison between Replicates of DEMO 2

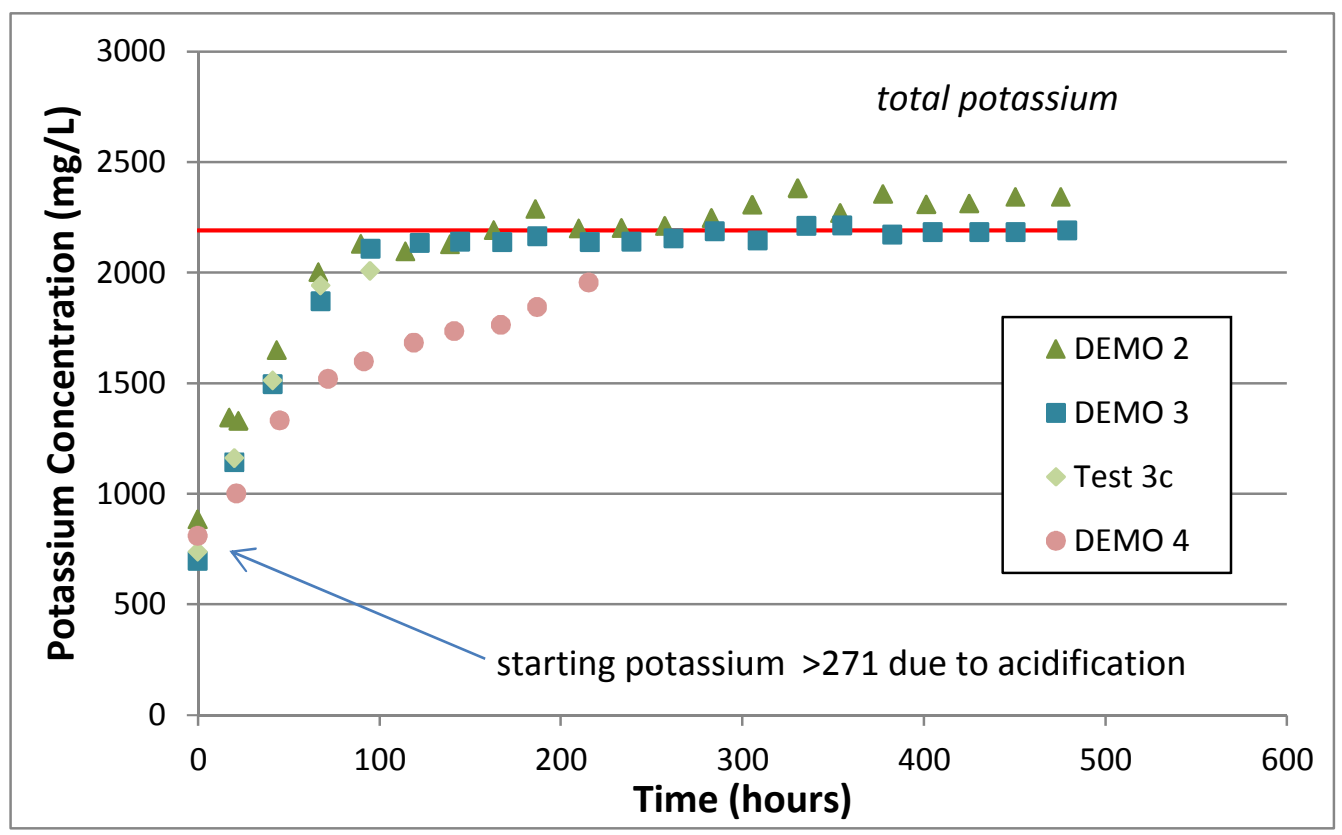

After each reaction was stopped the extent of potassium dissolution associated with the acid hydrolysis and peroxide oxidation reactions was calculated using the same methodology as in Section 3.1.1 (see Table 62). 
SRNL-STI-2012-00342

Revision 1

Table 62. Total TPB Destruction from Final Potassium Results between DEMO 2 Replicate Reactions

\begin{tabular}{|c|c|c|c|}
\hline \multicolumn{4}{|c|}{ Destruction by Acid } \\
\hline DEMO 2 & DEMO 3 & test 3c & DEMO 4 \\
\hline $27.2-36.4 \%$ & $18.6-25.8 \%$ & $20.4-28.0 \%$ & $23.9-32.3 \%$ \\
\hline \multicolumn{4}{|c|}{ Destruction by $\mathrm{H}_{2} \mathrm{O}_{2}$} \\
\hline DEMO 2 & DEMO 3 & test 3c & DEMO 4 \\
\hline 63.7-88.7\% & $65.8-89.7 \%$ & $54.8-77.0 \%$ & $48.6-70.6 \%$ \\
\hline \multicolumn{4}{|c|}{ Total Destruction } \\
\hline DEMO 2 & DEMO 3 & test 3c & DEMO 4 \\
\hline 95.3-120\% & $88.5-111 \%$ & $79.7-101 \%$ & $77.5-97.9 \%$ \\
\hline
\end{tabular}

The potassium data closely matches the trends noted in the boron data.

\subsubsection{Soluble Copper Results}

The copper concentrations in the filtrate were monitored for the reasons outlined in Section 3.1.3. After the start of the $\mathrm{H}_{2} \mathrm{O}_{2}$ addition the copper in the filtrate samples increased and then remained steady. See Figure 72.

These replicate reactions provide the same approximate results, except for DEMO 4. Copper solubility averages $\sim 110 \mathrm{mg} / \mathrm{L}$ over the main body of the experiment, with DEMO 4 averaging only a few $\mathrm{mg} / \mathrm{L}$ at any one time. 
Figure 72. Soluble Copper Concentration Comparison between DEMO 2 Replicate Reactions

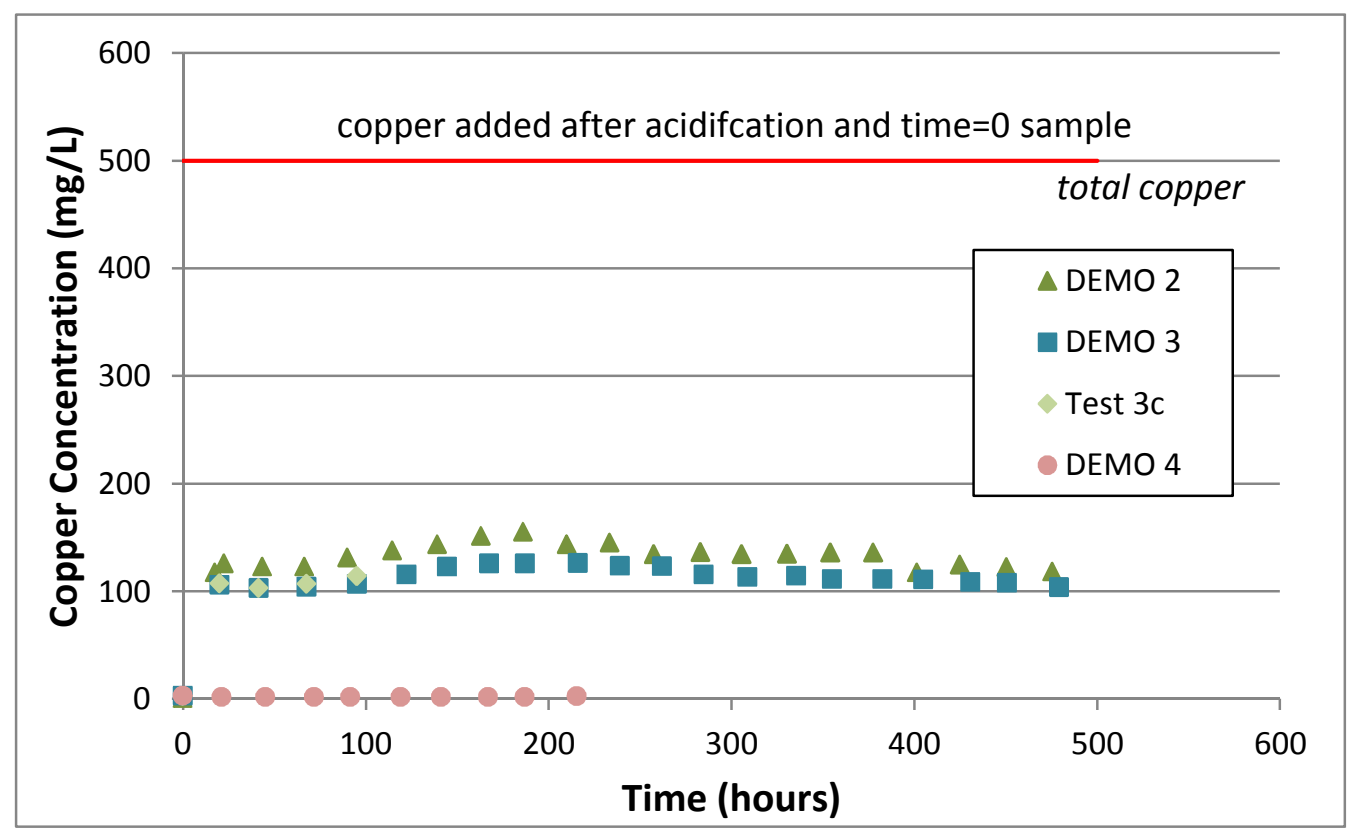

Previously, we noted that the replicate reactions provided similar boron and potassium concentration results, with the exception of DEMO 4. With the copper data, it is now possible to see why this is happening. In DEMO 4, the copper data clearly shows the lack of soluble copper. With little available copper, DEMO 4 only provides a slow TPB destruction and is not complete by 215 hours. A review of the work instructions shows that the proper amount of copper compound was weighed out. The most likely scenario is that the copper solution was inadvertently not added. Due to this, further comparisons to DEMO 4 must consider the effect of the lack of copper in DEMO 4.

\subsubsection{Soluble Titanium Results}

The titanium concentration in solution is monitored for the reasons outlined in Section 3.1.4. See Figure 73. 
Figure 73. Titanium Concentration Comparison between DEMO 2 Replicate Reactions

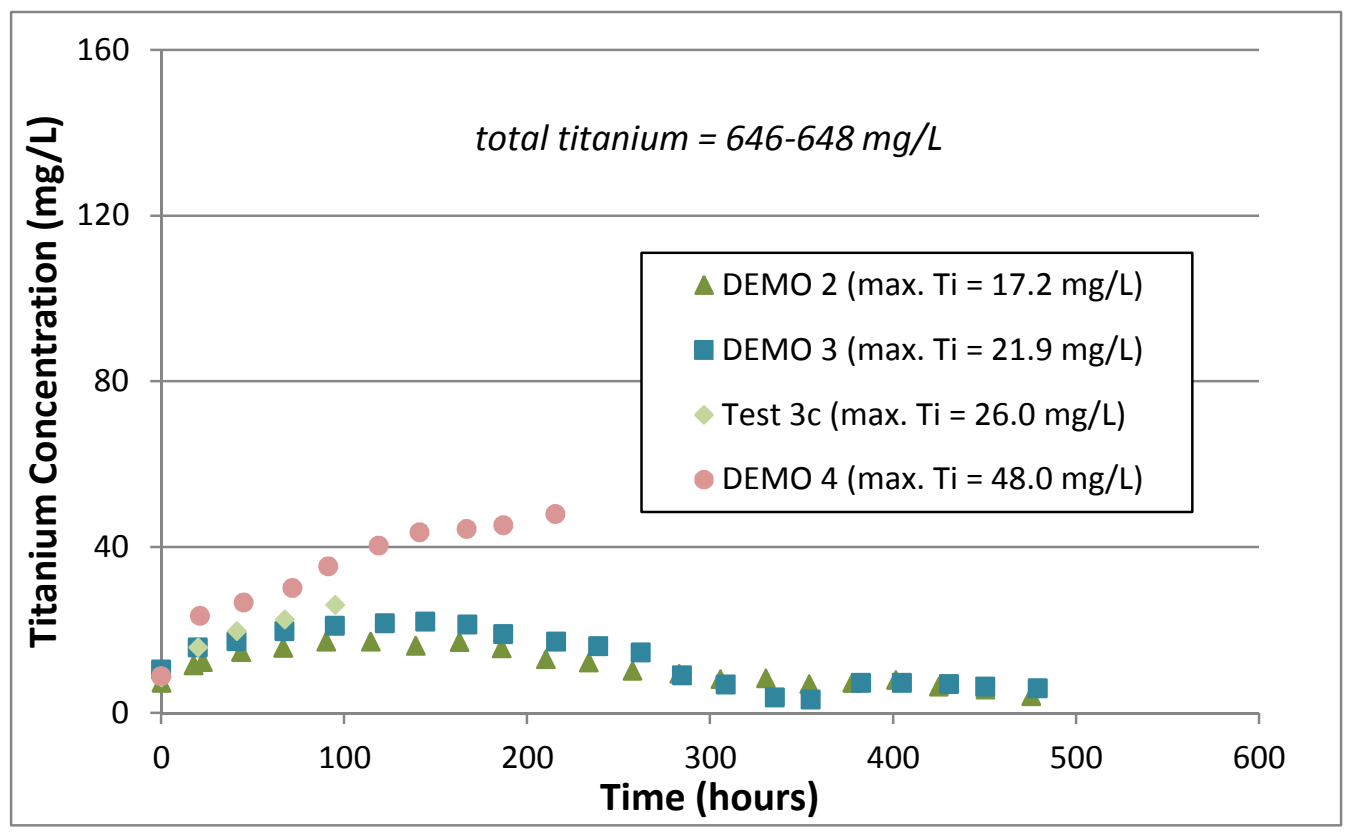

The titanium data indicates that the replicate reactions showed very close titanium values for most of the test, except for DEMO 4. In all cases, the titanium concentrations were below $\sim 20 \mathrm{mg} / \mathrm{L}$, except for DEMO 4. DEMO 4 shows an increasing amount of titanium over time, and does not show an indication of a decline. SRNL concludes that this is a clear illustration that in the absence of copper, the $\mathrm{H}_{2} \mathrm{O}_{2}$ is free to react with the MST, liberating titanium in solution.

\subsubsection{Analysis of Residual Slurry After Reaction}

After each reaction was complete, the residual material in the reactor was removed. The amount of recovered material is dependent on the efficiency of slurry removal.

From the bottle of reactor residuals, well-mixed (in an attempt to ensure homogeneity) duplicate samples were analyzed via HPLC, VOA and SVOA. Table 63 lists the HPLC results. Due to the lack of added copper, and the immediate effect of this, DEMO 4 is not included in the comparison. 
SRNL-STI-2012-00342

Revision 1

Table 63. HPLC Results from Residual Slurry after Reaction Analyses (mg/L)

\begin{tabular}{|c|c|c|c|c|c|c|}
\hline Reaction & TPB & 3PB & 2PB & 1PB & Phenol & \% Destruction \\
\hline DEMO 2 & $<4$ & $<4$ & $<4$ & $<4$ & $<4$ & $>99.97 \%$ \\
\hline DEMO 3 & $<4$ & $<4$ & $<4$ & $<4$ & $<4$ & $>99.97 \%$ \\
\hline Test 3c & $20(7.70 \%)$ & $<4$ & $<4$ & $<4$ & $7(0.00 \%)$ & $99.86-99.88 \%$ \\
\hline
\end{tabular}

The "\% Destruction" column is the calculated percent destruction. The value is based on the mass of TPB added to the simulant slurries and calculation of the mass of TPB in the residual slurry after reaction, after correcting for the mass of samples removed from the system during the reactions.

Given the apparent complete destruction indicated by the boron and potassium data, little, if any detectable levels of all the HPLC analytes were anticipated.

Samples of the residual slurry after reaction from DEMO 3 and Test $3 \mathrm{c}$ were analyzed using VOA and SVOA (see Tables 64 and 65). The values in parentheses are the \%RSD. In the results column, values that are shaded indicate only one measured value with the other being a detection limit result. In this case, the values in parentheses are the analytical uncertainties. In the analyte column, shaded cells indicate the presence of that analyte is doubtful due to chemical conditions or contaminants. The "total organic residuals" are the sum of all the mid-range values of the detected analytes, less benzene and the analytes that are declared to be from contaminants. These results are not normalized to the beginning volumes.

Table 64. VOA and SVOA Results for DEMO 3

\begin{tabular}{|c|c|}
\hline Analyte & Result (mg/L) \\
\hline terphenyl & $27.5(7.71 \%)$ \\
\hline [1,1-biphenyl]-3-amine & $26.5(8.00 \%)$ \\
\hline biphenyl & $24.0(5.89 \%)$ \\
\hline 5-nitro-2-furfurane methanol & $12.0(11.8 \%)$ \\
\hline diisooctyl adipate & $8.70(37.4 \%)$ \\
\hline diphenyl ether & $4.05(5.24 \%)$ \\
\hline diphenylamine & $1.95(10.9 \%)$ \\
\hline 2-phenoxy-1,1-biphenyl & $1.35(5.24 \%)$ \\
\hline triphenylmethane & $1.04-1.56$ \\
\hline 2-nitro-N-(2-nitrophenyl)benzeneamine & $1.12-1.68$ \\
\hline butanal & $0.40(1.79 \%)$ \\
\hline Total organic residuals & 100 \\
\hline
\end{tabular}


Table 65. VOA and SVOA Results for Test 3c

\begin{tabular}{|c|c|}
\hline Analyte & Result (mg/L) \\
\hline biphenyl & $985(2.15 \%)$ \\
\hline ethane dioic acid dimethyl ester & $38.5(42.2 \%)$ \\
\hline diisooctyl adipate & $33.5(31.7 \%)$ \\
\hline diphenyl ether & $40.5(1.75 \%)$ \\
\hline 5-nitro-2-furfurane methanol & $27.0(0.00 \%)$ \\
\hline terphenyl & $17.0(74.9 \%)$ \\
\hline 4-methyl-1-heptanol & $18.0(55.0 \%)$ \\
\hline N, N-diphenyl-benzeneamine & $16.5(12.9 \%)$ \\
\hline nitro-N-phenylenebenzeneamine & $12-18$ \\
\hline diphenylamine & $11.0(12.9 \%)$ \\
\hline 2,3-dimethylbutane & $5.76-8.64$ \\
\hline 2-phenoxy-1,1-biphenyl & $4.50(9.43 \%)$ \\
\hline 2-iodo-3-nitrotoluene & $3.68-5.52$ \\
\hline triphenylmethane & $3.05(25.5 \%)$ \\
\hline [1,1-biphenyl]-3-amine & $36.8-55.2$ \\
\hline p-terphenyl & $13.6-20.4$ \\
\hline 4-nitro-N-phenyl-benzeneamine & $3.84-5.76$ \\
\hline 5-methyl-1,1,3,1-terphenyl & $5.36-8.04$ \\
\hline 2-nitro-N-phenyl-benzeneamine & $4.8-7.2$ \\
\hline 4-nitro-N-(4-nitrophenyl)-benzeneamine & $3.84-5.76$ \\
\hline Napthol a & $3.44-5.16$ \\
\hline azobenzene & $2.56-3.84$ \\
\hline 2,4-dinitro-N-phenyl-benzeneamine & $2-3$ \\
\hline (Z)-9-Octadeceneamide & $1.36-2.04$ \\
\hline butanal & $0.061(1.17 \%)$ \\
\hline acetone & $1.60(0.00 \%)$ \\
\hline benzene & $0.097(4.37 \%)$ \\
\hline Total organic residuals & 1287 \\
\hline
\end{tabular}


The original DEMO 2 detailed in section 3.7 .5 gave $83.3 \mathrm{mg} / \mathrm{L}$ of residual organics.

A comparison of the three replicate reactions provides a very interesting result. While all three tests are effectively complete with respect to boron, potassium and HPLC data, the amount of residual organics varies tremendously. There is a correlation between the duration of the test, and the amount of residual organics. See Table 66.

Table 66. Correlation between Reaction Duration and Residual Organics

\begin{tabular}{|c|c|c|}
\hline Test & Duration (hours) & Residual organics (mg/L) \\
\hline DEMO 2 & 476 & 83.3 \\
\hline DEMO 3 & 479 & 100 \\
\hline Test 3c & 95 & 1287 \\
\hline
\end{tabular}

DEMO 2 and DEMO 3 had equivalent test durations, and provided for effectively the same final concentrations of residual organics. On the other hand, as the test duration decreased (Test 3c), the concentrations of residual organics increased dramatically. This is a very important point to consider. Even if the TPB and other phenylborates have been completely destroyed, there will still be a residual heel of material that remain unless sufficient time is given to allow these to be destroyed.

\subsection{6 pH Monitoring}

The $\mathrm{pH}$ was monitored during each reaction (see Figure 74).

In all the tests, the $\mathrm{pH}$ trended towards a final $\mathrm{pH}$ of $\sim 9$. The lack of copper in DEMO 4 did not make a noticeable difference. 
Figure 74. pH Readings for DEMO 2 Replicates

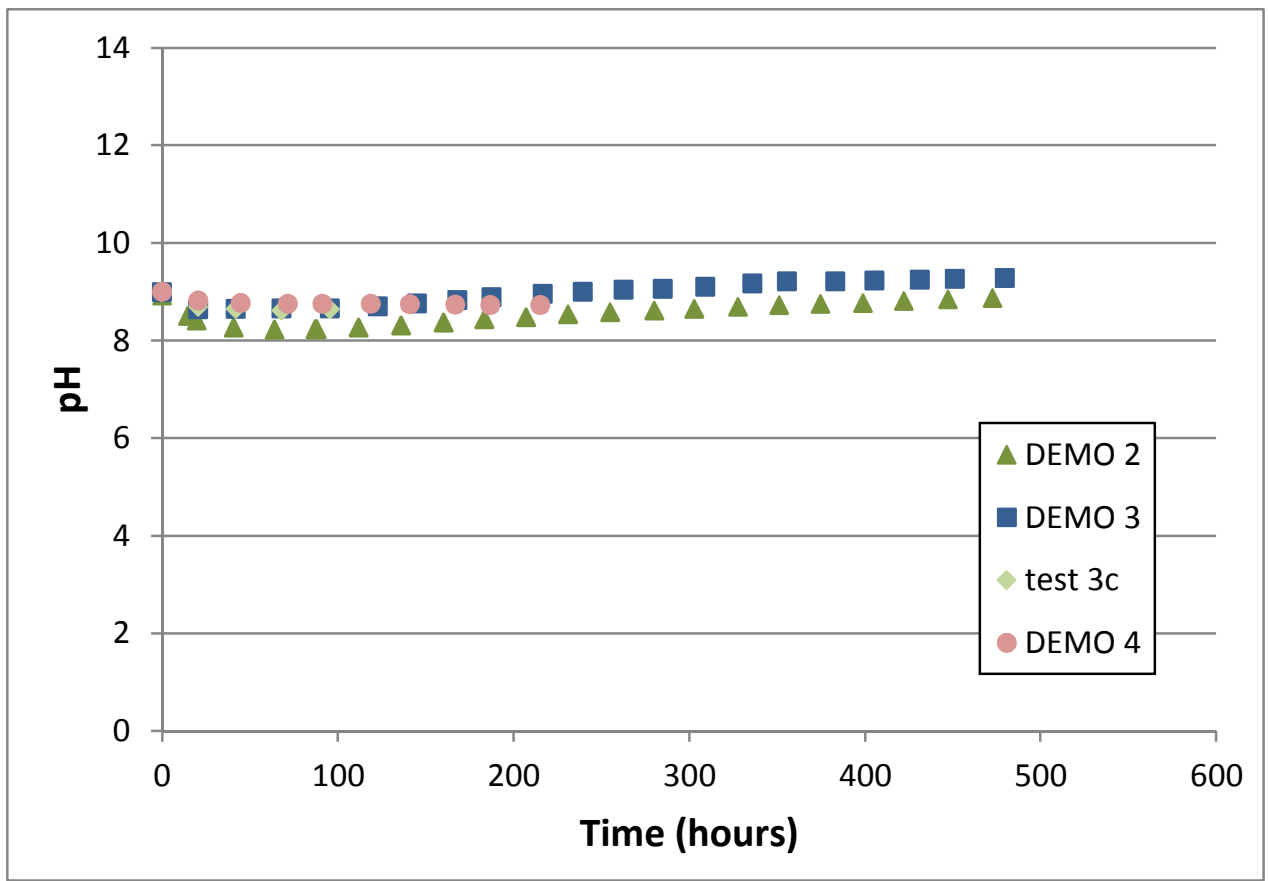

\subsubsection{Gas Chromatograph Data}

For the duration of the experiments, including the $\mathrm{pH}$ adjustment, the off-gas composition was monitored using GC. This enabled the important off-gas species such as benzene and $\mathrm{CO}_{2}$ to be tracked which can help determine how the organics are being broken down. See Figures 75-76.

All the concerns listed in regards to the GC data in Section 3.4.6 also pertain here. First, because of in-reactor acidification (as opposed to the 2004 work), it is impossible to deconvolute $\mathrm{CO}_{2}$ generated from acidification of carbonate in the simulant, and $\mathrm{CO}_{2}$ generated from organic oxidation. This is because degassing of the $\mathrm{CO}_{2}$ is not immediate and takes place over time. Second, the reactor vessel cannot be made gastight (the physical design has penetrations that cannot be completely sealed) and leaks are probable. 
Figure 75. Gas Release Rates for Demonstration 3

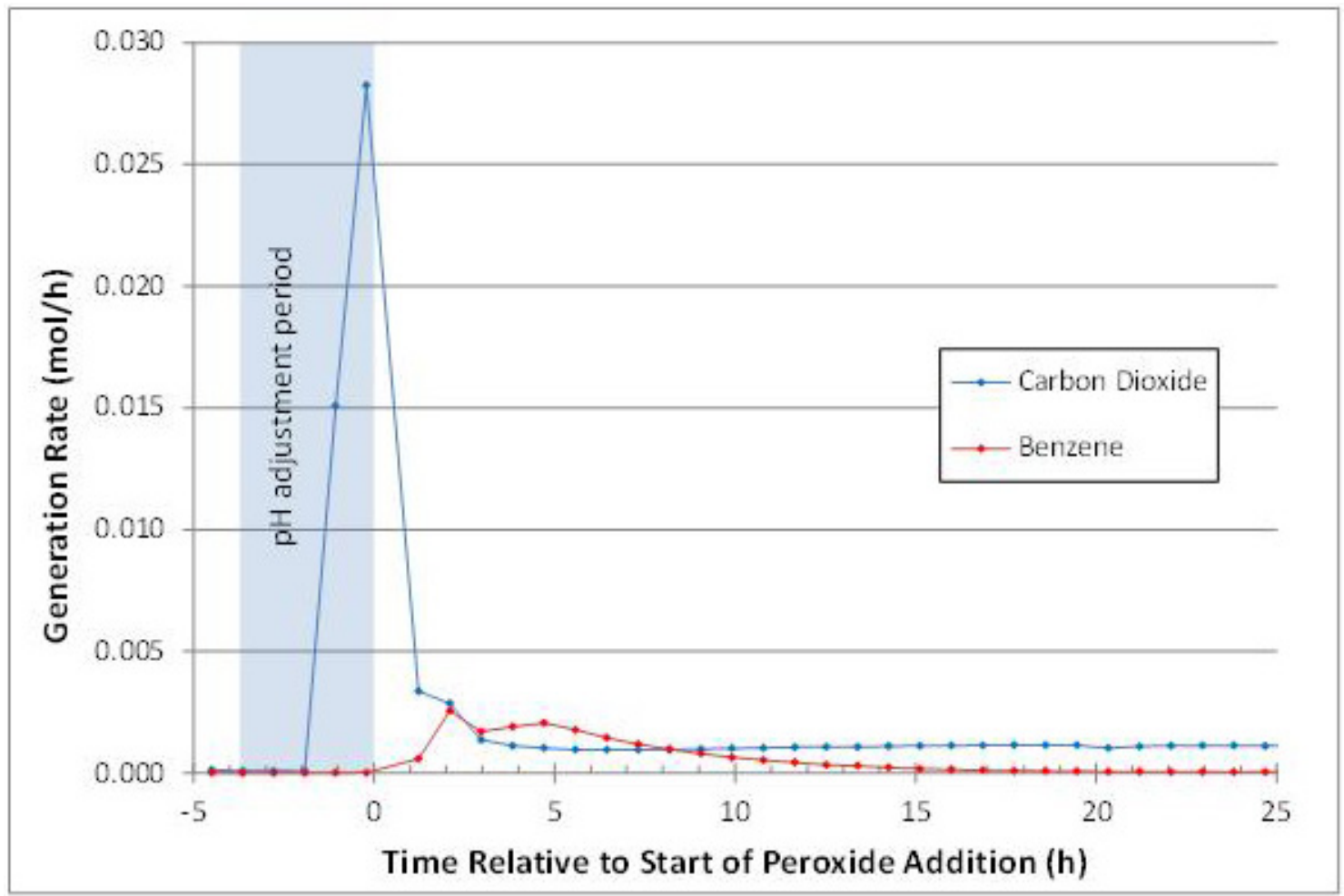

Figure 76. Gas Release Rates for Test 3c

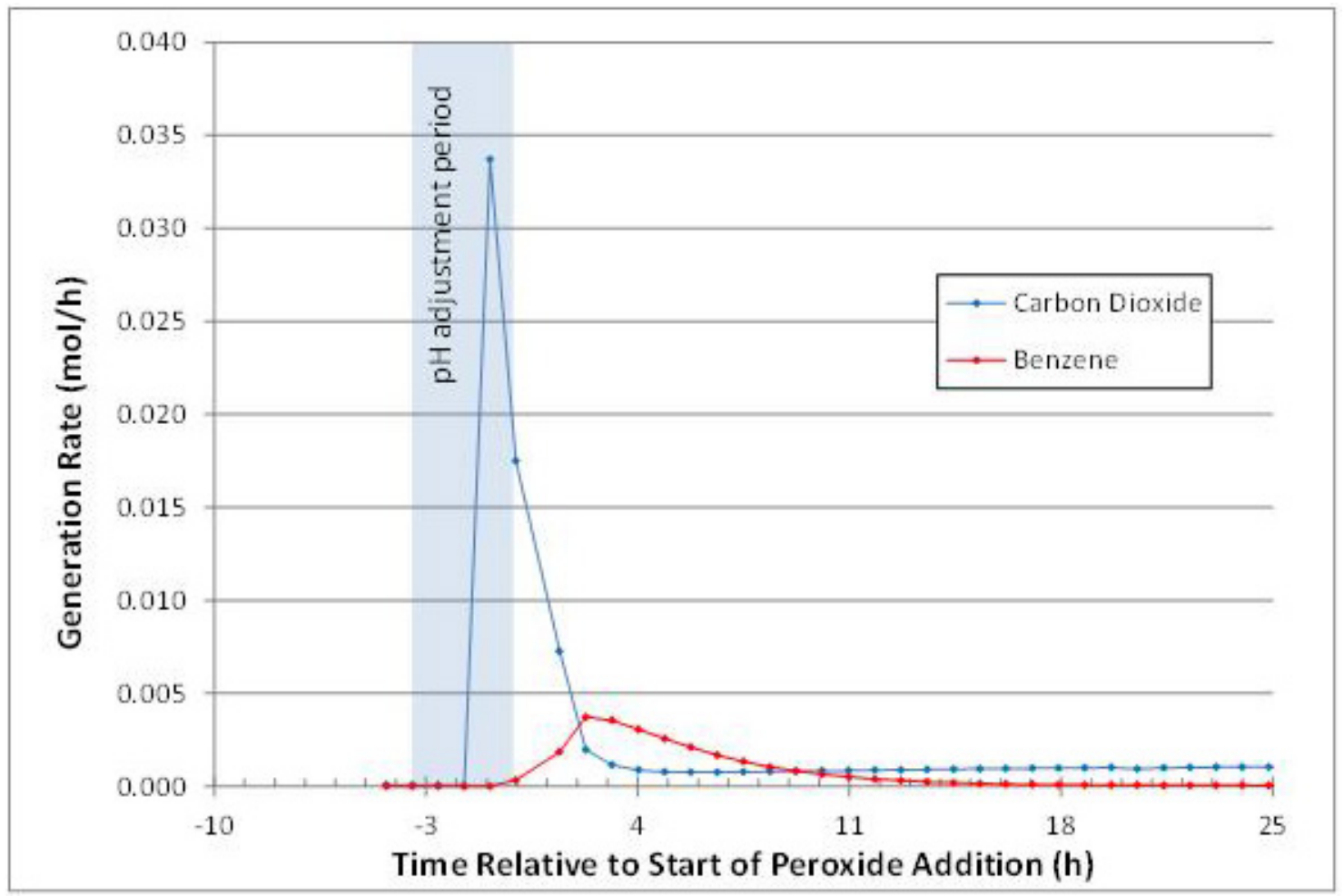


The major off-gas components are benzene and $\mathrm{CO}_{2}$. The benzene and $\mathrm{CO}_{2}$ are from the $\mathrm{pH}$ adjustment of the slurry, as well as degradation of organics (the presence of these two gases was observed throughout the reaction).

Each of the three tests shows the same general behavior. While $\mathrm{CO}_{2}$ can be detected coming into the headspace almost immediately, benzene in the headspace is only detected after the $\mathrm{H}_{2} \mathrm{O}_{2}$ addition starts. The initial spikes in gas generation must be due to the $\mathrm{pH}$ adjustment process, and a closer inspection of the data set shows the same general behavior as observed for DEMO 1 and DEMO 2- the benzene and $\mathrm{CO}_{2}$ generation spikes closely follow the $\mathrm{pH}$ adjustment and then taper off quickly.

The GC data can be used in attempt to determine a mass balance for each test. To do this, the moles of benzene and $\mathrm{CO}_{2}$ available in the simulant slurry before $\mathrm{pH}$ addition must be determined, and compared against the moles of benzene and $\mathrm{CO}_{2}$ remaining in the residual slurry after reaction.

Figures 77-78 show the cumulative amount of benzene and $\mathrm{CO}_{2}$ detected over the life of DEMO 3 and Test $3 \mathrm{c}$.

Figure 77. Cumulative Off-gas Release in Demonstration 3

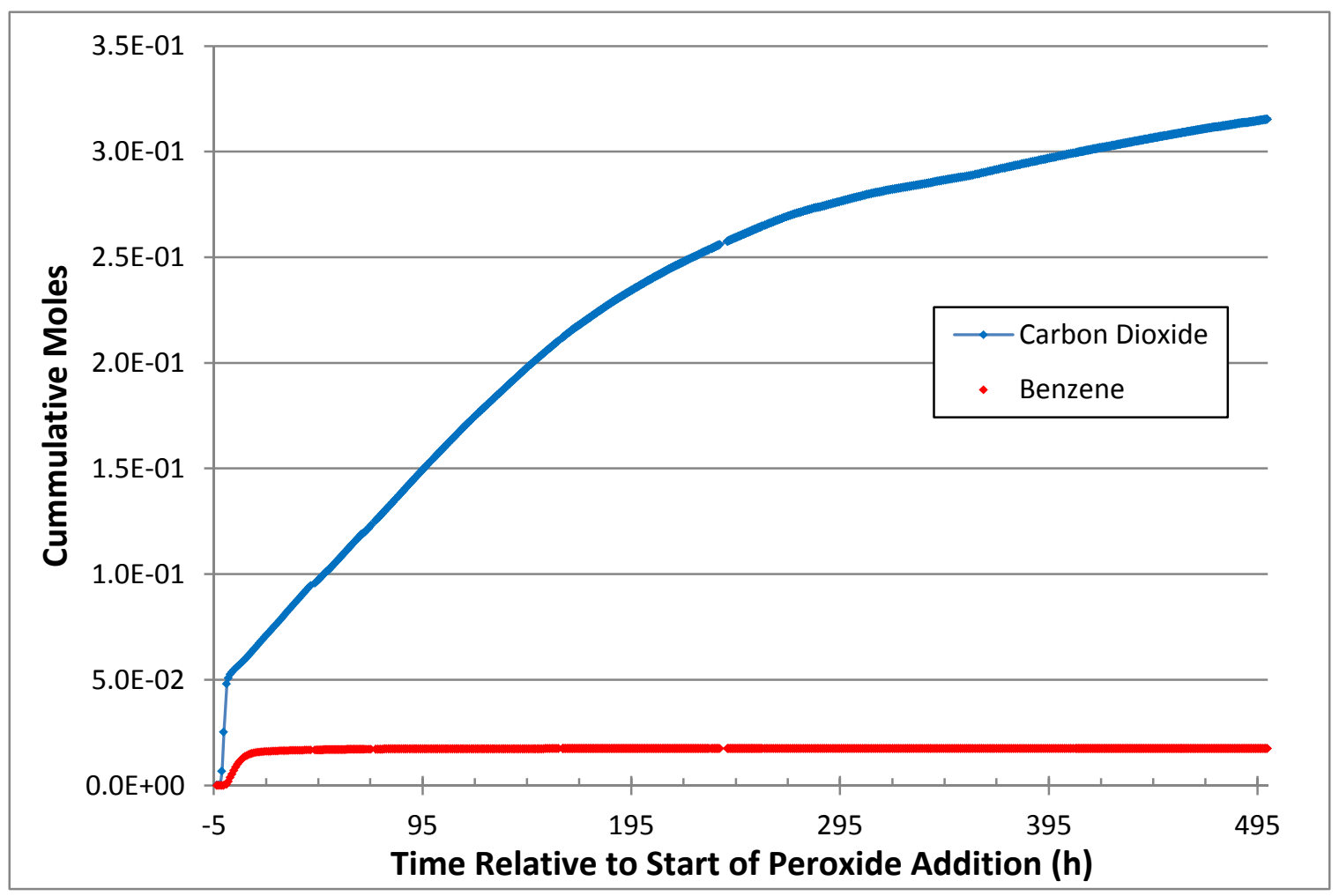


Figure 78. Cumulative Off-gas Release in Test 3c

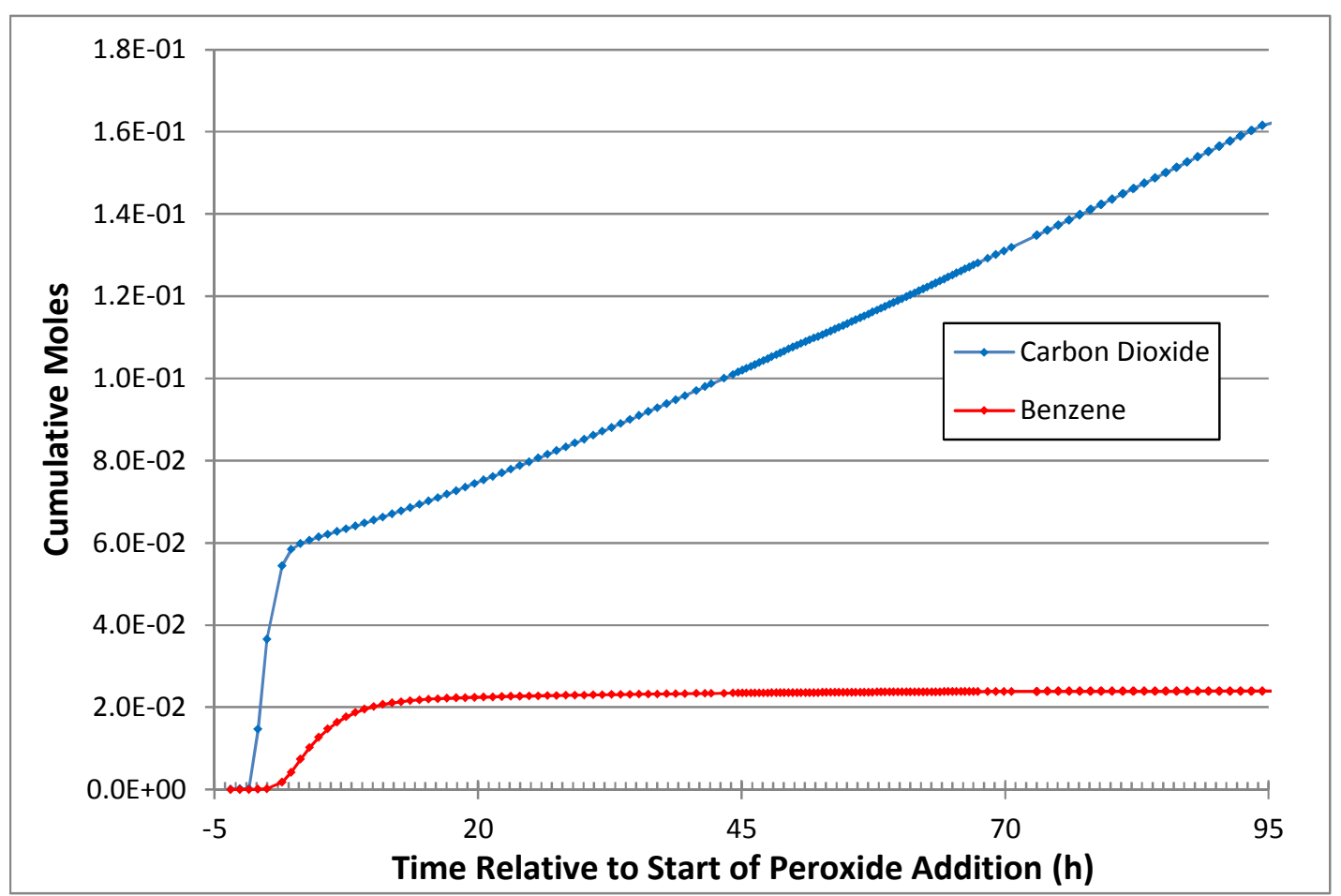

From the raw data the cumulative amount of $\mathrm{CO}_{2}$ and benzene produced can be tabulated. However, as each of the tests operated for a different duration it is important to compare equivalent data. Therefore, the $\mathrm{CO}_{2}$ and benzene data is presented in terms of $\mathrm{CO}_{2}$ and benzene at 95 hours (relative to time $=0$ ), and at the end of each experiment. See Table 67.

Table 67. $\mathrm{CO}_{2}$ and Benzene Generation for DEMO 2 Replicates

\begin{tabular}{|c|c|c|c|c|}
\hline \multirow{2}{*}{ Test } & \multicolumn{2}{|c|}{ Produced CO $\mathbf{O}_{\mathbf{2}}$ (moles) } & \multicolumn{2}{c|}{ Produced Benzene (moles) } \\
\cline { 2 - 5 } & 95 hours & Cumulative & 95 Hours & Cumulative \\
\hline DEMO 2 & 0.139 & 0.283 & 0.0319 & 0.0322 \\
\hline DEMO 3 & 0.149 & 0.315 & 0.0173 & 0.0175 \\
\hline Test 3c & 0.161 & 0.161 & 0.0239 & 0.0239 \\
\hline
\end{tabular}


From this distilled data, we can draw several conclusions. First, the benzene generation in each test is nearly over by 95 hours, which is also the approximate time required to completely destroy the TPB and phenylborates. Further organic degradation (presumably of the residual organics) does not liberate further benzene into the headspace.

Benzene production is the immediate result of TPB acid hydrolysis. Therefore, the amount of benzene produced should correspond to the \%TPB destruction from the boron and potassium data. A review of tables 61 and 62 shows that the highest TPB acid destruction is DEMO $2>$ Test 3c $>$ DEMO 3 (discounting DEMO 4 due to the lack of copper). This is very similar to the trend noted in Table 67, where DEMO $2>$ Test 3c $>$ DEMO 3 (discounting DEMO 4 due to the lack of copper).

On the other hand, $\mathrm{CO}_{2}$ production continues on for those tests that have durations $>95$ hours. As the residual organics are degraded through the $\mathrm{CCPO}$ process, $\mathrm{CO}_{2}$ is liberated. This is important to note - while we are defining destruction in terms of TPB destruction, the process of grinding down the residual organics takes longer. The more time spent after TPB destruction is complete, the lower the concentration of residual organics.

The same methodology in Section 3.6.6 is used to determine the percent of $\mathrm{CO}_{2}$ compared to the theoretical maximum $\mathrm{CO}_{2}$ generated can be used for DEMO 3, Test 3c and DEMO 4. For DEMO 3, 41\% of the maximum $\mathrm{CO}_{2}$ is detected. For Test $3 \mathrm{c}, \sim 58 \%$ of the maximum $\mathrm{CO}_{2}$ is detected.

Potential losses from the system due to leaks are being investigated to account for the differential, but it would appear that for GC measurements after DEMO 1, the leaking has been reduced.

\subsubsection{IC-Anions Data}

The fate of the various anions in the simulant was also evaluated. While most anions in the simulant slurry are likely unaffected by the reaction chemistry, it is known that the concentrations of certain anions, such as nitrite, oxalate or formate, may change during processing. In previous work, ${ }^{8}$ a number of reaction samples were examined to establish the effects on these types of anions. See Table 68.

There was no formate or oxalate added to the salt simulant, so the appearance of those species is significant and must be generated as part of the CCPO reaction. 
SRNL-STI-2012-00342

Revision 1

Table 68. IC-Anions Concentration Results for DEMO 2 Replicates

\begin{tabular}{|c|c|c|c|}
\hline \multirow{2}{*}{ Analyte } & \multicolumn{3}{|c|}{ Result (mg/L) } \\
\cline { 2 - 4 } & DEMO2 & DEMO 3 & Test 3c \\
\hline fluoride & $<100$ & $<100$ & $<100$ \\
\hline formate & 601 & 125 & 579 \\
\hline chloride & 303 & 164 & 176 \\
\hline nitrite & 22300 & 7190 & 12700 \\
\hline bromide & $<500$ & $<500$ & $<5000$ \\
\hline nitrate & 107000 & 115000 & 125200 \\
\hline phosphate & 113 & 415 & 195 \\
\hline sulfate & 247 & 156 & 211 \\
\hline oxalate & 3200 & 1518 & 1180 \\
\hline
\end{tabular}

The analytical uncertainty for each IC-Anions sample is $10 \%$.

Given the similarity in reaction conditions (other than for DEMO 4, which had no effective copper addition), differences in the anions results should be attributable to the differences in the duration of each experiment. Therefore, DEMO 2 and DEMO 3 should provide very similar results, while Test $3 \mathrm{c}$ should provide results far different from DEMO 2 or DEMO 3. However, this can be shown to be not the case. There are significant differences between all the analytes except fluoride, bromide and nitrate when comparing DEMO 2 and DEMO 3. Conversely, Test 3c, having a much shorter duration should show large differences when compared against DEMO 2 or DEMO 3. Yet, Test $3 \mathrm{c}$ has some analyte results similar to DEMO 2 (formate and sulfate), some similar to DEMO 3 (chloride) and some results that match neither DEMO 2 nor DEMO 3 (nitrite, phosphate, oxalate).

These test values are not normalized to each other, but from the ICPES data SRNL finds only a $12 \%$ variance between the sodium results in each test. Therefore, the lack or normalization cannot explain the large differences in results.

It is recognized that the CCPO chemical system is capable of generating formate and oxalate, but also is capable of destroying those anions. Nitrite is also subject to CCPO attack. It is not possible at this time to locate trends in these analytes. For those analytes that should not be subject to reduction-oxidation changes (chloride, phosphate, sulfate) these reasons for variations in those results are not known. 


\subsubsection{Conclusion}

The replicate reactions of DEMO 2 had different durations. This allowed SRNL to discern the effect of time on the residual organic concentrations. While the longer duration reactions produced smaller quantities of residual organics, shorter durations clearly did not allow for thorough destruction of residual organics. While DEMO 4 was performed under these conditions, it appears from the data that virtually no copper entered that system.

The presence of copper is important to shorten the time required to destroy the phenylborate compounds, but does not appear to be as important to destroy the residual organics.

The GC data for the replicates shows similar behaviors, although the extent of $\mathrm{CO}_{2}$ and benzene generated is strongly reaction dependent. The primary factor in benzene generation is the extent of acidification. For $\mathrm{CO}_{2}$ generation, the primary factor is time.

The replicate experiments show relatively good similarity of data with phenylborate destruction largely complete within 95 hours. Yield of carbon to benzene is nearly complete by that reaction time with the molar fraction converted to benzene ranging between 0.10 and 0.19 . [We suspect the relatively large variance in yield to benzene is due to mass transfer restrictions for the solid fuel. This variance may decrease for the actual process in which the solids are more nearly neutrally buoyant in the supernatant.] Only $\sim 50 \%$ of the total gas is released by 95 hours; with the remaining gas being largely carbon dioxide.

\subsection{Comparison of Tests with No Added Copper (DEMO 4 and Test 2c)}

A review of the DEMO 4 data indicates that this test had no added copper. Therefore, SRNL can use this opportunity to compare the DEMO 4 results to that of a similar previous test that also had no added copper - Test $2 \mathrm{c}$. The only difference between the two tests is the rate of added $\mathrm{H}_{2} \mathrm{O}_{2}$.

These experiments used the same reaction vessels and temperature controls $\left(50{ }^{\circ} \mathrm{C}\right)$ as described in Section 3.5. Other experimental details were as described in previous sections, except where noted below. It was noted that the "prototypical mixing" is in fact, very poor compared to reactions performed in poly bottles with a magnetic stirrer. The agitation was not sufficient enough to prevent a semi-stable floating solids mass. This may have effects in the overall reaction efficiency. 
Hydrogen peroxide was added at $0.2 \mathrm{~mL} /$ hour (Test $2 \mathrm{c}$ ) or $0.4 \mathrm{~mL} /$ hour (DEMO 4).

Each test continued for approximately 10-21 days. Filtrate samples were pulled one per day. From all reactions, a total of 10-21 samples were removed for analysis by ICPES.

\subsubsection{Soluble Boron Results}

After the start of the $\mathrm{H}_{2} \mathrm{O}_{2}$ addition the boron in the filtrate samples increased over time. See Figure 69. In the figure the data from Test $2 \mathrm{c}$ is included to show the effect of varying rates of $\mathrm{H}_{2} \mathrm{O}_{2}$ addition.

The reaction was halted after 215 hours, and the extent of boron dissolution associated with the acid hydrolysis and the peroxide oxidation reaction was calculated using the same methodology as in Section 3.1.1 (see Table 79).

Table 69. Total TPB Destruction from Boron Results - DEMO 4 vs. Test $2 \mathrm{c}$

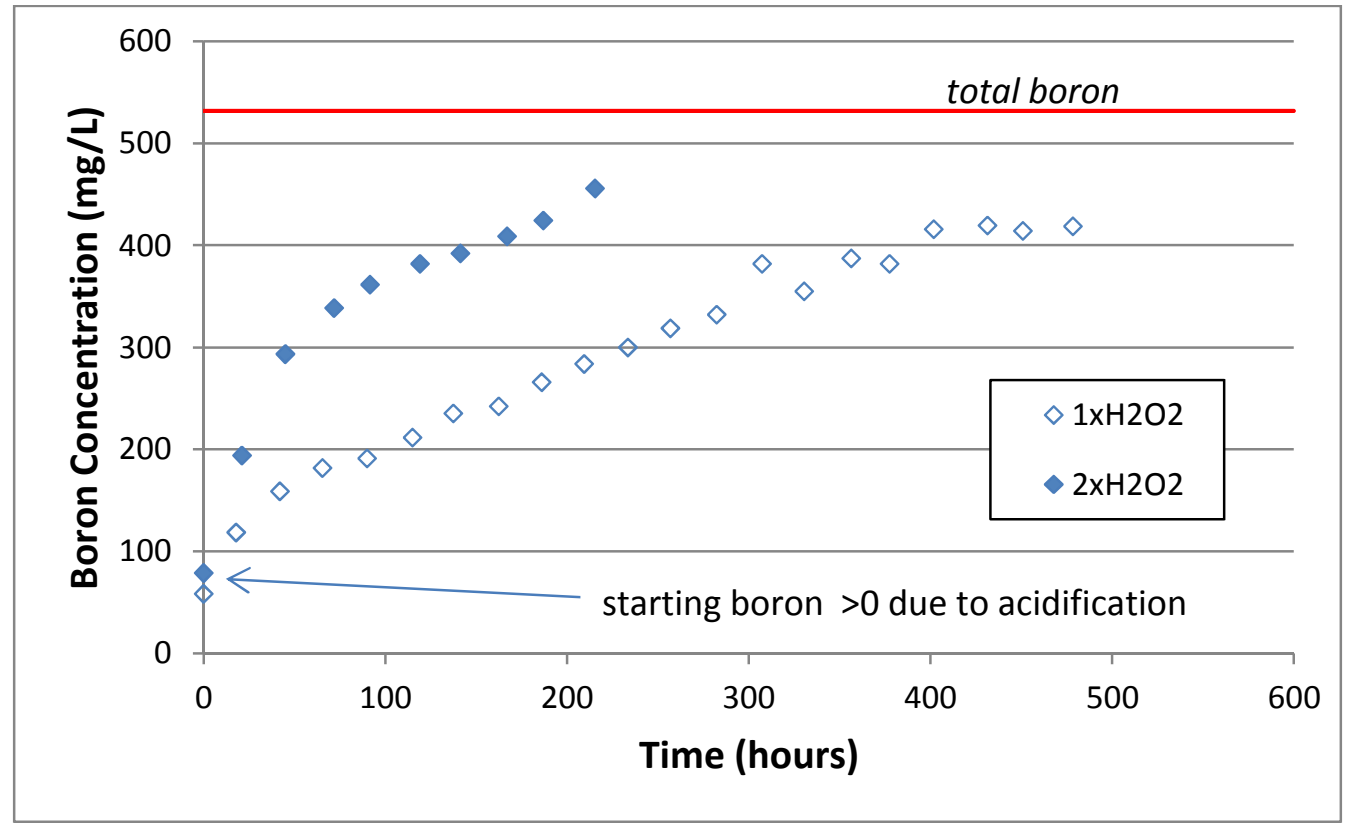

By the end of either test, the TPB destruction is not complete for either test. DEMO 4, with the higher $\mathrm{H}_{2} \mathrm{O}_{2}$ delivery rate, exhibits a higher rate of destruction. 
SRNL-STI-2012-00342

Revision 1

Figure 79. Boron Concentration Results Comparison at Varying Peroxide Addition Rates

\begin{tabular}{|c|c|c|c|c|c|}
\hline \multicolumn{2}{|c|}{ Destruction by Acid } & \multicolumn{2}{c|}{ Destruction by $\mathrm{H}_{2} \mathrm{O}_{2}$} & \multicolumn{2}{c|}{ Total Destruction } \\
\hline $1 \mathrm{xH}_{2} \mathrm{O}_{2}$ & $2 \mathrm{xH}_{2} \mathrm{O}_{2}$ & $1 \mathrm{xH}_{2} \mathrm{O}_{2}$ & $2 \mathrm{xH}_{2} \mathrm{O}_{2}$ & $1 \mathrm{xH}_{2} \mathrm{O}_{2}$ & $2 \mathrm{xH}_{2} \mathrm{O}_{2}$ \\
\hline $9.8-11.9 \%$ & $13.3-16.2 \%$ & $59.5-75.3 \%$ & $62.1-79.5 \%$ & $70.4-86.0 \%$ & $77.0-94.1 \%$ \\
\hline
\end{tabular}

\subsubsection{Soluble Potassium Results}

After the start of the $\mathrm{H}_{2} \mathrm{O}_{2}$ addition the potassium in the filtrate samples increased over time (see Figure 80). In the figure the data from Test $2 \mathrm{c}$ is included to show the effect of varying rates of $\mathrm{H}_{2} \mathrm{O}_{2}$ addition.

The reaction was halted after 215 hours, and the extent of potassium dissolution associated with the acid hydrolysis and the peroxide oxidation reaction was calculated using the same methodology as in Section 3.1.1 (see Table 70).

Figure 80. Potassium Concentration Results Comparison at Varying Peroxide Addition Rates

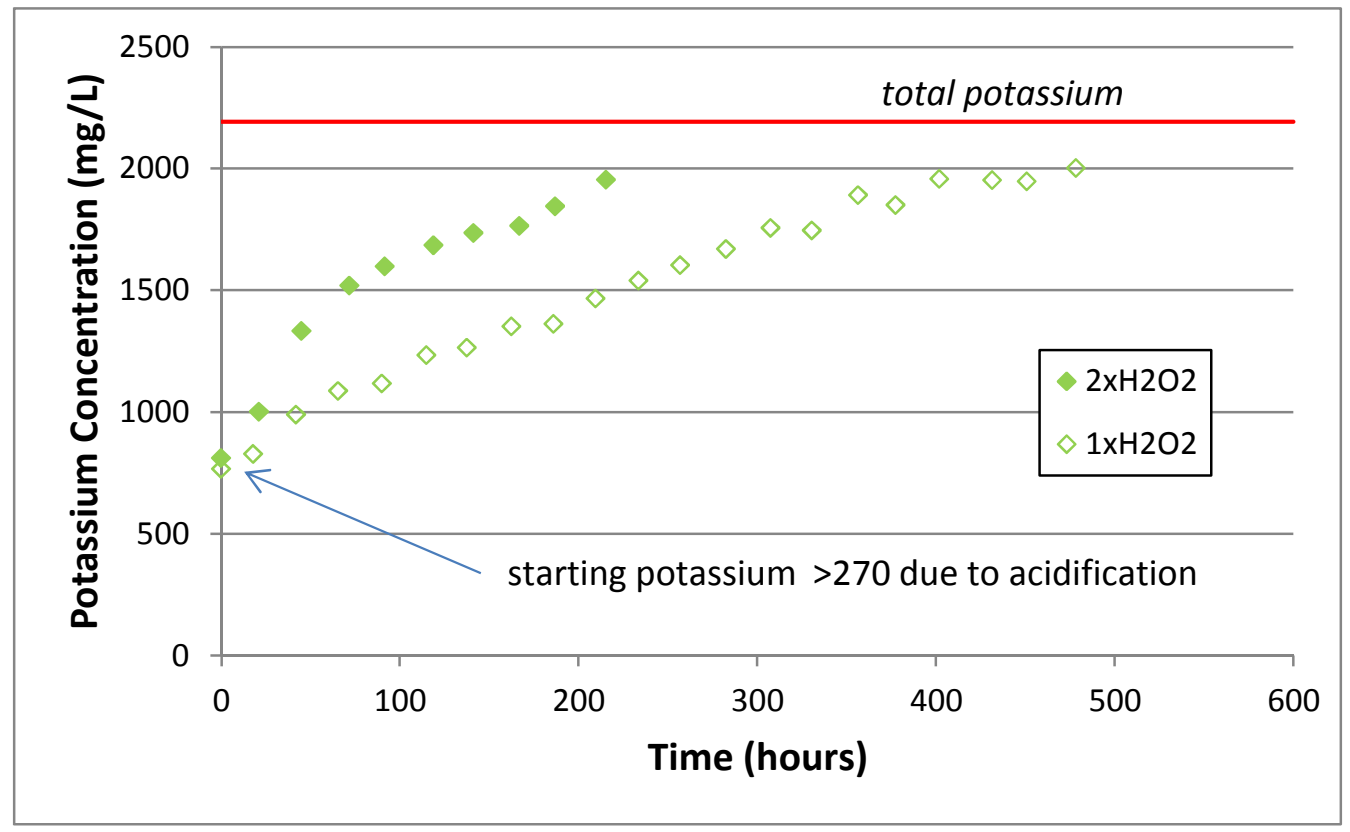


SRNL-STI-2012-00342

Revision 1

Table 70. Total TPB Destruction from Potassium Results - DEMO 4 vs. Test 2c

\begin{tabular}{|c|c|c|c|c|c|}
\hline \multicolumn{2}{|c|}{ Destruction by Acid } & \multicolumn{2}{c|}{ Destruction by $\mathrm{H}_{2} \mathrm{O}_{2}$} & \multicolumn{2}{c|}{ Total Destruction } \\
\hline $1 \mathrm{xH}_{2} \mathrm{O}_{2}$ & $2 \mathrm{xH}_{2} \mathrm{O}_{2}$ & $1 \mathrm{xH}_{2} \mathrm{O}_{2}$ & $2 \mathrm{xH}_{2} \mathrm{O}_{2}$ & $1 \mathrm{xH}_{2} \mathrm{O}_{2}$ & $2 \mathrm{xH}_{2} \mathrm{O}_{2}$ \\
\hline $21.6-29.5 \%$ & $23.9-32.3 \%$ & $52.9-75.1 \%$ & $48.6-70.6 \%$ & $79.2-100 \%$ & $77.5-97.9 \%$ \\
\hline
\end{tabular}

As with the boron data, the TPB destruction is incomplete by the end of either test.

\subsubsection{Soluble Copper Results}

No copper was added to either reaction.

\subsubsection{Soluble Titanium Results}

The titanium concentration in solution is monitored for the reasons outlined in Section 3.1.4. See Figure 81.

\section{Figure 81. Titanium Concentration Results for Increased $\mathrm{H}_{2} \mathrm{O}_{2}$ Addition}

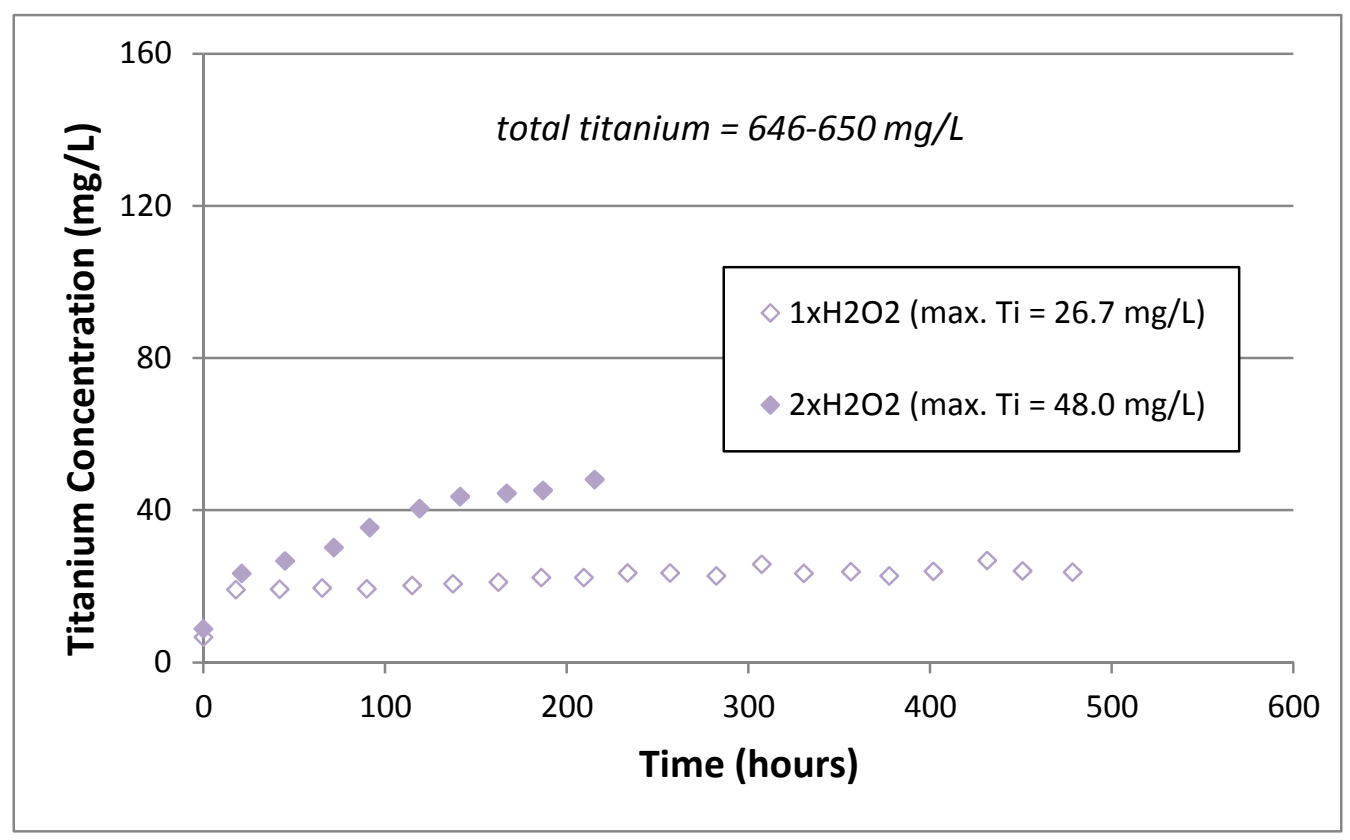

There is a clear trend that higher delivery rates generate higher titanium concentrations during the test. This is the same trend as noted in earlier comparisons of the effect of $\mathrm{H}_{2} \mathrm{O}_{2}$ addition rates in Sections 3.2 and 3.8. 


\subsubsection{Analysis of Residual Slurry After Reaction}

After the reaction was complete, the residual post-reaction slurry was removed. The amount of recovered material is dependent on the efficiency of slurry removal since some solids were caked on the upper parts of the reactor or difficult to remove.

From the bottle of bottoms, well-mixed (in an attempt to ensure homogeneity) duplicate samples were analyzed via HPLC, VOA and SVOA. Table 71 lists the HPLC results.

Table 71. HPLC Results from Residual Slurry After Reaction Analyses (mg/L)

\begin{tabular}{|c|c|c|c|c|c|c|}
\hline Reaction & TPB & 3PB & 2PB & 1PB & Phenol & \% Destruction \\
\hline $1 \times \mathrm{H}_{2} \mathrm{O}_{2}$ & $\begin{array}{c}2585 \\
(0.82 \%)\end{array}$ & 12 & $<10$ & $<10$ & 33 & $84.6-84.8 \%$ \\
\hline $2 \times \mathrm{H}_{2} \mathrm{O}_{2}$ & $\begin{array}{c}1182 \\
(19.8 \%)\end{array}$ & $\begin{array}{c}52.0 \\
(24.5 \%)\end{array}$ & $\begin{array}{c}70.5 \\
(55.2 \%)\end{array}$ & $\begin{array}{c}114 \\
(10.6 \%)\end{array}$ & $\begin{array}{c}268 \\
(1.85 \%)\end{array}$ & $89.6-91.3 \%$ \\
\hline
\end{tabular}

The "\% Destruction" column is the calculated percent destruction. The value is based on the mass of TPB added to the simulant slurries and calculation of the mass of TPB in the residual slurry after reaction, after correcting for the mass of samples removed from the system during the reactions.

Given the incomplete destruction indicated by the boron and potassium data, detectable concentrations of all the HPLC analytes were anticipated.

Samples of the reactor bottoms were analyzed using VOA and SVOA (see Table 72). The values in parentheses are the \%RSD. In the analyte column, shaded cells indicate the presence of that analyte is doubtful due to chemical conditions or contaminants. The "total organic residuals" are the sum of all the mid-range values of the detected analytes, less benzene and the analytes that are declared to be from contaminants. The concentrations are the measured values and are not normalized to the beginning volumes. 
Table 72. VOA and SVOA Results for DEMO 4

\begin{tabular}{|c|c|}
\hline Analyte & Result (mg/L) \\
\hline Biphenyl & $320(8.84 \%)$ \\
\hline Terphenyl & $82.0(1.72 \%)$ \\
\hline 4-nitrophenol & $11.5(43.0 \%)$ \\
\hline Triphenylboroxin & $11.4(57.1 \%)$ \\
\hline o-hydroxybiphenyl & $5.52-8.28$ \\
\hline diisooctyl adipate & $4.50(53.4 \%)$ \\
\hline 4-nitro-1,1-biphenyl & $3.45(14.4 \%)$ \\
\hline Azobenzene & $2.95(2.40 \%)$ \\
\hline Quaterphenyl & $3.20(48.6 \%)$ \\
\hline diphenyl ether & $2.05(10.4 \%)$ \\
\hline 4-nitro-N-phenyl-benzeneamine & $1.70(8.32 \%)$ \\
\hline diphenyl mercury & $1.2-1.8$ \\
\hline 2-phenoxy-1,1-biphenyl & $1.15(6.15 \%)$ \\
\hline [1,1-biphenyl]-3-amine & $11.2-16.8$ \\
\hline Butanal & $0.12-0.18$ \\
\hline Benzene & $0.63(41.9 \%)$ \\
\hline Total organic residuals & 463 \\
\hline
\end{tabular}

Test $2 \mathrm{c}$ provided a comparable total organic residual value of $380 \mathrm{mg} / \mathrm{L}$, indicating that under these test conditions, the extra $\mathrm{H}_{2} \mathrm{O}_{2}$ is not causing a noticeable difference in the degradation of the residual organics. Given the previous SVOA results from Section 3.8., it is possible that the residual organics are largely untouched until the TPB and phenylborates are degraded, suggesting these species are more easily destroyed by the peroxide.

The diisooctyl adipate is a known plasticizer and is more than likely leachate from contact with a plastic surface such as the bottle that contained the slurry prior to the experiment or from the analytical method equipment. The other analytes are in trace concentrations.

\subsection{6 pH Monitoring}

$\mathrm{pH}$ was monitored during the reaction. See Figure 82.

Again, the $\mathrm{pH}$ values remain at $\sim \mathrm{pH} 9$ for the duration of the reaction. There is no apparent effect of varying the $\mathrm{H}_{2} \mathrm{O}_{2}$ additional rates on the resulting $\mathrm{pH}$. 
Figure 82. pH Readings for Effects of $\mathrm{H}_{2} \mathrm{O}_{2}$ Addition Rates

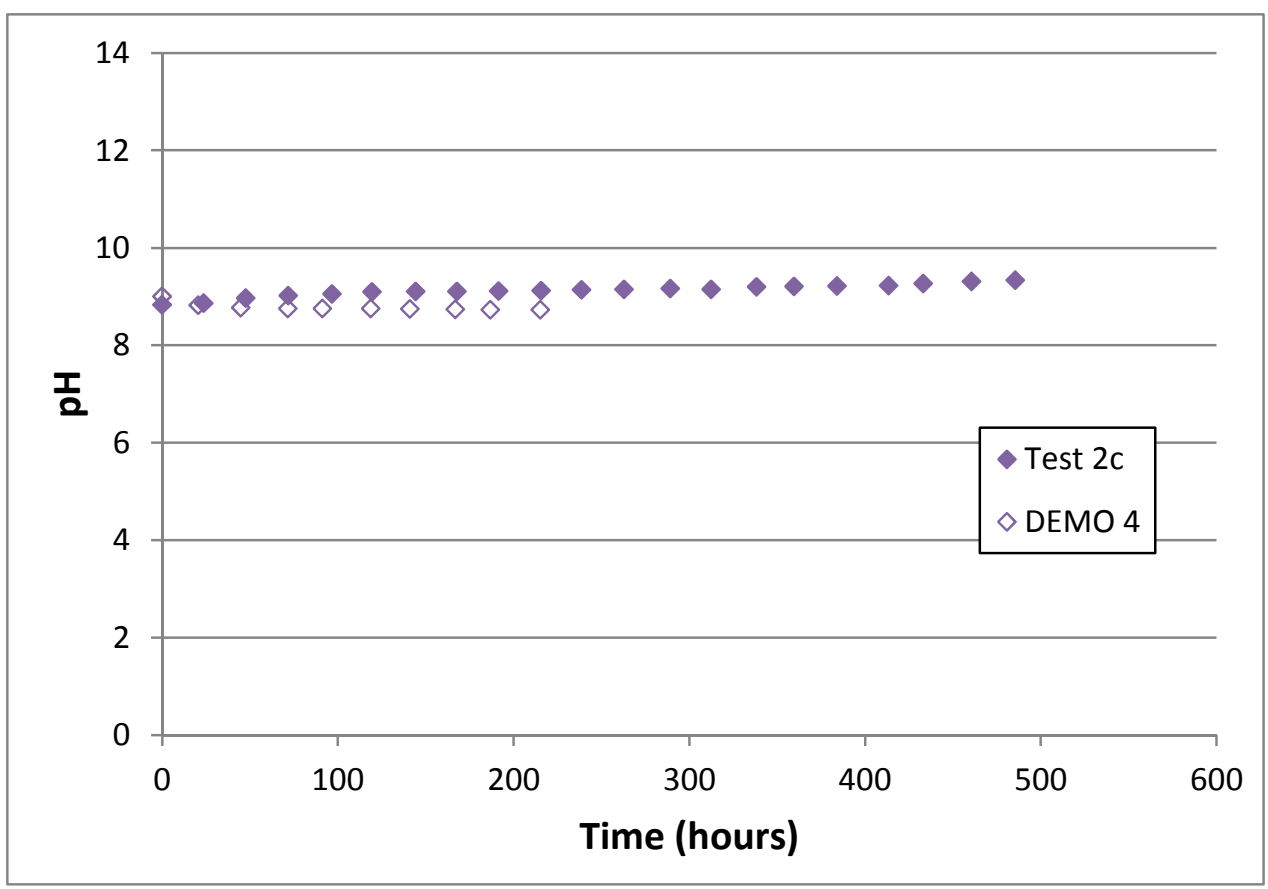

\subsubsection{GC Data}

For the duration of DEMO 4, including the $\mathrm{pH}$ adjustment, the off-gas composition was monitored using GC. There was no GC data available for Test $2 \mathrm{c}$. This enabled the important off-gas species such as benzene and $\mathrm{CO}_{2}$ to be tracked which can help determine how the organics are being broken down. See Figure 83.

All the concerns listed in regards to the GC data in Section 3.4.6 also pertain here. First, because of in-reactor acidification (as opposed to the 2004 work), it is impossible to deconvolute $\mathrm{CO}_{2}$ generated from acidification of carbonate in the simulant, and $\mathrm{CO}_{2}$ generated from organic oxidation. This is because degassing of the $\mathrm{CO}_{2}$ is not immediate and takes place over time. Second, the reactor vessel cannot be made gastight (the physical design has penetrations that cannot be completely sealed) and leaks are probable. 
Figure 83. Gas Release Rates for Demonstration 4

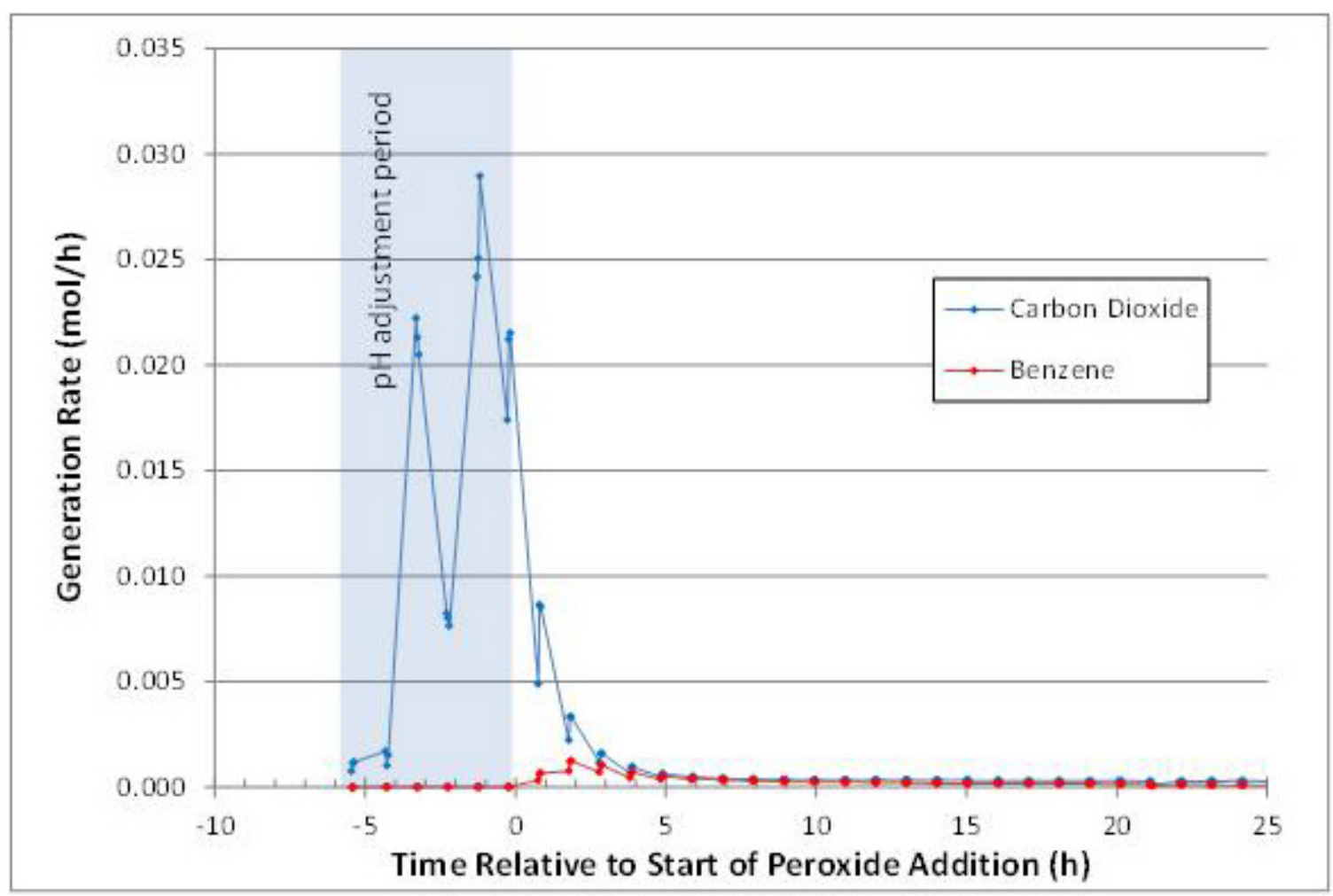

The major off-gas components are benzene and $\mathrm{CO}_{2}$. The benzene and $\mathrm{CO}_{2}$ are from the $\mathrm{pH}$ adjustment of the slurry, as well as degradation of organics (the presence of these two gases was observed throughout the reaction).

DEMO 4 shows the same general behavior as previously noted. While $\mathrm{CO}_{2}$ can be detected coming into the headspace almost immediately, benzene in the headspace is only detected after the $\mathrm{H}_{2} \mathrm{O}_{2}$ addition starts. The initial spikes in gas generation must be due to the $\mathrm{pH}$ adjustment process, and a closer inspection of the data set shows the same general behavior as observed for DEMO 1 and DEMO 2- the benzene and $\mathrm{CO}_{2}$ generation spikes closely follow the $\mathrm{pH}$ adjustment and then taper off quickly.

The GC data can be used in attempt to determine a mass balance for each test. To do this, the moles of benzene and $\mathrm{CO}_{2}$ available in the simulant slurry before $\mathrm{pH}$ addition must be determined, and compared against the moles of benzene and $\mathrm{CO}_{2}$ remaining in the residual slurry after reaction.

Figure 84 shows the cumulative amount of benzene and $\mathrm{CO}_{2}$ detected over the life of DEMO 4. 
Figure 84. Cumulative Off-gas Release in Demonstration 4

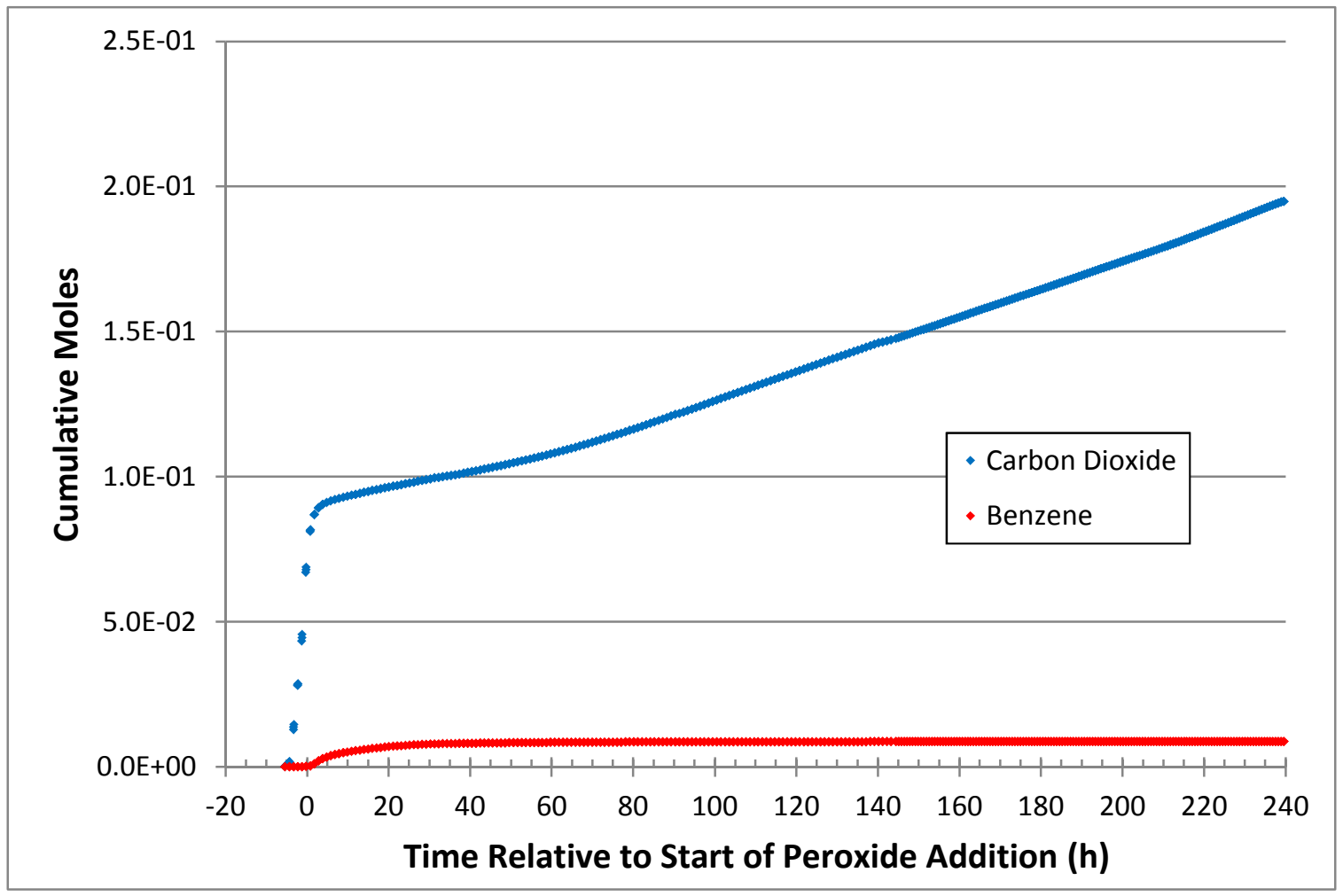

From the raw data the maximum amount of $\mathrm{CO}_{2}$ and benzene produced can be tabulated. However, as each of the tests ran for a different duration it is important to compare equivalent data. Therefore, the $\mathrm{CO}_{2}$ and benzene data is presented in terms of $\mathrm{CO}_{2}$ and benzene at 95 hours (relative to time $=0$ ), and at the end of each experiment. See Table 73.

Table 73. $\mathrm{CO}_{2}$ and Benzene Generation for DEMO 4

\begin{tabular}{|c|c|c|c|c|}
\hline \multirow{2}{*}{ Test } & \multicolumn{2}{|c|}{ Produced CO (moles) } & \multicolumn{2}{c|}{ Produced Benzene (moles) } \\
\cline { 2 - 5 } & 95 hours & Cumulative & 95 Hours & Cumulative \\
\hline DEMO 4 & 0.124 & 0.194 & 0.00857 & 0.00877 \\
\hline
\end{tabular}

From this table, we can draw several conclusions. First, the benzene generation in the test is effectively over by 95 hours Most of this benzene is generated right during the 
acidification. Further organic degradation (presumably of the residual organics) does not liberate further benzene into the headspace.

On the other hand, $\mathrm{CO}_{2}$ production continues on past 95 hours. As the residual organics are degraded through the $\mathrm{CCPO}$ process, $\mathrm{CO}_{2}$ is liberated. This is important to note while we are defining destruction in terms of TPB destruction, the process of grinding down the residual organics takes longer. The more time spent after TPB destruction is complete, the lower the concentration of residual organics.

The same methodology in Section 3.6.6 is used to determine the percent of $\mathrm{CO}_{2}$ compared to the theoretical maximum $\mathrm{CO}_{2}$ generated can be used for DEMO 4, giving $\sim 47 \%$ of the maximum $\mathrm{CO}_{2}$ is detected.

Potential losses from the system due to leaks are being investigated to account for the differential, but it would appear that for GC measurements after DEMO 1, the leaking has been reduced.

Curiously, DEMO 4 produced a smaller concentration of residual organics even though the copper concentration was very small compared to the other tests. It may be that the residual organics are more sensitive to the presence of $\mathrm{H}_{2} \mathrm{O}_{2}$ and not copper.

Alternatively, the lack of complete phenylborate destruction may be a factor is the apparent smaller quantity of residual organics.

\subsubsection{IC-Anions Data}

The fate of the various anions in the simulant was also evaluated. While most anions in the simulant slurry are likely unaffected by the reaction chemistry, it is known that the concentrations of certain anions, such as nitrite, oxalate or formate, may change during processing. In previous work, ${ }^{8}$ a number of reaction samples were examined to establish the effects on these types of anions. See Table 74.

There was no formate or oxalate added to the salt simulant, so the appearance of those species is significant and must be generated as part of the $\mathrm{CCPO}$ reaction. 
SRNL-STI-2012-00342

Revision 1

Table 74. IC-Anions Concentration Results for DEMO 4

\begin{tabular}{|c|c|}
\hline \multirow{2}{*}{ Analyte } & Result (mg/L) \\
\cline { 2 - 2 } & DEMO 4 \\
\hline fluoride & $<100$ \\
\hline formate & 155 \\
\hline chloride & 144 \\
\hline nitrite & 7650 \\
\hline bromide & $<500$ \\
\hline nitrate & 108000 \\
\hline phosphate & 334 \\
\hline sulfate & 156 \\
\hline oxalate & 545 \\
\hline
\end{tabular}

The analytical uncertainty for each IC-Anions sample is $10 \%$.

When compared to Table 68, we note a wide variety of results. It is difficult to locate a pattern in these results.

\subsubsection{Conclusion}

By using the DEMO 4 results, SRNL can provide an additional comparison on the effect of $\mathrm{H}_{2} \mathrm{O}_{2}$ addition rates. The same conclusions that were noted in previous sections $(3.2$ and 3.8) are also noted here.

\subsection{Alternate Acidification Strategies}

Concentrated (10.4M) nitric acid is used to $\mathrm{pH}$ adjust the caustic slurries. While effective in this role, it is known that this material is quite reactive and there is clear evidence that it will react with the phenylborates to produce undesirable benzene and generate undesirable organic compounds. SRNL performed a series of four, limited duration tests that examined the effects on benzene and residual organic production, from using different acidification strategies, using different acids, or lengthening the overall acidification process. Descriptions of these tests follow.

ACID 1: Standard operating parameters, except that after $\mathrm{pH}$ is reached, there was a 24 hour waiting period. The slurry was then heated to the $50{ }^{\circ} \mathrm{C}$ reaction temperature, followed by another 24 hour waiting period. At that point the standard operating 
procedures were continued (add benzene, copper, start $\mathrm{H}_{2} \mathrm{O}_{2}$ ). The total reaction time was 46 hours.

ACID 2: Standard operating parameters, except that $10.4 \mathrm{M}$ phosphoric acid $\left(\mathrm{H}_{3} \mathrm{PO}_{4}\right)$ was used in place of the nitric acid.

ACID 3: Standard operating parameters, except that $10.4 \mathrm{M}$ formic acid $\left(\mathrm{HCO}_{2} \mathrm{H}\right)$ was used in place of the nitric acid.

ACID 4: Standard operating parameters, except that during acidification, the $\mathrm{pH}$ was adjusted to 11 , followed by a 6 hour waiting period. Acidification was resumed until the slurry was adjusted to a $\mathrm{pH}$ of 9 , followed by the standard operating procedures.

GC data was also collected at this time to monitor the offgas.

\subsubsection{Soluble Boron Results}

After the start of the $\mathrm{H}_{2} \mathrm{O}_{2}$ addition the boron in the filtrate samples increased over time or all experiments. See Figure 85. The data from DEMO 3 (section 3.14.1) is also shows for comparative purposes.

Figure 85. Boron Concentration Comparison between Alternate Acidifications

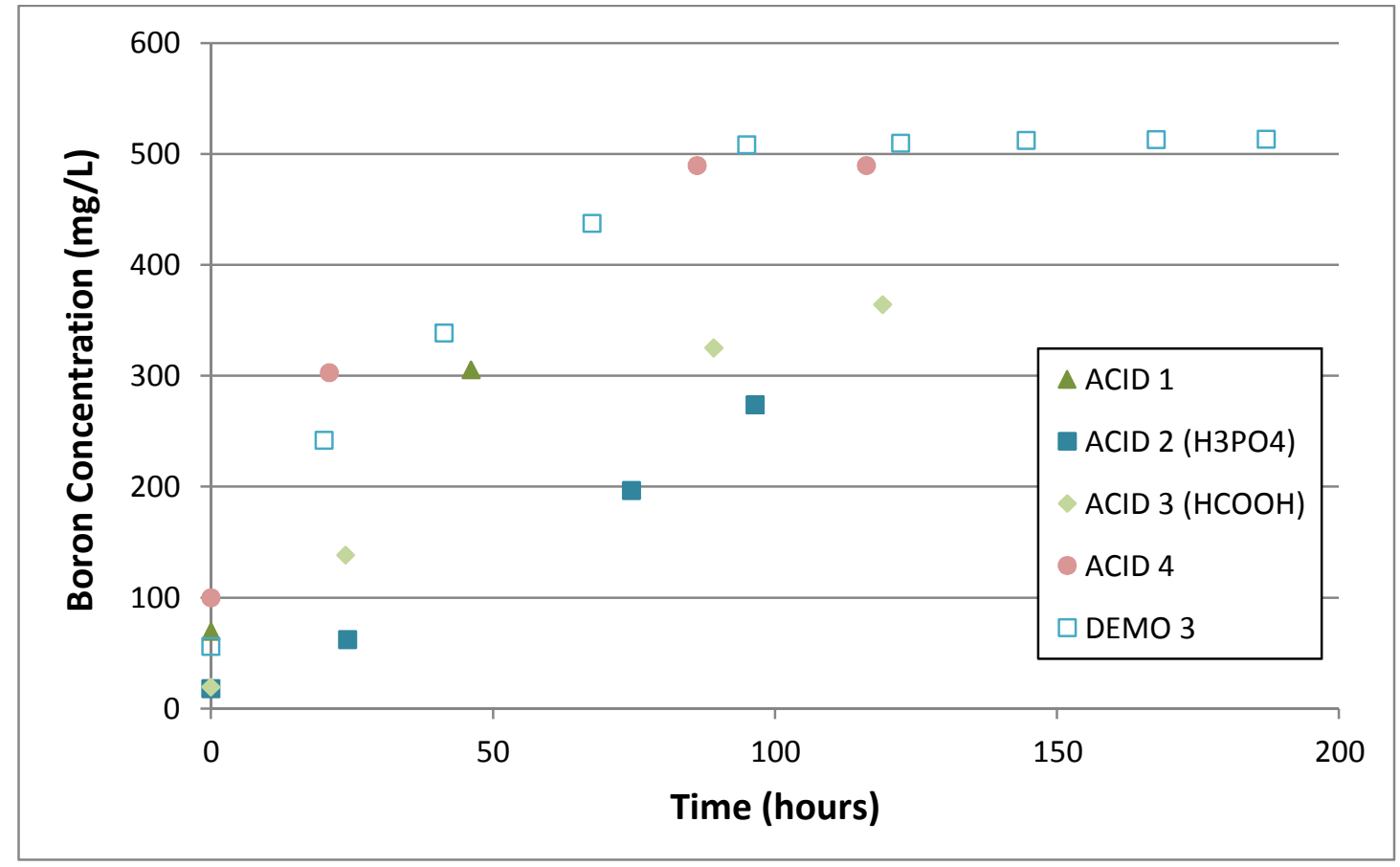


ACID 2 and ACID 3 give significantly lower starting boron results than ACID 1 and ACID 4.

After each reaction was halted the extent of boron dissolution associated with the acid hydrolysis and peroxide oxidation reactions was calculated using the same methodology as in Section 3.1.1 (see Table 75).

\section{Table 75. Total TPB Destruction from Final Boron Results between Alternate Acidifications}

\begin{tabular}{|c|c|c|c|}
\hline \multicolumn{4}{|c|}{ Destruction by Acid } \\
\hline ACID 1 & ACID 2 & ACID 3 & ACID 4 \\
\hline $11.7-14.3 \%$ & $2.68-3.28 \%$ & $3.24-3.96 \%$ & $16.7-20.4 \%$ \\
\hline \multicolumn{4}{|c|}{ Destruction by $\mathrm{H}_{2} \mathrm{O}_{2}$} \\
\hline ACID 1 & ACID 2 & ACID 3 & ACID 4 \\
\hline $38.2-49.9 \%$ & $38.7-48.0 \%$ & $58.1-71.8 \%$ & $63.2-81.8 \%$ \\
\hline \multicolumn{4}{|c|}{ Total Destruction } \\
\hline ACID 1 & ACID 2 & ACID 3 & ACID 4 \\
\hline $51.3-62.7 \%$ & $41.7-50.9 \%$ & $61.7-75.4 \%$ & $82.0-100 \%$ \\
\hline
\end{tabular}

ACID 1 (nitric acid) and ACID 4 (nitric acid) give higher acid destruction than ACID 2 (phosphoric acid) and ACID 3 (formic acid), but are comparable to the average of all the nitric acid acidifications to $\mathrm{pH} 9$ that SRNL has performed as part of this body of work; averaging $13.2 \%$.

As anticipated and desired, both ACID 2 (phosphoric acid) and ACID 3 (formic acid) reduced the amount of TPB that is converted into benzene through acid hydrolysis. Compare the "average destruction by acid" results for ACID 2 and ACID 3, 2.98\% and $3.60 \%$, respectively. This extent of TPB destruction is much lower than the average $\mathrm{pH} 9$ acid destruction. However, with lower acid destruction, it will take longer to degrade the remaining TPB though the CCPO mechanism. Given the short duration of these tests, SRNL cannot accurately estimate the minimum time required to completely destroy the TPB in these tests.

\subsubsection{Soluble Potassium Results}

As in previous experiments, the potassium in solution was measured as an indicator of organic destruction. After the start of the $\mathrm{H}_{2} \mathrm{O}_{2}$ addition the potassium in the filtrate samples increased over time. See Figure 86. 
Figure 86. Potassium Concentration Comparison between Alternate Acidifications

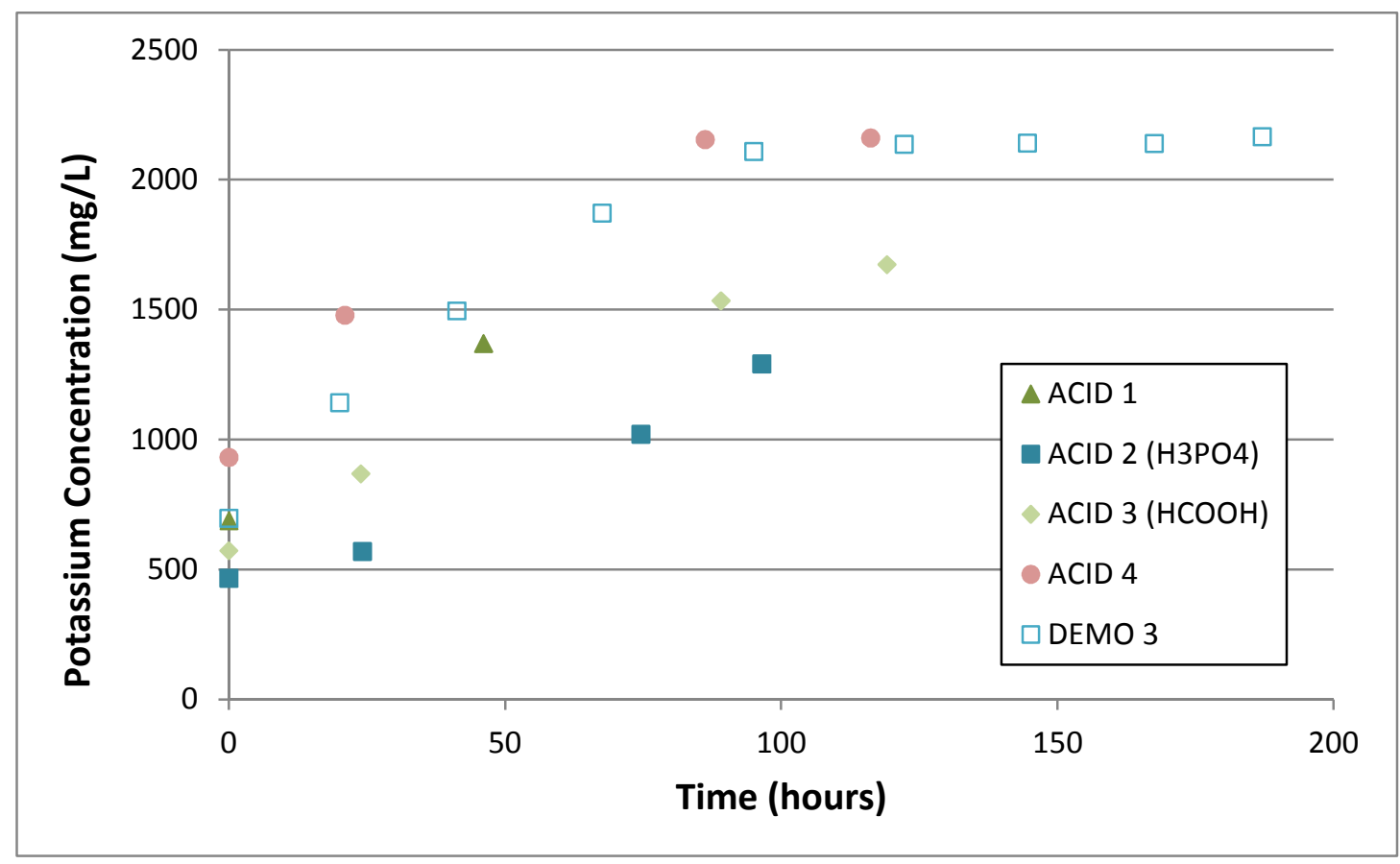

The potassium graph shows the same trends as the boron graph.

After each reaction was stopped the extent of potassium dissolution associated with the acid hydrolysis and peroxide oxidation reactions was calculated using the same methodology as in Section 3.1.1 (see Table 76).

Table 76. Total TPB Destruction from Final Potassium Results between Alternate Acidifications

\begin{tabular}{|c|c|c|c|}
\hline \multicolumn{4}{|c|}{ Destruction by Acid } \\
\hline ACID 1 & ACID 2 & ACID 3 & ACID 4 \\
\hline $18.0-25.1 \%$ & $5.55-9.90 \%$ & $12.7-18.7 \%$ & $29.1-38.8 \%$ \\
\hline \multicolumn{4}{|c|}{ Destruction by $\mathrm{H}_{2} \mathrm{O}_{2}$} \\
\hline ACID 1 & ACID 2 & ACID 3 & ACID 4 \\
\hline $27.4-43.2 \%$ & $32.2-45.0 \%$ & $48.2-66.6 \%$ & $51.2-75.4 \%$ \\
\hline \multicolumn{4}{|c|}{ Total Destruction } \\
\hline ACID 1 & ACID 2 & ACID 3 & ACID 4 \\
\hline 49.8-63.9\% & $40.3-52.4 \%$ & $64.4-81.8 \%$ & $86.2-108 \%$ \\
\hline
\end{tabular}


The average of all nitric acid-pH 9 destruction values is $26.0 \%$.

As with the boron data, there is a marked difference in the acid destruction for ACID 2 (phosphoric acid yielded 7.72\%) and ACID 3(formic acid yielded 15.7\%), compared to the average of all nitric acid destruction values $(26.0 \pm 5.48 \%)$. Again, the phosphoric and formic acids demonstrate a lesser degree of hydrolysis of the TPB solids.

\subsubsection{Soluble Copper Results}

The copper concentrations in the filtrate were monitored for the reasons outlined in Section 3.1.3. After the start of the $\mathrm{H}_{2} \mathrm{O}_{2}$ addition the copper in the filtrate samples increased and then remained steady. See Figure 87.

Figure 87. Soluble Copper Concentration Comparison between Alternate Acidifications

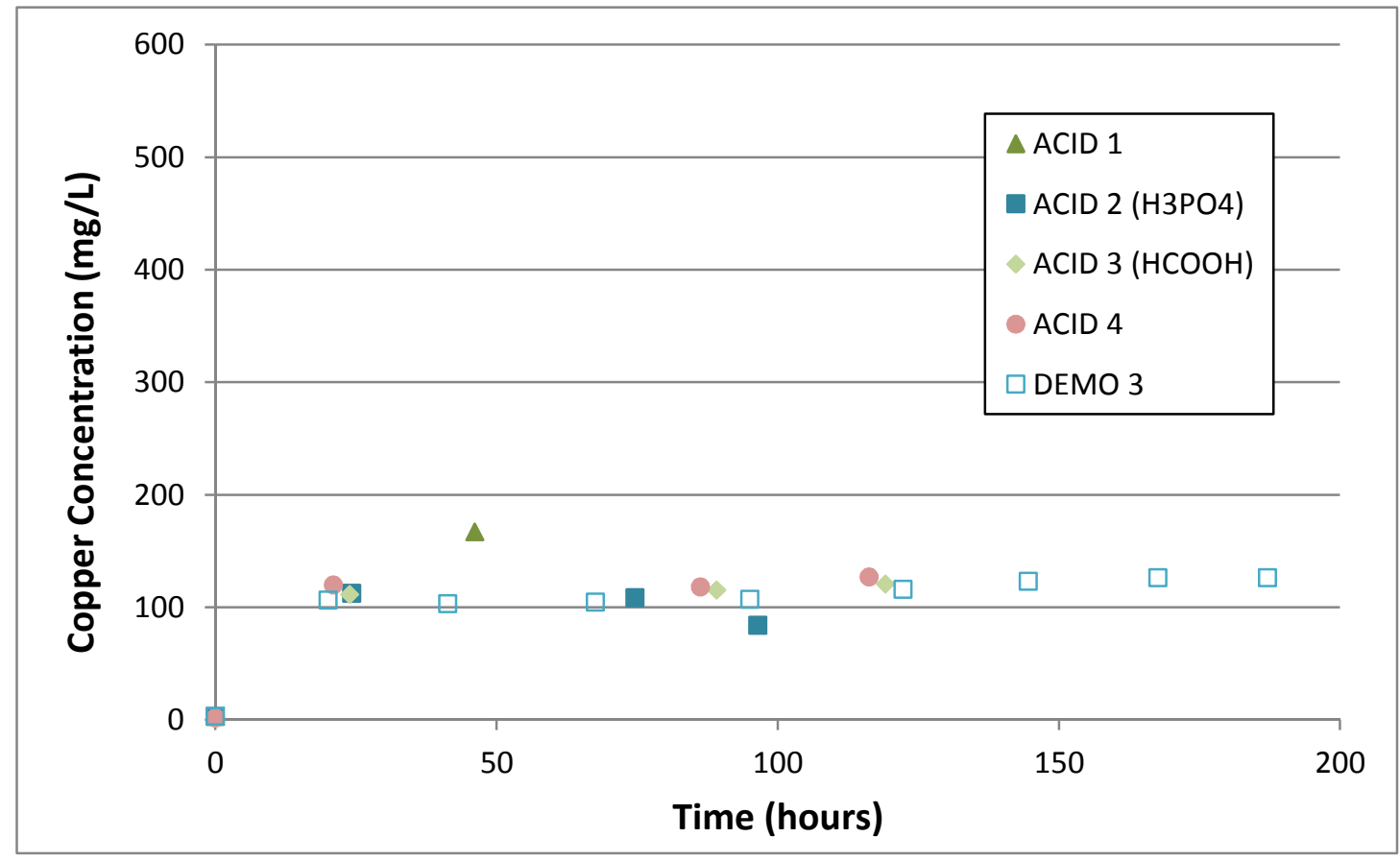

There is no clear distinction between the different tests. Solubility seems to plateau around $100 \mathrm{mg} / \mathrm{L}$, like most other tests that use $500 \mathrm{mg} / \mathrm{L}$ of copper catalyst. While ACID 1 has a single relatively high data point, without further data, SRNL cannot distinguish whether ACID 1 is displaying usual or unusual copper behavior. 


\subsubsection{Soluble Titanium Results}

The titanium concentration in solution is monitored for the reasons outlined in Section 3.1.4. See Figure 88.

Figure 88. Titanium Concentration Comparison between Alternate Acidifications

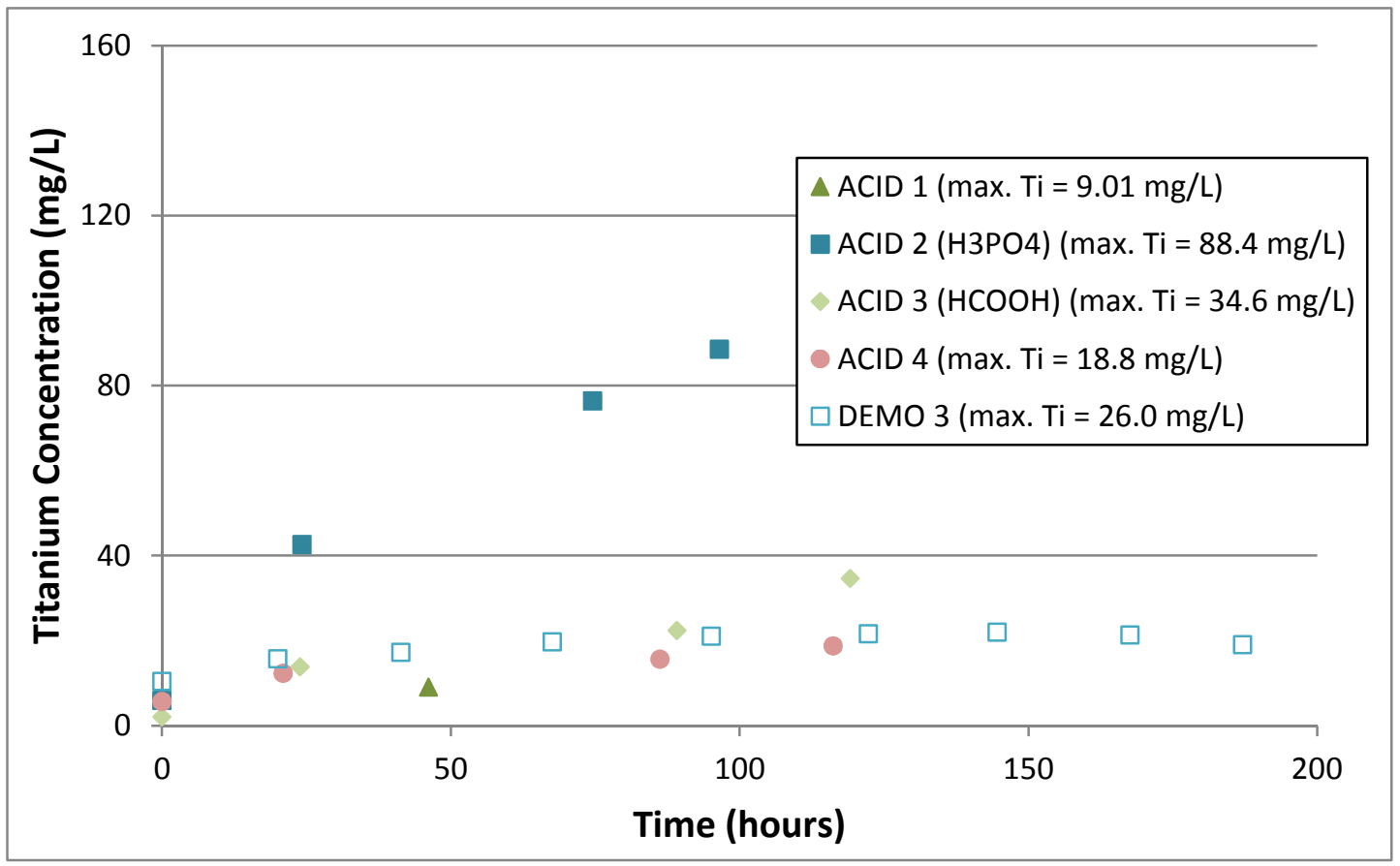

While ACID 1, ACID 3 and ACID 4 follow the typical pattern of titanium data, ACID 2 (phosphoric acid) shows a serious deviation from that pattern. This behavior must be investigated with further work to assess whether phosphoric acid cause appreciable release of fissile species from loaded MST. From this perspective, use of phosphoric acid appears less desirable.

\subsubsection{Analysis of Residual Slurry After Reaction}

After the reaction was complete, the reactor bottom was removed. The amount of recovered material is dependent on the efficiency of slurry removal since some solids were caked on the upper parts of the reactor or difficult to remove. 
From the bottle of residual slurry after reaction, well-mixed (in an attempt to ensure homogeneity) duplicate samples were analyzed via HPLC, VOA and SVOA. Table 77 lists the HPLC results (all the listed results are from single analyses). The analytical uncertainty for each measurable result is $10 \%$.

Table 77. HPLC Results from Residual Slurry After Reaction Analyses (mg/L)

\begin{tabular}{|c|c|c|c|c|c|c|c|}
\hline Reaction & Duration (h) & TPB & 3PB & 2PB & 1PB & Phenol & \% Destruction \\
\hline ACID 1 & 46 & 5750 & $<50$ & $<50$ & 45 & 300 & $57.7-65.4 \%$ \\
\hline ACID 2 & 97 & 7910 & $<50$ & $<50$ & $<4$ & 23 & $46.0-55.8 \%$ \\
\hline ACID 3 & 119 & 3950 & $<50$ & $<50$ & $<4$ & 42 & $69.8-75.3 \%$ \\
\hline ACID 4 & 116 & $<4$ & $<4$ & $<4$ & $<4$ & $<4$ & $>99.97 \%$ \\
\hline
\end{tabular}

The "\% Destruction" column is the calculated percent destruction. The value is based on the mass of TPB added to the simulant slurries and calculation of the mass of TPB in the residual slurry after reaction, after correcting for the mass of samples removed from the system during the reactions.

Given the varying destruction indicated by the boron and potassium data, detectable levels of most of the HPLC analytes were anticipated.

While these reactions generally show poor TPB destruction, recall that complete TPB destruction was not the goal - these reactions were deliberately performed with short durations. If the relatively short durations are taken into consideration, it is possible to derive $\mathrm{mg} / \mathrm{L} /$ hour destruction rates. Dividing the amount of TBP destroyed in each test by the duration leads to values of $271,106,120$, and $157 \mathrm{mg} / \mathrm{L} /$ hour, respectively. This shows that ACID 1 and ACID 4 (the nitric acid tests) show faster relative destruction, which is due to the higher degree of initial hydrolysis.

Samples of the residual slurry after reaction from each reaction were analyzed using VOA and SVOA (see Tables 78-81). The values in parentheses are the \%RSD. In this case, the values in parentheses are the analytical uncertainties. In the analyte column, pink shaded cells indicate the presence of that analyte is doubtful due to chemical conditions or contaminants. The "total organic residuals" are the sum of all the midrange values of the detected analytes, less benzene and the analytes that are declared to be from contaminants. These results are not normalized to the beginning volumes. 
Table 78. VOA and SVOA Results for ACID 1

\begin{tabular}{|c|c|}
\hline Analyte & Result (mg/L) \\
\hline biphenyl & $544-816$ \\
\hline terphenyl & $51.2-76.8$ \\
\hline 2-nitrophenol & $36-54$ \\
\hline [1,1-biphenyl]-3-amine & $20.8-31.2$ \\
\hline nitrosobenzene & $14.4-21.6$ \\
\hline diphenyl ether & $13.6-20.4$ \\
\hline methyldiphenylpyridine & $10.4-15.6$ \\
\hline diphenylamine & $8-12$ \\
\hline quaterphenyl & $6.8-10.2$ \\
\hline 4-nitro-N-phenyl-benzeneamine & $6.08-9.12$ \\
\hline diisooctyl adipate & $5.92-8.88$ \\
\hline nitrobenzene & $4.24-6.36$ \\
\hline butylated hydroxytoluene & $3.36-5.04$ \\
\hline $\mathrm{N}, \mathrm{N}$-diphenyl-benzeneamine & $2.96-4.44$ \\
\hline azobenzene & $2.32-3.48$ \\
\hline nitrobiphenyl & $2.24-3.36$ \\
\hline diphenyl-(2-pyridyl)methanol & $1.68-2.52$ \\
\hline benzene & $2.08-3.12$ \\
\hline Total organic residuals & 913 \\
\hline
\end{tabular}

Table 79. VOA and SVOA Results for ACID 2

\begin{tabular}{|c|c|}
\hline Analyte & Result (mg/L) \\
\hline biphenyl & $800-1200$ \\
\hline terphenyl & $49.6-74.4$ \\
\hline 2-nitrophenol & $39.2-58.8$ \\
\hline diisooctyl adipate & $10.4-15.6$ \\
\hline quaterphenyl & $8-12$ \\
\hline diphenyl ether & $1.52-2.28$ \\
\hline benzene & $0.152-0.228$ \\
\hline Total organic residuals & 1123 \\
\hline
\end{tabular}


Table 80. VOA and SVOA Results for ACID 3

\begin{tabular}{|c|c|}
\hline Analyte & Result (mg/L) \\
\hline biphenyl & $608-912$ \\
\hline terphenyl & $59.2-88.8$ \\
\hline nitrophenol & $11.2-16.8$ \\
\hline nitrobenzene & $7.52-11.3$ \\
\hline quaterphenyl & $6-9$ \\
\hline nitrobiphenyl & $3.04-4.56$ \\
\hline diphenyl ether & $2.16-3.24$ \\
\hline N-butyl-N-nitroso-1-butanamine & $1.76-2.64$ \\
\hline o-phenylene benzeneboronate & $1.28-1.92$ \\
\hline diphenylamine & $0.96-1.44$ \\
\hline azobenzene & $0.88-1.32$ \\
\hline benzene & $0.128-0.192$ \\
\hline Total organic residuals & 868 \\
\hline
\end{tabular}

Table 81. VOA and SVOA Results for ACID 4

\begin{tabular}{|c|c|}
\hline Analyte & Result (mg/L) \\
\hline biphenyl & $232-348$ \\
\hline diphenyl ether & $14.4-21.6$ \\
\hline terphenyl & $9.6-14.4$ \\
\hline diphenylamine & $7.2-10.8$ \\
\hline N, N-diphenyl-benzeneamine & $5.84-8.76$ \\
\hline diisooctyl adipate & $5.84-8.76$ \\
\hline 2-nitro-N-phenyl-benzeneamine & $1.92-2.88$ \\
\hline 4-nitro-N-phenyl-benzeneamine & $1.52-2.28$ \\
\hline 2-phenoxybiphenyl & $1.12-1.68$ \\
\hline azobenzene & $0.96-1.44$ \\
\hline butanal & $0.112-0.168$ \\
\hline benzene & $0.112-0.168$ \\
\hline Total organic residuals & 343 \\
\hline
\end{tabular}


From the VOA and SVOA data, it is possible to see a rough inverse correlation between the extent of TPB destruction and the concentration of residual organics. From highest to lowest TPB destruction, the sequence is ACID $4>$ ACID $3>$ ACID $1>$ ACID 2. The inverse sequence is observed for the concentration of organic residuals. However, the reader should consider that the different test durations may have had an impact on the residual organic production. If the reaction duration is considered (see Table 77), there is no obvious time dependency, other to note that the only test that completely destroyed the TPB (ACID 4) had the lowest quantity of residual organics. This would seem to indicate that the residuals are largely destroyed after the TPB.

It can also be seen that the tests using nitric acid (ACID 1 and ACID 4), the type of residuals is more varied than seen for ACID 2 (phosphoric acid). This is likely due to the less reactive nature of phosphoric acid. The formic acid, while a relatively weak acid, can undergo redox reactions and may effectively promote greater variety in the type of organic residuals.

\subsection{6 pH Monitoring}

The $\mathrm{pH}$ was monitored during each reaction (see Figure 89).

Figure 89. pH Readings between Alternate Acidifications

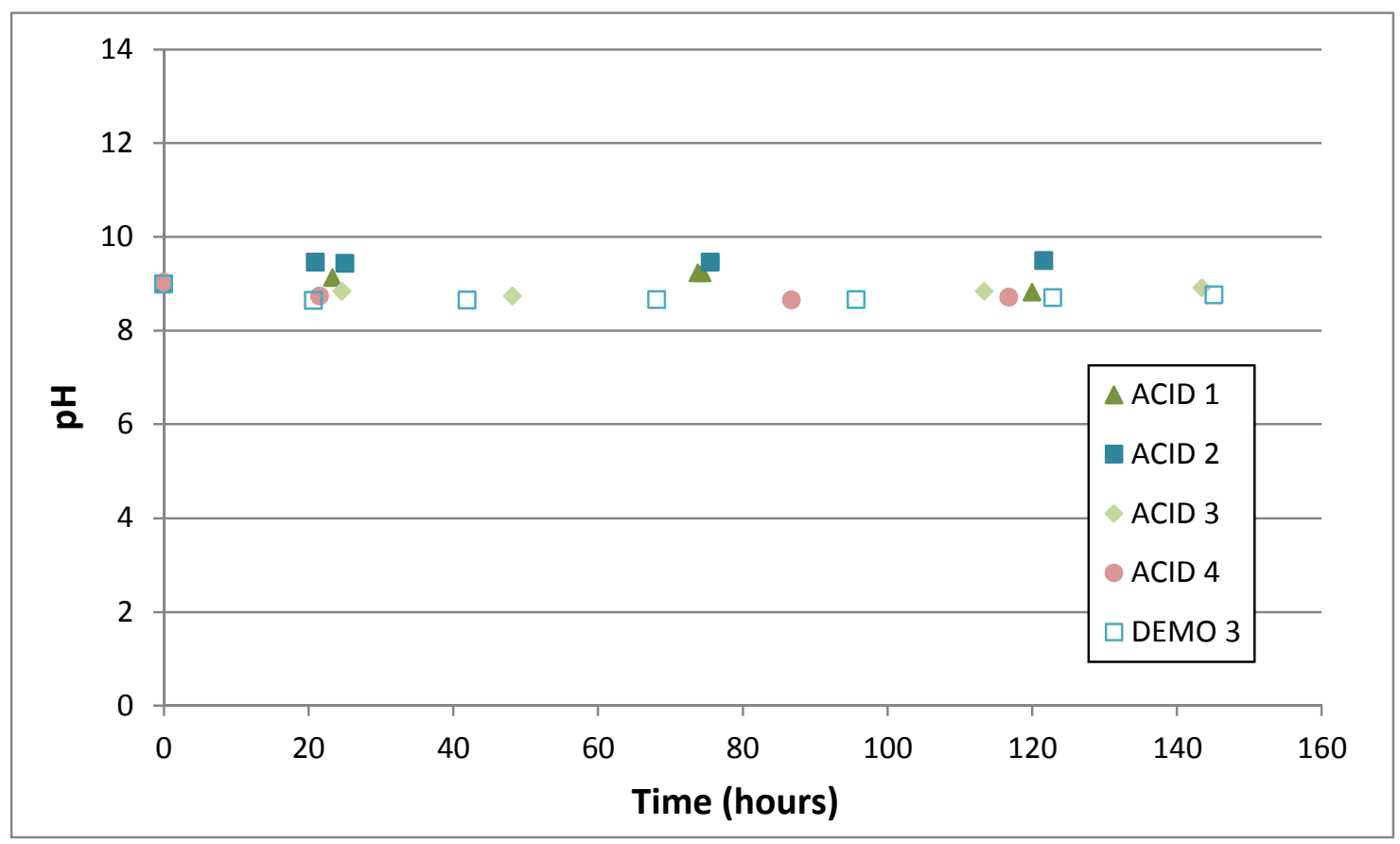


In all the tests, the $\mathrm{pH}$ trended towards a final $\mathrm{pH}$ of $\sim 9$, although ACID 2 trended slightly higher than the other tests. This may be due to the more complex $\mathrm{pH}$ chemistry of the triprotic phosphoric acid.

\subsubsection{Gas Chromatograph Data}

The headspace gasses were monitored during the tests to determine the impact of the alternate acidification strategies on generated gases with emphasis on benzene formation. See Figure 90. Data from DEMO 3 is also shown for comparative purposes.

All the concerns listed in regards to the GC data in Section 3.4.6 also pertain here.

Figure 90. Benzene Generation Rates in the Alternate Acidification Tests

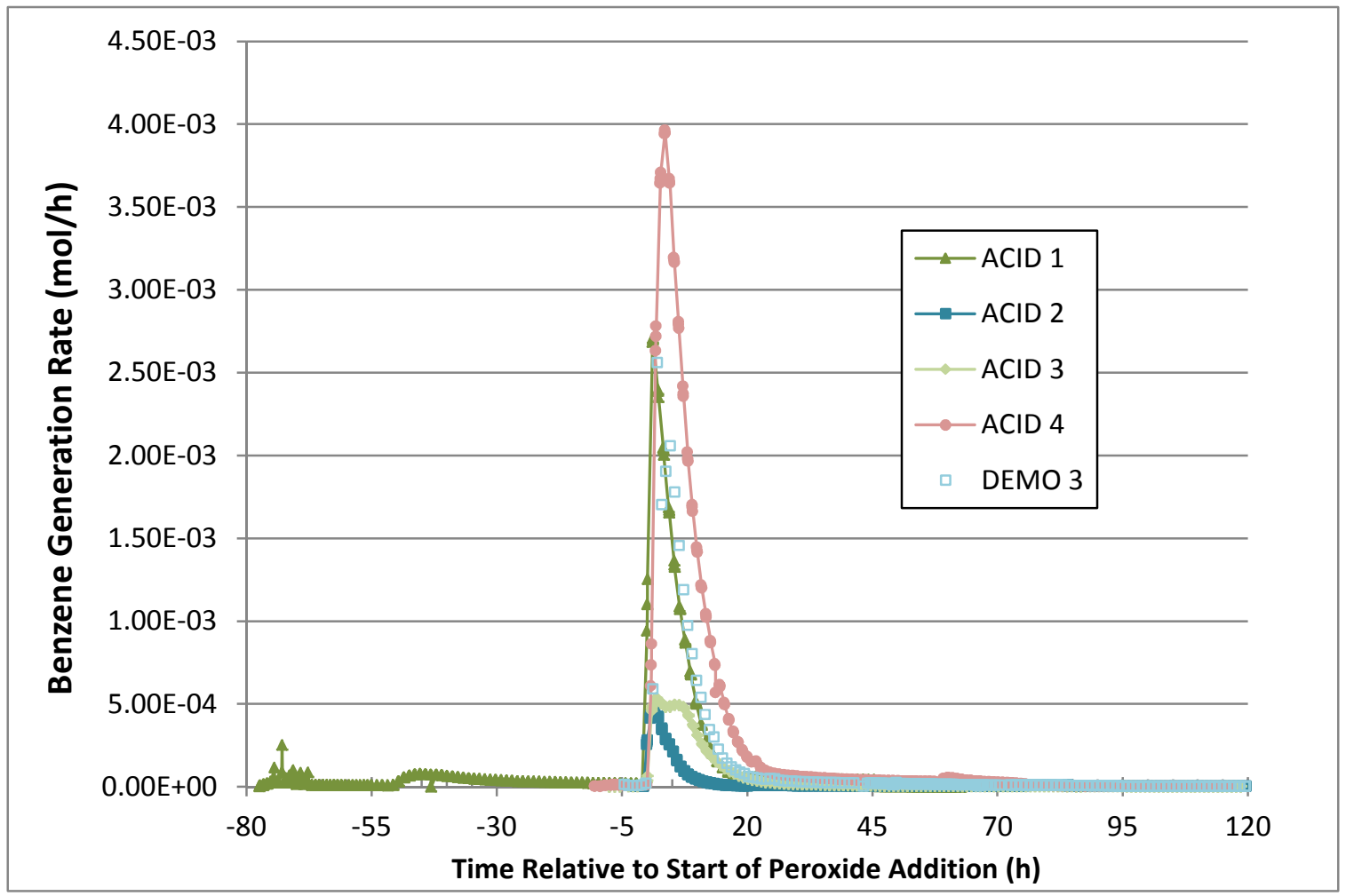

The peak generation rates are tabulated in Table 82. Data from DEMO 3 is shown for comparative purposes. 
Table 82. Peak Benzene Generation Rates in the Alternate Acidification Tests

\begin{tabular}{|c|c|c|}
\hline Test & $\begin{array}{c}\text { Peak Benzene Generation } \\
\text { Rate (mole/hour) }\end{array}$ & $\begin{array}{c}\text { Normalized to } \\
\text { DEMO3 }\end{array}$ \\
\hline ACID 1 & $2.71 \mathrm{E}-03$ & 1.04 \\
\hline ACID 2 & $4.66 \mathrm{E}-04$ & 0.18 \\
\hline ACID 3 & $5.35 \mathrm{E}-04$ & 0.21 \\
\hline ACID 4 & $3.94 \mathrm{E}-03$ & 1.52 \\
\hline DEMO 3 & $2.60 \mathrm{E}-03$ & 1 \\
\hline
\end{tabular}

The peak benzene generation rates for ACID 1 and ACID 4 show that the pauses in acidification did not provide greatly different behavior compared to DEMO 3. This can be more easily noted in Figure 91.

Figure 91. Detailed Examination of ACID 1 and ACID 4

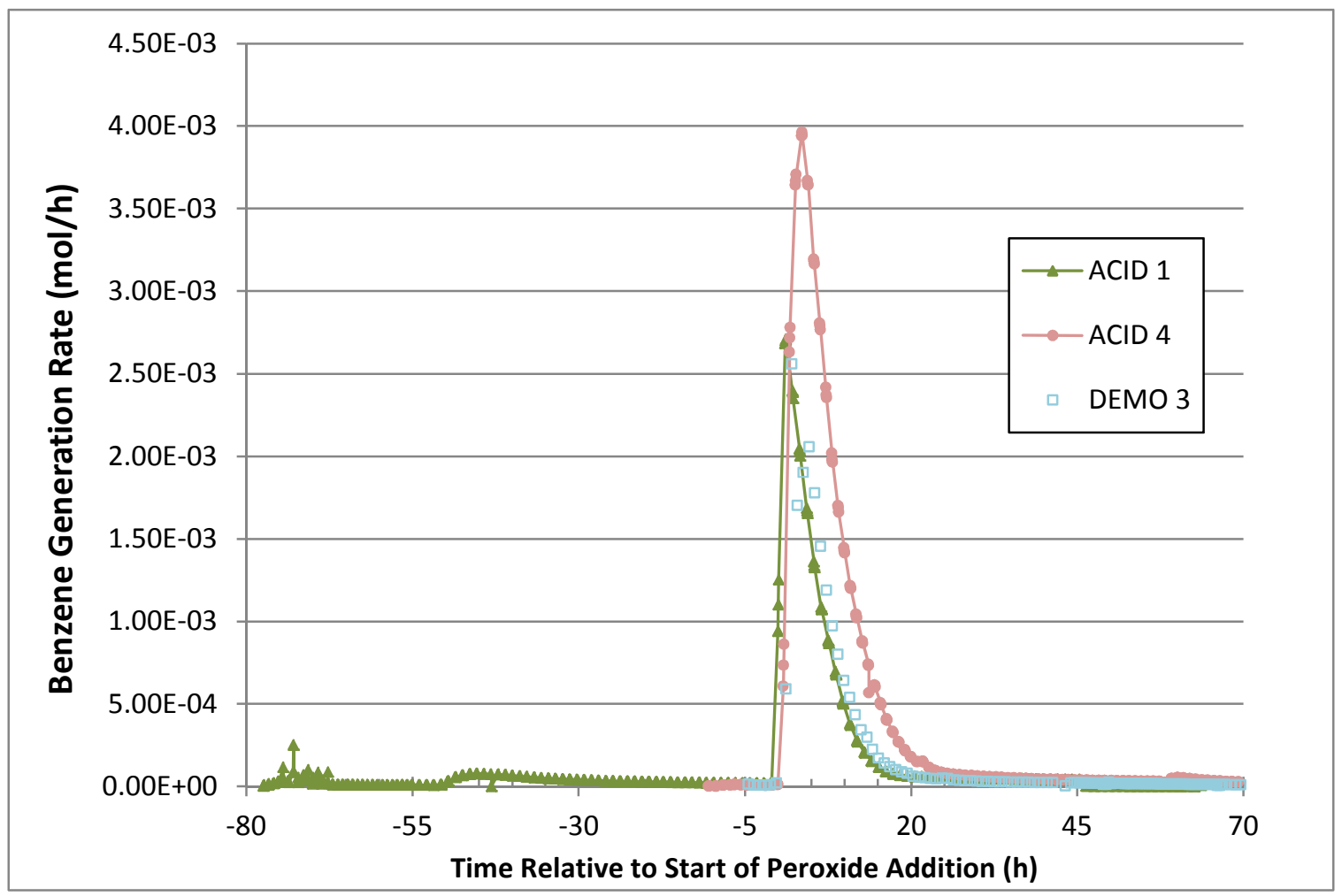


The GC data corroborates the boron and potassium data. Those tests that gave the highest boron and potassium destruction by acid (Sections 3.15.1 and 3.15.2) also showed the highest benzene generation - ACID 1 and ACID 4 - the nitric acid tests. Formic and phosphoric acids proved equally effective in reducing benzene yield by roughly $80 \%$. ACID 1 gave very similar results to DEMO 3, showing excellent replication under identical conditions.

The $\sim 50 \%$ higher peak concentration for ACID 4 is unexpected. This test deliberately reduced the rate of $\mathrm{pH}$ adjustment which intuitively should distribute the benzene release over longer periods. Instead, an increase in total benzene from $\mathrm{pH}$ adjustment is seen. The cause is unexplained at this time.

Figure 92 and Table 83 display the cumulative benzene produced as of 60 hours after the start of $\mathrm{H}_{2} \mathrm{O}_{2}$ addition in each test. 60 hours was the latest point with data available for all tests.

Figure 92. Cumulative Benzene Generation at 60 Hours in the Alternate Acidification Tests

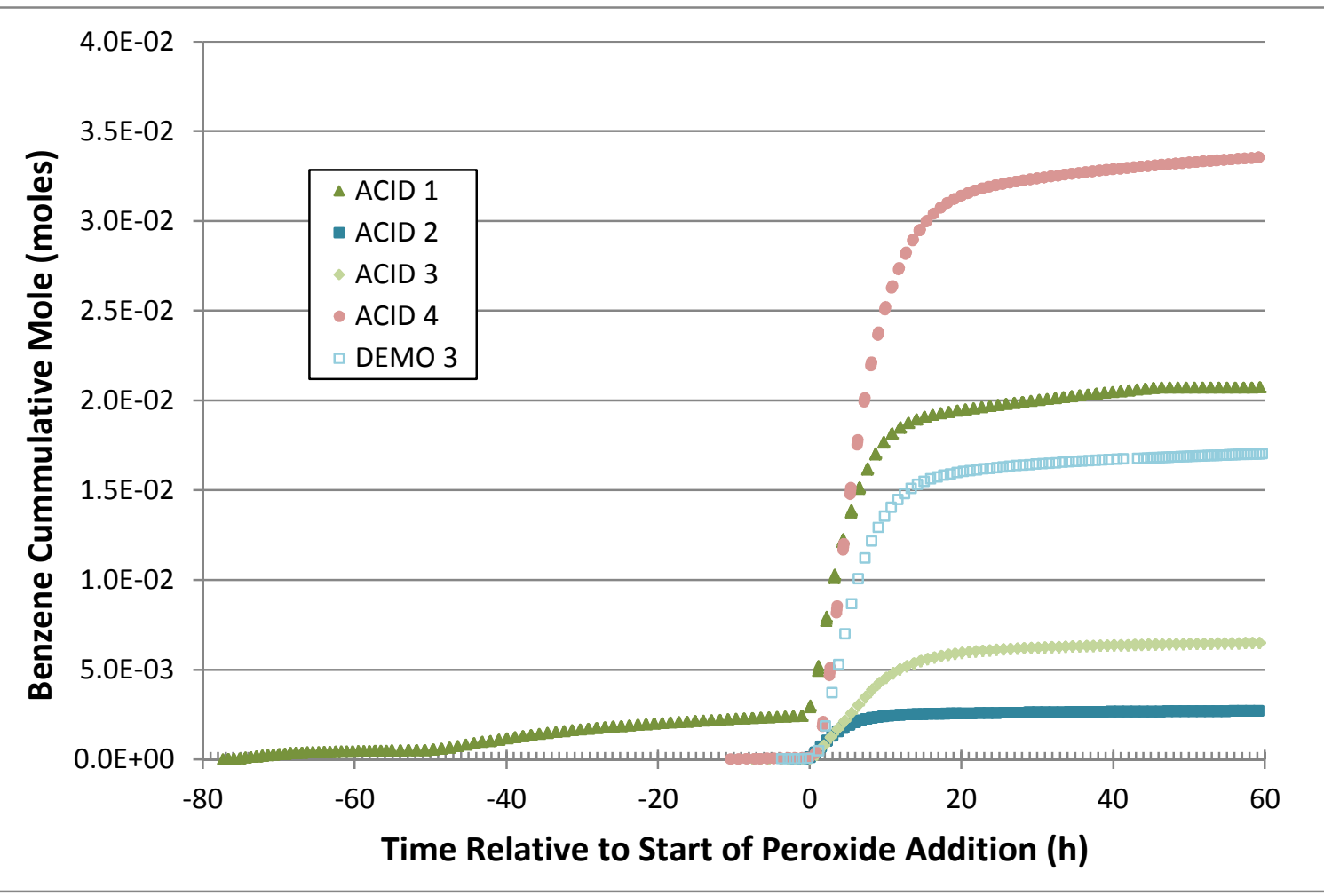


SRNL-STI-2012-00342

Revision 1

Table 83. Cumulative Benzene Generation at 60 Hours in the Alternate Acidification Tests

\begin{tabular}{|c|c|c|}
\hline Test & $\begin{array}{c}\text { 60 Hour Benzene } \\
\text { Generation (moles) }\end{array}$ & $\begin{array}{c}\text { Normalized to } \\
\text { DEMO 3 }\end{array}$ \\
\hline ACID 1 & $2.07 \mathrm{E}-02$ & 1.22 \\
\hline ACID 2 & $2.68 \mathrm{E}-03$ & 0.16 \\
\hline ACID 3 & $6.48 \mathrm{E}-03$ & 0.38 \\
\hline ACID 4 & $3.35 \mathrm{E}-02$ & 1.97 \\
\hline DEMO 3 & $1.70 \mathrm{E}-02$ & 1 \\
\hline
\end{tabular}

The total benzene generation data shows that the nitric acid tests not only provided the highest benzene point generation rates, but also the highest total quantity of benzene produced. On the other end, the phosphoric and formic acid provided the lowest amount of generated benzene. In the most extreme comparison, the ACID 2 test (phosphoric acid) generated less than $10 \%$ of the benzene produced by ACID 4 (nitric acid).

Comparison of ACID 1 and DEMO 3 suggests a $\sim 20 \%$ variance in cumulative generation for (nearly) replicate experiments. Conversely, the $20 \%$ offset may be a measure of the benzene that is destroyed by peroxide while during its residence time in the slurry. The benzene higher generation in ACID 4 is not understood at this time.

The $\mathrm{CO}_{2}$ was also monitored throughout the experiments. See Figure 93. 
Figure 93. $\mathrm{CO}_{2}$ Generation Generation Rates in the Alternate Acidification Tests

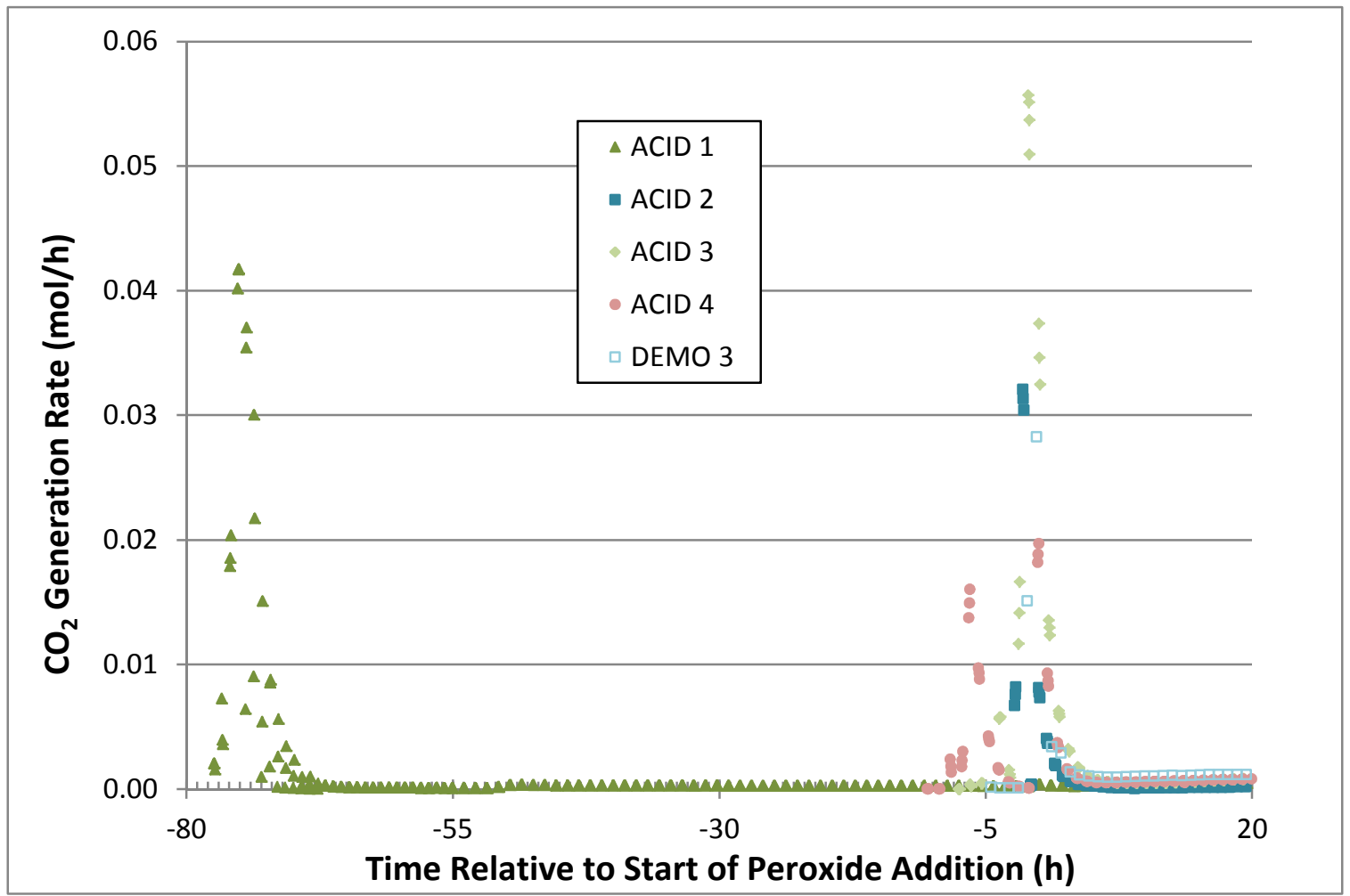

The peak rates are tabulated in Table 84.

Table 84. Peak $\mathrm{CO}_{2}$ Generation Rates in the Alternate Acidification Tests

\begin{tabular}{|c|c|c|}
\hline Test & $\begin{array}{c}\text { Peak CO2 Generation } \\
\text { Rate (mole/hour) }\end{array}$ & $\begin{array}{c}\text { Normalized to } \\
\text { DEMO3 }\end{array}$ \\
\hline ACID 1 & 0.0417 & 1.49 \\
\hline ACID 2 & 0.0325 & 1.16 \\
\hline ACID 3 & 0.0557 & 1.99 \\
\hline ACID 4 & 0.0197 & 0.703 \\
\hline DEMO 3 & 0.0280 & 1 \\
\hline
\end{tabular}

While for tests ACID 1 and ACID 4 it was not possible to discern two distinct periods of gas evolution for benzene, it is possible to note this with the $\mathrm{CO}_{2}$ data. The relatively high generation rates for ACID 2 and ACID 3 give confidence that these acids are consumed more by the free hydroxide in solution rather than the phenylborates. In the 
case of ACID 3, the picture is convolutes by the fact that formate from the acidification can degrade and produce $\mathrm{CO}_{2}$. Therefore, $\mathrm{CO}_{2}$ data from ACID 3 must be carefully considered.

Figure 94 and Table 85 display the total $\mathrm{CO}_{2}$ produced as of 60 hours after the start of $\mathrm{H}_{2} \mathrm{O}_{2}$ addition in each test. 60 hours was the latest point with data available for all tests.

Figure 94. Total $\mathrm{CO}_{2}$ Generation at 60 Hours in the Alternate Acidification Tests

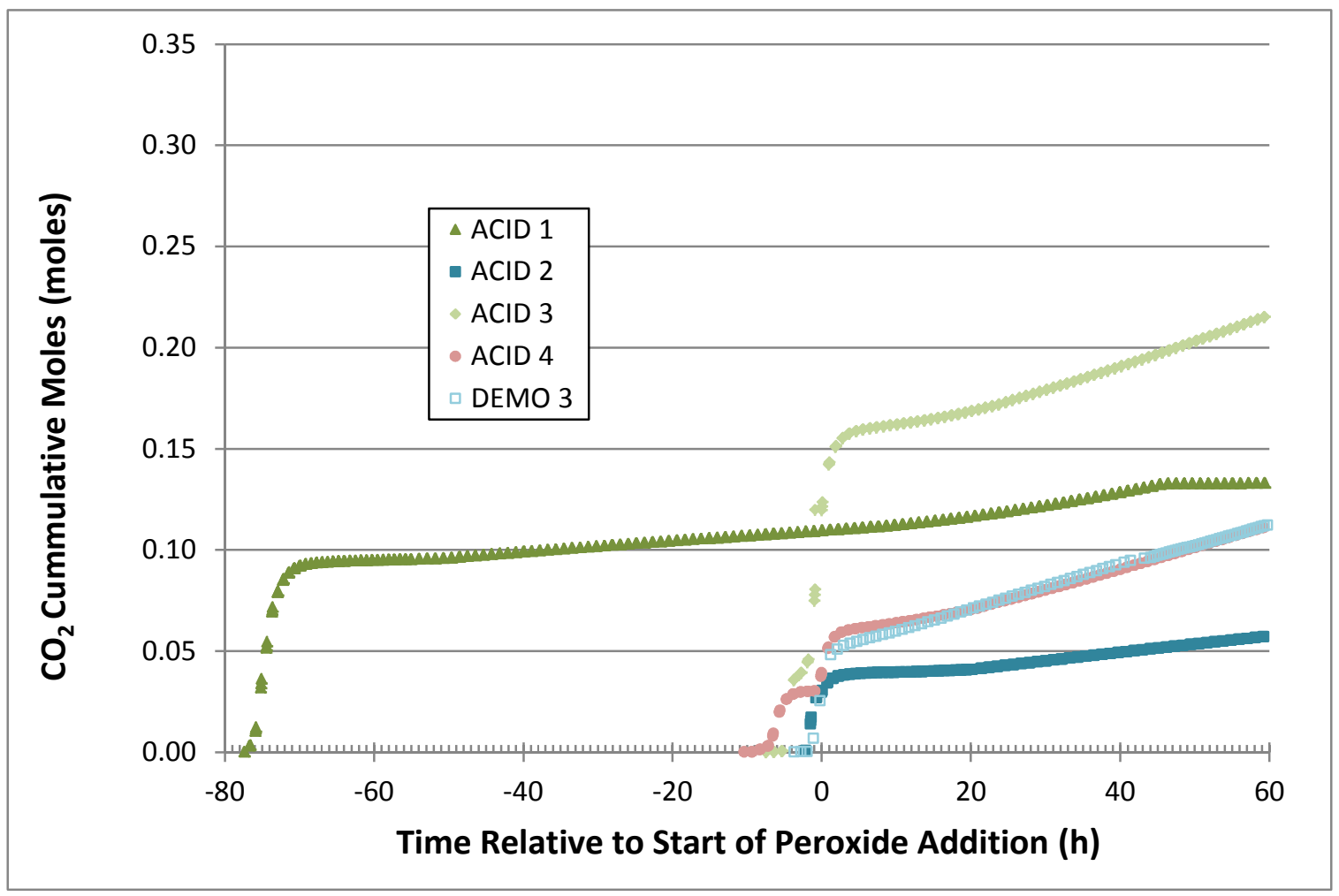

Table 85. Total $\mathrm{CO}_{2}$ Generation at 60 Hours in the Alternate Acidification Tests

\begin{tabular}{|c|c|c|}
\hline Test & $\begin{array}{c}\text { 60 Hour CO} \\
\text { (moles) }\end{array}$ & $\begin{array}{c}\text { Normalized to } \\
\text { DEMO 3 }\end{array}$ \\
\hline ACID 1 & 0.133 & 1.20 \\
\hline ACID 2 & 0.0564 & 0.508 \\
\hline ACID 3 & 0.214 & 1.93 \\
\hline ACID 4 & 0.111 & 1 \\
\hline DEMO 3 & 0.111 & 1 \\
\hline
\end{tabular}


The evidence so far clearly indicates that ACID 2 and ACID 3 produce less TPB destruction, and generate less benzene. Given that ACID 2 and ACID 3 also have a high peak $\mathrm{CO}_{2}$ generation rate, it is logical to assume that the total amount of produced $\mathrm{CO}_{2}$ should be high for ACID 2 and ACID 3. However, for ACID 2 this is not the case, and this is likely due to the low overall phenylborate destruction. In the case of ACID 3, the picture is convoluted by the fact that formate from the acidification can degrade and produce $\mathrm{CO}_{2}$. Therefore, $\mathrm{CO}_{2}$ data from ACID 3 must be carefully considered.

\subsubsection{Conclusion}

SRNL performed four tests that investigated variations on the methods of acidification. It is desirable to reduce the production of benzene and residual organics from the acid hydrolysis reactions that occur with nitric acid.

Adding waiting periods while acidifying with nitric acid does not provide for superior results. There was no apparent benefit in the rate of total amount of benzene produced. This is not entirely surprising. With the mass transfer resistance and delay in release of benzene, the retained benzene has longer to react with the peroxide and catalyst allowing some reduction in net benzene produced. However, the measure of that reduction is uncertain but is possibly on the order of $20 \%$.

Using phosphoric or formic acid does provide a direct benefit in that the amount and rate of benzene production is far reduced - as much as an order of magnitude. Less TPB and phenylborates are destroyed by the $\mathrm{pH}$ adjustment, resulting in smaller benzene production. This does have a side effect in a slightly lower overall rate of TPB destruction - more time must be spent in the CCPO operating region.

The HPLC data confirms the general lower degree of TPB destruction in these tests. From the VOA and SVOA data SRNL believes that the data implies that TPB and the phenyl borates are degraded preferentially, followed by the residual organics. From these and previous tests, it appears that a reaction duration longer than 4 days (minimum) will be necessary to reduce the final concentration of residual organics.

There are some potential downsides to the use of formic or phosphoric acid. First, there is some sensitivity to the use of these acids as they can have an effect on DWPF operations. While formic acid is currently being used, there is a drive to move towards the use of glycolic acid. There is also a limit on the phosphorus content in the glass from DWPF requirements. Second, phosphoric acid must be examined for its effect on MST and possible increased release of fissile species. The few data points we have suggest that phosphoric acid acts more aggressively on MST. 


\subsection{Mercury Measurements in Reactor Head Spaces}

Mercury vapor measurements were made for most of the copper/peroxide tests and showed low concentrations throughout. An estimation of less than $1 \%$ of the initial mercury was vaporized in each experiment. The Tank $48 \mathrm{H}$ simulant in the testing was spiked with $18 \mathrm{mg} / \mathrm{L}$ of diphenylmercury. This equates to an initial 5100 micrograms of mercury per experiment.

A Jerome J405 mercury analyzer was used to probe the reactor headspace at times during experiments. This instrument uses a gold film sensor which is sensitive to both elemental mercury (metal) vapor and dimethylmercury. It does not indicate form or species of detected mercury vapors. No more than $140 \mu \mathrm{g} / \mathrm{m}^{3}$ of mercury was indicated by the Jerome instrument in reactor head spaces at any time. To put this in perspective, the OSHA 8-hour total weight average (TWA) for a worker is $100 \mu \mathrm{g} / \mathrm{cubic}$ meter as elemental mercury vapor. ${ }^{21}$ Furthermore, Table 86 provides the vapor pressure of pure mercury metal as a function of temperature. ${ }^{22}$ While the mercury vapor level is always low as shown, it appears to peak in 100 to 300 hours after the start of peroxide addition. Previous to this mercury vapor concentrations were less than $60 \mu \mathrm{g} / \mathrm{m}^{3} \mathrm{during}$ acid additions.

Mercury at $100 \mu \mathrm{g} / \mathrm{m}^{3}$ is a reasonable order of magnitude for readings, and at this level the purge rate of mercury is $100 \mu \mathrm{g} / \mathrm{m}^{3}$ times $15.0 \mathrm{E}-06 \mathrm{~m}^{3} / \mathrm{min}$ of purge air for each experiment. This is $15.0 \mathrm{E}-04 \mu \mathrm{g}$ per minute or $45 \mu \mathrm{g}$ in 500 hours. This purge flow adds up to less than $1 \%$ of the mercury in the experiment.

Table 86. Vapor Pressure of Pure Mercury Metal

\begin{tabular}{|c|c|c|c|}
\hline Temperature, ${ }^{\circ} \mathbf{C}$ & $\begin{array}{c}\mathbf{m m ~ H g} \\
\text { Pressure }\end{array}$ & Moles $/ \mathbf{m}^{\mathbf{3}}$ & $\mu \mathbf{g} / \mathbf{m}^{\mathbf{3}}$ \\
\hline 10 & 0.00049 & $2.77 \mathrm{E}-05$ & $5.6 \mathrm{E}+03$ \\
\hline 20 & 0.001201 & $6.57 \mathrm{E}-05$ & $1.3 \mathrm{E}+04$ \\
\hline 30 & 0.002777 & $1.47 \mathrm{E}-04$ & $2.9 \mathrm{E}+04$ \\
\hline 40 & 0.006079 & $3.11 \mathrm{E}-04$ & $6.2 \mathrm{E}+04$ \\
\hline 50 & 0.01267 & $6.29 \mathrm{E}-04$ & $1.3 \mathrm{E}+05$ \\
\hline 60 & 0.02524 & $1.21 \mathrm{E}-03$ & $2.4 \mathrm{E}+05$ \\
\hline 70 & 0.04825 & $2.25 \mathrm{E}-03$ & $4.5 \mathrm{E}+05$ \\
\hline
\end{tabular}

Examples of mercury results are given in Figures 95, 96, and 97 below. The $\mathrm{pH}$ is also shown, but it changes slowly and does not appear to affect the mercury vapor concentration. 
Figure 95. Mercury Vapor Concentration for Test DEMO3

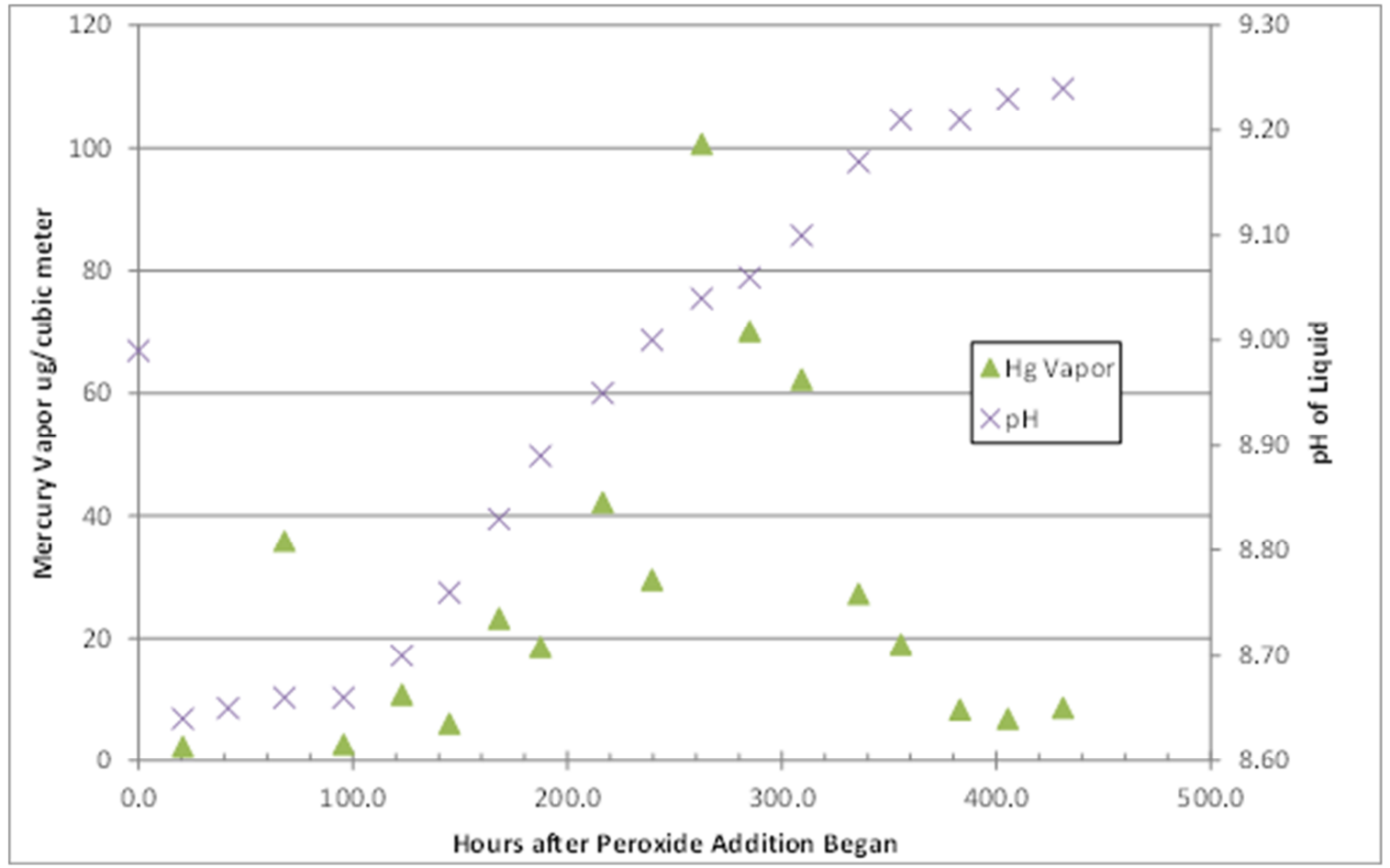


SRNL-STI-2012-00342

Revision 1

Figure 96. Mercury Vapor Concentration for Test 3b

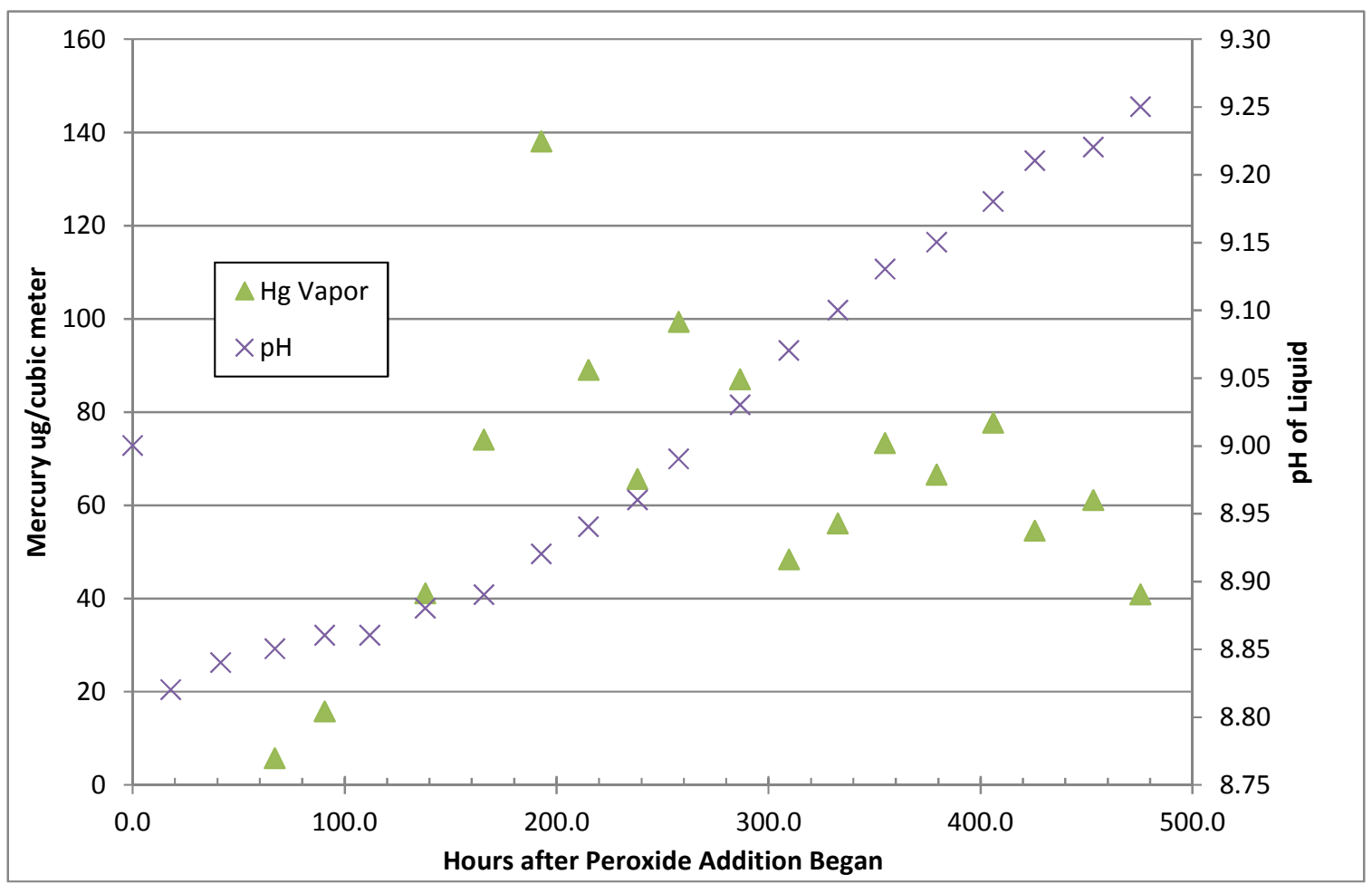




\section{Figure 97. Mercury Vapor Concentration for DEMO 4}

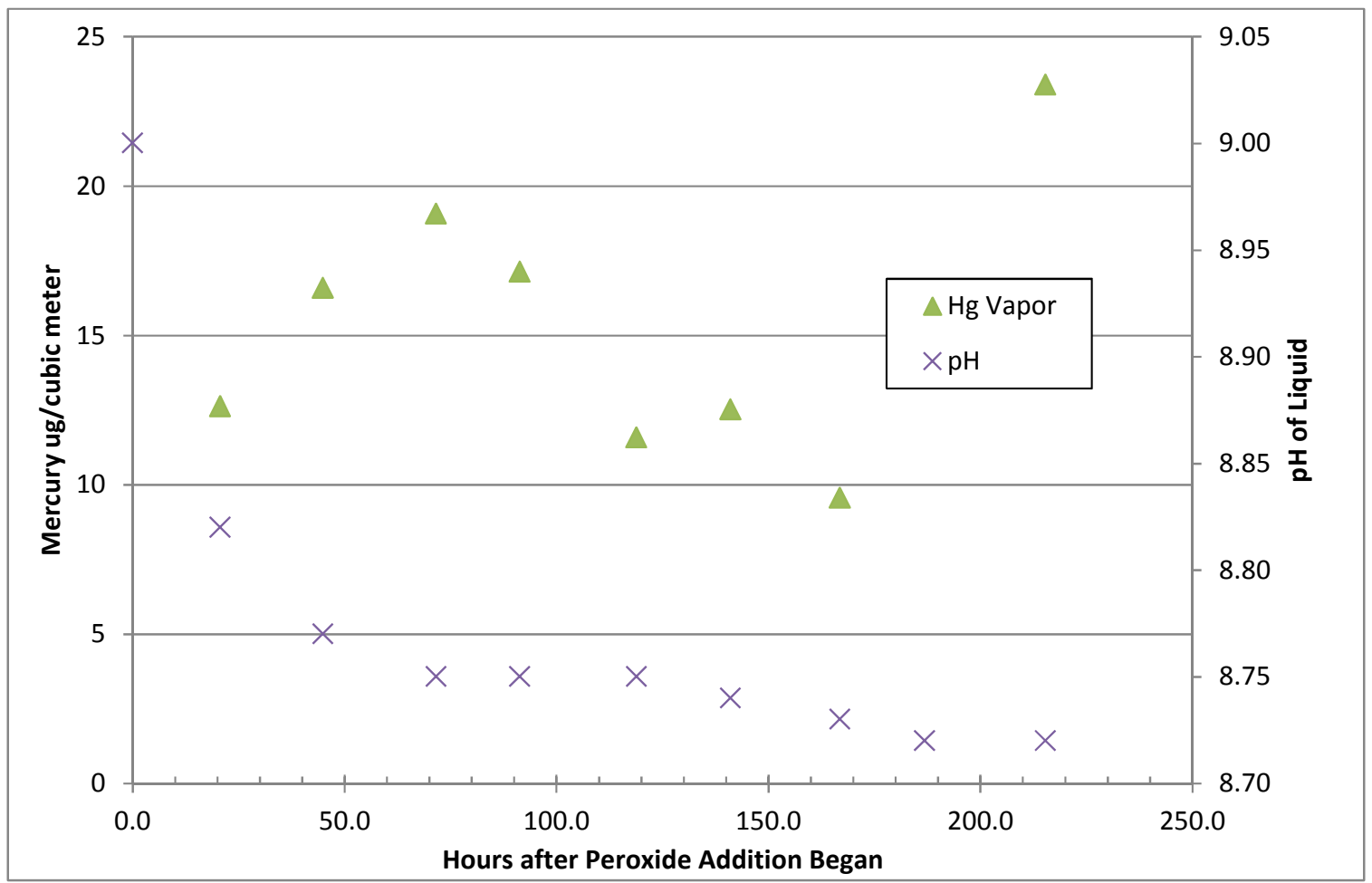

\subsection{Conclusions}

SRNL performed a series of reactions to define an ideal set of reaction conditions to destroy KTPB, its decomposition products, and other organic materials present in Tank 48H. The following CCPO process observations have been made.

Form of the added copper: There was no difference in the reactivity between hydrated copper nitrate and hydrated copper sulfate. It is most likely that copper salts with similar weakly coordinating anions will display the same levels of reactivity and solubility. However, at no point did all of the added copper dissolve into the simulant solution. This may indicate that an alternate copper catalyst may give superior performance. In the absence of further research, SRNL recommends using copper nitrate.

Effect of copper concentration added: Increasing the concentration of copper catalyst provided faster organic destruction. Reactions involving copper added to $500 \mathrm{mg} / \mathrm{L}$ provided destruction times as short as $\sim 1$ day, while lowering or eliminating the added copper entirely increases the destruction time considerably. Despite changing the amounts of added copper, at no point did all of the added copper completely dissolve into the simulant solution. While increased copper gave higher reaction rates, the highest 
concentration of copper did not give the lowest concentrations of residual organics. Intermediate levels of copper $(250 \mathrm{mg} / \mathrm{L})$ gave results nearly as effective as $500 \mathrm{mg} / \mathrm{L}$ but $100 \mathrm{mg} / \mathrm{L}$ yielded incomplete destruction of phenylborate groups within the proposed cycle time. SRNL recommends using either 250 or $500 \mathrm{mg} / \mathrm{L}$ of copper. Additional exploration of concentrations between 100 and $250 \mathrm{mg} / \mathrm{L}$ are warranted to further reduce the chemical cost.

Effect of reaction temperature: There is a clear increase in reactivity with an increase in reaction temperature. Reactions conducted at $35^{\circ} \mathrm{C}$ did not reach completion in 3 weeks, while reactions conducted at $65^{\circ} \mathrm{C}$ were complete within $\sim 1$ day. Furthermore, the $65^{\circ} \mathrm{C}$ reaction provided the least amount of residual organics by the end. Each $15{ }^{\circ} \mathrm{C}$ increase in reaction temperature provided a $2-3 \times$ decrease in the residual organics. Increased temperatures also provided for higher concentrations of soluble copper, but not titanium. An operating temperature of $50{ }^{\circ} \mathrm{C}$ allowed near complete destruction of benzene producing species within the proposed process cycle time, and this is the recommended operating temperature.

Effect of decreasing initial $\mathrm{pH}$ : Initial tests adjusted the slurry $\mathrm{pH}$ to 11 . Starting at $\mathrm{pH} 9$ provides for a faster reaction, and starting at $\mathrm{pH} 7$ is even faster, reducing the destruction time to $\sim 1$ day. For each reaction in which $\mathrm{pH}$ was monitored over time, the $\mathrm{pH}$ values in all of these tests tend to buffer at $\mathrm{pH}$ values of $\sim 9-10$, regardless of the initial $\mathrm{pH}$. While a starting $\mathrm{pH}$ of 7 provided faster TPB destruction, a starting $\mathrm{pH}$ of 9 provided a lesser quantity ( $\sim 40 \%$ of the $\mathrm{pH} 7$ reaction) of residual organics by the end of the reaction. The reaction at $\mathrm{pH} 9$ gave slightly higher copper and titanium concentrations. SRNL recommends an operating $\mathrm{pH}$ of 9 .

Acid addition rate: SRNL recommends that for $\mathrm{pH}$ adjustment, an acid addition rate 42 $\mathrm{mL} /$ hour, scaled to the full vessel, is used. This is the same addition rate used in the testing.

Effect of increasing $\mathrm{H}_{2} \underline{\mathrm{O}}_{2}$ rate: Faster additions of $\mathrm{H}_{2} \mathrm{O}_{2}$ provided a slight benefit in the rate of TPB destruction, although it is difficult to say if the benefit was statistically significant. This benefit may be outweighed by the additional generated volume. However, it can be stated that increased amounts of $\mathrm{H}_{2} \mathrm{O}_{2}$ provided for less amounts of residual organics. In a contiguous series of reactions $\left(\mathrm{pH} 9,50{ }^{\circ} \mathrm{C}, 500 \mathrm{mg} / \mathrm{L}\right.$ of copper) that varied only in the $\mathrm{H}_{2} \mathrm{O}_{2}$ delivery rates $(1 \times, 2 \times, 5 \times), 192.2,81.6$, and $7.75 \mathrm{mg} / \mathrm{L}$ of residual organics were generated, respectively. Increased $\mathrm{H}_{2} \mathrm{O}_{2}$ delivery clearly plays an important role in removing the residual organics. SRNL recommends using the equivalent of the $0.4 \mathrm{~mL} /$ hour for use in the plant.

Residual organic compounds: In each set of residual slurry after reaction analyzed, the presence of a variety of residual organic compounds, in varying concentrations was noted. From the types and amounts of residual materials, SRNL suspects that much of this 
residual material is caused by the method of $\mathrm{pH}$ adjustment $-50 \mathrm{wt} \%$ nitric acid. In the simulant reactions, the slurry maintains a mat of floating material that comes into contact with the added nitric acid. This direct contact is probably conducive to the formation of many of the aryl compounds noted in the SVOA analyses. Although the data set is limited, adjusting the $\mathrm{pH}$ by less harsh methods (phosphoric and formic acid) appears to provide for relatively smaller final concentrations of residual organics. Furthermore, it is possible that radioactive waste operations may provide for comparatively smaller amounts of residual organics as the TPB solids do not form a floating matt of material.

Formate and Oxalate production: Both formate and oxalate anions are produced as part of the $\mathrm{H}_{2} \mathrm{O}_{2}$ aided destruction. While the formate was ultimately reduced to below detection limits in some experiments, oxalate persists at the end of each test. Oxalate is probably destroyed by the CCPO process, but it may be the last material in sequence to react. The potential production of formate and oxalate should be considered for downstream impacts and may lead to the desire for longer reaction times or higher $\mathrm{H}_{2} \mathrm{O}_{2}$ delivery rates.

Use of Acids Other Than Nitric Acid: Nitric acid is highly reactive and known to readily acid hydrolyze TPB slurries. Phosphoric and formic acids at the same concentration $(10.4 \mathrm{M})$ were just as able to adjust the slurries to the reaction $\mathrm{pH}$, while providing much less acid hydrolysis and consequent benzene generation. This slowed the overall TPB destruction somewhat due to the lack of acid hydrolysis. More work is needed, as the phosphoric acid showed a possible negative impact on MST leaching.

Mercury Results: No more than $140 \mu \mathrm{g} / \mathrm{m}^{3}$ of mercury was indicated by the Jerome instrument in reactor head spaces at any time. An estimation of less than $1 \%$ of the initial mercury was vaporized in each experiment.

Titanium Leaching: Low level leaching on titanium occurred; however, the typical concentrations of released titanium are very low ( $\sim 40 \mathrm{mg} / \mathrm{L}$ or less $)$. Small amounts of leaching under these conditions are not surprising and is consistent with a previous study. ${ }^{1}$

Energetic Material Formation: Analyses of the post-reaction residual material indicate that slurry initially adjusted down to a $\mathrm{pH} 7$ produced a greater degree of energetic material than material initially adjusted to a $\mathrm{pH}$ of $9 .^{2}$

\subsection{Future Work}

Based upon the conclusions, SRNL proposes the following future work 
- A real waste test should be conducted to ensure that the simulant and real waste perform in a similar manner.

- Future reactions should be centered around the proven conditions of $\mathrm{pH} 9$ and $50{ }^{\circ} \mathrm{C}$. While temperatures $>50^{\circ} \mathrm{C}$ attain faster destruction rates, it may be problematic to achieve the elevated processing temperatures in the actual facility. Reactions below pH 9 also appear to generate large quantities of biphenyl, which could potentially plate out in the Building 241-96H process vessel vent system.

- $\mathrm{H}_{2} \mathrm{O}_{2}$ delivery rates should probably stay bounded within those of the current matrix $(1 \times$ to $5 \times)$. Higher addition rates reduce the residual organics, but generate a higher final volume.

- Consideration should be given to research into finding superior forms of copper catalyst. This could include different inorganic salts and/or organic ligand supported materials.

- Consideration needs to be given to the exit pathway for the treated material. The ultimate endpoint for the treated waste may influence the success criteria.

- Further investigations into the use of phosphoric and formic acids are advisable. The potential benefits of those acids are worth future experiments to determine overall TPB destruction times and extent of residual organics.

- Additional work is required to more accurately close the carbon mass balance. Additional analysis of formate and oxalate results will help close the material balance but some carbon species may not be tractable given the current analytical and sampling techniques. Use of mass flow controllers improved the certainty of $\mathrm{GC}$ data. Continuing gas analyses of the stirred slurry for an extended period after reaction completion may also help close the material balance gap. 


\section{Appendix A. Design of a Mixing Vessel for TPB/Peroxide Reactions}

Goal: Design and construct a mixing vessel with similarities to that of WSRC-TR-2005$00114,{ }^{4}$ using scaling laws where possible, to mimic Tank $48 \mathrm{H}$ slurry oxidation processing in the Building 241-96H reaction tank. This work is to provide equipment that will handle both simulant and actual Tank $48 \mathrm{H}$ sample slurries. The lab scale batch volume is to be approximately the same as the "Lab Scale Integrated Demonstrations" from the 2004 work. ${ }^{4}$ The process is now planned for the stainless steel tank in Building $241-96 \mathrm{H}$ rather than the carbon steel Tank $48 \mathrm{H}$, so the current work will also use a stainless steel vessel. The laboratory agitator will be scaled considering the agitator in the Building 241-96H reaction tank.

\section{A. General Direction}

1. Scaling shall consider the geometry of the Building 241-96H tank. The tank is made of stainless steel with a vertical mixer impeller with an upper and lower mixing turbine ( 4 blades each). The upper turbine has $45^{\circ}$ slanted blades designed for downflow and the lower turbine has vertical paddle blades that induce radial outward flow. The tank is a vertical cylinder of 12 foot diameter and has four vertical baffles at the side wall. The lab rig is to be built mostly of stainless steel to maintain similarity with the facility vessel. The chemistry uses hydrogen peroxide, so materials of construction may provide catalytically active surfaces that may produce bubbles or affect the process to some extent.

2. The dimensions of the facility tank and mixer are given in Table 43, with prior data $^{23,24}$.

3. Operating experience ${ }^{8}$ showed that the vessel temperature needs improved control over just a hot plate and stirrer. Prior work applied this lesson by using a water bath with the temperature being controlled to values in a range of $35^{\circ}$ to $75^{\circ} \mathrm{C}{ }^{4}$

4. Operating experience ${ }^{8}$ showed no benefit if chemical additions to the vessel used a downcomer (below liquid level). The facility design does not currently include downcomers.

5. Earlier work ${ }^{8}$ recommended an agitator and baffled vessel vs. the magnetic stir bar that was used. It suggested that the improvement in mixing should improve the results. One negative aspect of observed foaming was that tetraphenylborate solids were not in contact with the reaction liquid.

\section{B. Scaling of Mixing}

The current work is to use a 0.5 to 1 liter volume of reacting liquid, while the facility vessel processes 20,000 liter batches. Tatterson lists the general method to scale mixing using dimensional analysis. ${ }^{25}$ The variables for mixing equipment include fluid properties, geometric features including tank and impeller dimensions, and dimensionless numbers, the most common being the Impeller Reynolds Number (Re), Froude Number 
(Fr), and Power Number (Po). The current work is constrained in that fluid (simulant, hydrogen peroxide, and any acid) properties (density, viscosity, etc.), reaction rates, temperature, and pressure must be scaled $1: 1$ with the facility process.

Linear geometric scaling is recommended for mixing processes. ${ }^{26,27}$ It is recommended that the linear factor be no greater than 10:1, but the sample size in the current work dictates a greater scale factor (30:1). The current effort examined linear geometric scaling and found that Fr or mixing time are practical scaling strategies. Fr scaling is recommended because agitation is at good practical rates and the faster mixing time of the lab unit vs. facility tank can be easily addressed. However, slurry foaming may be an issue that influences agitator speed selection. ${ }^{28}$

The dimensionless numbers are defined as follows:

Reynolds number, $\mathrm{Re}=\mathrm{D}^{2} * \mathrm{~N} * \rho / \mu \quad$ [ratio of inertial to viscous force] Froude Number, $\mathrm{Fr}=\mathrm{D} * \mathrm{~N}^{2} / \mathrm{g} \quad$ [ratio of inertial to gravitational force] Power Number, Po $=\mathrm{P} * \mathrm{~g}_{\mathrm{c}} /\left(\rho * \mathrm{~N}^{3} * \mathrm{D}^{5}\right) \quad$ [ratio of drag force to inertial force]

A summary of data are provided in Table 43, with the lab scale rig being 1/30 linear scale of the Building 241-96H tank. Both the lower and upper impellers have the same diameter D. Density is $\rho$ and $\mathrm{N}$ is impeller speed.

\section{Table 87. Dimensional Data for Mixing Vessels}

\begin{tabular}{|l|c|c|}
\hline \multicolumn{1}{|c|}{ Quantity } & Building 241-96H Tank & Lab Scale Vessel \\
\hline Tank Diameter, T & $12.00 \mathrm{ft}$ & $12.20 \mathrm{~cm}$ \\
\hline Liquid Height, H & $6.28 \mathrm{ft}$ & $6.38 \mathrm{~cm}$ \\
\hline Flat Turbine Diameter, D & $2.83 \mathrm{ft}$ & $2.88 \mathrm{~cm}$ \\
\hline Slanted turbine Diameter, D & $2.83 \mathrm{ft}$ & $6.13 \mathrm{~cm}$ \\
\hline Baffle height & $6.03 \mathrm{ft}$ & $1.00 \mathrm{~cm}$ \\
\hline Baffle width & $1.00 \mathrm{ft}$ & $4.76 \mathrm{~cm}$ \\
\hline $\begin{array}{l}\text { Slanted Turbine height off } \\
\text { bottom }\end{array}$ & $4.69 \mathrm{ft}$ & $0.71 \mathrm{~cm}$ \\
\hline $\begin{array}{l}\text { Flat Turbine height off } \\
\text { bottom }\end{array}$ & $0.70 \mathrm{ft}$ & 0.75 liters \\
\hline Tank Volume & $710.63 \mathrm{cubic}$ feet $(5300$ gal $)$ & \\
\hline
\end{tabular}

B.1 Reynolds Number Scaling

Tables 43 and 44 list the geometric data and fluid properties along with results from further calculations. At equal lab and facility Fr the lab rig would have Re of $2.77 \mathrm{E}+03$ while the facility vessel would see a Re of $4.5 \mathrm{E}+05$. This difference in Re is actually not that significant given that Po is a weak function of Re when Re exceeds $1 \mathrm{E}+04$ (in the turbulent mixing regime). ${ }^{29}$ An attempt to match Re by increasing the lab scale agitator 
speed would not be practical and would eject the vessel contents from the beaker. The lab scale agitator would lose contact with the liquid and would be spinning at approximately $48,000 \mathrm{rpm}$.

\section{B.2 Froude Number Scaling}

Fr between plant and lab scale can be matched if the lab scale agitator is spinning at 462 $\mathrm{rpm}$. This is practical operation for lab work.

\section{B.3 Mixing Time Scaling}

Literature provides other means of scaling, including mixing time. This value would be the time, for example, to mix an injected miscible liquid into the agitated vessel and see high uniformity, such as $90 \%$. After the linear scaling and impeller speed was obtained, several different correlations for mixing time were applied to the geometry.

The Fr scaling method (462 rpm) is recommended as long as reagent additions to the lab unit are slow and steady, vs. pulsed. The estimated mixing time is of the order of magnitude 5 seconds.

Table 44 below is a summary of scaling results for $1 / 30$ length scaling and a lab impeller speed of $462 \mathrm{rpm}$. Froude number matching is exact, and mixing times given by several different correlations are in reasonable agreement with each other, showing that the lab unit mixing time is about 3 to 5 times faster than the facility tank on an absolute basis. This is not considered to be a problem since the chemical reaction characteristic time is much longer than the mixing time, so both facility and lab vessels are well mixed relative to other parts of the process. The facility tank contents sees higher power dissipation per volume, and this is typical of mixed tanks. The work here predicts that the facility agitator delivers $16 \mathrm{Hp}$ of shaft work to the liquid in that tank.

Norwood and Metzner ${ }^{30}$ expressed mixing time with turbines in a baffled tank using a dimensionless parameter " $\mathrm{f}_{\mathrm{t}}$ ":

$$
\mathrm{f}_{\mathrm{t}}=\mathrm{t}^{*}\left(\mathrm{ND}^{2}\right)^{2 / 3} * \mathrm{~g}^{1 / 6} *(\mathrm{D} / \mathrm{H})^{0.5} /\left(\mathrm{T}^{1.5}\right)
$$

where $\mathrm{t}$ is mixing time, $\mathrm{g}$ is gravitational acceleration, $\mathrm{N}$ is impeller speed, $\mathrm{D}$ is impeller diameter, $\mathrm{H}$ is fluid depth, and $\mathrm{T}$ is tank diameter. A graph in that paper allows determination of $f_{t}$ as a function of Reynolds number, and the values are shown in Table 44. The mixing time provided by the application of Norwood and Metzner's empirical work is shown in the line that follows in the table.

In a separate analysis Rushton presents an empirical graph, in this case providing Power Number (Po) as a function of Reynolds Number. ${ }^{31}$ The values of Po from the graph are shown in Table 44. An estimate of mixing time was calculated from a correlation by Grenville: ${ }^{32}$ 


$$
\text { Mixing time }=5.2 *(\mathrm{~T} / \mathrm{D})^{2} *\left(\mathrm{Po}^{(1 / 3)}\right) / \mathrm{N}
$$

Moo-Young presents a correlation using Reynolds number $(\mathrm{Re})$ directly for turbine mixers and baffled tanks: ${ }^{33}$

$$
\text { Mixing time }=\mathrm{A} *\left((\mathrm{Re})^{\mathrm{b}}\right) / \mathrm{N}
$$

where $\mathrm{A}$ and $\mathrm{b}$ are parameters that Moo-Young provides given ranges of Re. From MooYoung's work $\mathrm{A}$ is 36 and $\mathrm{b}$ is zero in the range of Re of $1.0 \mathrm{E}+03$ to $1.0 \mathrm{E}+05$.

The Van de Vusse Parameter in Table 44 determines if the tank geometry is adverse in the sense that there may be dead corners that affect the vessel mixing time. ${ }^{34}$ The parameter is defined below, and is to be between 0.001 and 0.04 for acceptable prediction of mixing time. The geometry and liquid fill height of the vessels considered here are within the acceptable range.

$$
\text { Van de Vusse Parameter (dimensionless) }=\mathrm{D}^{3} /\left(\mathrm{T}^{2.5} * \mathrm{H}^{0.5}\right)
$$

In all cases the mixing time for the facility and also lab vessels are predicted to be less than half a minute. Given that the chemical reactions take hours, the mixing keeps well ahead of chemical reaction rates and the liquid batches are well mixed.

Table 88. Mixing Time Predictions and Mixing Power

\begin{tabular}{|l|r|r|}
\hline \multicolumn{1}{|c|}{ Quantity } & $\begin{array}{c}\text { Building 241-96H } \\
\text { Tank }\end{array}$ & Lab Scale Vessel \\
\hline Impeller speed, rotations/s, N & 1.40 & 7.7 \\
\hline Reynolds Number, dimensionless & $4.52 \mathrm{E}+05$ & $2.77 \mathrm{E}+03$ \\
\hline Froude Number, dimensionless & 0.173 & 0.174 \\
\hline Impeller Tip speed, cm/s & 1180 & 219 \\
\hline Norwood \& Metzner Parameter ft, dimensionless & 4 & 7 \\
\hline Norwood \& Metzner Mix Time, $s$ & 27.7 & 8.8 \\
\hline $\begin{array}{l}\text { Power number for Grenville Mix Time, } \\
\text { dimensionless }\end{array}$ & 7 & 5 \\
\hline Grenville Mix Time, s & 25.2 & 5.1 \\
\hline Moo-Young Mix Time, s & 25.7 & 4.7 \\
\hline N times Grenville mix time & 35.3 & 39.5 \\
\hline Van de Vusse Dimensionless Parameter & 0.02 & 0.02 \\
\hline cgs power from Po, erg/s & $1.20 \mathrm{E}+11$ & $5.87 \mathrm{E}+05$ \\
\hline cgs power per volume, erg/s/cm & $5.96 \mathrm{E}+03$ & $7.87 \mathrm{E}+02$ \\
\hline convert power to total Hp for the vessel & 16.1 & $7.87 \mathrm{E}-05$ \\
\hline Hp/gal & $3.03 \mathrm{E}-03$ & $3.99 \mathrm{E}-04$ \\
\hline
\end{tabular}


C. Services to the Reactor Vessel

Earlier work ${ }^{4}$ showed many of the services needed to the vessel, and a list for the current work shall include:

1. central rotary mixing shaft, larger port,

2. thermocouple, probably $1 / 8$ " diameter,

3. small diameter tube for adding reagents (connected to a syringe pump source),

4. small diameter tube for sampling (withdraw using a syringe),

5. gas in (combination of oxygen and nitrogen, maybe air), using a small port and,

6. gas out through a glass condenser (on a larger port).

This describes the experimental program to demonstrate and optimize the laboratoryscale catalyzed peroxide oxidation process for the destruction of TPB in both simulated and real Tank $48 \mathrm{H}$ waste. This work builds off of previous work performed during the period of 2001-2005.

Experiments will initially be directed towards optimizing the peroxide oxidation of TPB utilizing a waste simulant and, once established, the process will be confirmed for real waste. This program may use various peroxide-based oxidants (hydrogen peroxide, sodium percarbonate, sodium perborate), catalysts and acids to decompose the TBP salts, as well as their decomposition products (such as triphenylborane, diphenylboronic acid, and phenylborinic acid). Copper will be the primary catalyst studied and hydrogen peroxide will be the primary oxidant, other catalysts and oxidants may be explored during this study. Where possible, optimization guidelines outlined in Perry's Chemical Handbook will be used ${ }^{35}$.

Although the precise scope of the experiments will be determined during testing, they fall into two categories. The first category is small scale experiments, in the $250-500 \mathrm{~mL}$ range. These experiments will typically involve only simulants. These smaller tests are designed to determine the effects of various operating parameters, such as temperature, agitation, amount of peroxide, etc.

Larger scale (1-2L) tests may be performed after to corroborate earlier results. These larger tests will involve either simulants or real waste. These larger tests will also typically utilize off-gas monitoring through the use of a gas chromatograph.

Nomenclature

D Impeller diameter

$\rho \quad$ Liquid Density

Fr Froude Number

g Value of gravitational acceleration

$\mathrm{g}_{\mathrm{c}} \quad$ Conversion factor for force and accelerated mass

$\mathrm{H} \quad$ Liquid depth in the tank 


$\begin{array}{ll}\mathrm{N} & \text { Impeller rotational speed } \\ \mathrm{P} & \text { Power } \\ \mathrm{Po} & \text { Power Number } \\ \mathrm{Re} & \text { Reynolds Number (for impeller) } \\ \mathrm{T} & \text { Tank diameter } \\ \mu & \text { Viscosity }\end{array}$


SRNL-STI-2012-00342

Revision 1

Appendix B

\section{Analysis for Tetraphenylborate and Decomposition Products}

\section{Sample Preparation}

\section{Chemicals}

Potassium phosphate monobasic $\left(\mathrm{KH}_{2} \mathrm{PO}_{4}\right)$

Deionized water

Acetonitrile

\section{Protocol}

In a $10 \mathrm{~mL}$ volumetric flask, add $1.0 \mathrm{~mL}$ of sample, $2.5 \mathrm{~mL}$ of saturated potassium phosphate solution, and mix. Determine the $\mathrm{pH}$ falls within the range of $6-7$. Fill the flask to the line with acetonitrile and mix. Allow to stand for 5 minutes and remove the top layer for analysis.

\section{Analyses}

\section{Chemicals}

Tetraphenylborate - Can use either the potassium or sodium salt.

Triphenylborane (3PB) - Flammable compound so you need to purchase the triphenylborane-sodium hydroxide adduct and precipitate the 3PB-ammonia adduct with ammonium hydroxide.

Diphenylborinic acid (2PB) - Sold as diphenylborinic acid, ethanolamine ester Phenylboric acid (1PB)

Phenol

Acetonitrile

Acetonitrile 33\% vol/Methanol 27\% vol/Buffer 40\% volume (La-Mar-Ka, Inc., Order \# 0980, MP320)

\section{Standards}

The instrument standards are prepared in acetonitrile. 
Table 89. Summary of Reversed-phase HPLC Methods for TPB and Degradation Products

\begin{tabular}{|l|c|}
\hline \multicolumn{1}{|c|}{ Method } & Conditions \\
\hline \hline \multicolumn{2}{|c|}{ Isocratic for tetraphenylborate (TPB), triphenylborane (3PB), diphenylborinic acid (2PB) } \\
Mobile Phase & $\begin{array}{c}\text { Acetonitrile (27\% vol)-ammonium phosphate buffer (33\% vol)- } \\
\text { methanol (40\% vol) }\end{array}$ \\
\hline Column & \begin{tabular}{c} 
Dychrom Chemcosorb 5-ODS-UH, 3.2 mm x 250 mm \\
\hline Oven Temperature
\end{tabular} \\
\hline Flow-rate & $0.5 \mathrm{~mL} / \mathrm{min}$ \\
\hline Stop Time Array & $20 \mathrm{minutes}$ \\
\hline $\begin{array}{l}\text { Diode } \\
\text { Detector }\end{array}$ & $219 \mathrm{~nm}, 240 \mathrm{~nm}$ \\
\hline Injection Volume & $5 \mu \mathrm{L}$ \\
\hline TPB Retention Time & $11 \min (219 \mathrm{~nm}), \mathrm{r}^{2}=0.999,1$ to $200 \mathrm{mg} / \mathrm{L}$ \\
\hline 3PB Retention Time & $16 \min (219 \mathrm{~nm}), \mathrm{r}^{2}=0.999,1$ to $200 \mathrm{mg} / \mathrm{L}$ \\
\hline 2PB Retention Time & $9 \min (240 \mathrm{~nm}), \mathrm{r}^{2}=0.999,1$ to $200 \mathrm{mg} / \mathrm{L}$ \\
\hline
\end{tabular}

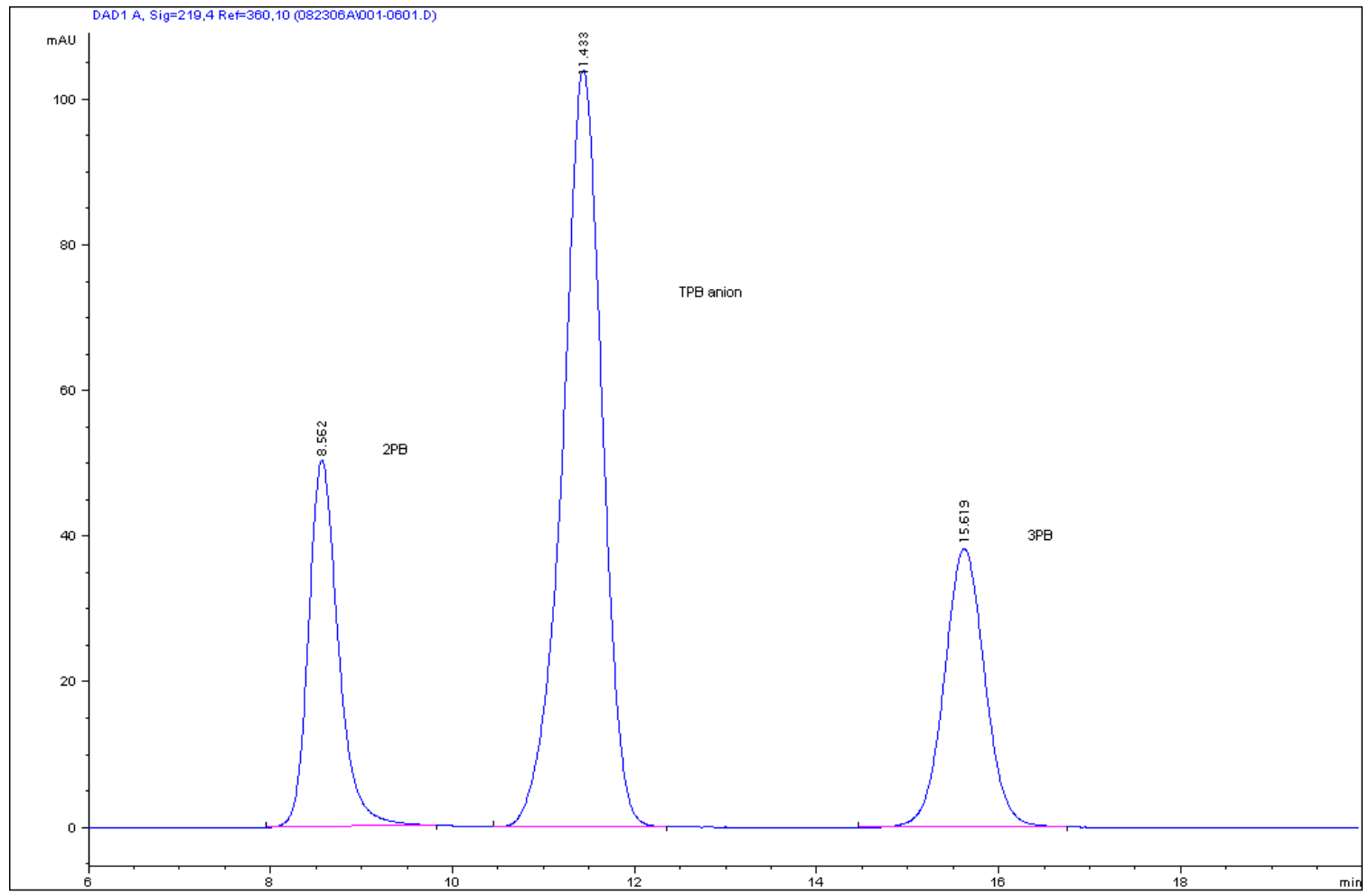

Figure 98. Chromatogram of TPB (11 min), 3PB (16 min) and 2PB (9 min) 50 min Gradient Method for PBA, Phenol and other Decomposition Products 
Table 90. Summary of Reversed-phase Gradient HPLC Method for Degradation Products

\begin{tabular}{|c|c|}
\hline Method & Conditions \\
\hline Mobile Phase & Acetonitrile $(25 \% \mathrm{vol})$ - Water $(75 \% \mathrm{vol})$ \\
\hline Column & Dychrom Chemcosorb 5-ODS-UH, $3.2 \mathrm{~mm}$ x $250 \mathrm{~mm}$ \\
\hline Oven Temperature & $\mathrm{N} / \mathrm{A}$ \\
\hline Flow-rate & $0.5 \mathrm{~mL} / \mathrm{min}$ \\
\hline $\mathrm{t}_{0}$ to $\mathrm{t}_{1}=14 \mathrm{~min}$ & $25: 75$ \\
\hline $\mathrm{t}_{2}=20 \mathrm{mn}$ & $50: 50$ \\
\hline $\mathrm{t}_{3}=29 \mathrm{~min}$ & $60: 40$ \\
\hline $\mathrm{t}_{4}=38 \mathrm{~min}$ & 100:0 \\
\hline $\mathrm{t}_{5}=45 \mathrm{~min}$ & 100:0 \\
\hline $\begin{array}{l}\text { Post time }=5(50 \mathrm{~min} \text { total } \\
\text { time })\end{array}$ & $25: 75$ \\
\hline Diode Array Detector & $217,222,262,281 \mathrm{~nm}$ \\
\hline Injection Volume & $10 \mu \mathrm{L}$ \\
\hline PBA Retention Time & $8.6 \mathrm{~min}$ \\
\hline Phenol Retention Time & $14.0 \mathrm{~min}$ \\
\hline Nitrobenzene Retention Time & $28.0 \mathrm{~min}$ \\
\hline $\begin{array}{l}\text { Nitrosobenzene Retention } \\
\text { Time }\end{array}$ & $29.6 \mathrm{~min}$ \\
\hline $\begin{array}{l}\text { 4-Phenylphenol Retention } \\
\text { Time }\end{array}$ & $31.0 \mathrm{~min}$ \\
\hline $\begin{array}{l}\text { 2-Phenylphenol Retention } \\
\text { Time }\end{array}$ & $32.8 \mathrm{~min}$ \\
\hline $\begin{array}{ll}\text { Diphenylamine } & \text { Retention } \\
\text { Time } & \\
\end{array}$ & $36.9 \mathrm{~min}$ \\
\hline Biphenyl Retention Time & $39.6 \mathrm{~min}$ \\
\hline$o$-Terphenyl Retention Time & $42.6 \mathrm{~min}$ \\
\hline$m$-Terphenyl Retention Time & $43.2 \mathrm{~min}$ \\
\hline$p$-Terphenyl Retention Time & $43.6 \mathrm{~min}$ \\
\hline
\end{tabular}




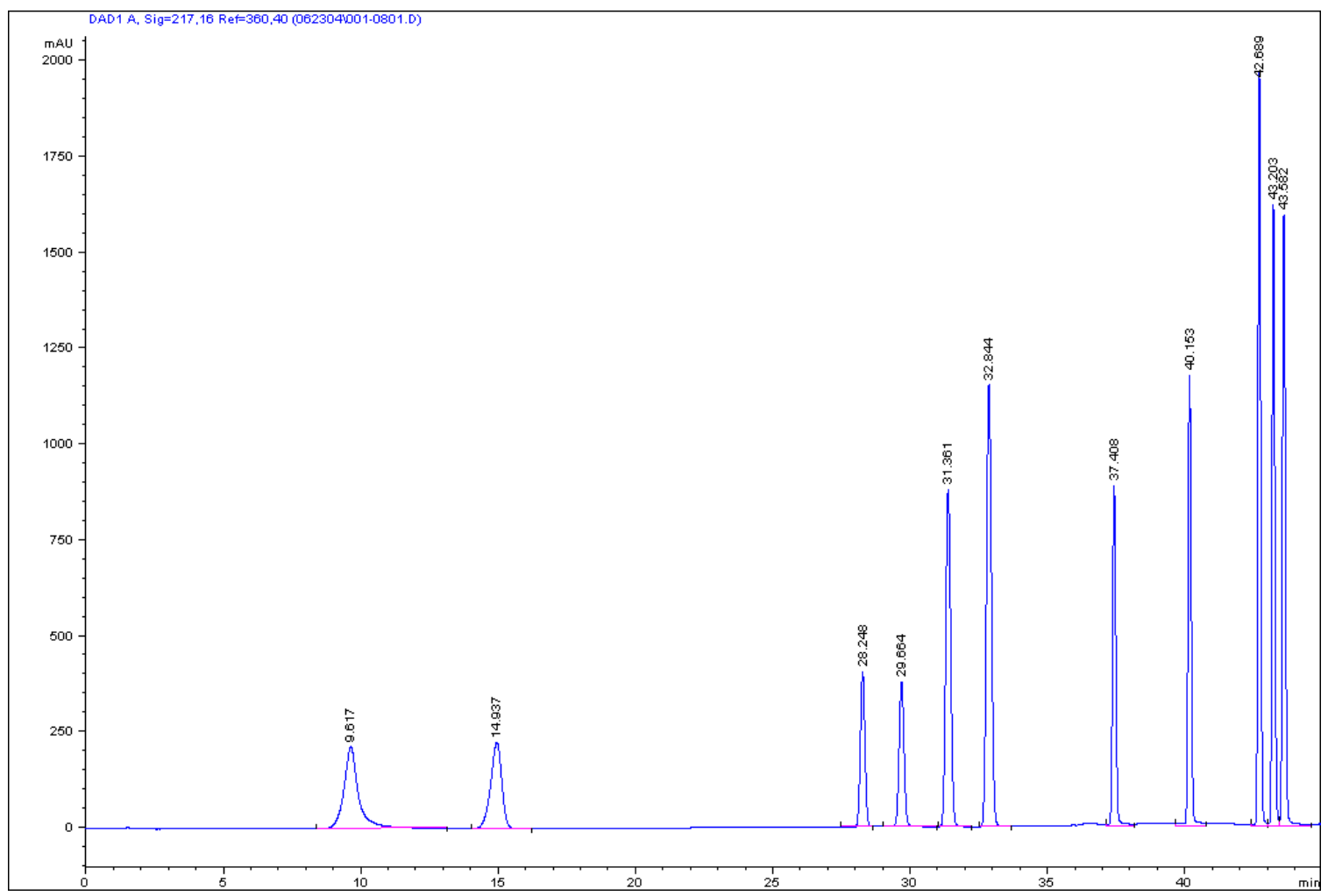

Figure 99. Chromatogram $100 \mathrm{mg} / \mathrm{L}$ Standard in Acentonitrile of PBA (10 min), Phenol (15 min), Nitrobenzene (28 min), Nitrosobenzene (30 min), 4-Phenylphenol (31 min), 2-Phenylphenol (33 min), Diphenylamine (37 min), Biphenyl (40 min), oTerphenyl (43 min), $m$-Terphenyl (43a min), and $p$-Terphenyl (44 min). 
Appendix C

List of Experiments and Conditions

\begin{tabular}{|c|c|c|c|c|c|c|c|c|c|c|c|c|c|c|}
\hline Test & $\begin{array}{l}\text { Simulant } \\
\text { Vol. (mL) }\end{array}$ & $\mathrm{pH}$ & $\begin{array}{c}\text { Temp. } \\
\left({ }^{\circ} \mathrm{C}\right)\end{array}$ & $\begin{array}{c}\mathrm{Cu} \\
(\mathrm{mg} / \mathrm{L})\end{array}$ & $\begin{array}{c}\mathrm{H}_{2} \mathrm{O}_{2} \text { Add. } \\
\text { Rate } \\
\text { (mL/h) }\end{array}$ & $\begin{array}{c}\text { Test } \\
\text { Time (h) }\end{array}$ & $\begin{array}{c}\text { Total } \\
\mathrm{H}_{2} \mathrm{O}_{2}(\mathrm{~mL})\end{array}$ & HPLC & $\begin{array}{c}\text { \% TPB } \\
\text { Decomp. } \\
\text { HPLC }\end{array}$ & $\begin{array}{l}\text { SVOA resdiual } \\
\text { organics }(\mathrm{mg} / \mathrm{L})\end{array}$ & $\begin{array}{c}\text { Time for } \\
100 \% \text { B in } \\
\text { Soln. (h) }\end{array}$ & $\begin{array}{c}\text { Time for } \\
100 \% \mathrm{~K} \text { in } \\
\text { Soln. (h) }\end{array}$ & $\begin{array}{c}\text { Max. Cu } \\
\text { Conc. } \\
\text { (mg/L) }\end{array}$ & $\begin{array}{l}\text { Max. } \mathrm{Ti} \\
\text { Conc. } \\
\text { (mg/L) }\end{array}$ \\
\hline Cu-nitrate & 250 & 11 & 21 & 500 & 0.1 & 508 & 50.8 & NA & NA & NA & NA & NA & 104 & 9 \\
\hline Cu-sulfate & 250 & 11 & 21 & 500 & 0.1 & 508 & 50.8 & NA & NA & NA & NA & NA & 104 & 10 \\
\hline $10 \times \mathrm{H} 2 \mathrm{O} 2$ & 250 & 11 & 21 & 500 & 1 & 284 & 284 & NA & NA & NA & NA & NA & 120 & 58 \\
\hline Thermal $35^{\circ} \mathrm{C}$ & 500 & 11 & 35 & 500 & 0.2 & 372 & 74.4 & \begin{tabular}{||c|} 
TPB: 7460 \\
3PB: $<100$ \\
2PB: $<100$ \\
1PB: $<100$ \\
Phenol: \\
$<100$ \\
\end{tabular} & |50.7-50.9 & 1957 & NA & NA & 75 & 25 \\
\hline Thermal $50^{\circ} \mathrm{C}$ & 500 & 11 & 50 & 500 & 0.2 & 372 & 74.4 & \begin{tabular}{||c|} 
TPB: 16 \\
3PB: $<10$ \\
2PB: $:<10$ \\
1PB: $<10$ \\
Phenol: $<10$
\end{tabular} & 99.9-99.9 & 1002 & $\sim 370$ & $\sim 370$ & 80 & 40 \\
\hline Thermal $65^{\circ} \mathrm{C}$ & 500 & 11 & 65 & 500 & 0.2 & 372 & 74.4 & \begin{tabular}{||l|} 
TPB: $:<10$ \\
3PB: $<10$ \\
2PB: $:<10$ \\
1PB: $<10$ \\
Phenol: $<10$
\end{tabular} & $>99.9$ & 354 & $<24$ & $<24$ & 100 & 25 \\
\hline DEMO 1 & 500 & 11 & $35-75$ & 500 & 0.2 & 497 & 99.4 & \begin{tabular}{||c|} 
TPB: 2420 \\
3PB: $<10$ \\
2PB: $:<10$ \\
1PB: $<10$ \\
Phenol: $<10$
\end{tabular} & $84.0-84.4$ & 898 & NA & NA & 340 & 5 \\
\hline Test 1b & 500 & 9 & 50 & 500 & 0.2 & 404 & 80.8 & \begin{tabular}{||l|} 
TPB: $:<10$ \\
3PB: $: 10$ \\
2PB: $:<10$ \\
1PB: $<10$ \\
Phenol: $<10$
\end{tabular} & $>99.9$ & 199 & $\sim 120$ & $\sim 120$ & 110 & 10 \\
\hline Test 1c & 500 & 7 & 50 & 500 & 0.2 & 404 & 80.8 & \begin{tabular}{||c|} 
TPB: $<10$ \\
3PB: $<10$ \\
2PB: $<10$ \\
1PB: $<10$ \\
Phenol: $<10$
\end{tabular} & $>99.9$ & 518 & $<24$ & $<24$ & 78 & 10 \\
\hline DEMO 2 & 500 & 9 & 50 & 500 & 0.4 & 476 & 190.4 & \begin{tabular}{|c} 
TPB: $:<4$ \\
3PB: $<4$ \\
2PB: $<4$ \\
1PB: $<4$ \\
Phenol: $<4$
\end{tabular} & $>99.9$ & 83.3 & $\sim 160$ & $\sim 180$ & 160 & 20 \\
\hline Test 2a & 500 & 9 & 50 & 500 & 1 & 472 & 472 & \begin{tabular}{|c|} 
TPB: $:<4$ \\
3PB: $<4$ \\
2PB: $<4$ \\
1PB: $<10$ \\
Phenol: $<4$
\end{tabular} & $>99.9$ & 7.75 & $\sim 100$ & $\sim 100$ & 180 & 60 \\
\hline Test 2b & 500 & 9 & 50 & 100 & 0.2 & 477 & 95.4 & \begin{tabular}{||c|} 
TPB: 245 \\
3PB: $<10$ \\
2PB: $: 10$ \\
1PB: $<10$ \\
Phenol: $<10$
\end{tabular} & 98.4-98.5 & 82.9 & $\sim 400$ & $\sim 400$ & $<10$ & 15 \\
\hline Test 2c & 500 & 9 & 50 & 0 & 0.2 & 479 & 95.8 & \begin{tabular}{||c} 
TPB: 2585 \\
3PB: 12 \\
2PB: $<10$ \\
1PB: $<10$ \\
Phenol: 33
\end{tabular} & 84.6-84.8 & 380 & NA & NA & NA & 30 \\
\hline
\end{tabular}




\begin{tabular}{|c|c|c|c|c|c|c|c|c|c|c|c|c|c|c|}
\hline Test & $\begin{array}{l}\text { Simulant } \\
\text { Vol. }(\mathrm{mL})\end{array}$ & pH & $\begin{array}{l}\text { Temp. } \\
\left({ }^{\circ} \mathrm{C}\right)\end{array}$ & $\begin{array}{c}\mathrm{Cu} \\
(\mathrm{mg} / \mathrm{L})\end{array}$ & $\begin{array}{c}\mathrm{H}_{2} \mathrm{O}_{2} \text { Add. } \\
\text { Rate } \\
(\mathrm{mL} / \mathrm{h})\end{array}$ & $\begin{array}{c}\text { Test } \\
\text { Time (h) }\end{array}$ & $\begin{array}{c}\text { Total } \\
\mathrm{H}_{2} \mathrm{O}_{2}(\mathrm{~mL})\end{array}$ & HPLC & $\begin{array}{c}\text { \% TPB } \\
\text { Decomp. } \\
\text { HPLC }\end{array}$ & $\begin{array}{l}\text { SVOA resdiual } \\
\text { organics }(\mathrm{mg} / \mathrm{L})\end{array}$ & $\begin{array}{c}\text { Time for } \\
100 \% \text { in } \\
\text { Soln. (h) }\end{array}$ & $\begin{array}{c}\text { Time for } \\
100 \% \mathrm{~K} \text { in } \\
\text { Soln. (h) }\end{array}$ & $\begin{array}{l}\text { Max. Cu } \\
\text { Conc. } \\
\text { (mg/L) }\end{array}$ & $\begin{array}{l}\text { Max. Ti } \\
\text { Conc. } \\
\text { (mg/L) }\end{array}$ \\
\hline Test 2d & 500 & 9 & 50 & 500 & 0.2 & 499 & 99.8 & $\begin{array}{c}\text { TPB: }<4 \\
\text { 3PB: }<4 \\
\text { 2PB: }<4 \\
\text { 1PB: }<4 \\
\text { Pheno: }<4\end{array}$ & $>99.97$ & 135 & 142 & 115 & 150 & 18 \\
\hline Test 2e & 500 & 7 & 50 & 500 & 0.2 & 500 & 100 & $\begin{array}{c}\text { TPB: }<4 \\
3 P B:<4 \\
\text { 2PB: }<8 \\
\text { 1PB: }<4 \\
\text { Phenol: }<4\end{array}$ & $>99.97$ & 326 & 19 & 19 & 239 & 8 \\
\hline Test $2 \mathrm{f}$ & 500 & 7 & 45 & 500 & 0.2 & 508 & 101.6 & $\begin{array}{c}\text { TPB: } 18 \\
\text { 3PB: }<4 \\
\text { 2PB: }<8 \\
\text { 1PB: }<4 \\
\text { Phenol: }<4 \\
\end{array}$ & 99.9 & 356 & 124 & 124 & 117 & 17 \\
\hline Test 2g & 500 & 9 & 50 & 250 & 0.2 & 508 & 101.6 & $\begin{array}{c}\text { TPB: }<4 \\
3 \text { PBB }:<4 \\
\text { 2PB: }<4 \\
\text { 1PB: }<4 \\
\text { Phenol: }<4\end{array}$ & $>99.97$ & 217 & 52 & 52 & 48 & 13 \\
\hline DEMO 3 & 500 & 9 & 50 & 500 & 0.4 & 479 & 191.6 & $\begin{array}{c}\text { TPB: }<4 \\
\text { 3PB: }<4 \\
\text { 2PB: }<4 \\
\text { 1PB: }<4 \\
\text { Phenol: }<4 \\
\end{array}$ & $>99.97$ & 100 & 95 & 95 & 126 & 22 \\
\hline Test 3a & & & & & & test & terminat & ed due to $\mathrm{h}$ & eeating bo & th failure & & & & \\
\hline Test 3b & 500 & 9 & 50 & 250 & 0.4 & 475 & 190 & \begin{tabular}{|c|} 
TPB: $:<4$ \\
3PB: $:<4$ \\
2PB: $<4$ \\
1PB: $<4$ \\
Phenol: $<4$ \\
\end{tabular} & $>99.97$ & 181 & 111 & 90 & 51 & 23 \\
\hline Test 3c & 500 & 9 & 50 & 500 & 0.4 & 95 & 38 & $\begin{array}{c}\text { TPB: } 20 \\
\text { 3PB: }<4 \\
\text { 2PB: }<4 \\
\text { 1PB: }<4 \\
\text { Phenol: }<7\end{array}$ & 99.9 & 1287 & 95 & 95 & 114 & 26 \\
\hline DEMO 4 & 500 & 9 & 50 & $500^{*}$ & 0.4 & 216 & 86.4 & \begin{tabular}{|c|} 
TPB: 1182 \\
3PB: 52 \\
2PB: 71 \\
1PB: 114 \\
Phenol: 268 \\
\end{tabular} & $89.6-93.0$ & 463 & NA & NA & 2.9 & 48 \\
\hline ACID 1 & 500 & 9 & 50 & 500 & 0.4 & 46 & 18.4 & \begin{tabular}{|c|} 
TPB: 5790 \\
3PB: $<50$ \\
2PB: $<50$ \\
1PB: 45 \\
Phenol: 300 \\
\end{tabular} & $57.7-65.4$ & 913 & NA & NA & 167 & 9 \\
\hline ACID 2 & 500 & 9 & 50 & 500 & 0.4 & 96.5 & 38.6 & $\begin{array}{c}\text { TPB: } 7190 \\
\text { 3PB: }<50 \\
\text { 2PB: }<50 \\
\text { 1PB: }<4 \\
\text { Phenol: } 23\end{array}$ & $46.0-55.8$ & 1123 & NA & NA & 112 & 88 \\
\hline ACID 3 & 500 & 9 & 50 & 500 & 0.4 & 119 & 47.6 & $\begin{array}{c}\text { TPB: } 3950 \\
\text { 3PB: }<50 \\
\text { 2PB: }<50 \\
\text { 1PB: }<4 \\
\text { Phenol: } 42 \\
\end{array}$ & 69.8-75.3 & 868 & NA & NA & 121 & 35 \\
\hline ACID 4 & 500 & 9 & 50 & 500 & 0.4 & 116 & 46.4 & \begin{tabular}{|c|} 
TPB: $<4$ \\
3PB: $<4$ \\
2PB: $<4$ \\
1PB: $<4$ \\
Phenol: $<4$ \\
\end{tabular} & $>99.97$ & 343 & 95 & 95 & 127 & 19 \\
\hline
\end{tabular}

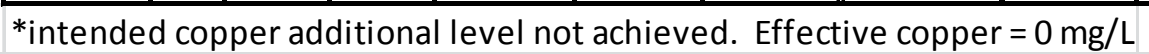




\section{Appendix D Nitric Acid Titration of Tank 48H Simulant Slurries}

Acid demand of the Tank 48H simulant was determined by titrating $100 \mathrm{~mL}$ of simulant with nitric acid. Nitric acid was added using a syringe pump at rates of 0.071 and 0.71 $\mathrm{mL} / \mathrm{min}$. Acid concentrations were 15,35 , and $70 \mathrm{wt} \%$ for each addition rate. $\mathrm{pH}$ data were logged using a laptop computer, and graphs were generated providing the molar amount of acid needed to reach a simulant $\mathrm{pH}$ of 5. Samples were collected at each $\mathrm{pH}$ interval and stored for future analysis.

Figure 100. Titration of Tank 48H Simulant Slurries

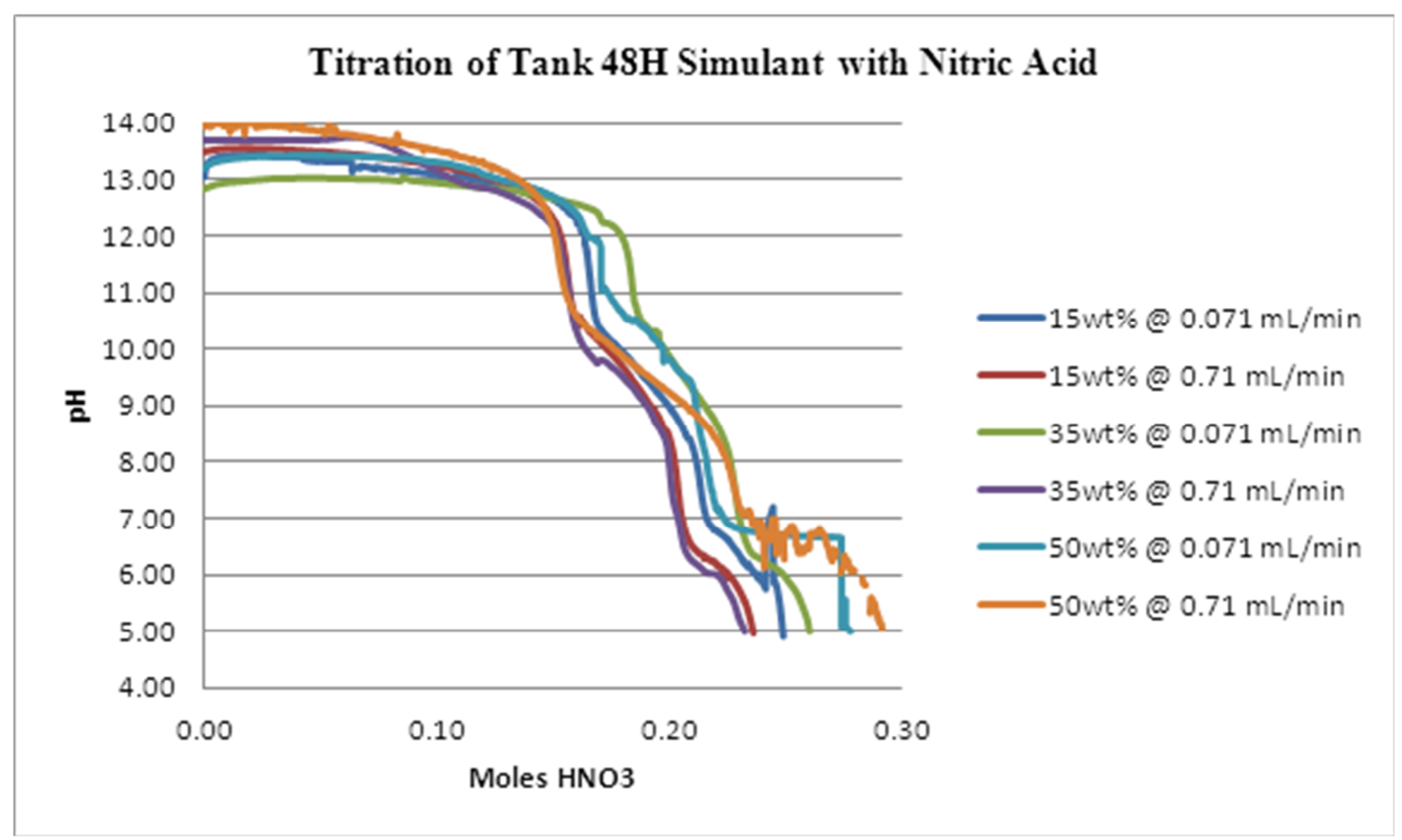

Vigorous foaming was noted when titrating with $50 \mathrm{wt} \%$ acid for both rates. Less intense foaming was seen when using $35 \mathrm{wt} \%$ and hardly any foaming was observed with $15 \mathrm{wt} \%$ nitric. Foaming began when the $\mathrm{pH}$ ranged between 7-6 in all cases. When excessive foaming occurred, acid addition was stopped and the foam was allowed to settle. Tapping the mixing vessel sometimes helped disperse the foam but resulted in $\mathrm{pH}$ oscillation, as seen during the $50 \mathrm{wt} \%$ titration at the $0.71 \mathrm{~mL} / \mathrm{min}$ rate. The quick drop off in $\mathrm{pH}$ seen in the $50 \mathrm{wt} \%$ titration at the $0.071 \mathrm{~mL} / \mathrm{min}$ rate was due to a loss of mixing. Tabulated results of the acid demand are presented below (see Table 46). 
Table 91. Acid Demand for Tank 48H Simulant Slurries

\begin{tabular}{|c|c|c|}
\hline $\begin{array}{c}\text { HNO }_{3} \text { conc. } \\
(\mathbf{w t ~ \% )}\end{array}$ & $\begin{array}{c}\text { addition rate } \\
\text { (mL/min) }\end{array}$ & $\begin{array}{c}\text { acid demand } \\
\text { (mol) }\end{array}$ \\
\hline 15 & 0.071 & 0.25 \\
\hline 15 & 0.710 & 0.24 \\
\hline 35 & 0.071 & 0.26 \\
\hline 35 & 0.710 & 0.23 \\
\hline 50 & 0.071 & 0.28 \\
\hline 50 & 0.710 & 0.29 \\
\hline
\end{tabular}




\subsection{References}

${ }^{1}$ K. M. L. Taylor-Pashow, F. F. Fondeur, S. D. Fink., "Leaching of Titanium from Mononsodium Titanate (MST) and Modified MST (mMST)", SRNL-STI-2012-00237, August 2012.

${ }^{2}$ F. F. Fondeur, J. D. Newell, T. B. Peters, S. D. Fink., "Thermal Screening of Residues from Acidification and Copper-Catalyzed Peroxide Oxidation of Tank 48H Simulant", SRNL-STI-2012-00480, September 2012.

${ }^{3}$ K. B. Burnau, “Tank 48 Treatment Execution Strategy”, WDPD-11-69, June 9, 2011.

${ }^{4}$ D. P. Lambert, T. B. Peters, S. D. Fink, "In-Tank Peroxide Oxidation Process for the Decomposition of Tetraphenylborate in Tank 48H", WSRC-TR-2005-00114, April 2005.

${ }^{5}$ S. P. Simner, "Process Optimization for Cu-Catalyzed Peroxide Oxidation of Tank $48 \mathrm{H}$

Tetraphenylborate", G-TTR-H-00005, 2012.

${ }^{6}$ S. P. Simner, Tank 48 Chemical Destruction - Flow-Sheet Options Report, SRR-CES-2012-00018, Rev. 0 (2012).

${ }^{7}$ D. P. Chew, and B. A. Hamm, Liquid Waste System Plan Revision 17, SRR-LWP-2009-00001, Rev. 17 (2012)

${ }^{8}$ D. P. Lambert, T. B. Peters, M. E. Stallings, S. D. Fink, "Process Development for Oxidative Destruction of Tetraphenylborate in Savannah River Site Tank 48H", WSRC-TR-2003-00404, REV. 0, April 13, 2004.

${ }^{9}$ W. R. Wilmarth, R. E. Eibling, D. D. Walker, C. L. Crawford, "Peer Review of Tank 48H Testing", WSRC-TR-2004-00437, June 4, 2004.

${ }^{10}$ D. P. Lambert, M. J. Barnes, S. D. Fink, "Task Technical and Quality Assurance Plan for Benzene Generation Testing Matrix: Pd Catalyzed Decomposition”, WSRC-RP-2004-00471, Rev. 0, June 18, 2004.

${ }^{11}$ T. B. Peters, C. A. Nash, F. F. Fondeur, K. M. Taylor-Pashow, T. L. White, D. J. Newell, S. D. Fink, "Task Technical and Quality Assurance Plan for Process Optimization for CU-Catalyzed Peroxide Oxidation of Tank 48H”, SRNL-RP-2011-01525, Rev. 1, March 2012.

${ }^{12}$ M. R. Williams, “Tank 48 Treatment Project - Preparing/Procuring Tank 48 Simulant”, SRNL-PSE2007-00248, Rev.0, November 14, 2007.

${ }^{13}$ D. P. Lambert, T. B. Peters, M. E. Stallings, S. D. Fink, "Analysis of Tank 48H Samples HTF-E-03-73 (June 03, 2003) and HTF-E-03-127 (September 17, 2003)", WSRC-TR-2003-00720, Rev. 0, January 20, 2004.

${ }^{14}$ H. E. Shook and R. E. Eibling, "Proposed Reaction Mechanisms in Precipitate Hydrolysis: Trip Report", DPST-88-1026, December 8, 1988.

${ }^{15}$ J. K. Taylor, "Quality Assurance of Chemical Measurements"; Lewis Publishers, Inc.: Chelsa, Michigan, 1987; p. 131.

${ }^{16}$ B. A. Bidlingmeyer, Practical HPLC Methodology and Applications; John Wiley \& Sons, Inc.: New York, 1992; p. 237.

${ }^{17}$ M. Nyman, and D. T. Hobbs, (2006) "A Family of Peroxo-titanate Materials Tailored for Optimal Strontium and Actinide Sorption." Chem. Mater. 18 (26): 6425. 
${ }^{18}$ Physical and Engineering Data, January 1978 ed. The Hague: Shell Internationale Petroleum Maatschappij BV, 1978

${ }^{19}$ P. M. Jarrell, C. E. Fox, M. H. Stein, S. L. Webb, 2002, Practical Aspects of CO2 Flooding, SPE Monograph 22, 220p

${ }^{20}$ M. R. Poirier, P. R. Monson, "Laboratory-Scale Study of Parameters Influencing Benzene Retention and Release in Potassium Tetraphenylborate Slurries", WSRC-TR-97-00375, September 5, 1997.

21 "Occupational Safety and Health Guideline for Mercury Vapor", http://www.osha.gov/SLTC/healthguidelines/mercuryvapor/recognition.html

${ }^{22}$ Lange's Handbook of Chemistry, $15^{\text {th }}$ edition, John A. Dean, editor, p. 5.24, McGraw-Hill, Inc. (New York, 1999).

23 SRS Drawings P-PM-H-08228 (rev. 0) and W752790 (Rev. 2)

${ }^{24}$ G. A. Taylor, “ARP Mixing Tank”, SRNL-ITB-2004-00026, October 6, 2004.

${ }^{25}$ G. B. Tatterson, Fluid Mixing and Gas Dispersion in Agitated Tanks, McGraw-Hill, New York, NY, 1991.

${ }^{26}$ C. M. Garrison, "How to Design and Scale Mixing Pilot-Plants", Chemical Engineering, pp. 63-70, February 7, 1983.

${ }^{27}$ R. R Rautzen, R. R. Corpstein, and D. S. Dickey, "How to Use Scale-Up Methods for Turbine Agitators", Chemical Engineering, pp. 119-126, October 25, 1976.

${ }^{28}$ WSRC-NB-2004-00148

29 J. H. Rushton, E. W. Costich, and H. J. Everett, "Power Characteristics of Mixing Impellers, Part I", Chemical Engineering Progress, Vol. 46, no. 8, pp. 395-404, 1950.

${ }^{30}$ K. W. Norwood, , and A. B. Metzner, "Flow Patterns and Mixing Rates in Agitated Vessels", A. I. Ch. E. Journal, vol. 6, no. 3, pp. 432-437, September 1960.

31 J. H. Rushton, E. W. Costich, and H. J. Everett, "Power Characteristics of mixing Impellers, Part II", Chemical Engineering Progress, vol. 46, no. 9, pp. 467 - 476, September 1950.

32 "Handbook of Industrial Mixing", Edited by E. L. Paul, V. A. Atiemo-Obeng, and S. M. Kresta, Wiley Interscience, p. 511, 2004.

${ }^{33}$ M. Moo-Young, K. Tichar, and F. Dullien, "The Blending Efficiencies of Some Impellers in Batch Mixing”, A. I. Ch. E. Journal, vol. 18, no. 1, pp. 178-182, January 1972.

34 J. G. Van de Vusse, "Mixing by Agitation of Miscible Liquids", Chemical Engineering Science, vol. 4 pp. 178-200, August 1955.

${ }^{35}$ Chemical Engineer's Handbook, $5^{\text {th }}$ Edition, R. H. Perry, and C. H. Chilton, editors, McGraw Hill Book Company, Ney York, NY, 1973. 


\section{Distribution:}

K. M. Fox, 999-W

S. D. Fink, 773-A

C. C. Herman, 999-W

S. L. Marra, 773-A

F. M. Pennebaker, 773-42A

W. R. Wilmarth, 773-A

Records Administration (EDWS)

C. Wilson, 773-A

D. P. Lambert, 999-W

J. Pareizs, 773-A

C. Martino, 773-42A

C. A. Nash, 773-42A

T. B. Peters, 773-42A

D. Newell, 999-W

T. L. White, 773-A

E. J. Freed, 704-56H

D. J. Martin, 241-152H

P. R. Jackson, DOE-SR, 703-46A

K. H. Subramanian, 766-H

J. S. Contardi, 766-H

C. J. Winkler, 766-H

E. A. Brass, 249-8H

S. P. Simner, 249-8H

C. Aponte, $249-8 \mathrm{H}$ 